\author{
Universidade de São Paulo \\ Instituto de Química de São Carlos
}

\title{
Bagaço de cana de açúcar como reforço de matrizes termorrígidas baseadas em macromoléculas de ligninas
}

\author{
Cristina Gomes da Silva
}

Orientadora: Profa. Dra. Elisabete Frollini

São Carlos 



\section{Sumário}

LISTAS DE FIGURAS I

LISTA DE TABELAS V V

$\begin{array}{lll}\text { LISTA DE ESQUEMAS VI } & \text { VI }\end{array}$

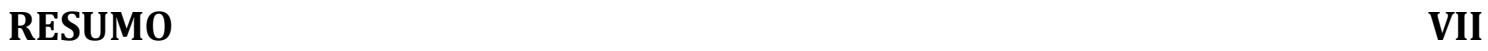

\begin{tabular}{ll} 
ABSTRACT & X \\
\hline
\end{tabular}

LISTA DE ABREVIATURAS E SIGLAS XIII

1. INTRODUÇÃO

1. 1. Resinas do tipo Fenólicas 4

1. 1. 1. Resinas Fenólicas 4

1. 1. 1. 1. Resina Fenólica do tipo Resol 5

1. 1. 1. 2. Reação de entrecruzamento de Resóis (Cura) 6

1. 2. Resinas do tipo fenólicas produzidas a partir de matéria-prima de fonte vegetal 9

1. 3. Compósitos de matriz polimérica 15

1. 3. 1. Aspectos gerais. 15

$\begin{array}{ll}\text { 1. 3. 2. Interface fibra matriz } & 17\end{array}$

1. 3. 3. Fibras lignocelulósicas como agentes de reforço em compósitos 18

1. 3. 3. 1. Fibras Lignocelulósicas: bagaço de cana de açúcar e sisal 19

1. 3. 3. 2. Tratamento das fibras de bagaço de cana de açúcar 22

2. OBJETIVOS

3.CARACTERIZAÇÃO DOS MATERIAIS: TÉCNICAS USADAS 26

$\begin{array}{lr}\text { 3. 1. Difração de raios } X & 26\end{array}$

$\begin{array}{lr}\text { 3.2. Análise Térmica } & 28\end{array}$ 
3. 4. Cromatografia Gasosa Inversa (Inverse Gas Chromatography - IGC)

(B) Determinação do teor de lignina Klason solúvel

4. 2. 1. 4. Determinação do teor de holocelulose (hemicelulose + celulose) 45

4. 2. 1. 5. Determinação do teor de $\alpha$-celulose 46

4. 2. 1. 6. Difração de Raios X 46

4. 2. 1. 7. Cromatografia Gasosa Inversa (Inverse Gas Chromatography - IGC) 47

4. 2. 2. Separação e caracterização das ligninas 48

4. 2. 2. 1. Separação e purificação 49

4. 3. Caracterização de ligninas e pré-polímeros $\quad 50$

4. 3. 1. Acetilação da lignina $\quad 50$

4. 3. 2. Fosforilação de lignina 
4. 4. 2. Síntese do pré-polímero formaldeído - lignina organossolve 54

4. 4. 3. Síntese do pré-polímero formaldeído - lignossulfonato de sódio

4. 4. 4. Síntese pré-polímero e glutaraldeído - lignina organossolve

\section{RESULTADOS E DISCUSSÕES}

\section{1. Caracterizações das fibras}


5. 2. 1. Separação e caracterização da lignina a partir do bagaço de cana de açúcar queimado (LBC) 79

5. 3. 1. 2. Lignossulfonato de sódio, resinas e termorrígidos baseados em lignossulfonato de sódio

90
9

5. 3. 1. 3. Lignina organossolve, resinas e termorrígidos baseados em lignina organossolve

5. 5. 1. Resinas: glutaraldeído-lignina organossolve (RGLO), glutaraldeído-lignina extraída do bagaço

5. 8. 1. 1. Compósitos reforçados com fibras de bagaço de cana queimado (CFenBCQ) 
$\begin{array}{ll}\text { 5. 8. 1. 2. 2. MEV } & 132\end{array}$

$\begin{array}{ll}\text { 5. 8. 1. 2. 3. DMTA } & 134\end{array}$

$\begin{array}{ll}\text { 5. 8. 1. 2. 4. Absorção de água } & 137\end{array}$

5. 8. 2. Compósitos de matriz formaldeído-lignossulfonato de sódio 138

5. 8. 2. 1. Compósitos reforçados com fibras de bagaço de cana queimadas (CFLBCQ) 138

$\begin{array}{ll}\text { 5. 8. 2. 1. 1. Ensaio de Impacto } & 138\end{array}$

$\begin{array}{ll}\text { 5. 8. 2. 1. 2. MEV } & 140\end{array}$

$\begin{array}{ll}\text { 5. 8. 2. 1. 3. DMTA } & 143\end{array}$

5. 8. 2. 1. 4. Ensaio de Flexão 145

$\begin{array}{ll}\text { 5. 8. 2. 1. 5. Absorção de água } & 147\end{array}$

5. 8. 2. 2. Compósitos reforçados com fibras de bagaço de cana queimado e tratado (CFBCQT) 148

5. 8. 2. 2. 1. Ensaio de Impacto 148

$\begin{array}{ll}\text { 5. 8. 2. 2. 2. MEV } & 149\end{array}$

$\begin{array}{ll}\text { 5. 8. 2. 2. 3. DMTA } & 151\end{array}$

5. 8. 2. 2. 4. Ensaio de Flexão 153

5. 8. 2. 2. 5. Absorção de água $\quad 155$

5. 8. 3. Compósitos de matriz formaldeído-lignina organossolve (FLO), glutaraldeído-lignina organossolve (GLO) e glutaraldeído-lignossulfonato de sódio (GL) 157

5. 8. 3. 1. Compósitos reforçados com fibras bagaço de cana queimado 157

$\begin{array}{ll}\text { 5. 8. 3. 1. 1. Ensaio de Impacto } & 157\end{array}$

$\begin{array}{ll}\text { 5. 8. 3. 1. 2. MEV } & 160\end{array}$

5. 8. 3. 1. 3. Ensaio de Flexão 162

5. 8. 3. 1. 4. Absorção de água 164

5. 8. 3. 2. Compósitos reforçados com fibras de sisal 165

5. 8. 3. 2. 1. Ensaio de Impacto 166

$\begin{array}{ll}\text { 5. 8. 3. 2. 2. MEV } & 168\end{array}$

5. 8. 3. 2. 3. Ensaio de Flexão 170

5. 8. 3. 2. 4. Absorção de água 173 
6. CONCLUSÕES

7. REFERÊNCIAS BIBLIOGRÁFICAS

8. ANEXOS 
Dedico este trabalho... ...à Dens...

...e à todos da minha famítia... ...aos mens pais, Aparecida e Vamberto... ...aos mens avós, Alice e Donato... ...pelo carinho, atenção e todo amor... 


\section{Agradeço à...}

...Professora Elisabete Frollini por sua atenção, dedicação $e$ compreensão em todos os momentos, pessoais e profissionais, deste doutorado.

...amigos do Instituto de Química de São Carlos: alunos $e$ funcionários...

...amigos de laboratório: Elaine, Daniele, Fernando, Talita, Rachel, Bruno, Dainiella, Bianca...

...amigos do grupo de orgânica: Erika, Jorge, Adriana, Sara, Daniella, Tonimar, Virginia, Andreson...

...amigos brasileiros, amigos franceses, professores $e$ colaboradores do estágio sanduíche em Bordeaux...

...amigos Luiz e Márcia...

...e todos que contribuíram direta ou indiretamente para minha formação e conclusão do meu trabalho de tese. 


\section{Listas de Figuras}

Figura 1: Produção anual de cana de açúcar mundial, ano de 2010 (IBGE, 2011). ................................. 3 Figura 2: Unidades presentes na lignina: (1) guaicila; (2) siringila e (3) p-hidroxifenila (Fengel, 1989). . 11

Figura 3: Modelo esquemático da associação dos componentes da parede celular de fibra vegetal em vista

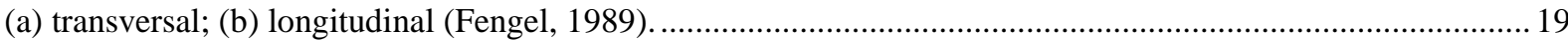

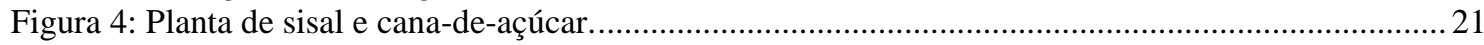

Figura 5: Representação esquemática da Lei de Bragg (MORGADO, 2009)........................................2 27

Figura 6: Resposta de um corpo viscoelástico a uma solicitação cíclica do tipo senoidal. A resposta está defasada com relação à solicitação de um ângulo $\delta$ (MURYAMA, 1978)...

30

Figura 7: (A) Tensão senoidal e curva de resposta de deformação, apresentando o atraso do ângulo de fase, devido ao comportamento viscoelástico; (B) A relação entre o módulo complexo $E^{*}$, sua componente real $E$ ' e sua componente imaginária $E$ ”. $E$ '= módulo de armazenamento, $E$ ”= módulo de perda (MURYAMA, 1978).

Figura 8: Representação esquemática do equipamento de ensaio de impacto Izod. Sendo: $\mathbf{F}$ a força gravitacional do martelo, $\mathbf{L}$ o comprimento da haste do martelo, $\mathbf{h}_{\mathbf{1}} \mathbf{e} \mathbf{h}_{\mathbf{2}}$ as alturas inicial e final do martelo, e $\alpha \mathrm{e}$ $\beta$ os ângulos relacionados às respectivas alturas inicial e final. ................................................................ 38

Figura 9: Equipamento de ensaio de flexão em três pontos. ................................................................... 39 D790......

Figura 10: Representação esquemática das dimensões para o ensaio de flexão segundo a norma ASTM

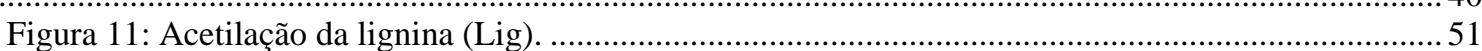

Figura 12: Reação de fosforilação dos grupos hidroxilas da lignina, $\mathrm{R}_{1}=\mathrm{H}, \mathrm{R}_{2}=\mathrm{CH}_{3}($ Granata, 1995) ..... 52

Figura 13: Micrografias da superfície de bagaço de cana de açúcar não queimado (a, b) da superfície e (c) ponta das fibras.

Figura 14: Micrografias da superfície (a) das fibras de bagaço de cana de açúcar queimado e (b) ponta da fibra.

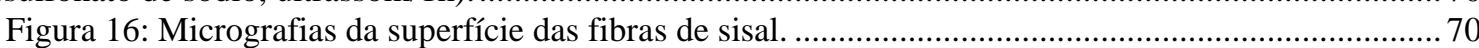

Figura 17: Difratogramas de raios X para as fibras de bagaço de cana: (a) não queimado (BCNQ); (b) queimado (BCQ); (c) queimado e tratado (solução de NaLS em banho de ultrassom/1h) (BCQT); (d) sisal (S).71

Figura 18: Espectro na região de infravermelho das fibras de sisal (S), bagaço de cana queimada (BCQ), bagaço de cana não queimada (BCNQ), bagaço de cana queimada e tratada (solução de NaLS em banho de ultrassom/1h) (BCQT).

Figura 19: Dados da análise de cromatografia gasosa inversa referente à coluna preenchida com fibras de bagaço de cana: queimado (BCQ); não queimado (BCNQ); queimado com tratamento (solução de NaLS em banho de ultrassom/1h) (BCT)

Figura 20: Curva Derivada Primeira da TG (dTG) fibra de bagaço de cana (a) não queimada (FBCNQ); (b) queimada (FBCQ); (c) queimada e tratada (FBCQT); (d) fibra de sisal (FS), em atmosfera de $\mathrm{N}_{2} 20 \mathrm{~mL} \mathrm{~min}^{-}$ ${ }^{1}$ e $10{ }^{\circ} \mathrm{C} \min ^{-1}$.

Figura 21: Curva DSC (a) fibras de bagaço de cana-de-açúcar não queimada, queimada, queimada e tratada (lignossulfonato de sódio+ ultrassom/1h); (b) fibra de sisal, em atmosfera de $\mathrm{N}_{2}$ com $20 \mathrm{~mL} \mathrm{~min}^{-1}$ e $10{ }^{\circ} \mathrm{C}$ $\min ^{-1}$.

Figura 22: Espectros de absorção FT-IR das ligninas organossolve (LO) e do bagaço de cana queimado (LBC), (a) acetiladas e (b) não acetiladas.

Figura 23: Espectro de $\mathrm{RMN}^{1} \mathrm{H}$ da lignina organossolve (LO) acetilada..............................................8. 82

Figura 24: Espectro de $\mathrm{RMN}^{1} \mathrm{H}$ da lignina do bagaço de cana acetilada. .............................................8. 83

Figura 25: Espectro de $\mathrm{RMN}{ }^{31} \mathrm{P}$ das (a) lignina organossolve (LO), (b) lignina do bagaço de cana queimado (LBC).

Figura 26: Curva TG e derivada primeira em atmosfera de ar $\left(20 \mathrm{~mL} \mathrm{~min}^{-1}\right)$ e taxa de aquecimento $10{ }^{\circ} \mathrm{C}$

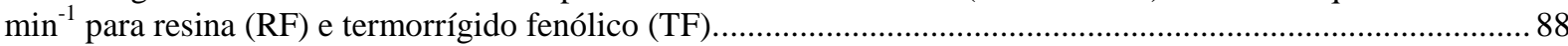

Figura 27: Curvas DSC do (a) resina fenólica (RF); (b) termorrígido fenólico (TF) em atmosfera de ar sintético, $20 \mathrm{~mL} \min ^{-1}$ e $10{ }^{\circ} \mathrm{C} \min ^{-1}$.

Figura 28: Curva TG e dTG (Derivada Primeira) e DSC: (a, b) Lignossulfonato de sódio; (c, d) Resina formaldeído-lignossulfonato de sódio (RFL) e (e, f) Resina glutaraldeído-lignossulfonato de sódio (RGL), em atmosfera de $\mathrm{N}_{2} \operatorname{com} 20 \mathrm{~mL} \mathrm{~min}^{-1}$ e $10^{\circ} \mathrm{C} \mathrm{min}^{-1}$. 
Figura 29: Curva TG e dTG e DSC: (a, b) termorrígido formaldeído-lignossulfonato (TFL); (c, d) termorrígido glutaraldeído-lignossulfonato (TGL), em atmosfera de $\mathrm{N}_{2} \operatorname{com} 20 \mathrm{~mL} \mathrm{~min}^{-1}$ e $10^{\circ} \mathrm{C} \mathrm{min}^{-1} \ldots \ldots \ldots \ldots . . . .93$

Figura 30: Curva TG e dTG para (a, b) lignina organossolve (LO), (c, d) resina formaldeído-lignina organossolve (RFLO); (e, f) resina glutaraldeído-lignina organossolve (RGLO), em atmosfera de ar $(20 \mathrm{~mL}$ $\left.\min ^{-1}\right)$ e taxa de aquecimento $10^{\circ} \mathrm{C} \mathrm{min}^{-1}$.

Figura 31: Curva TG e dTG para (a, b) termorrígido formaldeído-lignina organossolve (TFLO); (c, d) termorrígido glutaraldeído-lignina organossolve (TGLO), em atmosfera de ar $\left(20 \mathrm{~mL} \mathrm{~min}^{-1}\right)$ e taxa de aquecimento $10^{\circ} \mathrm{C} \min ^{-1}$......

Figura 32: Espectro na região de infravermelho da (a) lignossulfonato de sódio (NaLS); (b) lignina organossolve (LO).

Figura 33: Espectros na região de infravermelho das resinas de (a) glutaraldeído-lignossulfonato (RGL); (b) formaldeído-lignossulfonato (RFL); (c) glutaraldeído-lignina organossolve (RGLO); (d) formaldeído-lignina organossolve (RFLO); (e) resina fenólica (RF).

Figura 34: Espectros na região de infravermelho dos termorrígidos de (a) glutaraldeído-lignossulfonato (TGL); (b) formaldeído-lignossulfonato (TFL); (c) glutaraldeído-lignina organossolve (TGLO); (d) formaldeído-lignina organossolve (TFLO); (e) termorrígido fenólico (TF) .................................................. 102

Figura 35: Curvas de eluição SEC das resinas preparadas a partir de glutaraldeído e acetiladas: (ロ) lignina do bagaço de cana queimado (extração soda/antraquinona (AQ)) (RGLBC); (ロ) lignina organossolve (RGLO); (घ) lignossulfonato de sódio (RGL) ............................................................................................... 103

Figura 36: Espectro de $\mathrm{RMN}{ }^{31} \mathrm{P}$ da resina glutaraldeído-lignina organossolve (RGLO) ..................... 104

Figura 37: Espectro de $\mathrm{RMN}{ }^{31} \mathrm{P}$ da resina de (a) glutaraldeído-lignina do bagaço de cana queimado (extração soda/AQ) (RGLBC); (b) glutaraldeído-lignossulfonato de sódio (RGL)...................................106

Figura 38: Cromatograma referente à coluna preenchida com termorrígido formaldeído-lignossulfonato de sódio (TFL). 108

Figura 39: Espectro na região de infravermelho dos compósitos fenólico reforçados com fibras de bagaço de cana queimada (CFBCQ) e não queimada (CFBCNQ)..... 111

Figura 40: Curva TG e dTG para o compósito fenólico reforçado com fibras de bagaço de cana-de-açúcar queimada (CFenBCQ) e não queimada (CFenBCNQ), em atmosfera de $\mathrm{N}_{2} \operatorname{com} 20 \mathrm{~mL} \min ^{-1}$ e $10{ }^{\circ} \mathrm{C} \min ^{-1} . .113$

Figura 41: Curva TG e dTG para o compósito de resina formaldeído-lignossulfonato reforçado com fibras de bagaço de cana queimada (CFLBCQ); queimada e tratada (lignossulfonato de sódio+ ultrassom/1h) (CFLBCT); sisal (CFLS), em atmosfera de $\mathrm{N}_{2}$ com $20 \mathrm{~mL} \mathrm{~min}^{-1}$ e $10{ }^{\circ} \mathrm{C} \mathrm{min}^{-1}$....

Figura 42: Curva TG, dTG e DSC para o compósito de resina glutaraldeído-lignossulfonato de sódio reforçado com fibras de bagaço de cana queimada (CGLBCQ); compósito glutaraldeído-lignossulfonato sisal (CGLS), em atmosfera de $\mathrm{N}_{2} \operatorname{com} 20 \mathrm{~mL} \mathrm{~min}^{-1}$ e $10^{\circ} \mathrm{C} \min ^{-1}$. 116

Figura 43: Curva TG, dTG (Derivada Primeira) e DSC para o compósito de resina formaldeído-lignina organossolve reforçado com fibras de bagaço de cana queimada (CFLOBCQ); compósito glutaraldeído-lignina organossolve reforçado com fibras de bagaço de cana queimada (CGLOBCQ), em atmosfera de $\mathrm{N}_{2}$ com $20 \mathrm{~mL}$ $\min ^{-1}$ e $10{ }^{\circ} \mathrm{C} \min ^{-1}$. .118

Figura 44: Curva TG, dTG e DSC para o compósito de resina glutaraldeído-lignina organossolve com fibra de sisal (CGLOS) e formaldeído-lignina organossolve reforçado com fibra de sisal (CFLOS), em atmosfera de $\mathrm{N}_{2}$ com $20 \mathrm{~mL} \mathrm{~min}^{-1}$ e $10^{\circ} \mathrm{C} \mathrm{min}^{-1}$.

Figura 45: Resistência ao impacto Izod para termorrígido fenólico (TF) e compósitos reforçados com fibras de bagaço de cana queimadas (CFenBCQ) $(1,5 \mathrm{~cm})$ em função da porcentagem de fibra (em massa) na matriz.

Figura 46: Micrografias da região de fratura dos compósitos fenólicos reforçados com fibra de bagaço de cana queimada (CFenBCQ), (a) 30\%; (b) 50\%; (c) $70 \%$.

Figura 47: (a) Módulo de Armazenamento (E'); (b) Módulo de Perda E" e (c) tan $\delta$ em função da temperatura para compósitos fenólicos reforçados com fibras de bagaço de cana queimada (CFenBCQ): 30,50 e $\mathbf{7 0 \%}$ em massa; comprimento médio de $1,5 \mathrm{~cm}$ e termorrígido fenólico (TF).

Figura 48: Resultado do ensaio de resistência à flexão (MPa) dos compósitos fenólicos reforçados com fibras de bagaço de cana queimado (CFenBCQ) (30, 50 e 70\%, em massa).

Figura 49: Resultados de módulo de elasticidade (GPa) obtidos a partir do ensaio de resistência à flexão dos compósitos fenólicos reforçados com fibras de bagaço de cana queimado (CFenBCQ) (30, 50 e 70\%, em massa).

Figura 50: Resultado do ensaio de absorção de água: (a) compósitos fenólicos reforçados com fibras de bagaço de cana queimado (CFenBCQ) (30, 50 e 70\%, em massa) e (b) termorrígido fenólico (TF). .............130

Figura 51: Resistência ao impacto Izod para o termorrígido fenólico (TF) e compósitos fenólicos reforçados com fibras de bagaço de cana não queimada (CFenBCNQ); comprimento: 1, 2, 3, 4 e $5 \mathrm{~cm}$ (30\% em massa). 
Figura 52: MEV dos compósitos fenólicos reforçados com fibras de bagaço de cana não queimada (CFenBCNQ); comprimento: (a) $1 \mathrm{~cm}$; (b) $2 \mathrm{~cm}$; (c) $3 \mathrm{~cm}$; (d) $4 \mathrm{~cm}$; (e) $5 \mathrm{~cm}$; (30\% em massa).

Figura 53: (a) Módulo de Armazenamento E' (b) Módulo de Perda E” e (c) Tan $\delta$ em função da temperatura para o termorrígido fenólico (TF) compósitos fenólicos reforçados com fibras de bagaço de cana não queimada (CFenBCNQ): 1, 2, 3, 4 e 5cm (30\% em massa).

Figura 54: Resultados do ensaio de absorção de água compósitos fenólicos reforçados com fibras de bagaço de cana de não queimada (CFenBCNQ): 1, 2, 3, 4, 5cm (30\% em massa)...................................... 137

Figura 55: Ensaio de resistência ao impacto Izod para o termorrígido fenólico (TF) e os compósitos de formaldeído-lignossulfonato reforçados com fibras de bagaço de cana queimado em função da porcentagem de fibra na matriz (CFLBCQ) (30, 50 e 70\% em massa).

Figura 56: Microscopia eletrônica de varredura para compósitos de formaldeído-lignossulfonato reforçados com fibras de bagaço de cana queimado em função da porcentagem de fibra na matriz: (a, b) 30\%; (c, d) $50 \%$; (e, f) $70 \%$ (em massa) (CFLBCQ).

Figura 57: (a) Módulo de Armazenamento E'; (b) Módulo de Perda E” e (c) tan $\delta$ em função da temperatura para compósitos de formaldeído-lignossulfonato reforçados com fibras de bagaço de cana queimado em função da porcentagem de fibra na matriz (CFLBCQ) (30, 50 e 70\% em massa).................... 143

Figura 58: Resultados de resistência à flexão os compósitos de formaldeído-lignossulfonato reforçados com fibras de bagaço de cana queimada em função da porcentagem de fibra na matriz (CFBCQ) (30, 50 e $70 \%$ em massa).

Figura 59: Resultados de módulo de elasticidade para os compósitos de formaldeído-lignossulfonato reforçados com fibras de bagaço de cana queimada em função da porcentagem de fibra na matriz (CFBCQ) (30, 50 e $70 \%$ em massa).

Figura 60: Resultados do ensaio de absorção de água compósitos de formaldeído-lignossulfonato reforçados com fibras de bagaço de cana queimado em função da porcentagem de fibra na matriz (CFLBCQ) (30, 50 e $70 \%$ em massa).

Figura 61: Resultados de resistência ao Impacto Izod para os compósitos de formaldeídolignossulfonato reforçados com fibras de bagaço de cana queimado e tratado (lignossulfonato de sódio+ultrassom/1h) em função da porcentagem de fibra na matriz (30, 50 e $70 \%$ em massa) (CFBCQT), termorrígido fenólico (TF).

Figura 62: Microscopia eletrônica de varredura para compósitos reforçados com fibras de bagaço de cana queimado e tratado (lignossulfonato de sódio+ ultrassom/1h), em matriz de formaldeídolignossulfonato: (a, b) $30 \%$; (c, d) $50 \%$; (e, f) $70 \%$ (em massa). 150

Figura 63: (a) Módulo de Armazenamento E', (b) Módulo de Perda E” e (c) Tan $\delta$ em função da temperatura para compósitos formaldeído-lignossulfonato reforçados com fibras de bagaço de cana queimado e tratado (lignossulfonato de sódio+ ultrassom/1h) (CFLBCQT): 30\%, 50\% e 70\% (em massa). 151

Figura 64: Resultados de resistência à flexão para os compósitos de formaldeído-lignossulfonato reforçados com fibras de bagaço de cana queimado e tratado (lignossulfonato de sódio+ultrassom/1h) (CFLBCQT) em função da porcentagem de fibra na matriz (30, 50 e 70\%, em massa).

Figura 65: Resultados módulo de elasticidade para os compósitos de formaldeído-lignossulfonato reforçados com fibras de bagaço de cana queimado e tratado (lignossulfonato de sódio+ultrassom/1h) em função da porcentagem de fibra na matriz (30, 50 e $70 \%$ em massa)....

Figura 66: Resultado do ensaio de absorção de água para os compósitos de formaldeídolignossulfonato reforçados com fibras de bagaço de cana queimado e tratado (lignossulfonato de sódio+ultrassom/1h) em função da porcentagem de fibra na matriz (30, 50 e 70\% em massa)-(CFLBC)........ 156

Figura 67: Corpos-de-prova pós-fratura de compósitos: (a) formaldeído-lignossulfonato de sódio; (b) formaldeído-lignina organossolve, reforçados com fibras de bagaço de cana queimado (30\% em massa; comprimento médio: $1,5 \mathrm{~cm})$.

Figura 68: Resistência ao impacto Izod dos compósitos com diferentes tipos de matrizes: compósito fenólico (CFen); compósito glutaraldeído-lignina organossolve (CGLO); compósito formaldeído-lignina organossolve (CFLO); compósito formaldeído-lignossulfonato de sódio (CFL); compósito glutaraldeídolignossulfonato (CGL) reforçados com fibras de bagaço de cana queimado (BCQ, 30\% em massa).......... 159

Figura 69: Microscopia eletrônica de varredura dos compósitos de reforçados com fibras de bagaço de cana queimado reforçados com fibras de bagaço de cana queimado (30\% em massa) com diferentes tipos de matrizes; (a, b) compósito glutaraldeído-lignina organossolve (CGLOBC); (c, d) compósito formaldeído-lignina organossolve (CFLOBC); (e, f) compósito glutaraldeído-lignossulfonato de sódio (CGLBC). ...................... 161

Figura 70: Resistência à flexão Izod dos compósitos de reforçados com fibras de bagaço de cana queimado (30\% em massa) com diferentes tipos de matrizes; compósito fenólico (CFen); compósito glutaraldeído-lignina organossolve (CGLO); compósito formaldeído-lignina organossolve (CFLO); compósito formaldeído-lignossulfonato de sódio (CFL); compósito glutaraldeído-lignossulfonato (CGL) 
Figura 71: Resultados de módulo de elasticidade dos compósitos de reforçados com fibras de bagaço de cana queimado (30\% em massa) com diferentes tipos de matrizes; compósito fenólico (CFen); compósito glutaraldeído-lignina organossolve (CGLO); compósito formaldeído-lignina organossolve (CFLO); compósito formaldeído-lignossulfonato de sódio (CFL); compósito glutaraldeído-lignossulfonato (CGL).

Figura 72: Ensaio de absorção de água dos compósitos de reforçados com fibras de bagaço de cana queimado (30\% em massa) com diferentes tipos de matrizes; (a, b) compósito glutaraldeído-lignina organossolve (CGLOBCQ); compósito formaldeído-lignina organossolve (CFLOBCQ); (b) compósito formaldeído-lignossulfonato bagaço de cana queimado (CFLBCQ); compósito fenólico bagaço de cana queimado (CFenBCQ). 164

Figura 73: Ensaio de resistência ao impacto Izod para os compósitos de reforçados com fibras de sisal (30\% em massa) com diferentes tipos de matrizes; compósito glutaraldeído-lignina organossolve (CGLOS); compósito formaldeído-lignina organossolve (CFLOS); compósito formaldeído-lignossulfonato de sódio (CFLS); compósito glutaraldeído-lignossulfonato (CGLS). 166

Figura 74: Corpos-de-prova após o ensaio de Impacto Izod: (a) glutaraldeído-lignossulfonato de sódio/sisal (CGLS); (b) glutaraldeído-lignina organossolve/sisal (CGLOS). 167

Figura 75: Microscopia eletrônica de varredura para os compósitos de reforçados com fibras de sisal (30\% em massa) com diferentes tipos de matrizes: (a, b) compósito glutaraldeído-lignossulfonato (CGLS); (c, d) compósito glutaraldeído-lignina organossolve (CGLOS); (e, f) compósito formaldeído-lignossulfonato de sódio (CFLS); (g, h) compósito formaldeído-lignina organossolve (CFLOS). 169

Figura 76: Resultados de resistência à flexão dos compósitos de reforçados com fibras de sisal (30\% em massa) com diferentes tipos de matrizes; compósito glutaraldeído-lignina organossolve (CGLOS); compósito formaldeído-lignina organossolve (CFLOS); compósito formaldeído-lignossulfonato de sódio (CFLS)..........171

Figura 77: Resultados de módulo de elasticidade dos compósitos de reforçados com fibras de sisal (30\% em massa) com diferentes tipos de matrizes; compósito glutaraldeído-lignina organossolve (CGLOS); compósito formaldeído-lignina organossolve (CFLOS); compósito formaldeído-lignossulfonato de sódio (CFLS). 172

Figura 78: Absorção de água dos compósitos de reforçados com fibras de sisal (30\% em massa) com diferentes tipos de matrizes: (a) compósito glutaraldeído-lignina organossolve (CGLOS); compósito formaldeído-lignina organossolve (CFLOS); compósito formaldeído-lignossulfonato de sódio (CFLS). 


\section{Lista de Tabelas}

Tabela 1: Parâmetros característicos das sondas utilizadas nas análises de IGC (Belgacem et al., 1995). 48

Tabela 2: Ciclo de cura para compósitos fenólicos. .........................................................................59

Tabela 3: Ciclo de cura para os compósitos de formaldeído-lignina organossolve (FLO) e glutaraldeído-

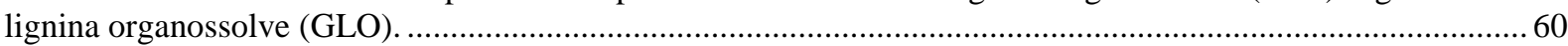

Tabela 4: Ciclo de cura para compósitos formaldeído-lignossulfonato de sódio....................................60 60

Tabela 5: Ciclo de cura para os compósitos glutaraldeído-lignossulfonato de sódio. ...............................60

Tabela 6: Caracterizações das fibras de bagaço de cana (BC) e sisal...................................................67

Tabela 7: Cristalinidade das fibras lignocelulósicas........................................................................ 72

Tabela 8: Principais atribuições para as bandas de absorção no IV para celulose, hemicelulose e lignina

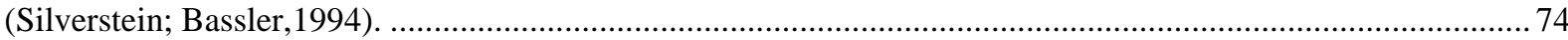

Tabela 9: Componentes de energia de dispersiva e caráter ácido/base da superfície das fibras de bagaço de cana: queimado (BCQ); não queimado (BCNQ); queimado com tratamento (solução de NaLS em banho de ultrassom/1h) (BCT).

Tabela 10: Porcentagem de lignina Klason, coeficiente de extinção molar a $280 \mathrm{~nm}$ e rendimento da fração de lignina isolada das fibras de bagaço de cana (LBC) e lignina organossolve (LO)............................... 80

Tabela 11: Análise do teor de açúcares nas frações de lignina nas fibras de bagaço de cana (LBC).........80

Tabela 12: Atribuições para os picos observados nos espectros de RMN ${ }^{1} \mathrm{H}$ das ligninas acetilas............84

Tabela 13: Quantificação dos grupos hidroxilas por $\mathrm{RMN}{ }^{31} \mathrm{P}\left(\mathrm{mmol} . \mathrm{g}^{-1}\right.$ de lignina) ligninas organossolve

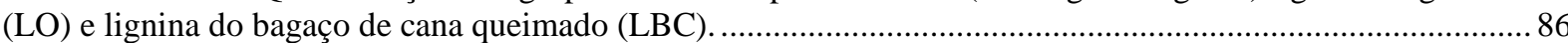

Tabela 14: Massa molar média $\left(\mathrm{g} \mathrm{mol}^{-1}\right)$ das ligninas organossolve (LO)e bagaço de cana queimada (LBC).

Tabela 15: Perdas de massa (\%) da resina (RF) e termorrígido fenólico (TF)...

Tabela 16: Bandas de absorção na região do infravermelho característica de lignossulfonato de sódio, (OLIVEIRA, 2010).

Tabela 17: Bandas de absorção na região de infravermelho características da lignina organossolve (RAMIRES, 2009)

Tabela 18: Principais atribuições de absorção na região do IV da resina e termorrígido fenólico (SILVERSTEIN; BASSLER,1994).

Tabela 19: Análise de massa molecular por SEC das resinas acetiladas: glutaraldeído-lignina do bagaço de cana queimado (extração soda/AQ) (RLBC); glutaraldeído-lignina organossolve (RGLO); glutaraldeídolignossulfonato de sódio (RGL).

Tabela 20: Quantificação dos grupos hidroxilas obtidos por $\mathrm{RMN}{ }^{31} \mathrm{P}\left(\mathrm{mmol} \mathrm{g}^{-1}\right.$ de lignina) das resinas preparadas a partir do glutaraldeído com: lignina organossolve (RGLO); lignina do bagaço de cana queimado (RGLBC); lignossulfonato de sódio (RGL)

Tabela 21: Componentes de energia de dispersiva e caráter ácido/base da superfície dos termorrígidos. 108

Tabela 22: Valores de Módulo de Armazenamento $\left(E^{\prime}\right.$ em $25^{\circ} \mathrm{C}$ ) para compósitos fenólicos reforçados com fibras de bagaço de cana queimada (CFenBCQ): 30, 50 e 70\% em massa; comprimento médio de 1,5cm.

Tabela 23: Resistência ao Impacto Izod (RI) para compósitos fenólicos reforçados com fibras de bagaço de cana (CFenBCNQ) (30\% em massa) ........................................................................................... 132

Tabela 24: Valores de Módulo de Armazenamento (E') em $25{ }^{\circ} \mathrm{C}$ para o termorrígido fenólico (TF) compósitos fenólicos reforçados com fibras de bagaço de cana não queimadas (CFenBCNQ): 1, 2, 3, 4 e 5cm ( $30 \%$ em massa).

Tabela 25: Valores de Módulo de Armazenamento (E', em $25{ }^{\circ} \mathrm{C}$ ) para compósitos fenólicos (CFenBCQ) e formaldeído-lignossulfonato (CFLBCQ) reforçados com fibras de bagaço de cana queimadas: 30, 50 e $70 \%$ em massa.

Tabela 26: Resultados de resistência à flexão e módulo de flexão para os compósitos fenólicos reforçados com bagaço de cana queimada (CFenBCQ) e compósitos de formaldeído-lignossulfonato reforçados com fibras de bagaço de cana queimada (CFLBCQ) em função da porcentagem de fibra na matriz. 146

Tabela 27: Valores de Módulo de Armazenamento (E') em $25{ }^{\circ} \mathrm{C}$ para compósitos lignossulfonatoformaldeído reforçados com fibras de bagaço de cana queimado tratado (NaLS+ultrassom/1h) (CFLBCQT) e compósitos lignossulfonato-formaldeído reforçados com fibras de bagaço de cana (CFLBCQ) (30, 50 e 70\%, em massa). 


\section{Lista de Esquemas}

Esquema 1: Autocondensação dos hidroximetilfenóis (SAUNDERS, 1998)..............................................6

Esquema 2: Entrecruzamento de resina fenólica. .....................................................................................

Esquema 3: Parte da estrutura do lignossulfonato de sódio (Fredheim, 2003) ............................................10

Esquema 4: Hidroximetilação de lignossulfonato de sódio....................................................................... 12 (LIG)......

Esquema 6: Reação de condensação de cadeias poliméricas para formação do pré-polímero formaldeído-

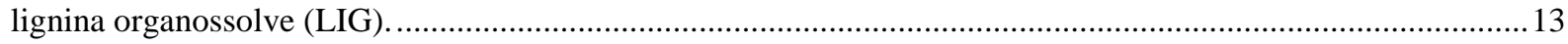

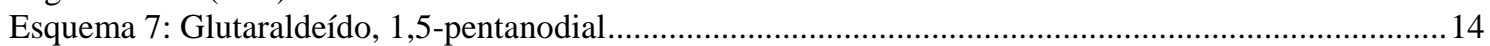

Esquema 8: Representação da reação glutaraldeído com a macromolécula de lignossulfonato de sódio (LIG)........

Esquema 9: Pré-polímero glutaraldeído-lignina organossolve (LIG)...................................................... 15

Esquema 10: Diferentes unidades que constituem a lignina......................................................................... 84 


\section{Resumo}

As resinas do tipo fenólica são amplamente utilizadas devido à sua diversidade de aplicações. Considerando as inúmeras vantagens desta resina (estabilidade térmica e dimensional, alta resistência à chama, etc.), este trabalho teve como um dos objetivos melhorar as propriedades mecânicas do termorrígido fenólico, pois estes são frágeis quando não reforçados. Fibras lignocelulósicas naturais foram usadas como reforço no termorrígido fenólico, o que levou a obtenção de biocompósitos. Devido a grande disponibilidade de fibras de bagaço de cana de açúcar no país, como subproduto de agroindústrias, estas fibras foram utilizadas na produção dos compósitos (sendo substituído em até $70 \%$ da matriz termorrígida por fibra natural), com a finalidade de atribuir maior valor agregado que o tradicionalmente encontrado para estas fibras. Tendo em vista que atualmente estas fibras podem ser obtidas como resíduo da agroindústria na forma queimada e não queimada, um estudo comparativo foi feito usando ambas as fibras. Compósitos fenólicos foram preparados com as fibras queimadas e não queimadas e os resultados obtidos de resistência ao impacto, módulo de armazenamento e absorção de água mostraram que não há diferenças significativas entre as propriedades de ambos. Considerando estes resultados, a continuidade do trabalho foi realizada com as fibras de bagaço de cana queimado, devido à maior disponibilidade atual destas fibras. Também foram utilizadas fibras de sisal, tradicionalmente conhecidas pelas excelentes propriedades mecânicas e disponibilidade em grande escala no país, para fins comparativos. Adicionalmente, visando aumentar a proporção de uso de matéria prima oriunda de fonte renovável, o lignossulfonato de sódio (NaLS) e lignina organossolve (LO), macromoléculas obtidas a partir de fibras lignocelulósicas, substituíram em 100\% o fenol nas reações de obtenção de resinas do tipo resol (obtidas em meio alcalino). Ainda, o formaldeído foi substituído pelo glutaraldeído, um dialdeído, visando-se síntese de resinas alternativas a fenol-formaldeído, tradicionalmente usada. Também, as fibras de bagaço de cana queimadas 
foram tratadas em solução de NaLS, em banho de ultrassom. Este tratamento foi escolhido por se tratar do uso de macromolécula oriunda de fontes renováveis, assim como pelo fato de a fibra (bagaço de cana) conter alto teor de lignina, o que leva à perspectiva de intensificação da afinidade fibra/agente de tratamento, além de intensificar as interações fibra/matriz, devido à presença de anéis do tipo fenólico em ambas, superfícies das fibras e matriz. As fibras foram caracterizadas quanto à composição química e analisadas via termogravimetria (TG), calorimetria exploratória diferencial (DSC), microscopia eletrônica de varredura (MEV), cromatografia gasosa inversa (IGC), espectroscopia na região de infravermelho (IV), cromatografia liquida de alta performance (HPLC, para determinação do teor de açúcares no bagaço de cana queimado) e difração de raios X. O termorrígido fenólico (não reforçado) e compósitos (matriz fenólica e matrizes baseadas em LO e NaLS reforçados por fibras com distribuição aleatória, em diferentes proporções e comprimentos) foram caracterizados por TG, DSC, IV, MEV, DMTA, resistência ao impacto Izod, resistência à flexão quanto à capacidade de absorção de água. Termorrígidos preparados a base de NaLS apresentaram grande fragilidade após a moldagem, tendo sido apenas submetidos a análises de TG, DSC e cromatografia gasosa inversa (IGC), devido à impossibilidade de realizar outros ensaios. As análises de IGC foram realizadas para fibras e matriz, obtendo-se parâmetros relacionados à energia de superfície e disponibilidade de sítios ácidos e básicos. Os resultados de IGC obtidos para as fibras, tratadas e não tratadas, confirmaram que houve a adsorção do lignossulfonato sódio à superfície destas devido ao aumento de sítios ativos (ácidos e básicos) disponíveis. Os valores de IGC obtidos para as matrizes sugerem que as interações fibra/matriz são favorecidas, principalmente quando o NaLS está presente em ambos os componentes (fibra/matriz). Os resultados obtidos na caracterização dos compósitos indicaram que o lignossulfonato de sódio e a lignina organossolve podem substituir o fenol na formulação de resinas. A utilização de fibras como reforço melhorou as propriedades 
mecânicas dos materiais, comparativamente aos termorrígidos. Dentre os compósitos preparados com bagaço de cana, a amostra que apresentou melhor desempenho nos ensaios de impacto foram os compósitos de matrizes baseadas em glutaraldeído-LO $\left(112 \mathrm{~J} \mathrm{~m}^{-1}\right)$ e glutaraldeído-NaLS $\left(82 \mathrm{~J} \mathrm{~m}^{-1}\right)$. Os compósitos de matriz baseada em formaldeído-NaLS reforçados com fibras de sisal apresentaram melhor desempenho no ensaio de resistência ao impacto (1029 $\mathrm{J} \mathrm{m}^{-1}$ ) e menor quantidade de água absorvida quando imerso em água, comparado aos demais compósitos preparados neste trabalho. As análises de MEV comprovaram a intensificação da adesão entre as fibras de sisal e a matriz, quando esta é preparada a partir de NaLS. Compósitos reforçados com fibras de sisal foram os que apresentaram melhor desempenho mecânico, tanto em resistência ao impacto quanto em flexão, provavelmente devido às propriedades intrínsecas das fibras de sisal. No geral, quando os termorrígidos foram reforçados com as fibras lignocelulósicas, bagaço de cana ou sisal, apresentaram resultados de estabilidade térmica e mecânica satisfatórios. Destaca-se que compósitos preparados com alto teor de material proveniente de fonte renovável, como os compósitos reforçados com até $70 \%$ de fibra, e os compósitos com matriz baseada em 100\% de lignossulfonato de sódio e lignina organossolve, apresentaram grande potencial para diferentes aplicações, tais como no setor de embalagens e automotivo, neste caso para aplicações não estruturais. 


\section{Abstract}

Phenolic resins are widely known due to their diverse applications. Considering the many advantages of this type of resin (flame resistance, thermal and dimensional stability, etc), this study has one objective: the improvement of the mechanical properties of the phenolic thermoset, because this material is fragile when it is not reinforced. Natural lignocellulosic fibers were used as reinforcement in the phenolic thermoset leading to the obtaining of biocomposites. Because the fibers from sugarcane bagasse are byproducts widely available by agricultural industries in this country, these fibers were used in the production of the composites (the thermoset phenolic was replaced by up to $70 \%$ natural fibers) - the purpose was to assign greater value than traditionally found for these fibers. Currently, sugarcane fibers can be obtained from natural and burned bagasse. A comparative study was realized using both fibers. Phenolic composites were prepared with the burned fibers and the results obtained from the impact resistance, storage modulus and water absorption showed that they are not significantly different when it comes to the properties of both. Considering these results, the continuity of this study was realized with the burned fibers of sugarcane due to the higher and current availability of this fiber. Lignocellulosic fibers, are traditionally known because of their excellent mechanical properties and wide availability, like the sisal ones used in the present work for comparative reasons. Sisal fibers are available in large scale, facilitating their use. Additionally, sodium lignosulphonate (NaLS) and organosolv lignin (LO), which are macromolecules obtained from the lignocellulosics fibers were used to increase the proportion of the raw materials from renewable sources for a possible phenol substitute in resin reaction, resol type (an alkaline medium). Also, formaldehyde was replaced by glutaraldehyde aiming at the synthesis alternative resin to phenol-formaldehyde, which is traditionally used. Furthermore, burned sugar cane bagasse fibers were treated in NaLS 
solution, in ultrasonic bath. This treatment was chosen because this macromolecule is from renewable resources and as well as the fibers (sugarcane bagasse) have high content of lignin, which leads to the perspective of affinity intensification between fibers/lignin and fibers/matrix, due to the presence of the aromatics rings in both surfaces. The fibers were characterized in terms of chemical composition and analyzed by thermogravimetry (TG), differential scanning calorimetry (DSC), scanning electron microscopy (SEM), inverse gas chromatography (IGC), infrared spectroscopy (IV), high performance liquid chromatography (HPLC, determination of the sugar content in the burned sugar cane bagasse) and X-ray diffraction. The lignin and resin were characterized by SEC, RMN 1H and RMN 31P. The thermosets (not reinforced) and composites (phenolic matrix and LO and NaLS matrix reinforced with randomly dispersed fibers) were characterized by TG, DSC, IV, Izod impact strength, MEV, flexural strength, DMTA and also the water absorption capacity was evaluated. Thermoset prepared based on NaLS showed great weakness after molding, being submitted only to analysis by TG, DSC and inverse gas chromatography (IGC), due to the impossibility of doing other tests. IGC analysis were realized for fibers and matrix. Parameters related to surface energy and availability of acids and basics sites were obtained. IGC results obtained for the fibers, treated and untreated, confirm that there was adsorption of lignosulphonate in these surfaces due to the increase of available active sites (acids and basics). IGC values obtained for matrix suggest that fiber/matrix interactions are favored, mainly when the NaLS is present in both components (fiber/matrix). The results obtained in the characterization of the composites indicated that lignosulphonate sodium and organosolv lignin can substitute the phenol in the resin formulation. Fibers used as reinforcement improved the mechanical properties of materials, compared to thermosets. Among the composites prepared with sugarcane bagasse, the sample that showed better performance in the impact test were the composites based on glutaraldehyde $-\mathrm{LO}(112 \mathrm{~J} \mathrm{~m}-1)$ and 
glutaraldehyde -NaLS (82 J m-1). Composites based on formaldehyde -NaLS reinforced with sisal fibers showed better performance in impact test (1009 J m-1) and less water absorbed when immersed in water, compared to others composites prepared in this study. SEM analysis confirmed the adhesion intensification between the sisal fibers and the matrix, when this is prepared from NaLS. Composites reinforced with sisal fibers showed the best mechanical performance, such as impact strength and flexural strength, probably due to the intrinsic properties of sisal fibers. In general, when the thermosets were reinforced with lignocellulosic fibers, sugarcane bagasse or sisal, they showed satisfactory results of the thermic and mechanical stability. It should be highlighted that composites prepared with high content of material from renewable sources, as the composites reinforced up to $70 \%$ fibers and composites with matrix based on $100 \%$ lignosulphonate and organosolv lignin, they showed great potential to different applications, such as in the packaging sector and the automotive one, in this case to non-structural applications. 


\section{Lista de Abreviaturas e Siglas}

\begin{tabular}{|c|c|}
\hline $\mathbf{A} \mathbf{N}_{\mathbf{S}}$ & Caráter ácido da superfície do sólido \\
\hline $\mathbf{A Q}$ & Antraquinona \\
\hline CFen & Compósito fenólico \\
\hline CFenBCNQ & Compósito fenólico reforçado com bagaço de cana não queimada \\
\hline CFL & Compósito formaldeído-lignossulfonato de sódio \\
\hline CFLBCQ & $\begin{array}{l}\text { Compósito formaldeído-lignossulfonato sódio reforçado com bagaço de cana } \\
\text { queimada }\end{array}$ \\
\hline CFLBCQT & $\begin{array}{l}\text { Compósito formaldeído-lignossulfonato sódio reforçado com bagaço de cana } \\
\text { queimada e tratada }\end{array}$ \\
\hline CFLO & Compósito formaldeído-lignina organossolve \\
\hline CFLOBCQ & $\begin{array}{l}\text { Compósito formaldeído-lignina organossolve reforçado com bagaço de cana } \\
\text { queimada }\end{array}$ \\
\hline CFLOS & Compósito formaldeído-lignina organossolve reforçado com fibra de sisal \\
\hline CFLS & Compósito formaldeído-lignossulfonato sódio reforçado com fibra de sisal \\
\hline CGLO & Compósito glutaraldeído-lignina organossolve \\
\hline CGLO & Compósito glutaraldeído-lignina organossolve \\
\hline CGLOBCQ & $\begin{array}{l}\text { Compósito glutaraldeído-lignina organossolve reforçado com bagaço de cana } \\
\text { queimada }\end{array}$ \\
\hline CGLOS & Compósito glutaraldeído-lignina organossolve reforçado com fibra de sisal \\
\hline $\mathrm{CHCl}_{3}$ & Clorofórmio \\
\hline DMTA & Análise Térmica Dinâmica-Mecânica (Dynamic Mechanical Thermoanalysis) \\
\hline $\mathbf{D N}_{\mathbf{S}}$ & Caráter básico da superfície do sólido \\
\hline DSC & Calorimetria Exploratória Diferencial (Differential Scanning Calorimetry) \\
\hline dTG & Primeira derivada da curva termogravimétrica \\
\hline E' & Módulo de armazenamento \\
\hline E” & Módulo de perda \\
\hline FBCNQ & Fibra bagaço de cana não queimada \\
\hline FBCQ & Fibra de bagaço de cana queimada \\
\hline FBCQT & Fibra bagaço de cana queimada e tratada \\
\hline FS & Fibra de sisal \\
\hline Ic & Índice de cristalinidade \\
\hline IGC & Cromatografia Gasosa Inversa (Inverse Gas Chromatography) \\
\hline
\end{tabular}


IV

LO

MEV

Mn

Mw

NaLS

RMN

SEC

TF

Tg

TG

THF

ton

$\mathbf{t}_{\mathbf{r}}$

Vn

$\gamma_{\mathrm{S}}^{\mathrm{d}}$
Espectroscopia na região de infravermelho

Lignina organossolve

Microscopia Eletrônica de Varredura

Massa molar numérica média

Massa molar ponderal média

Lignossulfonato de sódio

Ressonância Magnética Nuclear

Cromatografia de Exclusão por Tamanho (Size Exclusion Chromatography)

Termorrígido fenólico

Temperatura de transição vítrea

Termogravimetria

Tetraidrofurano

Toneladas

Tempo de retenção

Volume de retenção

Energia livre de superfície 


\section{Introdução}

Materiais de origem natural são considerados primordiais no desenvolvimento de novos materiais, que possam substituir produtos oriundos de rota petroquímica (Haensel, 2009). As fibras naturais são de grande interesse na substituição, parcial ou total, de fibras sintéticas, para uso como reforço de matriz polimérica. Esta classe de materiais de engenharia, matriz polimérica reforçada, é chamada de compósitos ou materiais compostos, correspondendo a materiais heterogêneos, compostos com duas fases distintas, sendo a fase continua chamada de matriz e a fase descontinua de reforço. Atualmente, estas fibras estão disponíveis em grande quantidade, seja pelo cultivo especificamente voltado para comercialização, ou como subprodutos agroindustriais (Gauder; Graeff-Hönninger; Claupein; 2011, Furtado; Scandiffio; Cortez; 2011).

Os biocompósitos, em que pelo menos um dos componentes é de origem natural, são atrativos devido à possível combinação de propriedades (Belgacem, 2005; John, 2008; Giancaspro, 2009; Alam, 2009; Bras, 2010). Estes materiais muitas vezes resultam em estruturas de baixo peso e aplicações diversificadas. Em torno de 1940, predominavam compósitos termorrígidos e termoplásticos reforçados com fibras de vidro. Pesquisas desenvolvidas à época, já mostravam que em certas aplicações, os compósitos reforçados com fibras naturais tinham competitiva performance com relação às fibras de vidro (Mohanty, 2005). 
Diversas plantas, como sisal, curauá, algodão, juta, são cultivadas e preparadas para serem comercializadas, com a finalidade de serem aplicadas nas indústrias de grande porte, para a substituição de materiais sintéticos (Johnson, 2008; Petinakis, 2009; Acha, 2009). Outras fibras como o bagaço de cana e palhas de milho, de arroz, de café, de soja, as quais correspondem a subprodutos agroindustriais abundantes, atualmente estão tendo novas aplicações na indústria. Um dos exemplos mais recentes vem da indústria automobilística, que tradicionalmente utilizava materiais como fibras de vidro ou carbono, entre outros para modificar a desempenho dos materiais plásticos. Atualmente, estas indústrias têm enorme interesse em desenvolver materiais do tipo compósito a base de fibras vegetais (Ashori, 2008).

A utilização de fibras naturais disponíveis em grande quantidade, como reforço em compósitos poliméricos, emerge com grande potencial por diversos motivos, dentre eles o baixo custo e a compatibilidade com o meio ambiente (Tayeb, 2008; Furtado, 2011; Rolz, 2010). Dentre as fibras naturais de grande interesse estão as fibras de bagaço de cana, por serem encontradas em grande escala na agroindústria brasileira (Pippo, 2007). O bagaço de cana-de-açúcar é um dos subprodutos agroindustriais mais abundantes no mundo, particularmente no Brasil (Figura 1), sendo o resíduo produzido em maior escala na agroindústria brasileira, tendo o país produzido 729559596 toneladas de cana de açúcar em $2010^{1}$. As sobras anuais são estimadas em torno de dezenas de milhões de toneladas. 


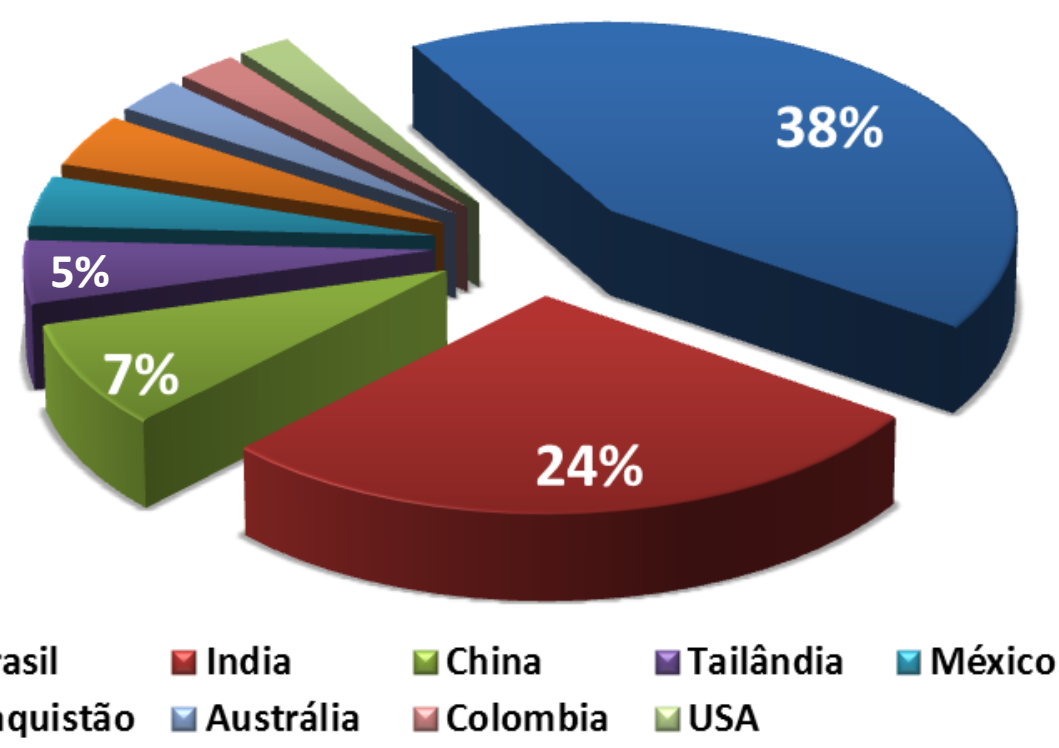

Figura 1: Produção anual de cana de açúcar mundial, ano de 2010 (IBGE, 2011).

Uma grande parte do bagaço gerado é utilizada como fonte de energia para a própria produção do açúcar. No entanto, as fibras podem também passar por hidrólise para produzir etanol (chamado atualmente de bioetanol, ou etanol celulósico) a partir dos seus açúcares fermentáveis (Silva, C. F., 2011; Gauder, 2011; Duarte-Almeida, 2011). A cana de açúcar é uma das tradicionais plantas cultivadas no Brasil, envolvendo programas cooperativos com laboratórios que têm como finalidade a valorização do bagaço, incorporando-o a outros materiais.

A mecanização da agroindústria tem levado à disponibilidade do bagaço de cana de açúcar que passa ou não previamente pela queima. Este fato, aliado à legislação ambiental, que impõe que gradualmente a cana de açúcar não seja mais queimada, leva a perspectiva que futuramente grandes quantidades de bagaço de cana não queimado sejam disponibilizadas.

As fibras de sisal são produzidas anualmente em todo o mundo, cerca de 4,5 milhões de toneladas. No Brasil, atualmente o maior produtor, a produção de sisal em 2010 chegou a 
253067 toneladas $^{2}$, sendo que 95,5\% desta produção é oriunda do estado da Bahia. Diferentemente do bagaço de cana, o sisal é produzido diretamente para a comercialização das fibras.

Assim, no presente trabalho pretendeu-se principalmente comparar a atuação do bagaço de queimado e não queimado como agente de reforço de matriz termorrígida, no preparo de compósitos. Adicionalmente, para fins comparativos, compósitos reforçados com fibras de sisal também foram preparados.

As resinas termorrígidas são muito utilizadas devido ao excelente desempenho em altas temperaturas e sob abrasão (KU, 2008). Há um grande interesse na utilização das fibras naturais como reforço de matrizes fenólicas (MEGIATTO, 2008; RAMIRES, 2009; RAMIRES, 2010; BARBOSA, 2010), pois estas são obtidas da biomassa, normalmente com baixo custo, não são tóxicas e são facilmente isoladas (ZÁRATE, 2008).

No presente trabalho, matrizes termorrígidas do tipo fenólica forma preparadas. Macromoléculas obtidas de fontes renováveis, lignina organossolve e lignossulfonato de sódio, foram usadas no preparo destas resinas poliméricas as quais foram reforçadas com fibras de bagaço de cana e sisal.

\section{1. Resinas do tipo Fenólicas}

\section{1. 1. Resinas Fenólicas}

Resinas fenólicas são tradicionalmente preparadas pela reação de fenol, ou de um fenol substituído no anel aromático, com um aldeído (normalmente o formaldeído), na presença de um catalisador (ácido ou base). Estas resinas são produtos de reação de polimerização do tipo policondensação (KNOP, 1985; FROLLINI, 2002; HANDBOOK, 1998). 
Devem ser consideradas três sequências de reação na obtenção de resinas fenólicas: adição do formaldeído ao fenol, crescimento da cadeia ou formação do pré-polímero e, finalmente, o entrecruzamento ou reação de cura (KNOP, 1985; FROLLINI, 2002; HANDBOOK, 1998).

\section{1. 1. 1. Resina Fenólica do tipo Resol}

As resinas fenólicas do tipo resol são produzidas, por exemplo, utilizando formaldeído, fenol e catalisador alcalino como NaOH ou KOH (KNOP, 1985).

Os resóis podem ser sólidos ou líquidos, solúveis ou insolúveis em água, de cura lenta ou rápida. Na etapa inicial forma-se o ânion fenolato (sob ação do catalisador), o qual reage, por exemplo, com formaldeído (que reage na forma de metileno glicol, já que uma solução aquosa do aldeído é usada), ocorrendo a introdução de grupos $o$-hidroximetila e $p$ hidroximetila, ou seja, nas posições ativadas para o ataque eletrofílico devido à “deslocalização" de elétrons.

Os hidroximetil-fenóis assim obtidos (da reação de ânion fenolato com o metileno glicol) são relativamente estáveis na presença de álcali, mas pode ocorrer autocondensação (Esquema 1), com liberação de água ou de formaldeído, formando fenóis dinucleares e polinucleares, nos quais os núcleos fenólicos estão geralmente ligados através de grupos metilênicos. 

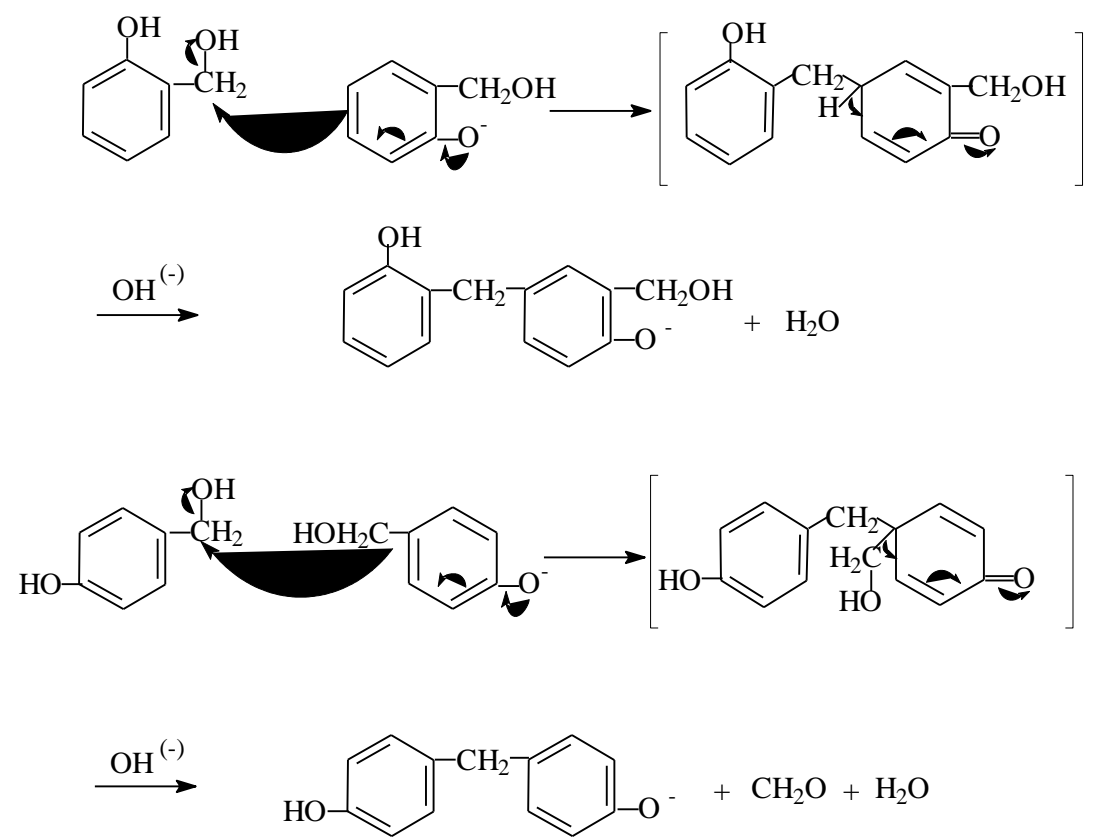

Esquema 1: Autocondensação dos hidroximetilfenóis (SAUNDERS, 1998).

A formação de pontes fenil-metilênicas é favorecida acima de $150^{\circ} \mathrm{C}$ e sob condições fortemente alcalinas. A formação de dibenzil-éter, originando as chamadas pontes etéreas, é favorecida a temperaturas mais baixas e meio neutro (KNOP, 1985), sendo que podem ocorrer rearranjos, originando pontes metilênicas.

No presente trabalho, as resinas preparadas corresponderam a fenólicas do tipo resol.

\section{1. 1. 2. Reação de entrecruzamento de Resóis (Cura)}

Os pré-polímeros do tipo resol, obtidos em condições alcalinas, são neutralizados ou deixados levemente ácidos antes de se realizar a etapa de entrecruzamento (cura), a qual geralmente ocorre por aquecimento, por catálise ácida, ou ambos (KNOP, 1985).

O processo de cura (entrecruzamento) é complexo, podendo envolver vários tipos de reações. Resumidamente, pode-se propor que na cura térmica, como a que foi considerada no presente trabalho, o carbono eletrofílico dos grupos hidroximetila livres interage com o 
anel aromático de uma cadeia vizinha, provocando o entrecruzamento, por meio de uma reação do tipo substituição eletrofílica em anel aromático (Esquema 2) (FROLLINI, 2002):
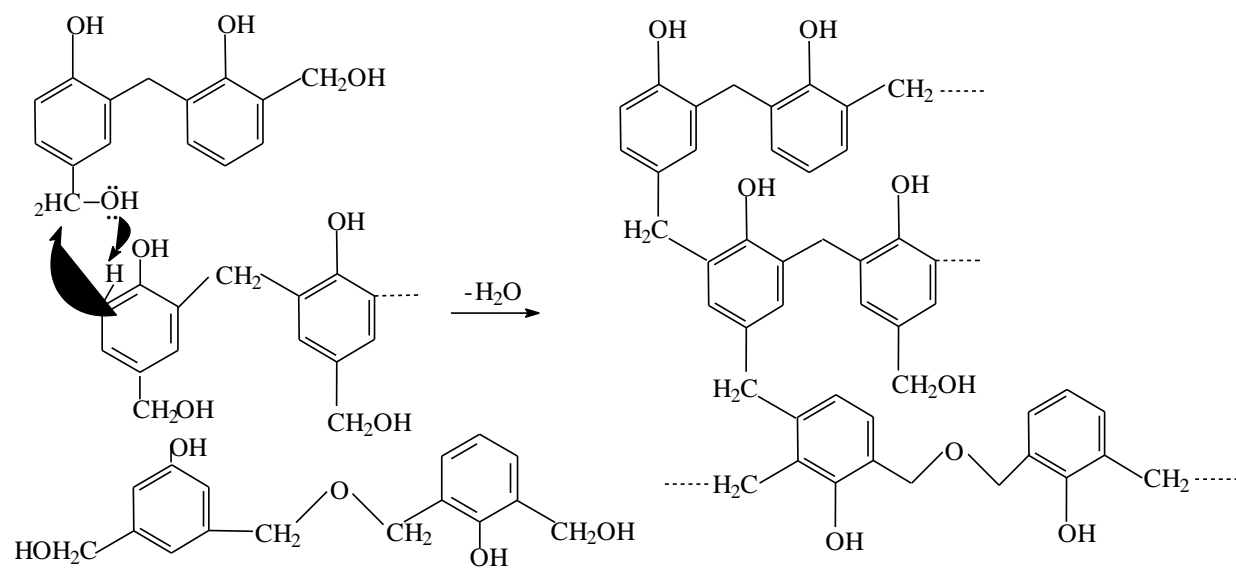

Esquema 2: Entrecruzamento de resina fenólica.

Como após o entrecruzamento o produto obtido é insolúvel, torna-se difícil a investigação a respeito de todos os tipos de reações que realmente ocorrem.

As ligações do tipo éter, que podem ligar os anéis fenólicos no pré-polímero (Esquema 2), não são muito estáveis e podem sofrer ruptura, dependendo das condições de reação, levando a formação de metileno-quinonas. Estruturas do tipo estilbeno podem ser obtidas a partir de metileno-quinona, e esta estrutura pode também estar incorporada à estrutura da macromolécula entrecruzada.

As resinas fenólicas são atrativas para aplicações em compósitos em larga escala, devido à baixa geração de fumaça e superior resistência ao fogo. Quando comparadas até mesmo a outras resinas termorrígidas, tais como poliésteres e epóxis, o custo é consideravelmente menor que muitas resinas de alto desempenho, tais como PEEK (poli-éteréter-cetona) (FRIED, 1995; PICKERING, 2008; CHAND, 2008).

A resistência ao fogo das resinas fenólicas está diretamente relacionada à estrutura e aos mecanismos de decomposição térmica destes polímeros termorrígidos. A decomposição 
térmica das resinas fenólicas leva à produção de uma cadeia estrutural entrecruzada, resultando em taxas de propagação de chamas extremamente baixas. As fenólicas possuem um alto índice crítico de oxigênio (45-70\%) e, portanto, são difíceis de iniciar a ignição e de se manter em condição de queima (incêndio). Em adição, as fenólicas produzem fumaça menos tóxica do que a maioria dos retardantes de chama dos plásticos (KUZAK, 1998; Hoareau, 2006).

As fenólicas também exibem estabilidade dimensional, estabilidade térmica e resistência química em temperaturas elevadas. Rotineiramente, engenheiros especificam as fenólicas para moldagens que exigem medidas de precisão e aplicação do material em ambientes agressivos. As excelentes propriedades "termoquímicas" das resinas fenólicas estão diretamente relacionadas à alta densidade de entrecruzamento (“crosslink") resultante da cura (polimerização) das mesmas. Entretanto, a alta densidade de entrecruzamento resulta em baixa resistência à fratura, tornando as resinas fenólicas mais frágeis, quando comparadas a muitos outros plásticos, o que impede a aplicação destas em alguns casos (KUZAK, 1998; FROLLINI, 2002).

Embora as resinas fenólicas apresentem diversas características atrativas, sua resistência ao impacto é comprometida pela liberação de água durante a reação de condensação, cuja vaporização provoca a formação de vazios ("voids") durante a cura, no caso dos resóis. Isto pode levar a microfraturas e/ou concentração de tensão no interior do moldado (KUZAK, 1998; FROLLINI, 2002).

Considerando as inúmeras vantagens de aplicação de resinas fenólicas, conforme previamente citado e que, a baixa resistência ao impacto deste termorrígido pode comprometer sua ampla utilização, buscou-se no presente trabalho melhorar esta propriedade com a introdução de reforços fibrosos oriundos de fontes vegetais. Além de melhorar propriedades mecânicas, a substituição de parte da resina por fibras vegetais 
diminui o custo do produto, colaborando com a utilização de material vegetal excedente, como é o caso de bagaço de cana-de-açúcar, ou expandir a aplicação de material vegetal, como o sisal, para produtos com maior valor agregado.

1. 2. Resinas do tipo fenólicas produzidas a partir de matéria-prima de fonte vegetal

A lignina, uma macromolécula natural abundantemente encontrada como subproduto, por exemplo, da indústria de papel e celulose, apresenta grande potencial para substituição do fenol no preparo de resinas.

Diversas espécies de plantas têm interesse comercial como fontes de celulose, para a produção de papel e outros produtos. Assim, nos processos de extração das fibras, como a polpação álcali ou sulfito, grandes quantidades de lignina são liberadas como álcali lignina ou sulfonatos de lignina (processo Kraft) (BELGACEM, 2008).

A lignina que resulta de processos tipo Kraft (lignossulfonato, ou lignina sulfonada, Esquema 3), é obtida como subproduto do processo de polpação do sulfito da madeira. Ao contrário das ligninas, os lignossulfonatos são solúveis em água devido à presença dos grupos sulfonatos introduzidos. 


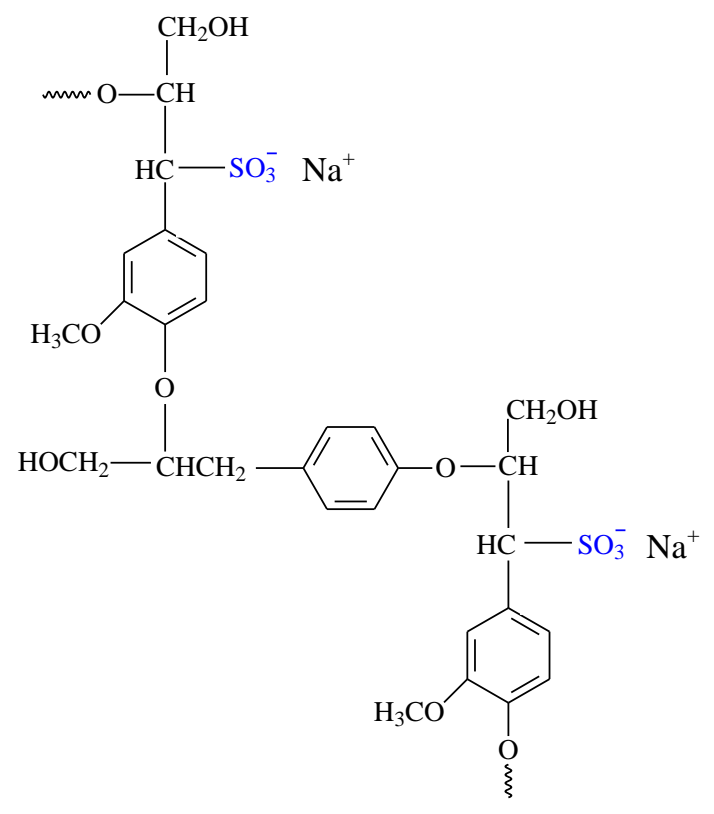

Esquema 3: Parte da estrutura do lignossulfonato de sódio (Fredheim, 2003).

As ligninas, tendo estrutura rica em anéis aromáticos e grupos polares $-\mathrm{OH}$, apresentam se como forte candidata para a substituição do fenol, como um dos componentes para a reação de obtenção da resina fenólica (ALONSO, 2004).

As ligninas, uma das macromoléculas naturais mais abundantes no planeta é formado por unidades de anéis fenilpropânicos substituídos (unidades $\mathrm{C}_{9}$ ), ligados através de diferentes tipos de ligações, como por exemplo, do tipo éter ou carbono-carbono (FENGEL, 1989; ROWELL, 2000). A lignina apresenta diferentes grupos ligados à sua estrutura, variando de acordo com a espécie de planta. Sua morfologia encontrada pode ser bi- ou tri-dimensional, dependendo do tipo de planta que a lignina foi extraída. O processo de extração pode interferir na estrutura final da lignina (HAGE, 2009; PEREIRA, 2007).

Os grupos funcionais presentes na lignina funcionam como centros ativos para interações químicas e biológicas. As principais unidades são: guaiacila, siringila e parahidroxifenila (Figura 2), estas unidades diferem entre si pela posição dos grupos orto-metil ligado ao anel aromático. 


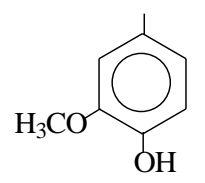

(1)

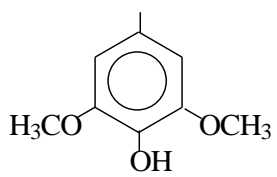

(2)

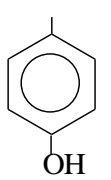

(3)

Figura 2: Unidades presentes na lignina: (1) guaicila; (2) siringila e (3) p-hidroxifenila (Fengel, 1989).

Grande quantidade de lignina é isolada como sub-produto de processo de polpação e sacarificação à partir de plantas como a cana-de-açúcar. As ligninas utilizadas neste trabalho correspondem ao produto do processo organossolve, o qual utiliza exclusivamente solvente orgânico para extração desta macromolécula, assim como do processo Kraft.

A lignina apresenta menor reatividade que o fenol nas reações com o formaldeído, por este motivo é necessário modificar sua estrutura para obter uma quantidade maior de sítios reacionais. Neste trabalho, a modificação da lignina foi realizada via hidroximetilação. Em uma primeira etapa da reação, o formaldeído reage com a lignina, principalmente envolvendo as posições orto disponíveis no anel aromático (Esquema 4). Em uma segunda etapa da síntese ocorre a condensação, na qual as moléculas de lignina hidroximetiladas reagem com outras moléculas de lignina dando origem aos oligômeros (RAMIRES, 2010A; PIMENTA, 2002). 

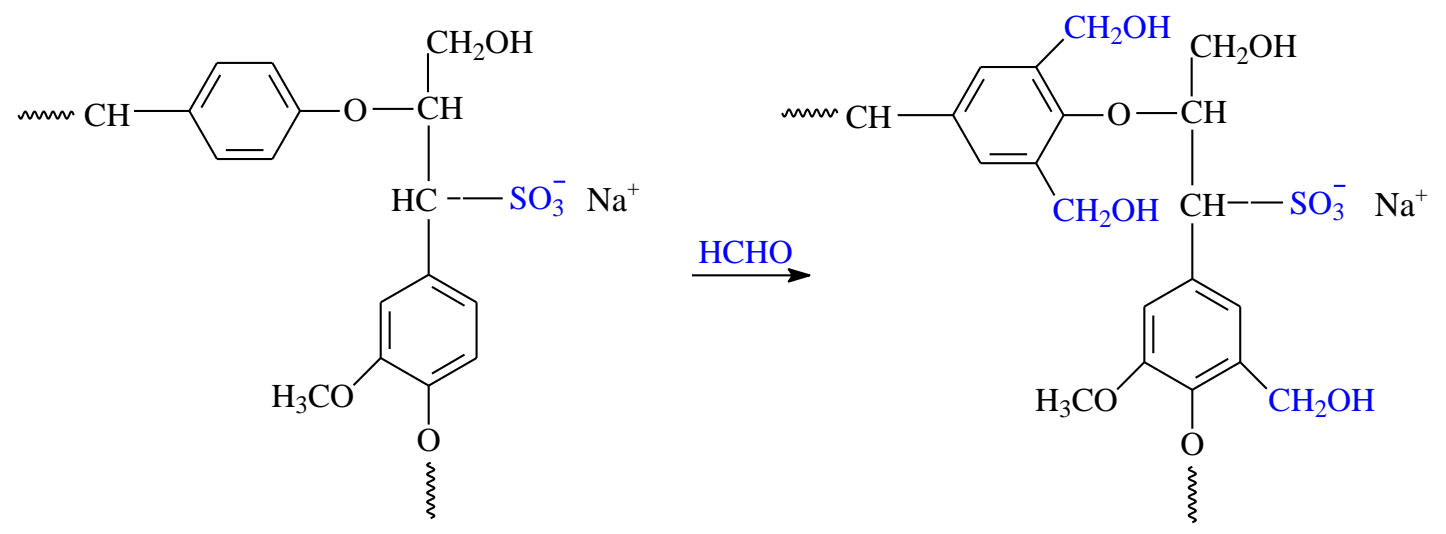

Esquema 4: Hidroximetilação de lignossulfonato de sódio.

O mecanismo proposto para obtenção da resina consiste na hidroximetilação da lignina com o formaldeído, ou seja, o formaldeído reage com a lignina nas posições orto e para disponíveis no anel aromático (Esquema 5). Esta etapa é seguida da auto-condensação das macromoléculas hidroximetiladas com outras moléculas de lignina (Esquema 6).

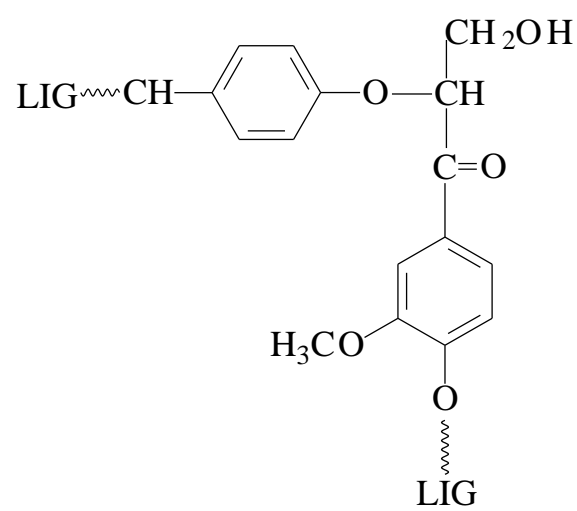

Lignina Organossolve

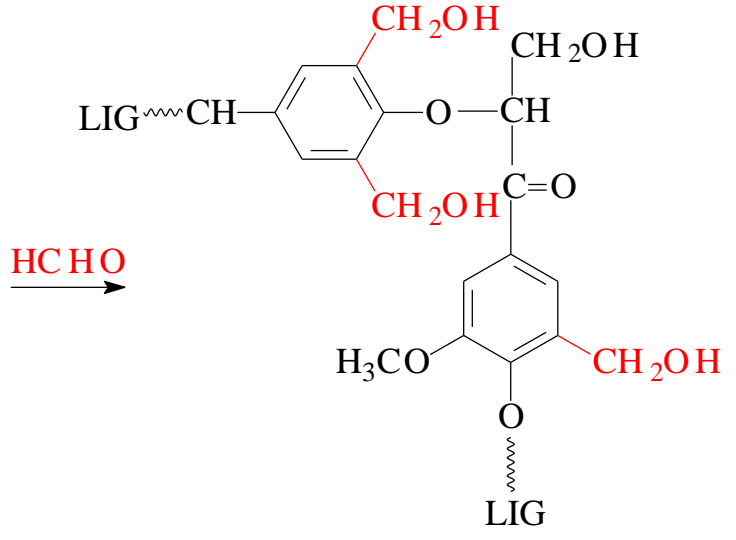

Lignina hidroximetilada

Esquema 5: Representação da reação de hidroximetilação dos anéis aromáticos da lignina organossolve (LIG). 
<smiles>CC(Cl)c1ccc(OC(C)(C)C)c(CO)c1</smiles><smiles>CC(C)c1ccc(OC(CO)C(=O)C#N)c(CCO)c1</smiles>

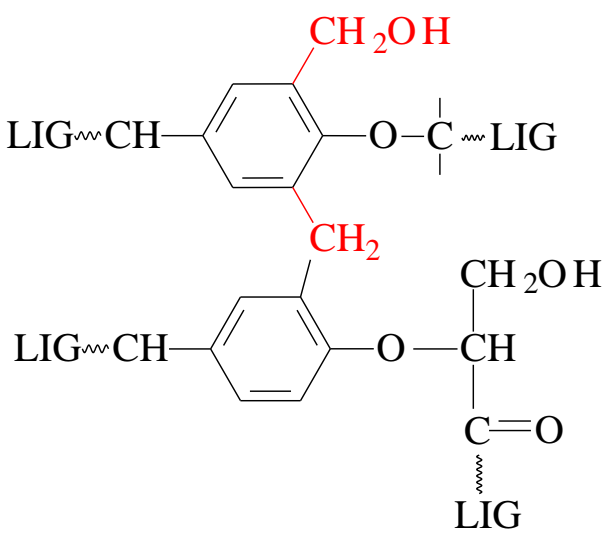

Esquema 6: Reação de condensação de cadeias poliméricas para formação do pré-polímero formaldeído-lignina organossolve (LIG).

Dentre os diversos trabalhos apresentados na literatura, majoritariamente é destacado o uso da lignina como substituto parcial do fenol para aplicações em adesivos, apresentando resultados satisfatórios para esta aplicação. Em outros trabalhos, encontrados em menor número, a substituição parcial de fenol por lignina visa a aplicação da resina em compósitos reforçados com fibras também obtidos de fontes renováveis. (ALONSO, 2004; PAIVA, 2006; RAZERA, 2006, RAMIRES, 2010a).

Neste trabalho, tendo como base o processo tradicional de obtenção das resinas fenólicas, foi realizada a substituição total do fenol por lignossulfonato de sódio e lignina organossolve, visando à aplicação como matriz em compósitos.

$\mathrm{O}$ glutaraldeído, 1,5-pentanodial $\left(\mathrm{C}_{5} \mathrm{H}_{8} \mathrm{O}_{2}\right)$, um dialdeído (Esquema 7), é extensamente utilizado na reticulação e imobilização de proteínas, através da reação com os grupos amino residuais destes (BEPPU, 1999; YANG, 2008), em bio-nanopartículas, compósitos de membranas poliméricas (ZANG, 2007), como agente modificante em biopolímeros e biosensores (TAN, 2009 ; SIMÕES, 2009). 


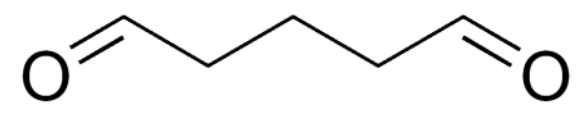

Esquema 7: Glutaraldeído, 1,5-pentanodial

No presente estudo o formaldeído, normalmente utilizado na síntese de resina fenólica, foi substituído por glutaraldeído na preparação de algumas resinas (Esquema 8).<smiles></smiles>

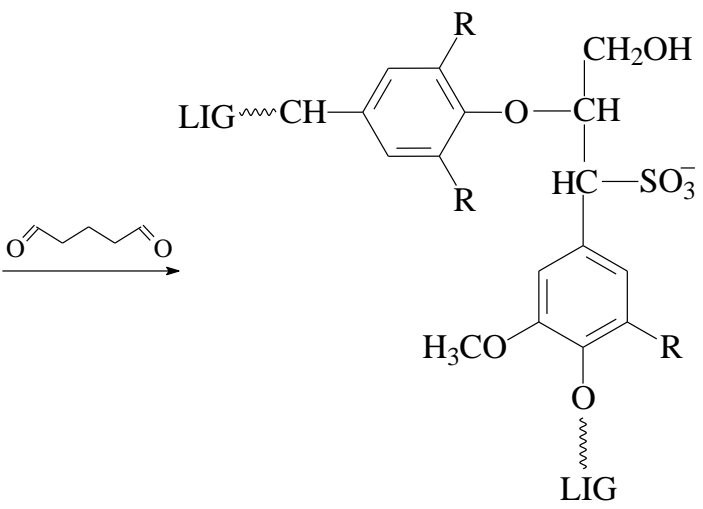

$\mathrm{R}=\mathrm{CHOHCH}_{2} \mathrm{CH}_{2} \mathrm{CH}_{2} \mathrm{COH}$

Esquema 8: Representação da reação glutaraldeído com a macromolécula de lignossulfonato de sódio (LIG).

Kumar et al (2010), preparou compósitos de matriz rica em proteínas de soja reforçadas com fibras lignocelulósicas, sendo utilizado glutaraldeído como agente de entrecruzamento. $\mathrm{O}$ resultado foi satisfatório, pois a resistência dos compósitos à água aumentou significativamente, sendo o material 100\% biodegradável.

Shiau et al. (1997) descrevem que a adição de pequenas porções do produto da reação entre resorcinol e glutaraldeído, à resina fenol-formaldeído, acelera a cura da resina. Este estudo inclui o uso da resina do tipo fenólica para a produção de uma variedade de compósitos reforçados com lascas de madeira, fibras e partículas (celulósicas e lignocelulósicas). 
No presente trabalho, a utilização das ligninas isoladas por processos distintos, e de glutaraldeído, na preparação de resinas, foi baseada na expectativa que no final ao processo se obteria resinas com boas propriedades para a aplicação em compósitos, sendo estes baseados em alto teor de matéria prima obtida de fontes naturais.

O formaldeído também foi substituído pelo glutaraldeído na preparação de resinas baseadas em lignina organossolve, seguindo o discutido para resinas baseadas em NaLS (Esquema 8).

Após a etapa de reação com glutaraldeído, ocorre a auto-condensação entre a molécula de lignina, sendo assim gerado com o pré-polímero glutaraldeído-lignina (Esquema 9).

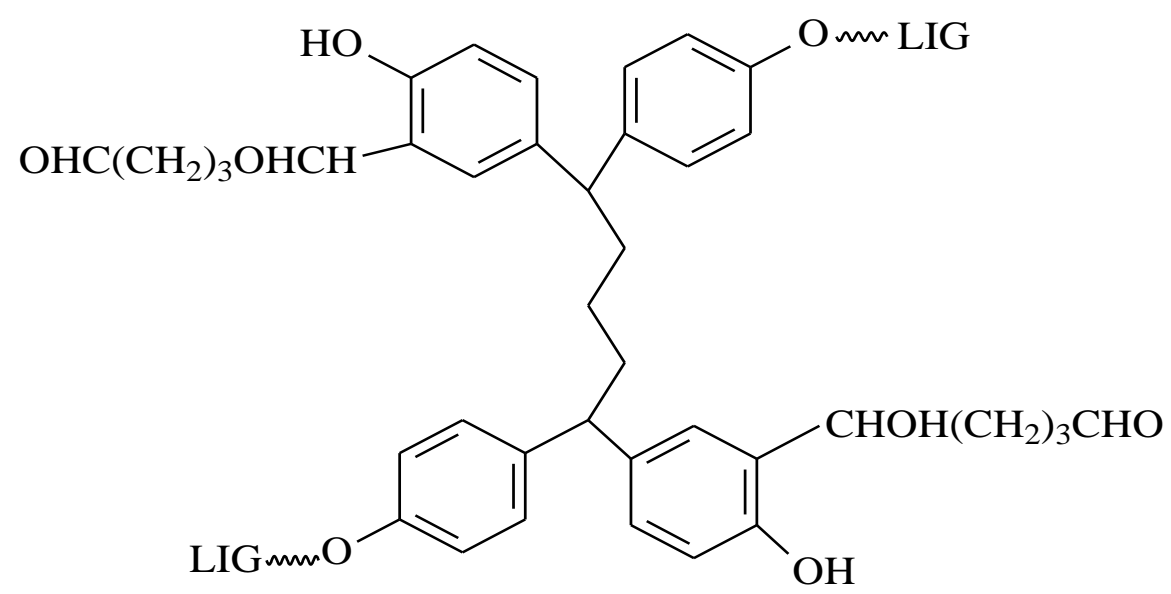

Esquema 9: Pré-polímero glutaraldeído-lignina organossolve (LIG).

\section{3. Compósitos de matriz polimérica}

1. 3. 1. Aspectos gerais.

Compósitos fibrosos podem ser considerados como materiais em que uma fase atua como reforço de uma segunda fase, chamada matriz. Reforços, como fibras, são adicionados a polímeros (matriz) para melhorar as propriedades dos mesmos, o que pode ainda estar aliado à busca pela redução de custos (KNOP, 1985; HERAKOVICH, 1998). O grande desafio consiste na combinação das fibras com a matriz, de tal forma que o material mais 
eficiente para determinada aplicação seja produzido (PICHERING, 2008; CHAND, 2008; GAUDER, 2011; PINJARI, 2010; HEBEISH, 2011).

Nos compósitos, a região de interação entre os componentes é referida como interface. $\mathrm{Na}$ mistura de dois componentes, de natureza química diversa, de qualquer dimensão ou forma, para que ocorra uma interação é essencial a existência de áreas de contato entre eles. Quanto maior for essa área, tanto maior será a possibilidade de ocorrer entre os dois componentes uma interação de natureza física, química ou físico-química (ALVEREZ, 2005; POTAN, 2000; BELLMANN, 2005). Em todos os casos, a interação entre a fase dispersa e a fase matricial depende da extensão da área de contato e da afinidade entre os componentes. A afinidade pode ser intensificada, por exemplo, por tratamentos físicos ou químicos aplicados à superfície das fibras (em se tratando de compósitos fibrosos) (BLEDZKI, 1996; JOSEPH, 1996; BLEDZKI, 1999; GHOSH, 2000; MANSOUR, 2001). As características da interface dependem, portanto, das propriedades químicas e físicas dos constituintes, o que faz com que a interface tenha uma forte influência na propriedade do material composto, por exemplo, no ensaio de resistência ao impacto, uma das propriedades que receberam destaques no presente trabalho.

As propriedades dos compósitos com fibras curtas são muito diferentes das propriedades dos compósitos com fibras contínuas. O processo de manufatura de compósitos com fibras longas é mais lento, quando comparado ao processo para fibras curtas. Para compósitos de matriz termorrígida, as fibras curtas são mais convenientes, por possibilitar um processamento mais rápido e resultar em um material de alta performance (MATTHEWS, 1994; JACOB, 2004).

Neste trabalho foram avaliadas propriedades, como resistência ao impacto e absorção de água, de compósitos de matriz termorrígida do tipo fenólica, em função do 
comprimento e da quantidade de reforço (fibras curtas de bagaço de cana de açúcar queimada e não queimada, e de sisal, com distribuição aleatória na matriz).

\section{3. 2. Interface fibra matriz}

A interface entre os constituintes de um compósito é um fator importante e influi nas propriedades finais do material. Processamentos não adequados para obtenção do material, podem ter como consequência a falta de interação intermolecular entre os componentes (MATTHEWS, 1995; BELLMANN, 2005).

A compatibilidade e molhabilidade entre os componentes são fatores essenciais para um resultado satisfatório no que diz respeito à adesão, o que normalmente é refletido nas demais propriedades do compósito. No caso das fibras celulósicas, por exemplo, grupos hidroxilas estão presentes na superfície, viabilizando ligações hidrogênio, o que influencia na melhora das propriedades mecânicas, desde que a natureza da matriz o permita. Mas, as fibras lignocelulósicas por serem extremamente hidrofílicas, podem levar à presença de água, o que

pode comprometer o desempenho do material. Também para as fibras lignocelulósicas, a interação com a matriz é um fator que determina algumas propriedades dos compostos. Para alguns tipos de matrizes e fibras, é necessário o uso de aditivos para facilitar a interação entre os componentes (ROWELL, 1996; HERRERA-FRANCO, 2005).

$\mathrm{Na}$ interface entre as fases pode ocorrer diferentes tipos de interação ou mecanismos, tais como, ligação química, adesão mecânica, atração eletrostática, interdifusão, entre outros (MATTHEWS, 1995). Componentes de matriz e reforço podem se difundir ou migrar para a região de interface, podendo ocorrer uma reação ou interdifusão. As propriedades dos compósitos são majoritariamente governadas pela interação fibra-matriz, daí a importância de estudos investigando a natureza da interface entre os constituintes do compósito (GASSAN, 2001). 


\section{3. 3. Fibras lignocelulósicas como agentes de reforço em compósitos}

Fibras sintéticas (aramidas, vidro, carbono) são de grande interesse das indústrias de compósitos de matriz termoplástica e termorrígida, mas por questões de custo e/ou restrições ambientais, novos materiais estão sendo investigados. Buscam-se nestes novos materiais boas propriedades mecânicas, acompanhado de menor impacto ambiental e baixo custo. Neste ponto se inserem as fibras vegetais que são resistentes, leves, não abrasivas, e que podem servir como um excelente agente de reforço, como já comprovado em diversos trabalhos apresentados na literatura (RAMIRES, 2010; BARBOSA, 2010; MEGIATTO, 2009; TRINDADE 2008; PICHERING, 2008; CHAND, 2008).

Atualmente, já é possível notar a gradual substituição de aditivos sintéticos tradicionais por fibras vegetais, o que sem dúvida representa uma excelente abertura de mercado para países com vocação agrícola. Nos últimos anos, principalmente as indústrias automobilísticas, estão lançando no mercado produtos já parcialmente substituídos por compósitos produzidos com materiais originados de fontes renováveis.

Os materiais lignocelulósicos são basicamente compostos por substâncias macromoleculares, tais como celulose, hemicelulose, lignina, e constituintes de baixa massa molecular, como extrativos e substâncias minerais (FENGEL, 1989).

Apesar do potencial das fibras na utilização como reforço em materiais compósitos, devido ao seu baixo custo, disponibilidade praticamente em todo o mundo (MISHRA, 2004; GAUDER, 2011), sua aplicação ainda não é tão efetiva quanto à de materiais sintéticos, e o seu uso ainda requer estudos que indiquem, por exemplo, as matrizes mais adequadas para serem usadas. As propriedades dos materiais podem ser melhoradas, se ocorrer melhora na interação entre a fibra e a matriz, conforme já mencionado. Este é um dos aspectos fundamentais desta área: modificar a fibra, a matriz, ou ambos, de tal forma que as interações fibra/matriz na interface sejam otimizadas. 
Quando se usa matriz do tipo fenólica reforçada com fibras lignocelulósicas, como no presente trabalho, os grupos polares em ambos os componentes podem favorecer a adesão na interface.

\section{3. 3. 1. Fibras Lignocelulósicas: bagaço de cana de açúcar e sisal}

As fibras lignocelulósicas apresentam uma estrutura composta por celulose, lignina e polioses (hemiceluloses), (Figura 3). A porcentagem de cada componente varia de acordo com o tipo de fibra vegetal e, também pode variar (em menor proporção) com as condições de cultivo, como, clima e solo.

Neste trabalho, dois tipos de fibras lignocelulósicas foram consideradas a fibra do bagaço-de-cana e a fibra de sisal.

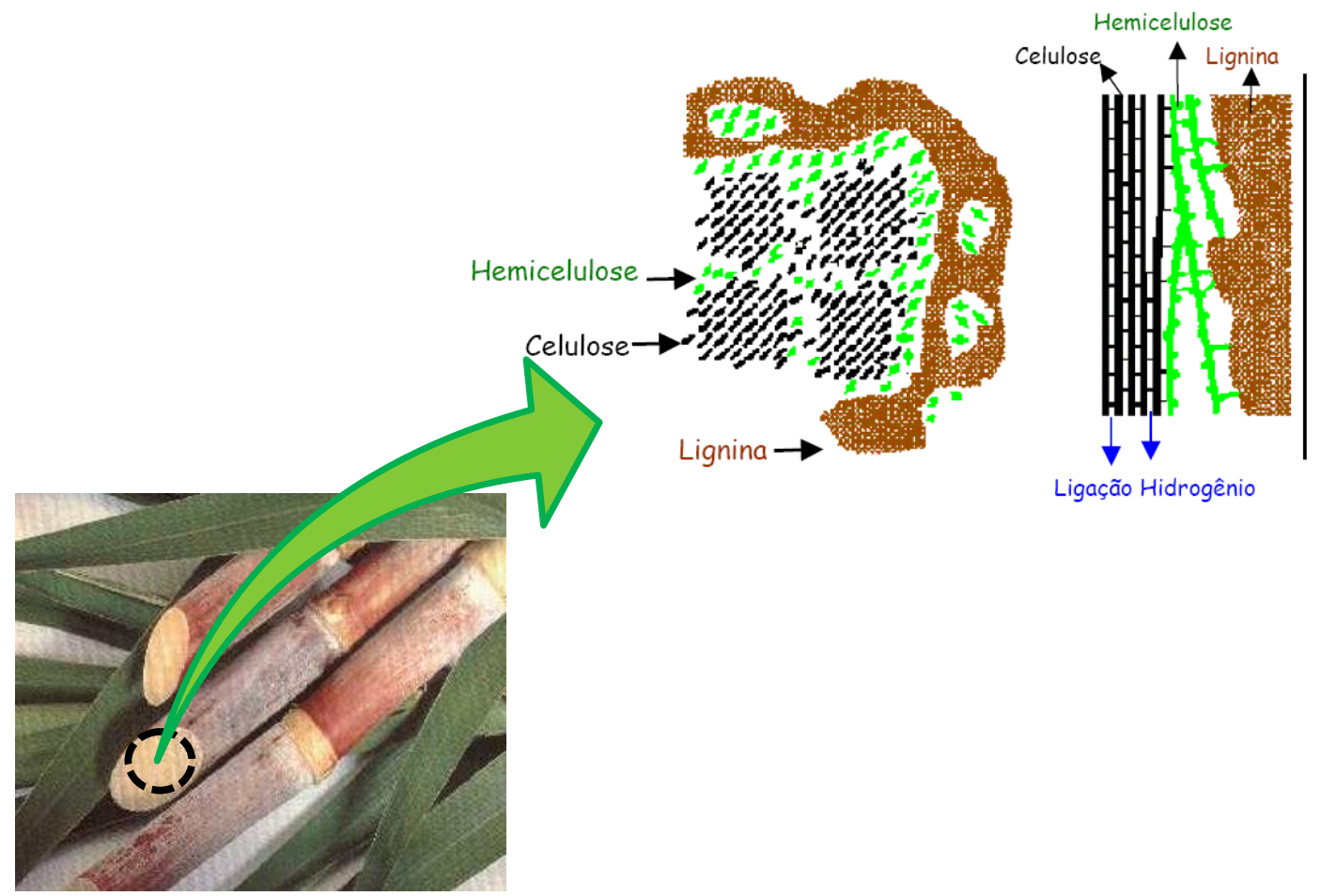

Figura 3: Modelo esquemático da associação dos componentes da parede celular de fibra vegetal em vista (a) transversal; (b) longitudinal (Fengel, 1989).

A cana-de-açúcar (Figura 4) é uma planta denominada cientificamente por "Saccaharum officinarum”, e pertence à classe das Monocotiledôneas, do tipo gramínea. O 
cultivo desta planta foi introduzido no Brasil desde o século XVI, e se expandiu rapidamente, sendo o açúcar um dos produtos pioneiros para exportação. Atualmente, as produções de açúcar, juntamente com o etanol, correspondem a produtos importantes obtidos a partir da cana-de-açúcar, gerando grande quantidade de resíduo, logo após a extração do suco (GAUDER ET AL, 2011; PAIVA, 2002). Fisicamente, o bagaço da cana-de-açúcar é formado por dois principais componentes, a medula e a fibra, derivados do interior e do exterior do caule, respectivamente. Quimicamente, o bagaço é composto por celulose, polioses, lignina, pequena quantidade de sais inorgânicos e água. O bagaço de cana seco pode variar a composição de $32-55 \%$ de celulose, $19-25 \%$ de lignina, $27-32 \%$ de hemicelulose e de 1-4\% de cinzas (GUIMARÃES et al, 2009).

Atualmente as fibras de bagaço de cana passam ou não pela etapa de queima antes da colheita, o que pode modificar suas propriedades físicas e químicas. No presente trabalho, pretendeu-se comparar as diferenças das propriedades destas fibras quando aplicadas como reforço em compósitos.

O sisal (Figura 4) é uma planta originária do México (Yacatán) e pertence à classe das Monocotiledônea, de gênero Avage e espécie Avage Sisalana, sendo cultivado no Brasil desde 1903, no estado da Bahia (MEDINA,1954). Além do Brasil, é cultivado em outros países como África, Índia, Filipinas, sendo a maioria países tropicais. 

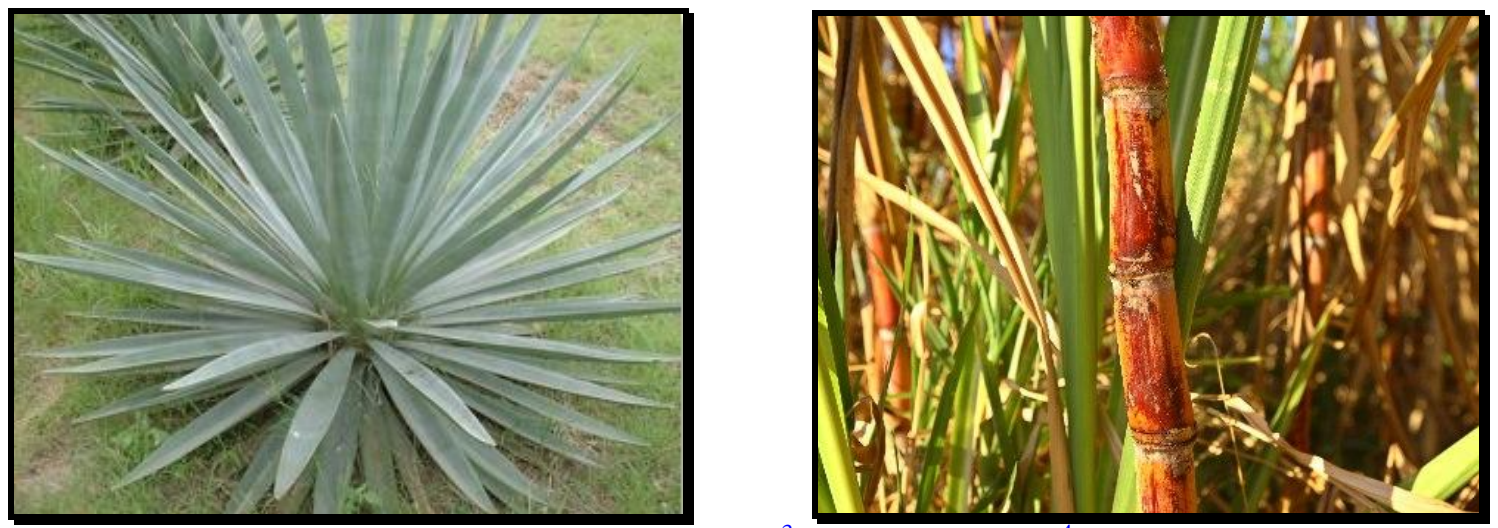

Figura 4: Planta de sisal ${ }^{3}$ e cana-de-açúcar ${ }^{4}$.

O cultivo desta planta tem grande importância socioeconômica para a região Nordeste do Brasil, pois possibilita a ocupação de extensa área de solos pobres da região semi-árida. Constitui fonte de renda e emprego para grande número de pessoas, sendo uma cultura que não agride o meio ambiente, entre outros fatores (BARROS et al, 1999).

As fibras de sisal se inserem no grupo das fibras denominadas "estruturais" cuja função é dar sustentação e rigidez às folhas. A fibra de sisal é uma das fibras vegetais mais rígidas, possuindo alta resistência à tração.

Após a extração, as fibras surgem na forma de feixes, variando de comprimento desde $40 \mathrm{~cm}$ até $2 \mathrm{~m}$. A extração das fibras das plantas é feita por corte e desfibrilamento da folha, seguido de lavagem, secagem e limpeza da fibra (PAIVA, 2001).

O suco (caldo ou mosto) desta planta pode ser aplicado em diversas áreas, como na indústria química (fabricação de álcool e açúcares) e na indústria farmacêutica (para alguns medicamentos). Além disso, na literatura são encontrados diversos trabalhos sobre materiais compostos envolvendo fibras de sisal, visando melhorar as propriedades mecânicas dos compósitos (PAIVA, 2006, MARTIN ET AL., 2010, BAKARE ET AL., 2010, OLIVEIRA, 2010; RAMIRES, 2010; MEGIATTO, 2006).

\footnotetext{
${ }^{3}$ http://www.sisal.ws; (acesso em: 18/04/2011)

${ }^{4}$ Agencia Jornal; (acesso em: 18/04/2011)
} 
As fibras lignocelulósicas em geral apresentam caráter hidrofílico devido à presença de grupos polares, principalmente hidroxilas, nos seus principais componentes (celulose, hemicelulose e lignina). Esta característica torna este tipo de fibra forte candidata à substituição de fibras sintéticas, em algumas matrizes poliméricas, como as do tipo fenólicas que dispõem grupos polares em sua estrutura.

Compósitos reforçados com fibras de sisal foram preparados neste trabalho para comparação de propriedades com aqueles reforçados com as fibras de bagaço de cana.

1. 3. 3. 2. Tratamento das fibras de bagaço de cana de açúcar

Os tratamentos de fibras vegetais (celulósicas ou lignocelulósicas) normalmente visam intensificar a capacidade de interação das fibras com a matriz polimérica, ou seja, a melhora da região de interface, com objetivo final de obter melhores propriedades (MEGIATTO, 2006).

Estes tratamentos têm como objetivo enriquecer e modificar a superfície das fibras com grupos que possam atuar como agentes compatibilizantes das fibras com a matriz polimérica, otimizando as propriedades dos materiais.

Tendo em vista que o tratamento é uma etapa adicional na preparação dos compósitos, este não deve apresentar alto custo, e nem desvalorizar a utilização das fibras naturais. Por estes motivos, no presente trabalho, fez-se o uso de produto obtido da biomassa, o lignossulfonato de sódio, como modificador da superfície de bagaço de cana. Considerando que as frações desta macromolécula também estarão presentes na matriz (baseadas em lignossulfonato de sódio), a interação fibra-matriz poderá ser intensificada com o tratamento.

Para auxiliar no tratamento, as fibras de bagaço de cana suspensas em solução de lignossulfonato de sódio foram imersas em um banho de ultrassom. 
O som corresponde a ondas de expansão e compressão que se propagam em um meio gasoso, líquido ou sólido. O ultrassom refere-se a ondas que estão acima da frequência de $20 \mathrm{kHz}$, ou seja, acima das ondas perceptíveis que estão entre $20 \mathrm{~Hz}$ e $16 \mathrm{kHzaos}$ ouvidos dos humanos. Estes sons de alta intensidade são produzidos geralmente através da energia elétrica, causando um movimento de expansão e compressão (FLANNINGAN, 2005 APUD OLIVEIRA, $2010^{5}$ ).

Em um meio liquido, os ciclos de expansão criam uma pressão negativa afastando as moléculas do líquido entre si. Se esta pressão for intensa, os ciclos de expansão poderão criar cavidades ou bolhas de ar no interior do líquido. Este evento pode variar de acordo com as características do líquido.

Os efeitos químicos se originam do crescimento e colapso das bolhas no liquido, podendo gerar espécies radicalares que estavam aprisionadas no interior das bolhas e que implodem. Repetitivos jatos de líquidos com radicais, em alta velocidade, podem colidir com o sólido presente, provocando mudanças na superfície, morfologia e até composição do sólido presente (FLANNINGAN, 2005 APUD OLIVEIRA, 2010).

Diversos trabalhos descrevem os efeitos do ultrassom no tratamento de fibras lignocelulosicas e celulosicas (geralmente polpas). A técnica normalmente é utilizada para separação, branquamento ou desfibrilamento da polpa de celulose. O ultrassom também é utilizado para o tratamento de fibras lignocelulosicas para a modificação da superficie seguida de aplicação em compositos ou filmes (MUKHOPADHYAY, 2009; PINJARI, 2010; HEBEISH, 2011).

Trabalhos citados na literatura mostram resultados de compósitos preparados com fibras modificadas quimicamente, na tentativa de melhorar a adesão das fibras com a matriz. Os tratamentos melhoram a região de interface, mas degradam parcialmente as fibras, o que

\footnotetext{
${ }^{5}$ Flannigan, D. J.; Hopkins, S. D.; Suslick, K. S. Sonochemistry and sonoluminescence in ionic liquids, molten salts, and concentrated electrolyte solutions. Journal of Organometallic Chemistry, v. 690, n. 15, p. 3513-3517, 2005.
} 
prejudica o desempenho da fibra como reforço (MEGIATTO et al., 2007; PIZZI et al., 2009; SGRICCIA; HAWLEY; MISRA, 2008). Com base nestes estudos, se optou por modificação das fibras via adsorção, do lignossulfonato de sódio à fibra, ao invés de modificação química. 


\section{Objetivos}

Este trabalho visou o preparo de compósitos com alto teor de materiais provenientes de biomassa, ou seja, biocompósitos. Para atingir esta meta, fibras de bagaço de cana de açúcar, não queimadas e queimadas, e de sisal, foram usadas como reforço de matriz polimérica do tipo fenólica. Esta última fibra foi usada somente em alguns compósitos, para fins comparativos.

Adicionalmente, lignossulfonato de sódio (NaLS) e lignina organossolve (LO) foram usados no preparo de resinas do tipo fenólica, substituindo em 100\% o fenol. Buscou-se também a intensificação das interações na interface fibra/matriz e, para tal, as fibras de bagaço de cana foram tratadas (com auxílio de um banho de ultrassom) com NaLS. 


\section{Caracterização dos materiais: Técnicas}

\section{usadas}

\section{1. Difração de raios $X$}

A técnica de análise por raio X é conhecida por ser não destrutiva e por permitir obter informações da estrutura cristalográfica, composição química e propriedades físicas de materiais diversificados.

No caso dos polímeros, o índice de cristalinidade $\left(\mathrm{I}_{\mathrm{c}}\right)$ expressa à porção da região cristalina com relação à não cristalina presente na amostra (SHEEHAN, 2009).

Segundo a lei de Bragg, proposta em 1913, planos paralelos de átomos a uma distância $\mathrm{d}$, refletem os feixes incidentes de raios $\mathrm{X}$, como mostra a figura 5. Os raios refletidos interferem construtivamente e produzem o máximo de intensidade. A diferença de caminho entre os raios refletidos é $\mathbf{2 d}$ sen $\boldsymbol{\theta}$, sendo $\mathbf{d}$ o espaço entre os planos cristalográficos e $\boldsymbol{\theta}$ é o ângulo entre o feixe incidente e o plano cristalino. A interferência construtiva ocorre quando (equação 1):

$$
2 d \operatorname{sen} \theta=\mathbf{n} \lambda
$$

isto é, a diferença entre os caminhos óticos for um número inteiro de comprimento de onda (n). Assim um feixe de onda será observado (NAIK, 2010). 


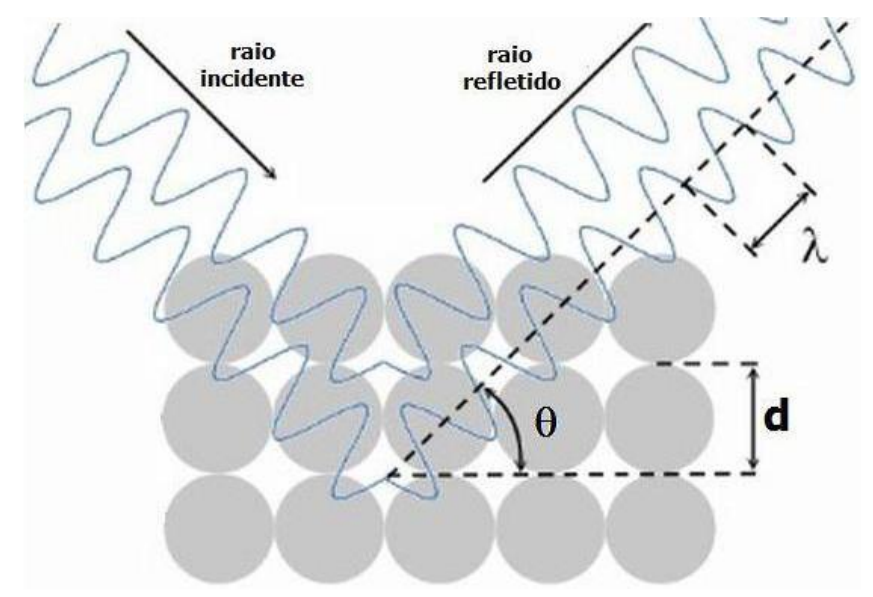

Figura 5: Representação esquemática da Lei de Bragg (MORGADO, 2009).

A reflexão de Bragg e o padrão de difração só são possíveis porque o espaçamento entre os planos cristalográficos é da ordem de poucos Angströns (Á), assim como o comprimento de ondas dos raios $\mathrm{X}$.

A técnica de difração de raios $X$ foi utilizada como ferramenta para avaliação do índice de cristalinidade das fibras de bagaço de cana de açúcar e a tratamento (em solução de lignossulfonato de sódio em banho de ultrassom), e das fibras de sisal aplicadas neste trabalho.

Nos difratogramas de raios $\mathrm{X}$ das fibras lignocelulósicas são observados picos de diferentes intensidades, referentes aos planos cristalográficos da celulose. A partir dos picos de celulose determina-se a cristalinidade das fibras naturais. A celulose apresenta ângulos de difração (20) entre $23^{\circ}$ e $13^{\circ}$ (MORGADO, 2009).

O índice de cristalinidade é calculado utilizando-se a equação 2 descrita por BuschleDiller e Zeronian (BUSCHLE, 1992):

$$
\mathbf{I}_{\mathbf{c r}}=\frac{\left(\mathbf{I}_{\max }-\mathbf{I}_{\min }\right) \mathbf{x} 100}{\mathbf{I}_{\max }}
$$

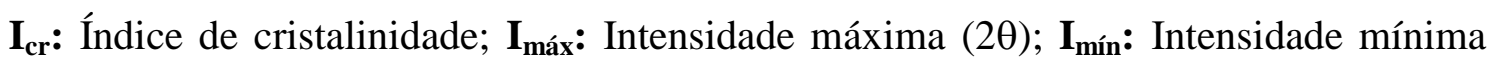
$(2 \theta)$. 


\subsection{Análise Térmica}

As técnicas de análise térmica são utilizadas para o estudo das propriedades dos materiais em função da temperatura, em um amplo intervalo. A substância é submetida a uma programação controlada de temperatura (temperatura-tempo) sob uma atmosfera específica (HATAKEYAMA, 1994).

Diversificados métodos são comumente utilizados e são diferenciados pelas propriedades de medidas, tais como, diferença de calor, diferença de temperatura, volumétrica, entre outras (BROWN, 2001).

Outros parâmetros são importantes para obtenção de um bom resultado, tais como, massa da amostra, condições de atmosfera, taxa de fluxo, taxa de aquecimento, entre outros. Assim, técnicas específicas de análise requerem parâmetros específicos.

Neste trabalho, foram utilizadas as técnicas de Termogravimetria (TGA), Calorimetria Exploratória Diferencial (DSC) e Análise Térmica Dinâmico-Mecânica (DMTA) para caracterizar os materiais quanto estabilidade térmica e propriedades mecânicas em função da temperatura.

\section{3. Análise Térmica Dinâmico-Mecânica (DMTA)}

A análise Térmica Dinâmico-Mecânica (DMTA) é uma técnica da caracterização para polímeros, com a detecção dos processos da relaxação, não somente macroscópica, mas também molecular, com sensibilidade superior quando comparada às técnicas térmicas convencionais da análise (DSC, TMA etc.).

Esta técnica fornece a informações a respeito do módulo dinâmico (E”), o módulo da perda (E') e amortecimento mecânico ou a fricção interna (tan $\left.\delta=E^{\prime \prime} / E^{\prime}\right)$ de um material quando sujeito a uma oscilação dinâmica. Destas variáveis pode-se correlacionar propriedades tais como tenacidade, resistência ao impacto, tempo de vida sob a fadiga, resistência à propagação de rachadura, rigidez em peças poliméricas moldadas (MURYAMA, 1978). 
A mais comum utilização DMTA consiste na determinação de temperatura transição vítrea (Tg), apresentando uma grande vantagem por ser um método direto de medida, sendo ainda é possível a determinação da temperatura de fusão cristalina do polímero semicristalino $\left(\mathrm{T}_{\mathrm{m}}\right)$ também pode ser determinada.

Em DMA (análise dinâmica mecânica) a amostra é deformada ciclicamente, normalmente sob condições de força vibracional, por monitoramento de tensão-deformação em função do tempo e variação da temperatura, a informação pode ser obtida sobre a relaxação procedendo com o teste com uma amostra do material (CAMPYBELL, 1989).

Embora seja usada a abreviação DMA, a variação da temperatura é uma importante característica do teste.

Quando um material viscoelástico é solicitado através da aplicação de uma tensão senoidal, dentro de seu limite de elasticidade linear, este responde imediatamente (sem atraso de tempo), através de uma deformação também senoidal (Figura 9), por exemplo, este comportamento toma-se a resposta de uma mola ideal deformada dentro do seu limite de deformação (MURYAMA, 1978).

Como todos os materiais poliméricos são viscoelásticos, mas quando deformados apresentam comportamento característico dos materiais plásticos e elásticos, solicitando-o com uma tensão cíclica, este apresentará uma resposta também senoidal e atrasada, em um ângulo $\delta$ com relação à solicitação (MURYAMA, 1978). 


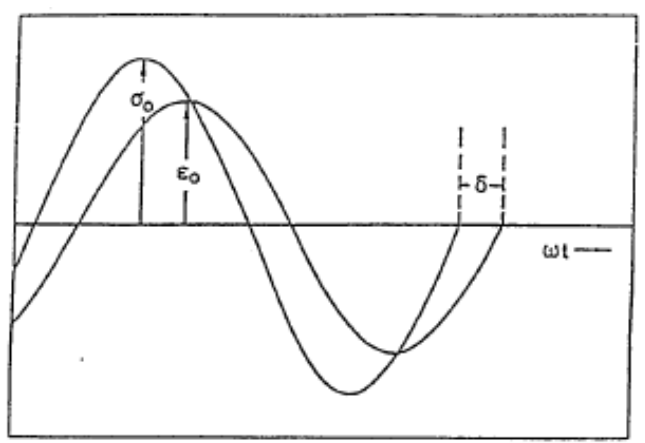

Figura 6: Resposta de um corpo viscoelástico a uma solicitação cíclica do tipo senoidal. A resposta está defasada com relação à solicitação de um ângulo $\delta$ (MURYAMA, 1978).

A tensão $(\sigma)$ e a deformação $(\varepsilon)$ podem, portanto ser descrito pela equação (15):

$$
\left(\sigma-\sigma_{m}\right)=\sigma_{0} \operatorname{sen} \omega . t
$$

sendo $\sigma_{0}$ é a tensão da amplitude, $\omega$ é a frequência cíclica e t é o tempo, $\sigma_{\mathrm{m}}$ é a tensão desprezível e a carga reversa sobre o qual a amplitude da elasticidade e da compressão são de magnitude igual a zero, $\varepsilon_{0}$ é a deformação da amplitude (MURAYAMA, 1978), equação (16):

$$
\varepsilon(t)=\varepsilon_{0} \operatorname{sen} \omega t
$$

Sendo $\boldsymbol{\varepsilon}(\mathbf{t})$ a deformação a um dado tempo, $\boldsymbol{\varepsilon}_{\mathbf{0}}$ a deformação a uma amplitude máxima, $\boldsymbol{\omega}$ a frequência de oscilação e $\mathbf{t}$ o tempo. A deformação máxima deve ser pequena, menor que 0,5\%, para que não se ultrapasse o limite de viscosidade do material. Como resposta a esta solicitação, a amostra responde com uma tensão máxima também cíclica, que pode ser expressa por (17) (CANEVAROLO, 2004b):

$$
\sigma(t)=\sigma_{0} \operatorname{sen}(w t+\delta)
$$

Sendo $\sigma(\mathrm{t})$ a tensão a um dado tempo, $\sigma_{0}$ a tensão máxima, $\delta$ o ângulo de fase ou defasagem e $\omega$ a frequência angular. Estendendo a equação acima, temos que (Equação 18):

$$
\sigma(t)=\sigma_{0} \operatorname{sen} \omega t \cdot \cos \delta+\sigma_{0} \cos \omega t \cdot \operatorname{sen} \delta
$$


A tensão pode ser considerada como formada de duas componentes, uma em fase com a deformação $\left(\sigma_{0} \cos \delta\right)$ e o outro deslocado $90^{\circ}$ da fase $\left(\sigma_{0} \operatorname{sen} \delta\right)$.

A partir de cada uma destas componentes, pode-se calcular um módulo de elasticidade para cada caso (Equação 19) (CANEVAROLO, 2004):

$$
E=\frac{\text { Amplitude det ensão }}{\text { Amplitudededeformação }}=\sigma / \varepsilon
$$

Então, pode-se separar os módulos em uma fase real (dentro da fase) e outra fase imaginária (fora da fase). Há uma relação (Equações 20 e 21):

$$
\begin{gathered}
\sigma=\sigma_{0} E^{\prime} \operatorname{sen} \omega t+\varepsilon_{0} E^{\prime \prime} \cos \omega t \\
E^{\prime}=\frac{\sigma_{0}}{\varepsilon_{0}} \cos \delta \quad \text { e } \quad E^{\prime \prime}=\frac{\sigma_{0}}{\varepsilon_{0}} \operatorname{sen} \delta
\end{gathered}
$$

sendo E' é a parte real do módulo e E" é a parte imaginária. A representação complexa para o módulo como mostra na figura 10 pode ser expressa como a seguir (MURAYAMA, 1978):

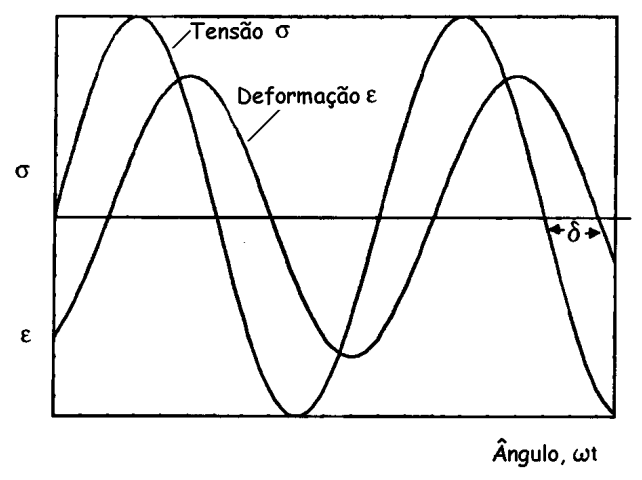

(A)

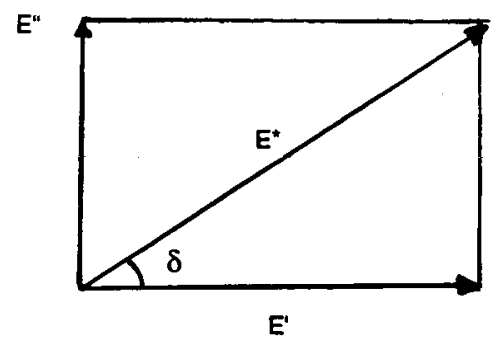

(B)

Figura 7: (A) Tensão senoidal e curva de resposta de deformação, apresentando o atraso do ângulo de fase, devido ao comportamento viscoelástico; (B) A relação entre o módulo complexo $E^{*}$, sua componente real $E^{\prime}$ e sua componente imaginária $E^{\prime \prime}$. $E^{\prime}=$ módulo de armazenamento, $E$ ”'= módulo de perda (MURYAMA, 1978). 
A soma vetorial do módulo relativo à componente elástica E' (conhecido por módulo de estocagem ou armazenamento) e o módulo relativo à componente plástica E” (conhecido por módulo de perda) fornece o módulo de elasticidade complexo do sistema $\mathrm{E}^{*}$, equação 22:

$$
\mathrm{E}^{*}=\mathrm{E}^{\prime}+\mathrm{i} \mathrm{E}^{\prime \prime}
$$

A razão adimensional entre a energia perdida por ciclo (normalmente dissipada na forma de calor) pela energia máxima estocada por ciclo (e, portanto, totalmente recuperável) é dito amortecimento, atrito interno ou tangente de perda tan ( $\delta$ ) é definida como (Equação 23):

$$
\tan (\delta)=\mathrm{E}^{\prime \prime} / \mathrm{E},
$$

O amortecimento é um indicativo de quão longe está o comportamento do material viscoelástico do comportamento puramente elástico. Materiais com alto amortecimento dissipam muito da energia que foi usada para deformá-lo. Materiais com comportamento puramente viscoso (materiais Newtonianos como a água são um exemplo) são casos extremos de total dissipação de energia em calor, tendo então, um amortecimento infinito $(\tan (\delta)=\infty$ ou $\delta=90^{\circ}$ ). Por outro lado, um material perfeitamente elástico ( por exemplo, uma mola ideal) não apresenta amortecimento $(\tan (\delta)=0)$. Materiais poliméricos apresentam um comportamento intermediário entre estes dois extremos e são chamados de viscoelástico, com $0<\tan (\delta)<\infty$ sendo na prática $0,001<\tan (\delta)<3$. Quando tan $\delta=1$, o ângulo de defasagem é de $45^{\circ}$ e os outros dois são iguais (CANEVAROLO, 2004b).

A temperatura é um dos parâmetros mais importantes no ensaio, pois as propriedades dos polímeros mudam com esta. Em uma temperatura particular tem-se que o coeficiente de expansão térmica da região não cristalina dos polímeros não cristalinos passa por uma mudança abrupta na região de transição vítrea, esta é definida como a temperatura de

\section{transição vítrea Tg.}

O módulo de relaxação da tensão comumente decresce aproximadamente três ordens de magnitude, e a facilidade de movimentação aumenta em aproximadamente três ordens de 
magnitude. Nos estudos de propriedades mecânicas, o módulo dinâmico diminui rapidamente, apresentando um valor de $\tan \delta$ máxima (MURAYAMA, 1978).

\section{4. Cromatografia Gasosa Inversa (Inverse Gas Chromatography - IGC)}

A investigação das características de novos materiais tem sido de grande interesse para pesquisadores da área de compósitos, visando buscar informações que permitam melhorar a compatibilidade entre a matriz e o reforço aplicado. Propriedades importantes, como energia livre de superfície e o caráter ácido-base podem ser avaliadas pela técnica de cromatografia gasosa inversa (IGC) (BELGACEM, 1996; BELGACEM, 2005; CORDEIRO ET AL, 2011; RAMIRES, 2009).

A cromatografia gasosa inversa (IGC) é uma das técnicas complementares utilizadas para caracterização de energia livre de superfície de materiais sólidos, que não podem ser obtidos com superfícies planas, tais como fibras ou pó. A partir do conhecimento destas propriedades dos materiais, é possível avaliar também a necessidade de tratamentos para modificação destes (BELGACEM, 1996; BELGACEM, 2005).

O principio da técnica de IGC consiste em investigar o material como uma fase estacionária na coluna de cromatografia através de injeções de sondas (série n-alcanos) conhecidas. Esta técnica corresponde a uma variação da cromatografia gasosa convencional (MEGIATTO, 2009).

\section{4. 1. Determinação do componente dispersivo}

O componente dispersivo ou de London da energia livre de superfície pode ser atribuído à habilidade da superfície de interagir com a sonda (série n-alcanos) através de forças de van der Waals. A componente ácido-base é decorrente das interações ácido-base de Lewis, e de ligações de hidrogênio. 
A técnica de IGC é baseada no tempo de retenção da séria de n-alcanos, sendo que cada soluto tem interação particular com a fase estacionária, sendo que os diferentes solutos são carregados por um gás inerte através da coluna, resultando em diferentes velocidades. Estes e outros parâmetros são influenciados pelas características do soluto (RANI et al., 2011). A variação de energia livre de adsorção padrão das fibras está relacionada aos volumes de retenção dos solutos (Vn) pela equação (3):

$$
\Delta \mathrm{G}=\mathrm{RT} \ln \mathrm{Vn}+\mathrm{C}
$$

sendo $\mathbf{C}$ uma constante que depende do estado de referência, $\mathbf{R}$ constante dos gases e $\mathbf{T}$ a temperatura da coluna (em Kelvin).

Para que a Lei de Henry seja aplicada, o mecanismo de interação soluto-soluto, do tipo adsorção-dessorção, deve ocorrer entre a sonda e o material em análise (material que preenche a coluna). Uma quantidade mínima de vapor do soluto é injetada no cromatógrafo para que ocorra a detecção deste no ionizador de chama (FID). Outros fenômenos, como difusão e absorção da sonda, devem ser desprezados. Portanto, se leva em consideração a proporção de soluto adsorvido (independente da concentração da sonda), que está diretamente ligado ao seu volume de retenção ( $\mathbf{V}_{\mathbf{n}}$, parâmetro termodinâmico utilizado nas medidas de IGC) (GUTIÉRREZ, 2005).

Dorris e Gray (1980 apud Belgacem ${ }^{6}$ ) assumiram que o trabalho de adsorção do grupo metileno $\left(\mathbf{W}_{\mathbf{A}}\right)$ entre o vapor da sonda (adsorbato) e o sólido da fase estacionária por unidade de área superficial, em uma primeira aproximação, pode ser associada à energia livre de $\left.\operatorname{adsorção~(~} \Delta \mathbf{G}_{\mathbf{A}}^{\mathbf{C H}_{2}}\right)$ (equação 4):

$$
\Delta \mathbf{G}_{\mathbf{A}}^{\mathbf{C H}_{2}}=\mathbf{N a}_{\mathbf{C H}_{2}} \mathbf{W}_{\mathbf{A}}
$$

sendo $\mathbf{N}$ o número de Avogadro, e $\mathbf{a}_{\mathbf{C H}_{2}}$ área de interação do grupo metileno.

6 DORRIS G. M.; GRAY D. G. J. Colloid Interface Sci. v.77, p.353, 1980. apud BELGACEM M. N.; GANDINI A. Inverse gas chromatography as a tool to characterize dispersive and acid-base properties of the surface of fibers and powders. In: Interfacial Phenomena in Chromatography. New York, Marcel Dekker, 1999. 56p. 
Vale ressaltar que o método baseia-se no cálculo de energia livre de adsorção de um grupo $-\mathrm{CH}_{2}-$, cujo o componente dispersivo da energia de superfície é conhecido, sendo de $35,6 \mathrm{~mJ} \mathrm{~m}^{-2}$ a $20^{\circ} \mathrm{C}$.

Duas aproximações foram elaboradas para o cálculo do componente dispersivo da energia de superficie do sólido, para investigação via IGC, na condição de diluição infinita, baseadas no formalismo de Fowke (1999 apud BELGACEM ${ }^{7}$ ).

O trabalho de adsorção $\left(\mathbf{W}_{\mathbf{A}}\right)$ entre o gás e a superfície do sólido, pode ser expresso pela soma do trabalho resultante das interações dispersivas, $\mathbf{W}_{\mathbf{A}}^{\mathbf{D}}$ (fracas, devido às forças de van der Waals), e $\mathbf{W}_{\mathbf{A}}^{\mathbf{S P}}$ que inclui todos os demais tipos de interações (polares, ligações hidrogênio, interações ácido-base, ligações $\pi$ etc), assim temos (equação 5):

$$
\mathbf{W}_{\mathbf{A}}=\mathbf{W}_{\mathbf{A}}^{\mathbf{D}}+\mathbf{W}_{\mathbf{A}}^{\mathbf{S P}}
$$

A energia livre de superfície $\left(\gamma_{\mathrm{S}}\right)$ também é expressa pela soma da energia livre de todos os sítios ativos da superfície sólida, pois esta é formada por um conjunto de sítios ativos acessíveis e heterogêneos quimicamente, segundo a equação (6):

$$
\gamma_{\mathrm{S}}=\gamma_{\mathrm{S}}^{\mathrm{d}}+\gamma_{\mathrm{S}}^{\mathrm{SP}}
$$

sendo $\gamma_{\mathrm{S}}^{\mathrm{d}}$ ou componente dispersivo da energia livre (corresponde à soma de todas as energias livres dos sítios ativos que podem interagir com as moléculas sondas através de interações de van der Waals) e $\gamma_{\mathbf{S}}^{\text {SP }}$ ou componente especifica de energia livre (corresponde à soma de todos os outros sítios ativos de natureza polar).

De acordo com Girifalco apud Belgacem ${ }^{8}$, para este caso, o trabalho de adesão é dominado por interações dispersivas na interface, sendo $\mathbf{W}_{\mathbf{A}}^{\text {SP }}$ igual a zero, sendo assim, o trabalho dispersivo de adesão pode ser expresso como (equação 7):

7 FOWKES F. M. Ind. Eng. Chem. V. 56, p. 40, 1964. apud BELGACEM M. N.; GANDINI A. Inverse gas chromatography as a tool to characterize dispersive and acid-base properties of the surface of fibers and powders. In: Interfacial Phenomena in Chromatography. New York, Marcel Dekker, 1999. 56p. 


$$
\mathbf{W}_{\mathbf{A}}=2\left(\gamma_{\mathrm{S}}^{\mathbf{d}}+\gamma_{\mathrm{L}}^{\mathbf{d}}\right)^{1 / 2}
$$

sendo $\gamma_{\mathrm{S}}^{\mathrm{d}}$ o componente dispersivo da energia de superfície da molécula da sonda no estado líquido e $\gamma_{\mathbf{L}}^{\mathbf{d}}$ componente dispersiva da energia livre de superfície do sólido.

No método utilizado por Dorris e $\mathrm{Gray}^{9} \boldsymbol{\gamma}_{\mathrm{S}}^{\mathrm{d}}$ (energia livre de adsorção do grupo metileno) é determinado pela inclinação da reta obtida plotando $\Delta \mathbf{G}_{\mathbf{A}}$ versus o numero de átomos de carbono da série de n-alcanos. A partir das equações 4 e 7 é possível obter $\gamma_{\mathrm{S}}^{\mathbf{d}}($ equação 8):

$$
\gamma_{\mathbf{S}}^{\mathbf{d}}=\left(\Delta \mathbf{G}_{\mathbf{C H}_{2}}\right)^{2} / 4 \mathbf{N}^{2}\left(\mathbf{a}_{\mathbf{C H}_{2}}\right)^{2} \gamma_{\mathbf{C H}_{2}}
$$

onde $\mathbf{a}_{\mathbf{C H}_{2}}$ é a área superficial um grupo metileno (valor aproximado da área seccional $\left.6 \AA^{2}\right)$.

Schultz et al. ${ }^{10}$ propõe um segundo método para determinação da componente dispersiva da energia livre de superfície do sólido investigado pela combinação das equações 3 e $6:$

$$
\mathbf{R T} \ln \mathbf{V}_{\mathbf{R}}=2 \mathbf{N}\left(\gamma_{\mathbf{S}}^{\mathbf{d}}\right)^{1 / 2} \mathbf{a}\left(\gamma_{\mathbf{L}}^{\mathbf{d}}\right)^{1 / 2}+\mathbf{C}
$$

Utilizando os resultados da série de n-alcanos é possível plotar $\Delta \mathbf{G}_{\mathbf{A}} \operatorname{versus} \mathbf{a}\left(\gamma_{\mathbf{L}}^{\mathbf{d}}\right)^{1 / 2}$, e através da inclinação da reta (esta é uma função linear, usualmente chamada linha de referência) é possível calcular o valor de $\gamma_{\mathrm{S}}^{\mathrm{d}}$.

\footnotetext{
${ }^{8}$ GIRIFAlCO L. A.; GOOD R. J. J. Phys. Chem. v.61, p.904. 1957. apud BELGACEM M. N.; GANDINI A. Inverse gas chromatography as a tool to characterize dispersive and acid-base properties of the surface of fibers and powders. In: Interfacial Phenomena in Chromatography. New York, Marcel Dekker, 1999. 56p.

${ }^{9}$ DORRIS, C.M.; GRAY, D.G. Adsorption of $n$-alkanes at zero surface coverage on cellulose paper and wood fibers. J. Colloid Interface Sci. 77 (1980), 353.

${ }^{10}$ SHULTZ, J.; LAVILLE, L.; MARTIN, C. J. Adhesion 23, 45, 1987 apud GUTIERREZ, M.C.; RUBIO, J.; RUBIO, F.; OTEO, J.L. Inverse gas chromatography: a new approach to the estimation of specific interactions. Journal of Chromatography A, 845 (1999) 53-66.
} 


\section{4. 2. Determinação das propriedades ácido-base}

O estudo mais simples proposto para avaliar o caráter ácido-base da superfície de um sólido pela técnica de IGC é correspondente ao uso de duas moléculas polares de referência, sendo uma sonda com característica doadora e outra com característica aceptora de elétrons.

Algumas sondas polares, moléculas voláteis, podem elucidar o caráter ácido ou básico da fase estacionária: benzeno, clorofórmio, acetona, tetraidrofurano, entre outros. Os valores de caráter doador e aceptor de elétrons são identificados na literatura como $\mathbf{D N}_{\mathbf{S}}$ e $\mathbf{A N}_{\mathbf{S}}$, respectivamente (BELGACEM, 1999). O valor de $\Delta \mathbf{G}$ é determinado para cada sonda relacionado aos valores correspondentes de $\mathbf{A N}_{\mathbf{S}}$ e $\mathbf{D N}_{\mathbf{S}}$ (equações 10 e 11).

$$
\begin{aligned}
& \Delta \mathbf{G}_{\mathrm{A}}^{\mathrm{SP}} \text { doador } \equiv \mathbf{A N}_{\mathbf{S}} \\
& \Delta \mathbf{G}_{\mathrm{A}}^{\mathrm{SP}} \text { aceptor } \equiv \mathrm{DN}_{\mathrm{S}}
\end{aligned}
$$

Assume-se que, a razão destes parâmetros descreve o caráter ácido-base da superfície, $\mathbf{A} \mathbf{N}_{\mathbf{S}} / \mathbf{D N}$. Portanto tem-se (equação 12):

$$
\left[\frac{\Delta \mathbf{G}_{\mathbf{A} \text { doador }}^{\mathbf{S P}}}{\Delta \mathbf{G}_{\mathbf{A}_{\text {aceptor }}}^{\mathrm{SP}}}\right] \equiv\left[\frac{\mathbf{A} \mathbf{N}_{\mathbf{S}}}{\mathbf{D N _ { \mathbf { S } }}}\right]
$$

A partir destas relações, foi proposto (BELGACEM, 1999) que:

Superfície ácida: $\mathbf{A N}_{\mathrm{S}} / \mathbf{D N}_{\mathrm{s}} \geq \mathbf{1 , 1}$

Superfície básica: $\mathbf{A N}_{\mathrm{S}} / \mathbf{D N}_{\mathrm{s}} \leq \mathbf{0 , 9}$

Superfície anfótero: $\mathbf{0 , 9}<\mathbf{A N}_{\mathrm{S}} / \mathbf{D N}_{\mathrm{S}}<\mathbf{1 , 1}$

Superfície neutra ou não polar: $\mathbf{A N}_{\mathbf{S}} \approx \mathbf{D N}_{\mathbf{S}} \approx 0$

No presente trabalho, as fibras naturais e as matrizes termorrígidas foram caracterizadas via IGC, utilizando como sonda o par doador/aceptor de elétrons tetraidrofurano/clorofórmio. 


\section{5. Ensaios mecânicos}

\section{5. 1. Ensaio de Impacto Izod (amostras não entalhadas)}

O ensaio de impacto Izod se destina à avaliação de corpos de prova sob esforço de flexão mediante impacto, assim como avaliação da fragilidade ou tenacidade dentro dos limites das condições de ensaio. Esta propriedade é considerada uma das mais importantes de compósitos, tendo em vista a aplicação dos mesmos (CHAWLA, 1998).

Este ensaio também permite avaliar a melhora das propriedades dos termorrígidos (classificados como frágeis) quando reforçados com fibras, naturais como as lignocelulósicas.

O ensaio de impacto Izod utiliza um equipamento com martelo instrumentado acoplado a um pêndulo, como representado de forma esquemática na figura $6 \mathrm{a}$.

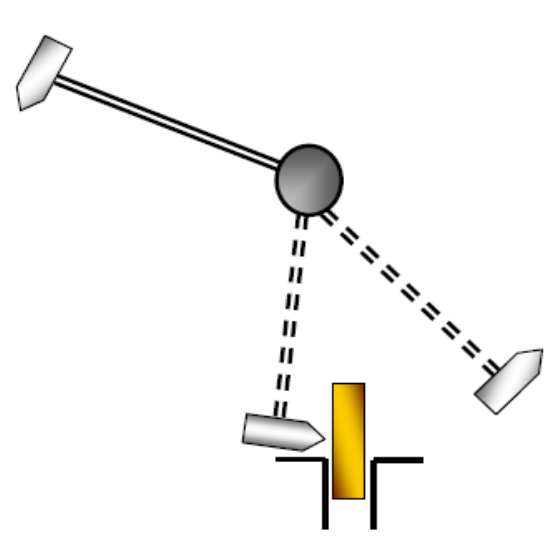

(a)

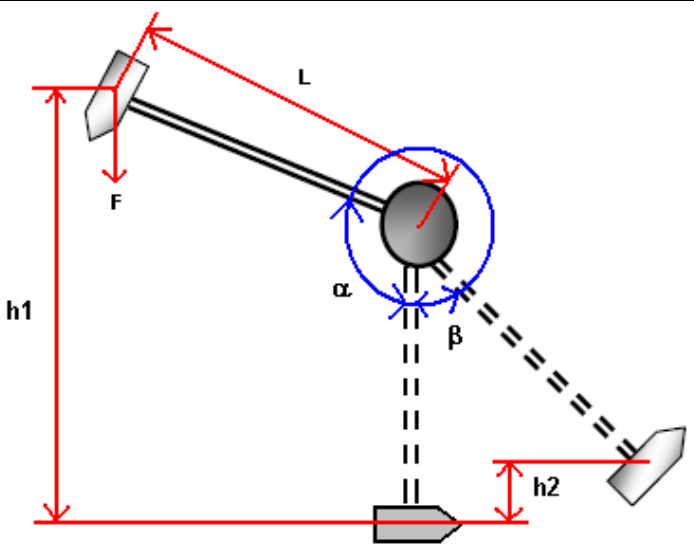

(b)

Figura 8: Representação esquemática do equipamento de ensaio de impacto Izod. Sendo: $\mathbf{F}$ a força gravitacional do martelo, $\mathbf{L}$ o comprimento da haste do martelo, $\mathbf{h}_{\mathbf{1}} \mathbf{e} \mathbf{h}_{\mathbf{2}}$ as alturas inicial e final do martelo, e $\alpha$ e $\beta$ os ângulos relacionados às respectivas alturas inicial e final.

$\mathrm{Na}$ figura $6 \mathrm{~b}$ tem-se a representação dos princípios envolvidos neste ensaio. Os parâmetros $\mathrm{F}, \mathrm{L}, \mathbf{h}_{\mathbf{1}}, \mathbf{h}_{\mathbf{2}}$ e os ângulos $\alpha$ e $\beta$ estão relacionados pela equação 13:

$$
E=m g\left(h_{1}-h_{2}\right)
$$

sendo: $h=L(1-\cos \alpha)$; E: energia; m: massa da amostra 
No teste de impacto Izod, a perda de energia cinética do pêndulo é o fator que determina a energia necessária para o rompimento da amostra (CHAWLA, 1998).

\section{5. 2. Ensaio de Resistência à Flexão}

A resistência à flexão é definida como a capacidade de um material resistir à deformação sob carga. O teste de flexão transversal é mais frequentemente utilizado com o carregamento de um sistema, de três (Figura 7), utilizado neste trabalho, ou quatro pontos. No ensaio de flexão de três pontos, a amostra é apoiada sob dois pontos fixos em um suporte, e o carregamento é realizado por um terceiro ponto (móvel). O ensaio de flexão mede a força requerida para dobrar um corpo de prova apoiado em três pontos (Norma ASTM D790 - 02).

Figura 9: Equipamento de ensaio de flexão em três pontos ${ }^{11}$.

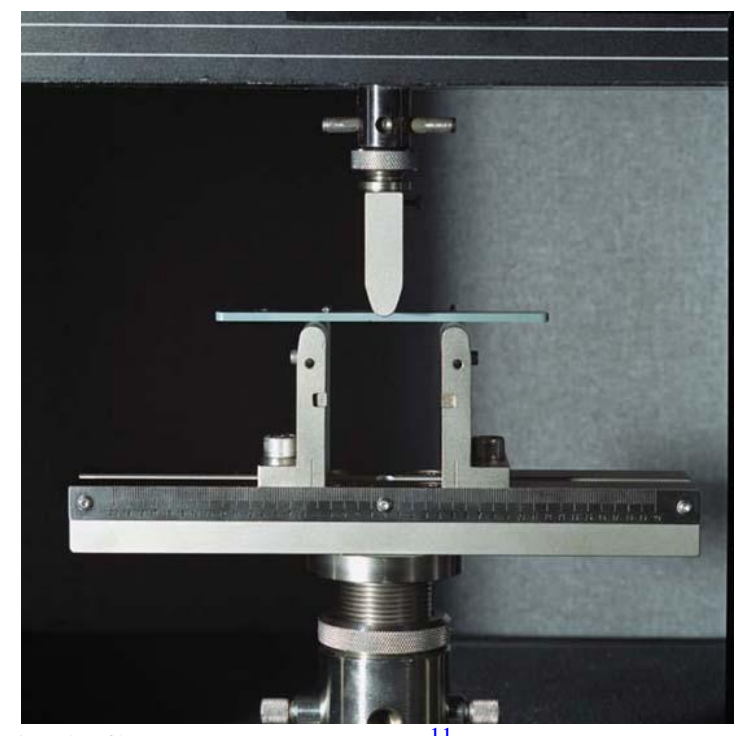

Os dados são muitas vezes utilizados para selecionar materiais para o preparo de peças que irão suportar as cargas. O módulo flexural é usado como uma indicação da rigidez de um material quando flexionado. Uma vez que as propriedades físicas de muitos materiais (especialmente os termoplásticos) podem variar dependendo da temperatura ambiente, é

\footnotetext{
${ }^{11}$ http://www.ptli.com/testlopedia/tests/flex-d790.asp; acessado em 28/03/2011.
} 
necessário realizar testes em ambientes de temperatura controlada, simulando o ambiente de uso pretendido (CASTRO, 2010).

Este teste é geralmente aplicado à materiais rígidos ou semi-rígidos, ou seja, materiais que quebram ou que apresentam falhas na superfície externa do corpo de prova dentro do limite maximo 5,0\% de deformação, para este método de ensaio. A deflexão, na qual esta deformação máxima permitida $(5,0 \%)$ ocorrerá, poderá ser calculada através da seguinte equação (14):

$$
\mathbf{D}=\frac{\mathbf{r} \mathbf{L}^{2}}{6 \mathbf{d}}
$$

sendo $\mathbf{r}=\mathbf{0 , 0 5} \mathbf{~ m m} / \mathbf{m m} ; \mathbf{D}$ a deflexão no ponto médio entre os dois apoios, $\mathbf{r}$ a deformação, L a distência entre os dois apoios e d a espessura do corpo de prova, como mostra a figura 8.

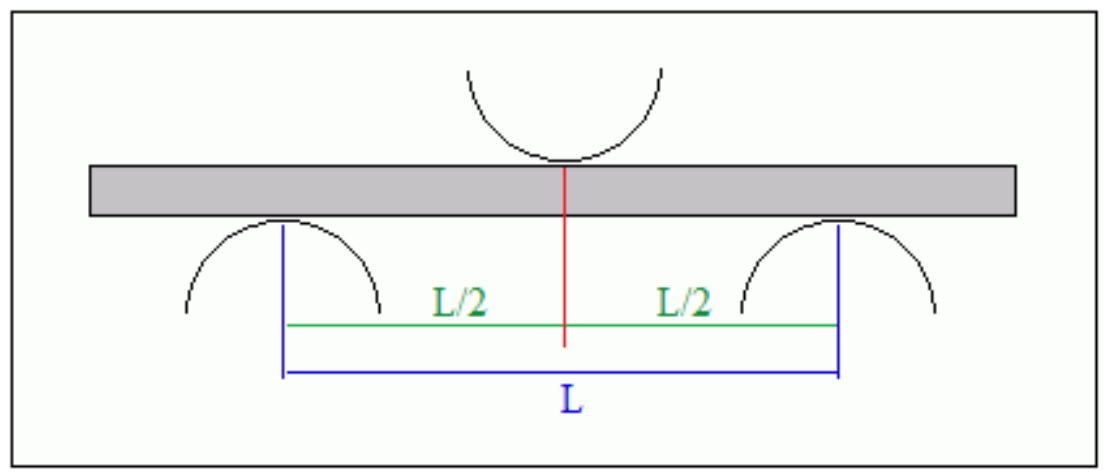

Figura 10: Representação esquemática das dimensões para o ensaio de flexão segundo a norma ASTM D790.

Entretanto, para um material que não rompe, ou não falha na superfície oposta ao carregamento, dentro de um limite máximo de 5,0\% de deformação durante o ensaio de flexão, é necessário utilizar o ensaio de flexão com carregamento em quatro pontos. A diferença entre os dois métodos está na localização do momento da carga máxima, e na tensão de tração máxima axial na superfície oposta ao carregamento. A tensão de tração máxima 
axial ocorre debaixo do ponto de carregamento no ensaio de três pontos, enquanto no ensaio de quatro pontos ocorre na área entre os dois pontos de carregamento (CASTRO, 2010).

Os corpos de prova para os ensaios de resistência à flexão devem ser preparados na forma de barras retangulares, com seção transversal plana. A separação dos apoios para o corpo de prova dividido pela profundidade do corpo de prova deve apresentar uma razão de 16:1, e o corpo de prova deve ser posicionado nos apoios de forma deitada (CALLISTER, 2007).

\section{6. Ensaio de Absorção de Água}

As fibras naturais possuem propriedades hidrofílicas, absorvendo e retendo facilmente as moléculas de água. Por serem fortes candidatas a reforço de compósitos, estudos relacionados à absorção de água são importantes. Também os polímeros sintéticos, ou e naturais, utilizados como matriz nos compósito, podem absorver água quando expostos à umidade.

Os principais fatores que interferem no processo de difusão de água em um material são: presença de grupos químicos capazes de formar ligações hidrogênio com a molécula de água, grau de entrecruzamento (se existir), cristalinidade.

O comportamento de difusão e transporte das moléculas de água em polímeros pode estar relacionado à mobilidade, tanto destas moléculas que se difundem, como dos segmentos poliméricos (ESPERT, 2004; COMYN, 1985). Normalmente, o comportamento de difusão das moléculas de água nas fibras vegetais difere do comportamento de difusão na matriz polimérica, quando analisados individualmente.

No presente trabalho, o ensaio de absorção de água foi realizado também com o objetivo de se buscar informações sobre a interface fibra/matriz, conforme descrito posteriormente, além de informações sobre afinidade do material pela água. 


\section{Experimental}

\section{1. Materiais}

Neste trabalho foram utilizadas fibras de bagaço de cana processadas de duas maneiras distintas:

(1) a cana de açúcar não queimada (gentilmente cedida por Sítio São Judas Tadeu, São Carlos, SP) foi passada por um moinho para a retirada do suco, e as fibras foram separadas manualmente da casca, lavadas em água quente, aproximadamente $70^{\circ} \mathrm{C}$, por $2 \mathrm{~h}$, para a extração de açúcares residuais e outros compostos solúveis em água. As fibras foram então secas e cortadas no comprimento desejado, para a posterior moldagem de compósitos. As fibras já cortadas foram desmeduladas em despolpador para separar as fibras da medula, novamente lavadas em água corrente e secas em estufa, sendo então reservadas para o processo de moldagem;

(2) bagaço de cana de açúcar que passou pelo processo tradicional de queima e moagem em usina, para a produção de etanol (gentilmente cedidas pela Usina de Cana Santa Lúcia, Araras, SP). O material recebido foi peneirado, para a separação da medula e de outros subprodutos vindos do processamento na usina. As fibras foram lavadas com água quente e secas, como descrito em (1). Após estas etapas, as fibras passaram por peneiras de mesh 16 e 12, estando então prontas para uso posterior de moldagem de compósitos.

As fibras de sisal foram adquiridas na forma de fios longos (na empresa Sisal Sul Indústria e Comércio Ltda., São Paulo, SP). As fibras de sisal são obtidas de processos de 
cultivo, corte, desfibramento, lavagem e secagem tradicionais. Em laboratório, as fibras passaram apenas pelo processo de extração, imersas em cicloexano/etanol (1:1 v/v) durante 10 min sob refluxo, lavagem com água destilada (temperatura ambiente) e secagem em estufa $\left(105^{\circ} \mathrm{C}\right)$ até massa constante.

O lignossulfonato de sódio utilizado para a preparação da resina e tratamento das fibras foi gentilmente cedido pela LignoTech Brasil (Grupo Borregaard, Cambará do Sul, RS), sendo obtido como subproduto do processo de polpação do sulfito da madeira.

A lignina organossolve utilizada na preparação de resinas (lignina-formaldeído e lignina-glutaraldeído) foi gentilmente cedida pela Usina Dedini (Piracicaba, SP). Esta lignina é obtida pelo processo organossolve (solvente: água/etanol; catalise ácida: ácido sulfúrico). A lignina organossolve utilizada no presente estudo é um subproduto do processo DHR (Dedini Hidrólise Ácida) cuja matéria-prima inicial é o bagaço de cana de açúcar.

O processo se divide nas seguintes operações: separação da lignina, purificação, separação e fermentação do mosto hidrolisado (hexoses). Antes da utilização da lignina no preparo das resinas, estas foram lavadas em água destilada, para a retirada de açúcares residuais e impurezas, à temperatura de $70^{\circ} \mathrm{C}$ por 30 min e seca em estufa com circulação de ar a $105^{\circ} \mathrm{C}$ até massa constante.

Outros reagentes utilizados: fenol, formaldeído (solução a 37\%), hidróxido de potássio, ácido sulfúrico (solução a 72\%), ácido acético glacial, hidróxido de sódio, ácido clorídrico e resorcinol, todos sendo da marca Synth. Glutaraldeído (25\%, Vetec) para o preparo de resinas utilizadas para o preparo de placas de compósitos e glutaraldeído (50\%, Sigma-Adrich) para o preparo dos pré-polímeros para caracterização inicial (RMN e SEC). 


\section{2. Métodos}

\section{2. 1. Caracterização das fibras (SILVA, 2006)}

\section{2. 1. 1. Determinação do teor de lignina (Método Klason)}

Este método é fundamentado na hidrólise ácida dos polissacarídeos, com a separação e a determinação da lignina insolúvel e solúvel em meio ácido (FENGEL, 1984).

\section{(A) Determinação do teor de lignina Klason insolúvel em meio ácido}

Para determinar o teor de lignina Klason insolúvel, pesa-se cerca de 1g de amostra seca em estufa por $4 \mathrm{~h}$ a $105^{\circ} \mathrm{C}$. Coloca-se em um almofariz com $15 \mathrm{~mL}$ de ácido sulfúrico (72\%) macera-se e deixa-se por $24 \mathrm{~h}$, a temperatura ambiente. Decorrido este período, transfere-se para um balão de 1L, adicionando $345 \mathrm{~mL}$ de água destilada, seguido de refluxo por $4 \mathrm{~h}$ (após o início da ebulição).

Em temperatura ambiente, filtra-se a lignina insolúvel em funil de vidro sinterizado (com porosidade $\mathrm{M}$ ) previamente tarado, lavando com água várias vezes (até que o $\mathrm{pH}$ da solução esteja próximo de 7). A lignina é seca em estufa, a $105^{\circ} \mathrm{C}$, até massa constante. As análises foram realizadas em triplicatas.

Uma alíquota da água de lavagem é retirada para análise em UV-vis, quando o volume de lavagem for de $500 \mathrm{~mL}$, a fim de determinar a porcentagem de lignina solúvel.

\section{(B) Determinação do teor de lignina Klason solúvel}

O filtrado obtido a partir da determinação da lignina Klason insolúvel foi analisado através de espectroscopia na região de ultravioleta, sendo determinadas as absorbâncias nos comprimentos de onda de 280 e $215 \mathrm{~nm}$, como descrito no método TAPPI T13M-54 (FENGEL, 1984). A análise foi realizada em um equipamento da marca Beckman, modelo DU-7. 


\section{2. 1. 2. Determinação do teor de umidade}

Este teste foi realizado de acordo com a Norma ABNT (NBR 9656), em triplicata. Com $1 \mathrm{~g}$ de massa inicial da amostra, esta foi colocada em pesa filtros, previamente tarados. As amostras foram secas em estufa com circulação de ar à temperatura de $105^{\circ} \mathrm{C}$ por $4 \mathrm{~h}$, e logo após foram colocadas em dessecador, resfriadas e pesadas até massa constante.

\section{2. 1. 3. Determinação do teor de cinzas}

Foram utilizados cadinhos previamente secos em mufla e tarados à temperatura de 600 ${ }^{\circ} \mathrm{C}$, por $4 \mathrm{~h}$. Pesou-se $1 \mathrm{~g}$ de amostra de fibra, moída e seca, em triplicata. Estas foram colocadas nos cadinhos e aquecidas em bico de Bunsen para combustão lenta da amostra, até desaparecer a chama de seu interior. Então, os cadinhos foram levados a mufla à temperatura de $600{ }^{\circ} \mathrm{C}$ por $4 \mathrm{~h}$, para calcinar. Estas foram colocadas em dessecador, resfriadas e pesadas até massa constante.

\section{2. 1. 4. Determinação do teor de holocelulose (hemicelulose + celulose)}

Foi realizada a determinação do teor de holocelulose para as fibras de acordo com a norma TAPPI T19m54 (1991). Em um erlenmeyer de 1L adicionou-se 3g de amostra moída e seca, livre de umidade em $120 \mathrm{~mL}$ de água destilada, $1 \mathrm{~mL}$ de ácido acético glacial e 2,5g de hipoclorito de sódio, sendo tampado com outro erlenmeyer pequeno.

O conjunto foi colocado em um banho termostatizado, a temperatura de $70 \pm 2{ }^{\circ} \mathrm{C}$ e mantido em agitação por $1 \mathrm{~h}$. Logo após, foi adicionado uma alíquota de $1 \mathrm{~mL}$ de ácido acético glacial e 2,5g de hipoclorito de sódio. Esta adição de alíquota deve ser repetida por 2 vezes de hora em hora, totalizando ao final de $4 \mathrm{~h}, 4 \mathrm{~mL}$ adicionados. Na sequência, a mistura foi resfriada à temperatura abaixo de $10^{\circ} \mathrm{C}$ (em banho). Em seguida a solução foi filtrada em funil de vidro sinterizado (de porosidade C), previamente tarado. 
O resíduo sólido (holocelulose) foi lavado com água destilada até que o filtrado estivesse incolor (ou com pH em torno de 7). Logo após, o resíduo foi lavado com 3 porções $(10 \mathrm{~mL})$ de metanol e seco em estufa a $105 \pm 5^{\circ} \mathrm{C}$. As amostras foram armazenadas em dessecador e pesadas até massa constante.

\section{2. 1. 5. Determinação do teor de $\alpha$-celulose}

O teor de celulose foi determinado de acordo com o método descrito na norma TAPPI T19m54, adaptada para as fibras lignocelulósicas (PAIVA, 2006), e em triplicata, conforme descrito a seguir.

Pesou-se 1,0g de amostra de holocelulose (obtido como produto da caracterização anterior), previamente seca em estufa por $4 \mathrm{~h}$. A esta foi adicionada $10 \mathrm{~mL}$ de solução de $\mathrm{NaOH} 17,5 \%$, num almofariz, deixada em repouso por $2 \mathrm{~min}$, sendo então triturado por 8 min com pistilo. Em seguida, foi acrescentado mais $10 \mathrm{~mL}$ de solução de $\mathrm{NaOH}$ 17,5\% e deixado em repouso por $20 \mathrm{~min}$. Após o repouso, adicionou-se $40 \mathrm{~mL}$ de água destilada e filtrou-se à vácuo em filtro sinterizado (de porosidade C).

O filtrado foi lavado com $200 \mathrm{~mL}$ de água, $200 \mathrm{~mL}$ de ácido acético glacial (diluído 20\%) e mais $200 \mathrm{~mL}$ de água, sendo então seco em estufa com circulação de ar a $105{ }^{\circ} \mathrm{C}$, sendo em seguida colocado em dessecador e pesado até massa constante.

\section{2. 1. 6. Difração de Raios $X$}

O Índice de Cristalinidade $\left(\mathbf{I}_{\mathbf{c}}\right)$ das fibras foi avaliado por difração de raios $\mathbf{X}$. Esta análise foi realizada para as amostras de fibras de bagaço de cana não queimado, bagaço de cana queimado, bagaço de cana queimado e tratado, e sisal.

Através dos difratogramas de raio $\mathrm{X}$ das fibras é possível observar a presença de picos característicos da celulose, referente aos planos cristalográficos, ângulos de Bragg (20). O índice 
de cristalinidade é calculado utilizando-se a equação 2 descrita por Buschle-Diller e Zeronian (BUSCHLE, 1992).

Para esta análise utilizou-se um Difratômetro Universal de raios-X URD-6, VEB CARL ZEISS-JENA, potência de $40 \mathrm{kV} / 20 \mathrm{~mA}$ e $\lambda\left(\mathrm{CuK}_{\alpha}\right)=1,5406 \AA$ A. As amostras, em forma de pó, foram secas em estufa a $105^{\circ} \mathrm{C}$ por $4 \mathrm{~h}$.

O índice de cristalinidade das amostras é determinado pela relação entre intensidades máxima e mínima, pela equação 2 , mostrada previamente. Os ângulos de intensidade máxima

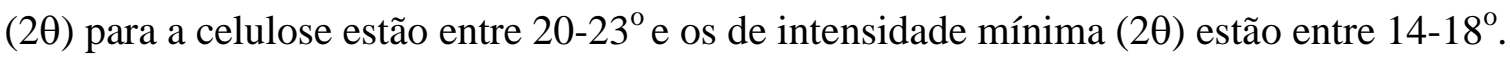

\section{2. 1. 7. Cromatografia Gasosa Inversa (Inverse Gas Chromatography - IGC)}

As fibras utilizadas neste trabalho foram analisadas por IGC em uma cromatógrafo Gas Chromatograph GC-17A, da marca Shimadzu. As análises foram realizadas em atmosfera de nitrogênio $\left(\mathrm{N}_{2}\right)$ e detector de ionização de chama (FID), nas seguintes condições:

Temperatura do injetor: $150{ }^{\circ} \mathrm{C}$

Temperatura do detector: $150{ }^{\circ} \mathrm{C}$

Temperatura das colunas: $30{ }^{\circ} \mathrm{C}$

Fluxo do gás de arraste $\left(\mathrm{N}_{2}\right): 30 \mathrm{~mL} \mathrm{\textrm {min } ^ { - 1 }}$

As colunas utilizadas foram confeccionadas de material aço inox $316^{1 / 4}$ com $2 \mathrm{~m}$ de comprimento de diâmetro interno de $5 \mathrm{~mm}$. As pontas da coluna foram adaptadas em aço para encaixe no sistema interno do cromatógrafo.

As colunas foram preenchidas com fibras cortadas no comprimento de $1 \mathrm{~mm}$, aproximadamente, previamente secas em estufa durante $4 \mathrm{~h}$, a $105^{\circ} \mathrm{C}$.

Para a padronização das colunas, estas foram mantidas durante $24 \mathrm{~h}$, com fluxo de $\mathrm{N}_{2}$ constante de $50 \mathrm{~mL} \mathrm{~min}{ }^{-1}$, na temperatura interna do forno de $110{ }^{\circ} \mathrm{C}$. Este procedimento também é necessário para a remoção de umidade dos materiais e contaminantes voláteis. 
Após este período, iniciou-se a análise da coluna com injeções do vapor do metano $(0,1$ $\mathrm{mL}$ ) para determinar o tempo morto da coluna. Em seguida o vapor das sondas da série de nalcanos (pentano, hexano, heptano, octano, nonano e decano) foi injetado para determinação das propriedades dispersivas. Para determinação do caráter ácido/base da amostra foram utilizados o clorofórmio $\left(\mathrm{CHCl}_{3}\right)$ e o tetraidrofurano (THF). Todas as sondas injetadas são de grau analítico, da marca Signa-Aldrich, com pureza de $99 \%$.

Para os cálculos da componente de energia dispersiva superficial $\left(\gamma_{\mathrm{s}}^{\mathbf{d}}\right)$, e para os cálculos do caráter ácido/base $\left(\mathbf{A N}_{\mathbf{S}} / \mathbf{D} \mathbf{N}_{\mathbf{S}}\right)$ das fibras, são necessários dados de energia dispersiva superficial das sondas $\left(\gamma_{\mathrm{L}}^{\mathbf{d}}\right)$ e a área superficial (da molécula) para cada sonda. Estas informações estão descritas na tabela 1.

Tabela 1: Parâmetros característicos das sondas utilizadas nas análises de IGC (Belgacem et al., 1995).

\begin{tabular}{|c|c|c|c|}
\hline Sonda & $\mathbf{a}\left(\AA^{2}\right)$ & $\gamma_{\mathrm{L}}^{\mathrm{d}}\left(\mathrm{mJ} \mathrm{m}^{-2}\right)$ & Caráter \\
\hline pentano & 45,5 & 15,5 & Neutro \\
\hline hexano & 51,5 & 18,4 & Neutro \\
\hline heptano & 57,0 & 20,3 & Neutro \\
\hline octano & 62,8 & 21,3 & Neutro \\
\hline nonano & 68,9 & 22,7 & Neutro \\
\hline decano & 74,9 & 23,4 & Neutro \\
\hline $\mathrm{CHCl}_{3}$ & 44,0 & 25,0 & Ácido \\
\hline THF & 45,0 & 22,5 & Base \\
\hline
\end{tabular}

\section{2. 2. Separação e caracterização das ligninas}

Esta etapa do trabalho fez parte do projeto de Doutorado Sanduíche no Exterior realizado na Université de Bordeaux I, Unité Sciences du Bois et des Biopolymères, sob orientação do Prof. Alain Castellan (França). 


\section{2. 2. 1. Separação e purificação}

A extração da lignina contida nas fibras de bagaço de cana queimado ocorreu através do processo de cozimento, descrito por Huang et al. (2007), envolvendo o uso de amônia, potássio e antraquinona $\left(\mathrm{KOH}(5 \%) / \mathrm{NH}_{4} \mathrm{OH}(35 \%)\right.$ / $\left.\mathrm{AQ}(0,1 \%)\right)$. O cozimento foi realizado sob pressão em um reator rotativo de $2 \mathrm{~L}$ em aço inox, aquecidos eletricamente, controlados eletronicamente. A taxa de aquecimento utilizada foi de $2,75^{\circ} \mathrm{C} \min ^{-1}$ até a temperatura de $165{ }^{\circ} \mathrm{C}$, mantida por $1 \mathrm{~h}$. Após o cozimento, de acordo com estas condições, as fibras do bagaço apresentaram pouca deslignificação, sendo dificeis de isolar. Por essa razão, optou-se por utilizar o método de soda/antraquinona (HUANG, 2007).

Para a extração da lignina das fibras através do método soda/antraquinona, as fibras foram previamente suspensas em água por $48 \mathrm{~h}$, em seguida, filtradas, drenadas e secas. Em seguida, adicionados a $1 \mathrm{~L}$ de $\mathrm{NaOH}(1 \mathrm{M})$ e $0,1 \%$ de antraquinona comercial (AQ), com rampa de aquecimento de $1 \mathrm{~h}$ e permanecendo $1 \mathrm{~h} 30$ min na temperatura de $172{ }^{\circ} \mathrm{C}$. A polpa foi filtrada e o licor negro recolhido. A polpa foi lavada com água até pH igual ao da água de partida, em seguida, prensadas, secas (ao ar, até um teor de umidade de 30\%), sendo então conservados sob refrigeração $\left(4^{\circ} \mathrm{C}\right)$. A separação da lignina do licor negro foi realizado segundo o protocolo descrito por Mousavioun e Doherty (2010), por acidificação até pH 3 com ácido sulfúrico concentrado, a temperatura ambiente. A mistura foi mantida em banho à $65{ }^{\circ} \mathrm{C}$ durante 45 min, sendo o precipitado recolhido por centrifugação e lavado com água à $50{ }^{\circ} \mathrm{C}$. A secagem foi realizada em estufa com circulação de ar a $30^{\circ} \mathrm{C}$. As frações de lignina, por volta de $70 \%$ de pureza (determinado por UV-visível), foram utilizadas para estudos posteriores.

As ligninas foram caracterizadas segundo o método Klason (TAPPI (T222 om- 88)) e absorção no UV-visível, para determinar sua pureza e obter o rendimento do cozimento. 
Em uma mistura de dioxano/água (9/1 v/v) as ligninas foram solubilizadas para registar os espectros de absorção no UV-vis. A medida em 280nm permite determinar o coeficiente de extinção molar $(\varepsilon)$ neste comprimento de onda, obtendo-se assim informações sobre a pureza das amostras de lignina determinadas por Klason (HOAREAU, 2004).

\section{3. Caracterização de ligninas e pré-polímeros}

Ligninas e pré-polímeros preparados nesta etapa do trabalho foram analisadas por Cromatografia de Exclusão por Tamanho (Size Exclusion Chromatography -SEC), HPLC (Cromatografia Líquida de Alta Performance - High-performance Liquid Chromatography (para determinação de açúcares da lignina), $\mathrm{RMN}$ de ${ }^{1} \mathrm{H}$ e $\mathrm{RMN}{ }^{31} \mathrm{P}$.

\section{3. 1. Acetilação da lignina}

As análises de massa molar média por Cromatografia de Exclusão por Tamanho (Size Exclusion Chromatography - SEC) e RMN de ${ }^{1} \mathrm{H}$ requisitaram de acetilação prévia das amostras, a fim de impedir (ou pelo menos dificultar) a agregação decorrente das interações intermoleculares envolvendo grupos hidroxila.

A acetilação torna o material solúvel no eluente usado em SEC, o THF (tetrahidrofurano). Além disso, a acetilação da lignina permite diferenciar com maior facilidade os grupos alifáticos e grupos hidroxilas aromáticas por espectroscopia de RMN de ${ }^{1} \mathrm{H}$, pois os sinais de prótons dos grupos hidroxilas não são observáveis no espectro, mas os sinais de prótons dos grupos acetila introduzidos podem ser detectados.

As ligninas foram acetiladas em uma mistura de piridina/anidrido acético $(1: 1 \mathrm{v} / \mathrm{v})$ durante $18 \mathrm{~h}$ à temperatura de $60^{\circ} \mathrm{C}$ (Figura 11). Em seguida, fez-se reagir o anidrido acético (não reagido) com metanol $(50 \mathrm{~mL})$ durante $3 \mathrm{~h}$ em refluxo (à temperatura de $80{ }^{\circ} \mathrm{C}$ ). $\mathrm{O}$ acetato de metila formado nesta reação foi rotoevaporado. A piridina foi evaporada por co-deslilação com tolueno $(2 \times 10 \mathrm{~mL})$. O tolueno foi eliminado por co-destilação com metanol. O metanol 
foi evaporado, e o sólido foi solubilizado em $\mathrm{CH}_{2} \mathrm{Cl}_{2}(50 \mathrm{ml})$ e filtrado. Este último filtrado foi seco por rotoevaporação e mantido em dessecador na presença de $\mathrm{CaCl}_{2}$ (HOAREAU, 2006). As ligninas acetiladas foram obtidas com um rendimento quantitativo. Após a acetilação, as amostras foram analisadas por SEC e RMN ${ }^{1} \mathrm{H}$.<smiles>CC(=O)OC(C)=O</smiles>

Figura 11: Acetilação da lignina (Lig).

Os espectros de RMN de ${ }^{1} \mathrm{H}$ foram registrados no aparelho Bruker Avance 300 (Bruker AS, Wissemburg, France) operado a 300 e 75,47 MHz para próton e carbono 14, respectivamente. Os espectros foram calibrados com relação ao sinal de clorofórmio residual em $\delta=7,26 \mathrm{ppm}\left({ }^{1} \mathrm{H}\right)$ e $\delta=77,36 \mathrm{ppm}\left({ }^{13} \mathrm{C}\right)$.

As análises de SEC foram efetuadas em um aparelho Thermo Séparation Spectra Physics equipado com uma bomba P100, um injetor automático AS3000, um detector UV 2000 e um refratômetro Waters 410. Para as análises de SEC utilizou-se 3 colunas Tosohas (G 2000 HXL, G 3000 HXL e G 4000 HXL) e tetraidrofurano (THF) como solvente de eluição a uma taxa de $1 \mathrm{ml} \min ^{-1}$ a uma temperatura de $25^{\circ} \mathrm{C}$. O tempo de retenção foi calibrado com padrões de poliestireno.

\section{3. 2. Fosforilação de lignina}

Os espectros da $\mathrm{RMN}{ }^{31} \mathrm{P}$ foram obtidos a partir das ligninas não acetiladas. O método descrito por Argyropoulos et al. (1994a,b; GRANATA, 1995) tornou-se uma ferramenta para aquisição dos espectros (256 acumulativos para cada um). Previamente a esta análise, a lignina foi derivatizada de acordo com o procedimento descrito por Granata (1995). 
As amostras de lignina (30 a $40 \mathrm{mg}$ ) foram solubilizadas em DMF anidro $(0,5 \mathrm{~mL}) \mathrm{em}$ um recipiente vedado, sob agitação magnética, em atmosfera de nitrogênio. Após 10 min de agitação, foi adicionado sucessivamente uma mistura de piridina/ $\mathrm{CDCl}_{3}(0,3 \mathrm{ml} ; 1 \mathrm{v} / 1,6 \mathrm{v})$, uma solução $(0,1 \mathrm{~mL})$ de colesterol $\left(43 \mathrm{mg} \mathrm{mL}^{-1}\right.$, em uma mistura de piridina/ $\left.\mathrm{CDCl}_{3} 1 \mathrm{v} / 1,6 \mathrm{v}\right)$, uma solução $(0,1 \mathrm{~mL})$ de acetilacetonato de cromo (III) $\left(5,28 \mathrm{mg} \mathrm{mL}^{-1}\right)$ em uma mistura de piridina/ $\mathrm{CDCl}_{3}$ 1v/1,6v) e 2-cloro-4,4,5,5-tetrametil-1,3,2-dioxafosfolano $(0,1 \mathrm{~mL})$ (Figura 12). A amostra permaneceu sob agitação em atmosfera de nitrogênio durante $1 \mathrm{~h}$, em seguida a mistura foi filtrada (em algodão para retirar as impurezas sólidas) e transferida para um tubo (5mm) de RMN. A taxa dos diferentes grupos de hidroxilas foi calculada com relação ao sinal de colesterol em concentração conhecida.

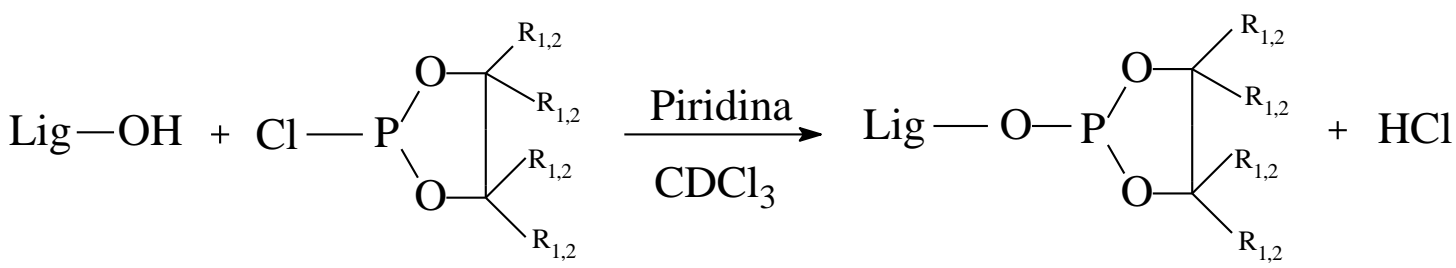

Figura 12: Reação de fosforilação dos grupos hidroxilas da lignina, $\mathrm{R}_{1}=\mathrm{H}, \mathrm{R}_{2}=\mathrm{CH}_{3}(\mathrm{Granata}, 1995)$.

A escolha de mistura do solvente piridina/ $\mathrm{CDCl}_{3}$ foi igual a $1 \mathrm{v} / 1,6 \mathrm{v}$ ao invés de $1,6 \mathrm{v} / 1 \mathrm{v}$, conforme descrito por Argyropoulos et al. (1994a,b; GRANATA, 1995). O aumento na proporção de clorofórmio deuterado permite precipitar o $\mathrm{HCl}$, formado após a reação de despolimerização das ligninas, e filtrar antes de registrar o espectro de $\mathrm{RMN}{ }^{31} \mathrm{P}$. O colesterol foi utilizado como referência interna por apresentar um sinal único em 144,8 ppm (WU, 2003).

Os espectros quantitativos de $\mathrm{RMN}{ }^{31} \mathrm{P}$ foram registrados no aparelho Bruker Avance 400 (Bruker SA, Wissemburg, France) operando a 162,06 MHz para fósforo 31. Os espectros foram calibrados utilizando o sinal final em 132,2 ppm proveniente da reação de água residual com o 2-cloro-4,4,5,5-tetrametil-1,3,2-dioxidofosfolano. As condições de aquisição dos 
espectros são descritos por Argyropoulos et al. (1994a,b; 1995), exceto a escolha de mistura do solvente piridina/ $\mathrm{CDCl}_{3}$ que no lugar de $1,6 \mathrm{v} / 1 \mathrm{v}$ foi igual a $1 \mathrm{v} / 1,6 \mathrm{v}$.

\section{3. 3. Caracterização de açúcares da lignina extraída do bagaço de cana queimado \\ O teor de açúcares residuais presentes nas amostras de lignina extraída do bagaço de} cana queimado, gerados a partir de hemicelulose (produzida a partir do cozimento das fibras de bagaço de cana após a extração do licor negro) foi analisada por HPLC. Para esta análise fez-se a despolimerização da hemicelulose em açúcares simples por hidrólise em meio ácido.

Pesou-se 0,5 g de amostra (seca) sendo adicionado $10 \mathrm{~mL}$ de $\mathrm{H}_{2} \mathrm{SO}_{4}(72 \%)$. A mistura foi mantida em repouso $4 \mathrm{~h}$ a $20{ }^{\circ} \mathrm{C}$ e, em seguida, transferiu-se a mistura para um frasco Erlenmeyer de 1L, equipado com um condensador. A mistura foi deixada em refluxo por $4 \mathrm{~h}$, filtrada através de vidro sinterizado $\mathrm{N}^{\circ} 2$ para remoção do enxofre insolúvel. As amostras foram lavadas com água 3 vezes, a temperatura de $35^{\circ} \mathrm{C}$. O filtrado foi adicionado a um balão volumétrico de $250 \mathrm{~mL}$, completando-se o volume. Retirou- se uma aliquota de $150 \mathrm{~mL}$ para neutralização com barita (pH 7). A barita é eliminada por centrifugação (10 min à 3000 rpm $\min ^{-1}$ ). A fase liquida é concentrada até $50 \mathrm{~mL}$ em rotavapor à $60{ }^{\circ} \mathrm{C}$. Os diversos açúcares foram analisados por HPLC, e os resultados foram expressos em \% com relação à massa de sólido analisada.

As análises de HPLC foram efetuadas em um aparelho Thermo Séparation Spectra Physics equipado com uma bomba P100, um auto injetor AS3000, um detector UV 2000 e um refratômetro Waters 410. Uma coluna de Biorad Aminex HPX87P300 (300 x 7,8 mm) foi utilizada para análise de açúcares simples, com água como eluente a uma taxa de $1 \mathrm{~mL} \min ^{-1}$ à uma temperatura de $25^{\circ} \mathrm{C}$. 


\section{4. Preparação de termorrígidos e compósitos}

\section{4. 1. Síntese do pré-polímero fenólico}

Em um balão de três bocas foram adicionados o fenol, formaldeído (solução 37\%) e $\mathrm{KOH}$, na proporção 1,0:1,38:0,06 em massa, respectivamente. Esta mistura foi aquecida até $70{ }^{\circ} \mathrm{C}$, retirando-se a manta de aquecimento após $97^{\circ} \mathrm{C}$, devido à reação ser exotérmica. Após 40 min, o sistema retornou a temperatura de $70{ }^{\circ} \mathrm{C}$, sendo mantida nesta temperatura por $1 \mathrm{~h}$. Logo após, a manta foi retirada e o sistema resfriado até temperatura ambiente, sendo então o meio neutralizado com solução de $\mathrm{HCl}$.

Para o uso do pré-polímero para moldagem, foi evaporada a água, sob pressão reduzida (rotaevaporador), em temperatura em torno de $50{ }^{\circ} \mathrm{C}$, até que não se observasse mais a condensação de voláteis. Logo em seguida, este foi armazenado em recipiente vedado, a temperatura de $10{ }^{\circ} \mathrm{C}$.

\section{4. 2. Síntese do pré-polímero formaldeído - lignina organossolve}

A um béquer contendo formaldeído, foi adicionado gradativamente a lignina organossolve, mantendo-se o sistema com agitação mecânica por 15 min, para a solubilização da mesma. A mistura foi mantida sob agitação por mais 15 min, seguida da adição do KOH. Os reagentes foram adicionados na proporção (1,38:1:0,07 em massa). Manteve-se a mistura por 40 min sob agitação, sem aquecimento, sendo o pH medido para a confirmação de meio básico ( $\mathrm{pH}$ 8). Após este período de tempo, o aquecimento foi acionado e a temperatura elevada até $97{ }^{\circ} \mathrm{C}$, sendo mantida por $2 \mathrm{~h}$. Ao final deste período, o aquecimento foi retirado e o sistema resfriado, sendo o $\mathrm{pH}$ novamente medido. Quando necessário, o meio foi neutralizado com $\mathrm{HCl}$. Estes parâmetros de reação foram estabelecidos por estudos realizados previamente (RAZERA, 2006). 


\section{4. 3. Síntese do pré-polímero formaldeído - lignossulfonato de sódio}

A síntese do pré-polímero formaldeído-lignossulfonato de sódio seguiu o mesmo procedimento descrito no item para a preparação da resina formaldeído-lignina organossolve, item 4.3.2, mantendo-se as proporções de reagentes. Apenas o tempo de reação foi alterado, sendo a temperatura elevada até $70{ }^{\circ} \mathrm{C}$ e mantida por $1 \mathrm{~h}$. Em seguida, a temperatura foi elevada até $97{ }^{\circ} \mathrm{C}$ e mantida por $2 \mathrm{~h}$. Ao final deste período, o aquecimento foi retirado e o sistema resfriado, sendo o $\mathrm{pH}$ novamente medido. Quando necessário, o meio foi neutralizado com $\mathrm{HCl}$. O pré-polímero foi rotoevaporado com pressão reduzida e armazenada em recipiente vedado (temperatura de $10{ }^{\circ} \mathrm{C}$ ).

\section{4. 4. Síntese pré-polímero e glutaraldeído - lignina organossolve}

Um pré-polímero do tipo fenólico foi preparado utilizando lignina organossolve, substituindo o fenol, e glutaraldeído $\left(\mathrm{HOCCH}_{2} \mathrm{CH}_{2} \mathrm{CHO}\right)$, como substituto do formaldeído. A lignina organossolve reagiu com glutaraldeído em solução alcalina, na proporção 1:1:0,3 (lignina:glutaraldeído: $\mathrm{KOH}$, em massa). A mistura foi agitada durante $4 \mathrm{~h}$ a $80{ }^{\circ} \mathrm{C}$, depois foi acidificada com ácido clorídrico (10\%) até pH 5.

Tolueno foi adicionado, sendo o meio mantido sob agitação por mais $2 \mathrm{~h}$, para precipitar o pré-polímero. Ao precipitado foi adicionado $5 \mathrm{~mL}$ de tolueno, com a finalidade de evaporar à vácuo (em rotoevaporador à $40{ }^{\circ} \mathrm{C}$ ) a água residual contida no material. Foi obtido um sólido (rendimento: 90\%) de cor marrom, sendo parte deste produto acetilado segundo o procedimento já descrito para as análises de SEC e RMN ${ }^{1} \mathrm{H}$. O pré-polímero não acetilado foi caracterizado por FT-IR, RMN ${ }^{31} \mathrm{P}$.

Este pré-polímero foi preparado posteriormente em uma escala maior, seguindo as proporções 1:1:0,075 (lignina:glutaraldeído:KOH) e o tempo/temperatura de reação de 2h/97 ${ }^{\circ} \mathrm{C}$, seguiu-se o procedimento de preparo, descrito anteriormente, para formaldeído-lignina 
organossolve. Estes parâmetros foram ajustados após a realização de alguns testes, para adequar a resina ao processo de preparo de placas de compósitos.

\section{4. 5. Síntese do pré-polímero glutaraldeído - lignossulfonato de sódio}

Com base no estudo realizado para o pré-polímero (resina) glutaraldeído-lignina organossolve, o pré-polímero glutaraldeído-lignossulfonato de sódio foi preparado.

A um béquer contendo glutaraldeído foi adicionado gradativamente o lignossulfonato de sódio, sendo o sistema mantido com agitação mecânica por 15 min para a solubilização da lignina. A mistura foi mantida sob agitação por mais 15 min, seguida da adição do KOH. Os reagentes lignossulfonato de sódio, glutaraldeído e $\mathrm{KOH}$ foram adicionados na proporção 1:1:0,075 (lignina, glutaraldeído, KOH, em massa). Manteve-se a agitação da mistura por 40 min, sem aquecimento. $\mathrm{O}$ pH foi medido para a confirmação de meio básico. Após este período de tempo, a temperatura foi elevada até $70{ }^{\circ} \mathrm{C}$, sendo mantido por $1 \mathrm{~h}$. Em seguida, a temperatura foi elevada até $97{ }^{\circ} \mathrm{C}$ e mantida por $2 \mathrm{~h}$. Ao final deste período, o sistema foi resfriado, o pH foi ajustado para 7. O pré-polímero foi rotaevaporado sob pressão reduzida.

\section{4. 6. Preparação das fibras para moldagem de compósitos}

Para a eliminação de extrativos orgânicos solúveis em cicloexano/etanol, as fibras de bagaço de cana (queimado e não queimado) passaram pelo processo de extração com ciclohexano/etanol (1:1, v/v) por 10h, em balão com refluxo. Para a determinação do tempo de extração ideal (10h), foi realizado um estudo com tempos de extração variando de $5 \mathrm{~h}$ até 60h. Posteriormente à extração, as fibras foram lavadas exaustivamente e secas em estufa com circulação de ar, à temperatura de $105^{\circ} \mathrm{C}$.

O mesmo procedimento foi seguido para o preparo das fibras de sisal, mantendo-as na mistura (cicloexano/etanol) em ebulição por $10 \mathrm{~min}$. O tempo de extração das fibras de sisal foi estabelecido por estudos realizados no trabalho descrito por Oliveira (2010). 


\section{4. 6.1. Tratamento das fibras de bagaço de cana}

As fibras de bagaço de cana queimadas (já extraídas em cicloexano/etanol) foram tratadas com solução de lignossulfonato de sódio (NaLS), visando a adsorção do NaLS na superfície da fibra. Neste tratamento, as fibras foram suspensas em solução de lignossulfonato de sódio saturada $\left(50 \mathrm{~g} \mathrm{~L}^{-1}\right)$ em um béquer, e mantidas dentro de um banho de ultrassom (modelo USC-1800, frequência de $40 \mathrm{kHz}$ e potência 120W) durante $1 \mathrm{~h}$. As fibras foram agitadas periodicamente com auxilio de uma pinça (a cada $10 \mathrm{~min}$, em média). A temperatura da solução de lignossulfonato de sódio foi mantida em aproximadamente $30{ }^{\circ} \mathrm{C}(\mathrm{pH} 7,0)$. Logo após foram retiradas do banho, secas em temperatura ambiente e em estufa, até massa constante, a $105^{\circ} \mathrm{C}$.

\section{4. 7. Moldagem dos compósitos}

A massa de pré-polímero fenólico a ser na sequência utilizada para a moldagem foi aquecida até à temperatura de $50{ }^{\circ} \mathrm{C}$, sendo e adicionado o acelerador de cura (resorcinol) gradativamente, com agitação, por 30 min.

Para o pré-polímero onde o lignossulfonato de sódio estava presente, a temperatura foi mantida em $40{ }^{\circ} \mathrm{C}$, o acelerador de cura (resorcinol) foi adicionado rapidamente com agitação por $20 \mathrm{~min}$. Este procedimento foi definido por estudos prévios de análise térmica, TGA e DSC, os quais indicaram a temperatura de inicio para o ponto de cura deste pré-polímero.

O resorcinol foi o reagente de cura utilizado para este processo, correspondendo a $10 \%$ da massa total de pré-polímero utilizado para moldagem. Este mesmo procedimento de preparo do pré-polímero foi utilizado, tanto para a preparação dos termorrígidos quanto dos compósitos.

Para a moldagem dos compósitos, as resinas foram preparadas como descrito anteriormente e a impregnação das fibras ocorreu com o auxilio de misturador mecânico (JVJ, 
Pardinho, SP). As fibras foram previamente secas em estufa com circulação de ar à temperatura de $105^{\circ} \mathrm{C} \pm 5^{\circ} \mathrm{C}$, por um período de tempo mínimo de $4 \mathrm{~h}$.

Foram preparados compósitos com fibras de bagaço de cana não queimado de comprimento 1, 2, 3, 4 e 5cm (30\% em massa) e impregnadas com resina fenólica, com auxílio do misturador mecânico.

Também, foram preparados compósitos com fibras de bagaço de cana queimadas (não tratadas e tratadas com solução de lignossulfonato em banho de ultrassom) de comprimento médio de $1,5 \mathrm{~cm}$, pois o comprimento de fibra gerado pelas usinas impede que outros comprimentos de fibra sejam considerados (30, 50 e $70 \%$ em massa) e sisal, impregnadas com resina (fenólica, formaldeído-lignossulfonato de sódio, formaldeídolignina organossolve, glutaraldeído-lignossulfonato de sódio e glutaraldeído-lignina organossolve) com auxílio do misturador mecânico.

Destaca-se que a resina fenólica (pré-polímero) é vertida no recipiente do misturador e mantida a temperatura de aproximadamente $50^{\circ} \mathrm{C}$, e conduzida gradativamente por uma tubulação até o tambor, com o auxílio de injeção de ar comprimido acoplado ao misturador, logo após a acomodação das fibras neste. As demais resinas, devido ao início de cura a baixas temperaturas, foram misturadas manualmente às fibras com auxílio de pinças, e levadas ao tambor rotativo para melhor homogeneização da resina com as fibras.

O início da adição do pré-polímero e a rotação do tambor ocorrem simultaneamente. A rotação do tambor foi mantida em $30 \mathrm{rpm}$, durante $20 \mathrm{~min}$. Os vapores formados do prépolímero foram conduzidos através de um duto até uma capela.

Para o pré-polímero em que a lignina organossolve estava presente, toda a vidraria e reagentes utilizados foram resfriados (aproximadamente $10{ }^{\circ} \mathrm{C}$ ) para uso posterior, pois a lignina organossolve reage rapidamente com a resorcina a temperatura ambiente. A resina e a resorcina foram misturadas manualmente em almofariz, seguida da impregnação das fibras. 
As fibras após secagem em estufa $\left(4 \mathrm{~h} / 105^{\circ} \mathrm{C}\right)$ foram embaladas a vácuo e resfriadas. Fibras e resina foram levadas ao misturador mecânico para homogeneização (20 min/30 rpm).

Após a impregnação, as fibras foram distribuídas em molde metálico portátil, previamente revestido com cera de carnaúba (utilizado como agente desmoldante), levado a prensa, iniciando a programação de moldagem e compressão.

A programação de moldagem e compressão para a resina fenólica, que foi utilizada no presente trabalho, foi estabelecida em estudos anteriores (PAIVA, 2001), tabela 2.

A programação de moldagem e compressão para a resina formaldeído-lignina organossolve foi desenvolvida com base em trabalhos anteriores (RAZERA, 2006; RAMIRES, 2010) e análises realizadas via TGA e DSC, tabela 3.

Para as demais resinas desenvolvidas neste trabalho, com base na programação de moldagem para a resina formaldeído-lignina organossolve e testes realizados de análise térmica (via TGA e DSC) determinou-se a programação descrita na tabela 4 e 5.

O aquecimento foi programado em um sistema controlador de temperatura, ligado ao molde portátil. Este molde constitui-se de duas placas, as quais possuem resistências elétricas embutidas, tanto em sua placa superior quanto inferior. A compressão deste molde foi realizada gradativamente, com auxílio de uma prensa manual.

Tabela 2: Ciclo de cura para compósitos fenólicos.

\begin{tabular}{c|c|c}
\hline Tempo (mim) & Temperatura $\left({ }^{\circ} \mathbf{C}\right)$ & Força (ton) \\
\hline $\mathbf{2 5}$ & 65 & 0 \\
\hline $\mathbf{6 5}$ & 75 & 0 \\
\hline $\mathbf{9 5}$ & 85 & 0 \\
\hline $\mathbf{3 5}$ & 95 & 16 ton \\
\hline $\mathbf{3 5}$ & 105 & 16 ton \\
\hline $\mathbf{6 5}$ & 115 & 16 ton \\
\hline $\mathbf{9 0}$ & 125 & 16 ton \\
\hline
\end{tabular}


Tabela 3: Ciclo de cura para os compósitos de formaldeído-lignina organossolve (FLO) e glutaraldeído-lignina organossolve (GLO).

\begin{tabular}{c|c|c|c}
\hline Tempo $(\mathbf{m i m})$ & Temperatura $\left({ }^{\circ} \mathbf{C}\right)$ & \multicolumn{2}{|c}{ Força (ton) } \\
\hline $\mathbf{9 0}$ & & FLO & GLO \\
\hline $\mathbf{1 0}$ & 50 & 0 & 2 \\
\hline $\mathbf{6 0}$ & 50 & 16 ton & 2 \\
\hline $\mathbf{6 0}$ & 65 & 16 ton & 16 ton \\
\hline $\mathbf{3 0}$ & 80 & 16 ton & 16 ton \\
\hline $\mathbf{3 0}$ & 95 & 16 ton & 16 ton \\
\hline $\mathbf{6 0}$ & 105 & 16 ton & 16 ton \\
\hline $\mathbf{1 2 0}$ & 115 & 16 ton & 16 ton \\
\hline $\mathbf{6 0}$ & 125 & 16 ton & 16 ton \\
\hline
\end{tabular}

Tabela 4: Ciclo de cura para compósitos formaldeído-lignossulfonato de sódio.

\begin{tabular}{c|c|c}
\hline Tempo $(\mathbf{m i m})$ & Temperatura $\left({ }^{\circ} \mathbf{C}\right)$ & Força $($ ton $)$ \\
\hline $\mathbf{5 0}$ & 50 & 0 \\
\hline $\mathbf{1 0}$ & 50 & 16 ton \\
\hline $\mathbf{6 0}$ & 65 & 16 ton \\
\hline $\mathbf{6 0}$ & 80 & 16 ton \\
\hline $\mathbf{3 0}$ & 95 & 16 ton \\
\hline $\mathbf{3 0}$ & 105 & 16 ton \\
\hline $\mathbf{6 0}$ & 115 & 16 ton \\
\hline $\mathbf{1 2 0}$ & 125 & 16 ton \\
\hline
\end{tabular}

Tabela 5: Ciclo de cura para os compósitos glutaraldeído-lignossulfonato de sódio.

\begin{tabular}{c|c|c}
\hline Tempo (mim) & Temperatura $\left({ }^{\circ} \mathbf{C}\right)$ & Força (ton) \\
\hline $\mathbf{9 0}$ & 50 & 0 \\
\hline $\mathbf{1 0}$ & 50 & 16 ton \\
\hline $\mathbf{6 0}$ & 65 & 16 ton \\
\hline $\mathbf{6 0}$ & 80 & 16 ton \\
\hline $\mathbf{3 0}$ & 95 & 16 ton \\
\hline $\mathbf{3 0}$ & 110 & 16 ton \\
\hline $\mathbf{1 2 0}$ & 125 & 16 ton \\
\hline $\mathbf{6 0}$ & 150 & 16 ton \\
\hline
\end{tabular}

Como descrito nas tabelas 2-5, após a programação de temperatura, a pressão é aplicada variando para cada tipo de resina utilizada (até 16 ton). Neste ponto, a resina encontra-se no ponto de gel, em que a resina se torna mais viscosa devido ao início do entrecruzamento da 
rede polimérica, sendo esta a temperatura adequada para aplicação da pressão, pois a resina penetrará e permanecerá no interior das fibras. O processo de desmoldagem ocorreu após o resfriamento do molde até temperatura ambiente.

O termorrígido (não reforçado) obtido de resinas baseadas em lignossulfonato de sódio e lignina organossolve foram moldados, mas após cura a placa se tornou frágil e quebradiça, não sendo possível realizar alguns testes em que corpos de prova com dimensões específicas são necessários.

\section{5. Caracterização das fibras, termorrígidos e compósitos}

Amostras de fibras de bagaço de cana (queimadas e não queimadas) não tratadas e tratadas com solução de lignossulfonato (em banho de ultrassom), fibras de sisal, termorrígidos e compósitos foram analisadas pelas técnicas descritas a seguir.

\section{5. 1. Microscopia Eletrônica de Varredura (MEV)}

O Microscópio Eletrônico de Varredura da marca Zeiss-Leica modelo 440, aceleração de elétrons de $20 \mathrm{kV}$ foi usado. No porta-amostra de alumínio foram fixadas as amostras com fitas de carbono, pintadas somente nas laterais com tinta-prata e revestidas com uma fina camada de ouro (20 nm) utilizando-se o equipamento "Coating System", modelo MED 020 da marca BAL-TEC. As análises de MEV dos compósitos foram realizadas na superfície de fratura do material, após o ensaio de impacto.

\section{5. 2. Termogravimetria (TGA)}

Para a análise termogravimétrica, utilizou-se o equipamento da marca Shimadzu, modelo TGA-50, nas seguintes condições: Massa da amostra: 4-5 mg; Temperatura: 20$800{ }^{\circ} \mathrm{C}$; Fluxo de $\mathbf{N}_{\mathbf{2}}: 20 \mathrm{~mL} \min ^{-1}$; Razão de Aquecimento: $10^{\circ} \mathrm{C} \mathrm{min}^{-1}$. 


\section{5. 3. Calorimetria Exploratória Diferencial (DSC)}

Para a análise de Calorimetria Exploratória Diferencial, utilizou-se o equipamento da marca Shimadzu, modelo DSC-50, nas seguintes condições para todas as amostras: Massa da amostra: 6-8 mg; Temperatura: $20-500^{\circ} \mathrm{C}$; Fluxo de $\mathbf{N}_{2}$ : $20 \mathrm{~mL} \min ^{-1}$; Razão de Aquecimento: $10^{\circ} \mathrm{C} \min ^{-1}$.

\section{5. 4. Espectroscopia na região do Infravermelho (IV) e Ultravioleta visível (UV-} vis)

Para análise espectroscópica na região de infravermelho, utilizou-se um equipamento da marca BOMEM, modelo MB-102, na região de 400 a $4000 \mathrm{~cm}^{-1}$, utilizando pastilhas de $\mathrm{KBr}$ (1mg de amostra para 100mg de $\mathrm{KBr}$ ). As amostras e o $\mathrm{KBr}$ foram secas em estufa com circulação de ar a $105{ }^{\circ} \mathrm{C}$ por $4 \mathrm{~h}$. As amostras analisadas foram: fibras bagaço de cana (não queimada, queimada, queimada e tratada) e sisal, pré-polímero, termorrígidos e compósitos.

Os espectros IV da lignina organossolve, lignina do bagaço de cana queimado e seus respectivos pré-polímeros foram registrados em um espectrômetro Thermo Nicolet Avatar 370. As amostras foram misturadas ao $\mathrm{KBr}$ seco em uma concentração de $1 \%$ (massa) e prensada a vácuo para formar as pastilhas. Os espectros de UV-visível foram registrados em um aparelho Perkin Elmer Lambda 18. As amostras de lignina foram dissolvidas em uma mistura de dioxano/água (9/1; v/v). Estas análises (IV e UV-visível) correspondem a parte do projeto de Doutorado Sanduiche no Exterior realizado na Université de Bordeaux I, Unité Sciences du Bois et des Biopolymères, sob orientação do Prof. Alain Castellan (França).

\section{5. 5. Cromatografia Gasosa Inversa (Inverse Gas Chromatography - IGC)}

Termorrígidos preparados neste trabalho, fenol/formaldeído, lignossulfonato de sódio/formaldeído, lignossulfonato de sódio/glutaraldeído, lignina organossolve/formaldeído 
e lignina organossolve/glutaraldeído foram analisados por IGC. O lignossulfonato de sódio e a lignina organossolve foram analisados seguindo o mesmo procedimento de preparo descrito para as colunas de fibras (item 4.2.1.7).

Os termorrígidos foram moídos (em moinho analítico), peneirados passando por peneiras 60 e 150 mesh, lavado com acetona e secos em estufa $\left(105^{\circ} \mathrm{C} / 4 \mathrm{~h}\right)$.

As análises foram realizadas em atmosfera de nitrogênio $\left(\mathrm{N}_{2}\right)$ e detector de ionização de chama (FID), nas mesmas condições utilizadas para as fibras, exceto a temperatura da coluna, a qual foi de $50{ }^{\circ} \mathrm{C}$.

\section{6. Caracterização dos compósitos}

Compósitos reforçados com fibras de bagaço de cana não queimadas, queimadas (não tratadas e tratadas (solução de lignossulfonato em banho de ultrassom) e com fibras de sisal foram caracterizados conforme descrito nos itens seguir.

\section{6. 1. Ensaio de Impacto Izod (amostras não entalhadas)}

As amostras de compósitos foram ensaiadas segundo a norma ASTM D256 com o objetivo de avaliar a fragilidade ou tenacidade dos materiais dentro dos limites das condições do ensaio, que avalia corpos de prova sob esforço de flexão mediante impacto. $\mathrm{O}$ equipamento correspondeu a CEAST Resil 25 com martelo instrumentado. Este ensaio permite avaliar a melhora das propriedades dos termorrígidos (classificados como frágeis) quando reforçados com fibras naturais.

Para este ensaio utilizou-se um martelo instrumentado de 5,5 $\mathrm{J}$ e 2,75 $\mathrm{J}$ para os compósitos e termorrígido fenólico, respectivamente. O ensaio foi realizado a temperatura ambiente $\left(25^{\circ} \mathrm{C} \pm 2{ }^{\circ} \mathrm{C}\right)$ na Universidade Federal de São Carlos (São Carlos, SP), laboratório sob responsabilidade de Prof. Dr. Elias Hage Jr. 
Os corpos-de-prova foram cortados e lixados a partir das placas moldadas (compósitos fenólicos), nas dimensões especificadas pela norma ASTM D256: 63,5 mm de comprimento; $12,7 \mathrm{~mm}$ de largura e 4,5mm de espessura, sem entalhe.

Todas as amostras preparadas de compósitos e termorrígido fenólico foram ensaiadas. Os demais termorrígidos (material não reforçado) não foram ensaiados, pois após diversos testes para a moldagem e obtenção do termorrígido, não foi possível a obtenção de amostras nas dimensões ideais para esta análise, devido à fragilidade do material obtido.

\section{6. 2. Análise Térmica Dinâmica-Mecânica (DMTA)}

O ensaio de DMTA foi realizado utilizando o equipamento da TA Instruments modelo 2980. As dimensões dos corpos de prova (comprimento, largura e espessura) foram de $35,0 \mathrm{~mm} \times 12,0 \mathrm{~mm} \times 3,2 \mathrm{~mm}$. O equipamento foi calibrado com um padrão metálico. $\mathrm{O}$ módulo DMA Multi-Frequência - Flexão com garra 3-point-bending foi utilizado no intervalo de temperatura de 25 a $230{ }^{\circ} \mathrm{C}$, com incremento de $2{ }^{\circ} \mathrm{C} \min ^{-1}$, amplitude de oscilação de 20 $\mu \mathrm{m}, 1 \mathrm{~Hz}$ de frequência.

\section{6. 3. Ensaio de Resistência à Flexão}

O ensaio de flexão foi realizado para todos os compósitos preparados neste trabalho. Este ensaio teve a finalidade de avaliar o material quanto a sua capacidade de deflexão que pode ser calculada pela equação 14 (mostrada previamente), na qual a máxima deformação permitida $(5,0 \%)$ ocorrerá (Norma ASTM-D790).

O ensaio ocorreu segundo a norma ASTM-D790, sendo a velocidade do ensaio (R) calculada pela equação 24 :

$$
\mathbf{R}=\frac{\mathbf{Z L}^{2}}{6 \mathbf{d}}
$$


sendo $\mathrm{Z}$ a taxa de deformação da superfície oposta, $\mathbf{L}$ a distância entre dois pontos e $\mathbf{d}$ espessura do corpo de prova.

A resistência à flexão $\left(\boldsymbol{\sigma}_{\text {máx }}\right)$ (Equação 25 ) é a máxima tensão sob flexão sustentada pelo corpo de prova durante o ensaio.

$$
\sigma_{\max }=\frac{3 \mathbf{P}_{\max } \mathbf{L}}{2 \mathbf{b d}^{2}}
$$

sendo $\mathbf{P}$ a carga máxima de ruptura, $\mathbf{L}$ distância entre dois pontos, $\mathbf{b}$ largura do corpo de prova e d espessura do corpo de prova.

O módulo de elasticidade $\left(\mathbf{E}_{\mathbf{f}}\right)$ é a razão dentro do limite elástico, entre a tensão e a deformação correspondente. Calcula-se, o mesmo desenhando uma reta na região inicial linear da curva carga-deformação, e utilizando a equação 26:

$$
\mathbf{E}_{\mathbf{f}}=\frac{\mathbf{L}^{3} \mathbf{m}}{4 \mathbf{b d}^{3}}
$$

sendo $\mathbf{m}$ a inclinação da tangente da reta na região linear da curva de desvio de carga.

\section{6. 4. Ensaio de Absorção de Água}

O ensaio de absorção de água foi realizado segundo norma ASTM D570 o qual consiste na determinação da absorção das moléculas de água por imersão durante 24 h, seguida de imersão por longo tempo até a saturação.

Dois corpos-de-prova de cada compósito moldado, e do termorrígido foram usinados nas seguintes dimensões: $76,2 \mathrm{~mm}$ de comprimento, $25,4 \mathrm{~mm}$ de largura, $3,2 \mathrm{~mm}$ de espessura. As amostras foram imersas em um béquer contendo água destilada, e mantidas a temperatura ambiente.

As amostras foram pesadas uma a uma, sendo em seguida recolocadas na água. Antes de cada pesagem, o excesso de água foi eliminado, secando a superfície das amostras que 
permaneceram imersas em água. As pesagens foram realizadas até que a diferença de aumento de massa (em relação à ultima pesagem) fosse menor que $1 \%$.

A porcentagem de aumento de massa é determinada de acordo com a equação 27:

$$
\% \text { Aumento de Massa }=\frac{(\text { massa final })-(\text { massa inicial })}{\text { massainicial }} \times 100
$$

Intervalo de tempo entre as pesagens: $1^{\circ}$ dia: $1 \mathrm{~h} ; 2^{\circ}$ dia: $3 \mathrm{~h} ; 1^{\mathrm{a}}$ semana: $24 \mathrm{~h} ; 2^{\mathrm{a}}$ semana: $48 \mathrm{~h}$; a partir da $3^{\mathrm{a}}$ semana: 7 dias. 


\section{Resultados e Discussões}

\section{1. Caracterizações das fibras}

As caracterizações das fibras de bagaço de cana (BC) não queimadas, queimadas, queimadas e tratadas (solução de lignossulfonato de sódio, NaLS, banho de ultrassom por 1h) e sisal, levaram aos resultados descritos na tabela 6 .

Tabela 6: Caracterizações das fibras de bagaço de cana (BC) e sisal.

\begin{tabular}{lcccc}
\multicolumn{1}{c}{ Componentes $\%$} & $\begin{array}{c}\text { BC não } \\
\text { queimada }\end{array}$ & BC queimada & $\begin{array}{c}\text { BC queimada e } \\
\text { tratada (NaLS) }\end{array}$ & Sisal \\
lignina Klason total & $23,6 \pm 0,3$ & $20,9 \pm 0,2$ & $22,5 \pm 0,6$ & $9,3 \pm 0,1$ \\
\hline umidade & $6,2 \pm 0,2$ & $5,5 \pm 0,2$ & $7,7 \pm 0,01$ & $9,9 \pm 0,1$ \\
\hline cinzas & $0,63 \pm 0,04$ & $0,75 \pm 0,04$ & $3,6 \pm 0,2$ & $0,49 \pm 0,04$ \\
\hline holocelulose & $78,1 \pm 0,2$ & $78,3 \pm 0,3$ & $67,5 \pm 0,4$ & $85,3 \pm 0,9$ \\
\hline $\boldsymbol{\alpha}$-celulose & $56,0 \pm 0,2$ & $56,5 \pm 0,3$ & $55,2 \pm 1,3$ & $64,2 \pm 1,0$ \\
\hline hemicelulose & $22,1 \pm 0,2$ & $21,8 \pm 0,3$ & $12,3 \pm 0,9$ & $21,1 \pm 0,9$ \\
\hline
\end{tabular}

A tabela 6 apresenta os valores médios de caracterização das fibras livres de umidade, após serem extraídas em cicloexano/etanol. Para as duas fibras de bagaço (queimada e não queimada) e a de sisal os valores de umidade e cinzas estão próximos aqueles de fibras lignocelulósicas encontrados na literatura (5,0-10,0\% de umidade; 0,5-4,0\% de cinzas) bem como os demais componentes (FENGEL, 1989; BLEDZKI, 1999; ONÉSIPPE, 2010). O teor de cinzas corresponde a compostos inorgânicos de cálcio, sódio, potássio e sílica que ficam aderidos às fibras na forma de sais (ROWELL, 1997). A composição de fibras lignocelulósicas pode variar dependendo da natureza das mesmas e, para uma mesma fibra, das condições de cultivo e processamento da fibra. 
Os valores obtidos para as fibras de bagaço de cana (queimada e não queimada) estão de acordo com o intervalo citado na literatura por Guimarães et al. (2009) e Satyanarayama et al. (2010), 32-55\% de celulose, $27-32 \%$ de hemicelulose e $19-25 \%$ de lignina.

Nota-se que a fibras queimadas apresentaram uma quantidade menor de lignina, quando comparada às fibras de bagaço de cana não queimadas (Tabela 6), sugerindo que a lignina pode ser parcialmente eliminada na queima. O tratamento das fibras com lignossulfonato de sódio eleva o teor de lignina nestas fibras, acompanhado da diminuição na porcentagem de hemicelulose, indicando que o tratamento pode parcialmente degradar este polissacarídeo.

Os dados de lignina Klason devem ser somados aos valores de lignina solúvel e insolúvel em ácido sulfúrico (72\%). Este ácido atua na clivagem das ligações glicosídicas, na solubilização dos carboidratos, e de pequena parte de lignina (lignina Klason solúvel). Os valores obtidos de celulose, hemicelulose e lignina para a fibra de sisal estão de acordo com o intervalo citado na literatura por Martin et al. (2011) e Ramires et al; (2010). Os autores caracterizaram fibras de sisal (cultivadas no Brasil) obtendo proporções de lignina de 9,7\%, de $73 \%$ e $65 \%$ de celulose e $11 \%$ e $24 \%$ de hemicelulose, respectivamente. Para as fibras naturais, a composição química pode variar dependendo das condições climáticas, época e processamento, que influenciam não somente na estrutura das fibras, mas também na composição química (GASSAN, 1999).

Os valores de teor de umidade das fibras de sisal estão próximos ao valor relatado em trabalhos anteriores (RAMIRES, 2009; ZÁRATE, 2008). A fibra de sisal, como outras lignocelulósicas, contém hemicelulose (polioses) que são polissacarídeos, presentes na região não cristalina, responsáveis em grande parte pela absorção de água. A variação no teor de hemicelulose da fibra pode implicar na variação de umidade destas.

A morfologia das fibras do bagaço de cana não queimadas, queimadas, queimadas tratadas e sisal foram analisadas a partir das imagens de Microscopia Eletrônica de Varredura (MEV). Nas imagens das figuras 13 e 14, é possível observar a morfologia da superfície da 
fibra de bagaço de cana não queimado e queimado, respectivamente, na qual se observa várias camadas ou células.

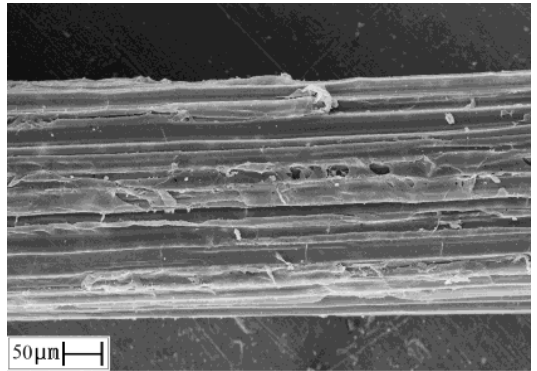

(a)

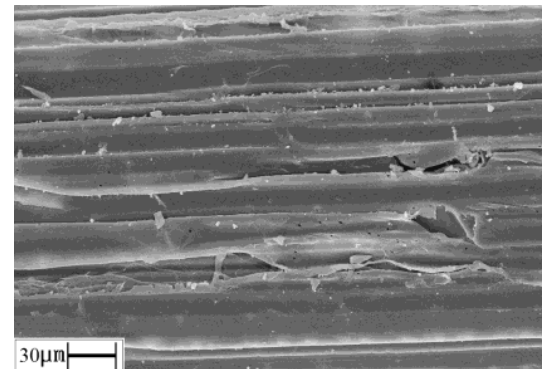

(b)

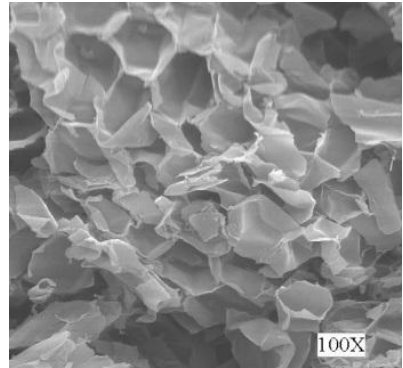

(c)

Figura 13: Micrografias da superfície de bagaço de cana de açúcar não queimado (a, b) da superfície e (c) ponta das fibras.

Observando as imagens das figuras $13(\mathrm{a}, \mathrm{b})$ e 14 (a) é possível verificar a diferença de rugosidade na superfície das fibras não queimadas e queimadas, respectivamente. As imagens 10c e 11b mostram regiões do interior da fibra, observando-se canais que são de grande importância quando as fibras são utilizadas como reforço nos compósitos, pois facilitarão a difusão da resina para o interior da fibra, aumentando a interação fibra/matriz (TRINDADE, 2005; MEGIATTO, 2006).

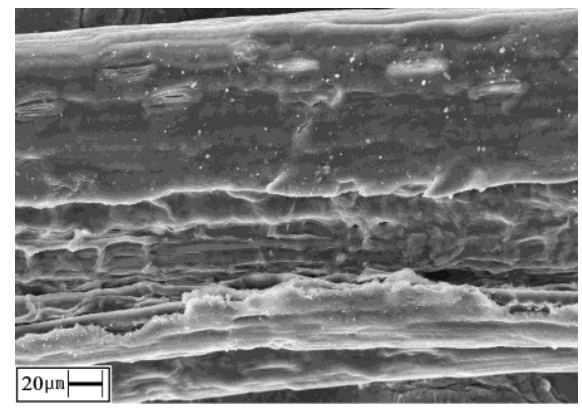

(a)

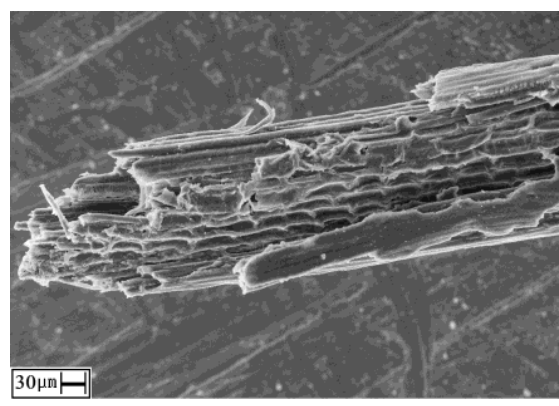

(b)

Figura 14: Micrografias da superfície (a) das fibras de bagaço de cana de açúcar queimado e (b) ponta da fibra.

As fibras de bagaço de cana queimadas passaram pelo tratamento com NaLS em banho de ultrassom e foram analisadas por MEV (Figura 15). Conforme discutido posteriormente, 
estas fibras foram utilizadas de forma mais ampla na preparação de compósitos, tendo sido então escolhidas para a aplicação do tratamento.
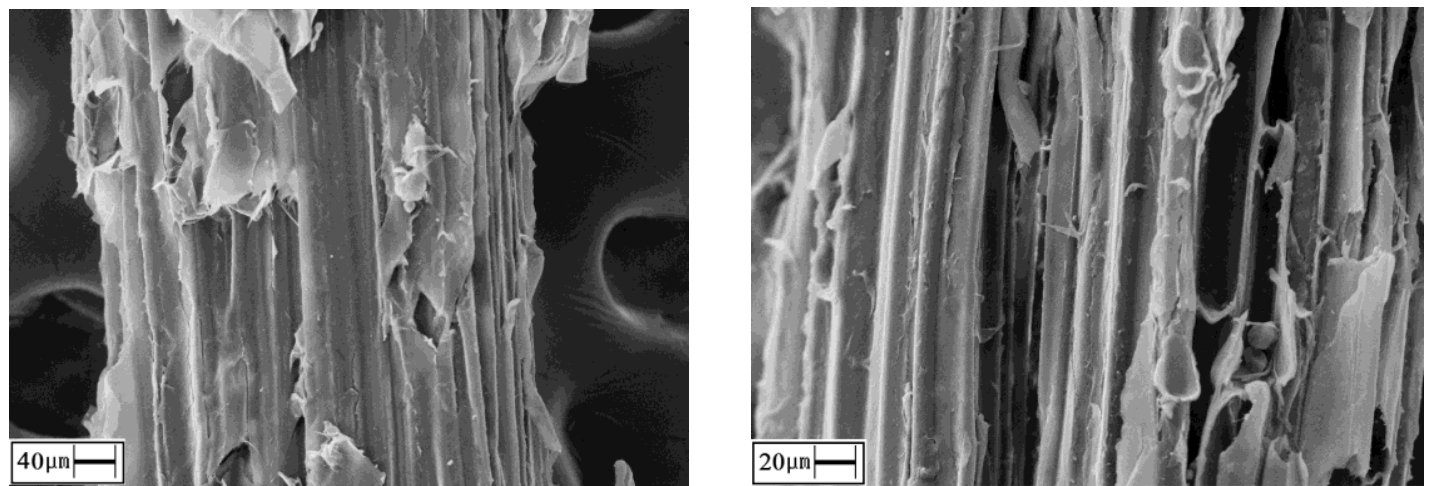

Figura 15: Micrografias da superfície das fibras de bagaço de cana de açúcar queimadas e tratadas (lignossulfonato de sódio, ultrassom/1h).

As fibras apresentaram diferenças em sua superfície após o tratamento, como pode ser observado comparando-se as figuras 14 e 15, mostrando uma superfície mais irregular para as fibras tratadas. Estas características podem ajudar na interação física das fibras com a resina, na preparação dos compósitos, aumentando a interação fibra-matriz e, consequentemente, a resistência mecânica dos materiais.

As fibras de sisal também foram caracterizadas via MEV (Figura 16).
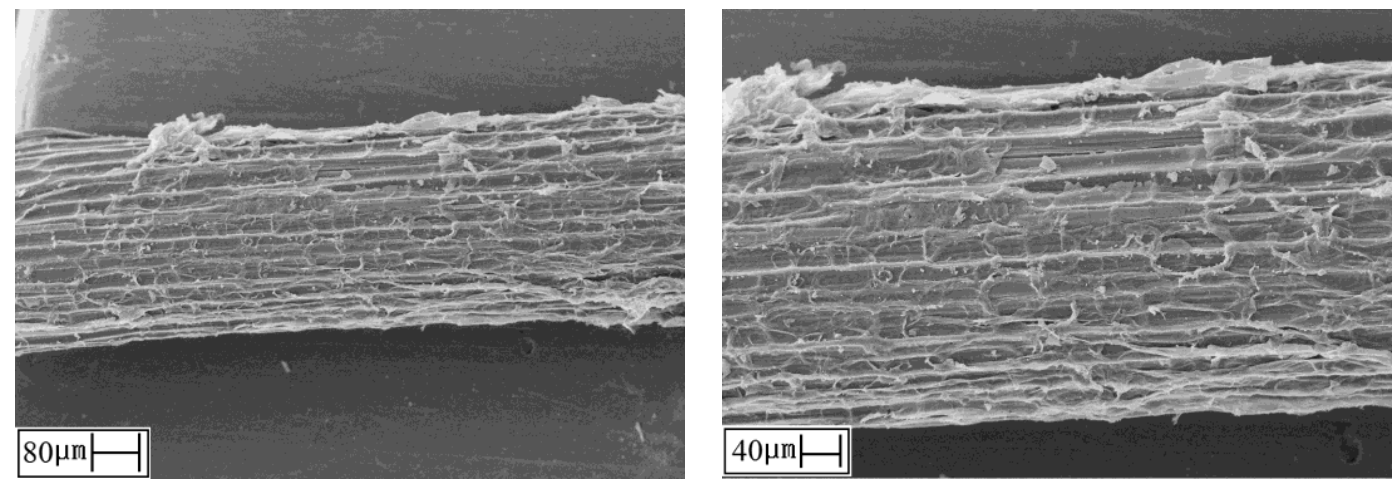

Figura 16: Micrografias da superfície das fibras de sisal.

As fibras de sisal possuem características de rugosidade na superfície, próximas às observadas nas fibras de bagaço de cana não queimadas (Figura 13). 


\section{1. 1. Índice de cristalinidade por difração de raios $X$}

As amostras de fibras foram analisadas por difração de raios X para a determinação da cristalinidade. A figura 17 apresenta os difratogramas referentes às amostras das fibras de bagaço de cana e sisal.

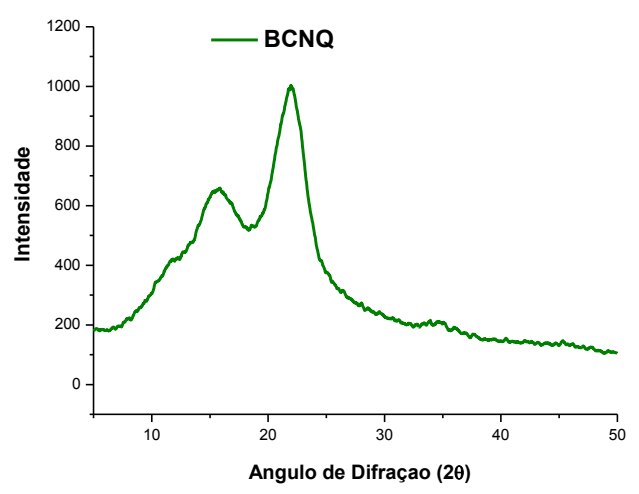

(a)

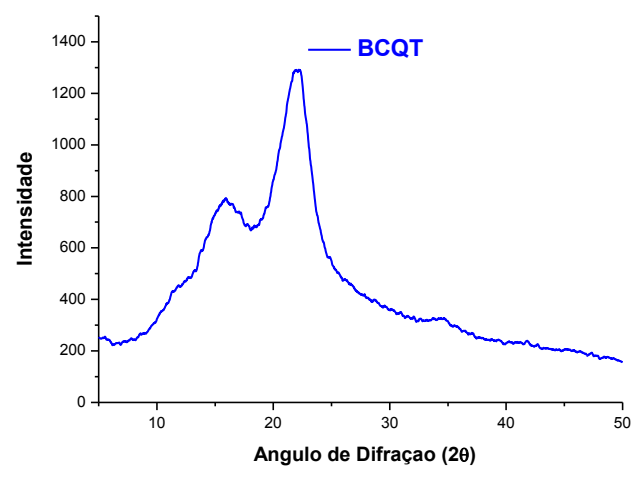

(c)

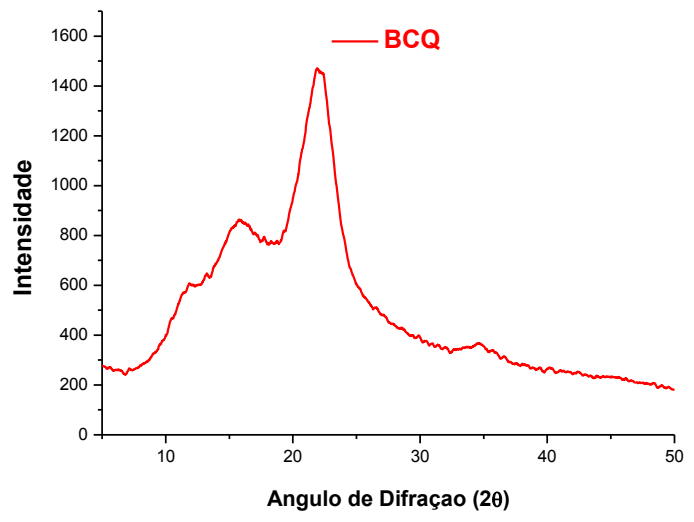

(b)

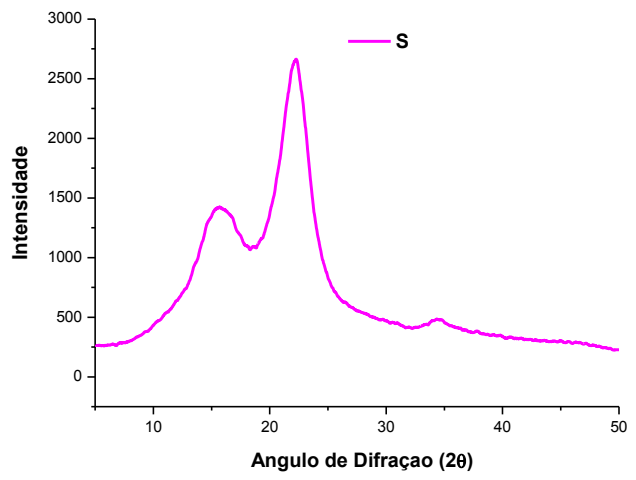

(d)

Figura 17: Difratogramas de raios X para as fibras de bagaço de cana: (a) não queimado (BCNQ); (b) queimado (BCQ); (c) queimado e tratado (solução de NaLS em banho de ultrassom/1h) (BCQT); (d) sisal $(\mathbf{S})$.

A partir da equação 2 (mostrada previamente), o índice de cristalinidade para cada amostra foi determinado (Tabela 7). 
Tabela 7: Cristalinidade das fibras lignocelulósicas.

\begin{tabular}{cc} 
Fibras & Cristalinidade (\%) \\
BCNQ & 48 \\
\hline BCQ & 47 \\
\hline BCQT* & 48 \\
\hline Sisal & 60 \\
\hline$*($ solução de NaL S em banho de ultrassom/1h).
\end{tabular}

*(solução de NaLS em banho de ultrassom/1h).

As fibras de sisal apresentam maior índice de cristalinidade que as demais (Tabela 7) devido ao maior teor de celulose que esta fibra contém em sua estrutura (Tabela 6), quando comparado às outras fibras. A celulose representa a fração cristalina presente na fibra vegetal, enquanto que a lignina e a hemicelulose apresentam a fração não cristalina da fibra.

Quanto às fibras de bagaço de cana, aparentemente os processos de queima e tratamento não atingiram os domínios cristalinos, pois a cristalinidade destas amostras é praticamente a mesma (Tabela 7).

\section{1. 2. Espectroscopia na região do infravermelho (IV)}

As fibras utilizadas neste trabalho (sisal, bagaço de cana queimado, bagaço de cana não queimado, bagaço de cana queimado e tratado) foram analisadas por espectroscopia na região de infravermelho, e apresentaram os espectros mostrados na figura 18. 

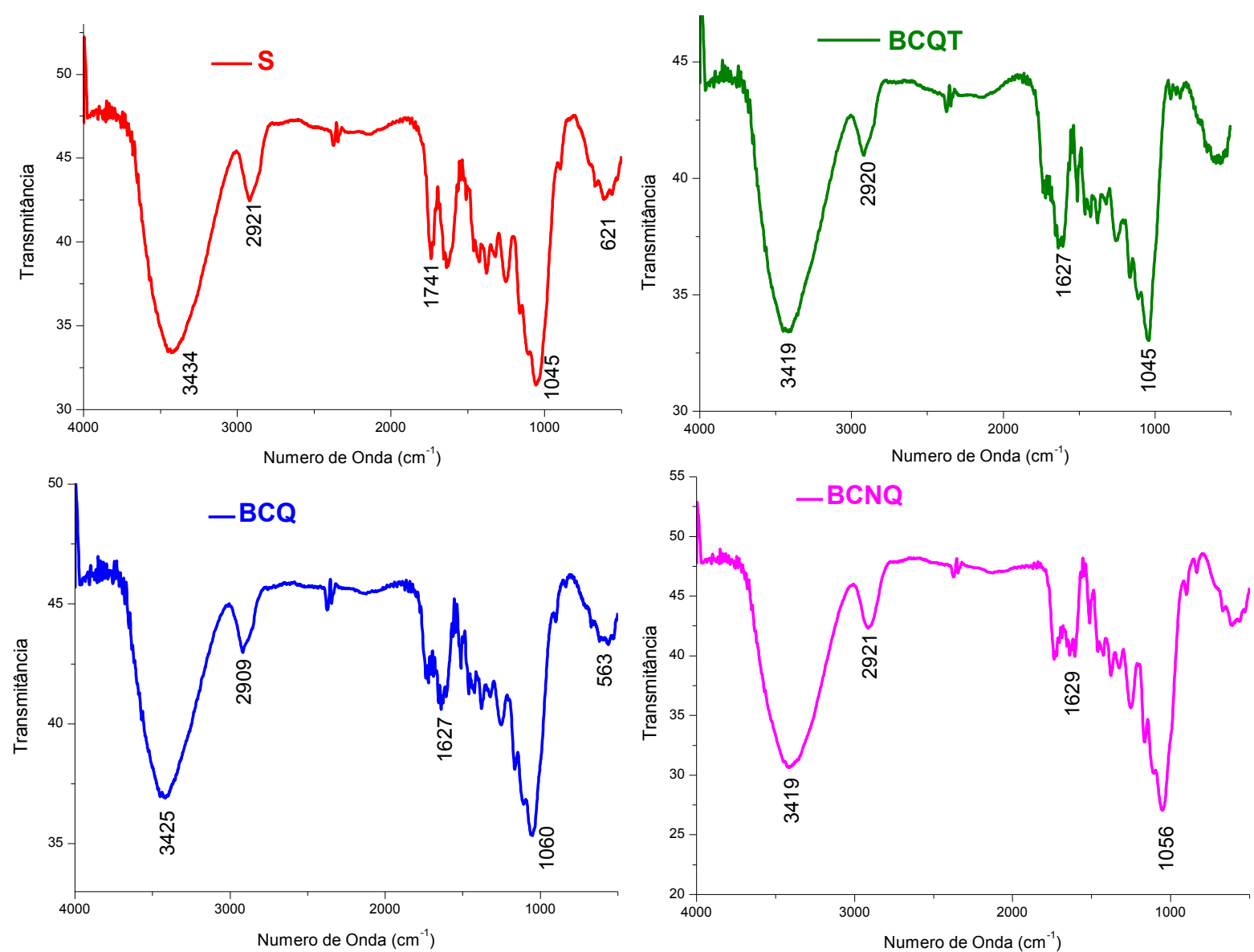

Figura 18: Espectro na região de infravermelho das fibras de sisal (S), bagaço de cana queimada (BCQ), bagaço de cana não queimada (BCNQ), bagaço de cana queimada e tratada (solução de NaLS em banho de ultrassom/1h) (BCQT).

As fibras apresentaram bandas de absorção de mesmo tipo, com intensidades variadas.

A banda característica de grupo O-H (estiramento ou deformação axial) aparece na região de $3420 \mathrm{~cm}^{-1}$ para todas as fibras. Esta banda representa contribuições de grupos $\mathrm{OH}$ envolvidos em ligações hidrogênio intra e intermoleculares.

As bandas em $2920 \mathrm{~cm}^{-1}$ estão relacionadas ao estiramento da ligação C-H referentes aos hidrocarbonetos saturados. Na região de 1600 a $1400 \mathrm{~cm}^{-1}$ aparecem bandas características de estiramento das ligações C-C do anel aromático da lignina. Outras bandas relativas à lignina aparecem em torno de 1170 e $1050 \mathrm{~cm}^{-1}$, e são relacionadas à deformação de grupos metoxilas. Outras bandas estão descritas na tabela 8 . 
O bagaço de cana queimado, o qual passou pela etapa de tratamento em solução de lignossulfonato de sódio (em banho de ultrassom), apresentou maior intensidade na banda em torno de $1630 \mathrm{~cm}^{-1}$, quando comparado às demais fibras de bagaço de cana não queimado e queimado. A intensificação na banda desta região é resultado da presença do lignossulfonato adsorvido à fibra, já que é típica de anéis aromáticos da lignina (Tabela 8) Conforme será visto posteriormente, o lignossulfonato de sódio apresenta no espectro de infravermelho uma banda intensa em aproximadamente $1606 \mathrm{~cm}^{-1}$, característico dos grupos sulfônicos na lignina.

Tabela 8: Principais atribuições para as bandas de absorção no IV para celulose, hemicelulose e lignina (Silverstein; Bassler,1994).

\begin{tabular}{|cc|}
$\begin{array}{c}\text { Comprimento de } \\
\text { onda aproximado } \\
\left(\mathbf{c m}^{-1}\right)\end{array}$ & Atribuições \\
\hline $3440-3400$ & Estiramento ou deformação axial de O-H (ligações hidrogênio intra e intermoleculares). \\
\hline $2912-2900$ & Estiramento da ligação C-H de hidrocarbonetos saturados. \\
\hline 1730 & Deformação axial de C=O. \\
\hline $1630,1513,1427$ & Estiramento (deformação axial) das ligações C-C do anel aromático (lignina). \\
\hline 1375 & Deformação assimétrica e simétrica da ligação C-H em grupos metila. \\
\hline 1250 & Deformação angular de O-H. \\
\hline $1170-1162$ & Deformação axial assimétrica da ligação C-O-C de grupos metoxila (lignina). \\
\hline $1050-1040$ & Deformação axial simétrica da ligação C-O-C de grupos metoxila (lignina). \\
\hline
\end{tabular}

\section{1. 3. Cromatografia gasosa inversa (IGC)}

A técnica de IGC foi aplicada com a finalidade de avaliar algumas propriedades físicoquímicas das superfícies das fibras. A componente dispersiva da energia livre da superfície $\left(\gamma_{\mathrm{S}}^{\mathbf{d}}\right)$ foi determinada através da equação 9 , assim como os parâmetros que descrevem a habilidade de um material agir como superfície aceptora ou doadora de elétrons.

Com base nas informações descritas na Introdução, item 4.5, e os dados gerados nos cromatogramas (de cada amostra), a partir dos valores dos tempos de retenção da série de nalcanos, foi possível calcular os parâmetros referente a cada sonda. Segundo o método proposto por Schultz et al. (Equação 9) a partir das equações apresentadas no item 3.4 e dos 
cromatogramas das sondas hidrocarbônicas apolares $\left(\mathrm{C}_{5}\right.$ : pentano; $\mathrm{C}_{6}$ : hexano; $\mathrm{C}_{7}$ : heptano; $\mathrm{C}_{8}$ : octano; $\mathrm{C}_{9}$ : nonano; $\mathrm{C}_{10}$ : decano) tem-se o gráfico 19 , referente as fibras de bagaço de cana queimados.

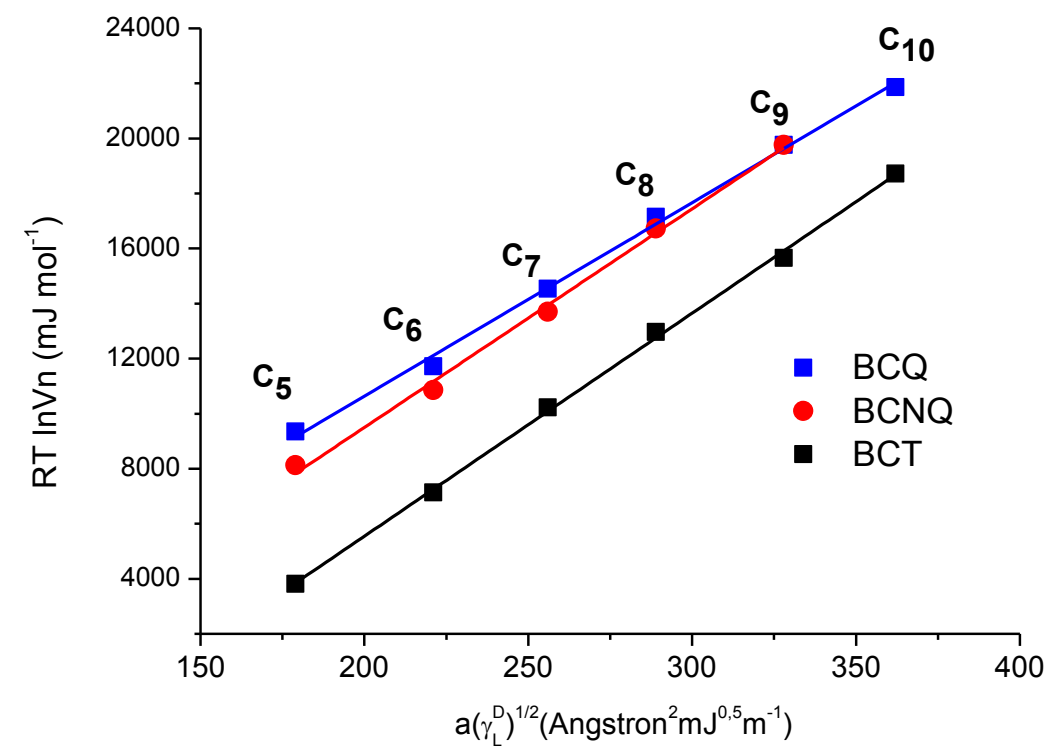

Figura 19: Dados da análise de cromatografia gasosa inversa referente à coluna preenchida com fibras de bagaço de cana: queimado (BCQ); não queimado (BCNQ); queimado com tratamento (solução de NaLS em banho de ultrassom/1h) (BCT).

A partir do gráfico foi possível calcular os valores de energia dispersiva e o caráter ácido/base para as fibras. Estes dados estão apresentados na tabela a seguir (Tabela 9). A fibra de sisal usada no presente trabalho ainda não foi analisada por esta técnica.

Tabela 9: Componentes de energia de dispersiva e caráter ácido/base da superfície das fibras de bagaço de cana: queimado (BCQ); não queimado (BCNQ); queimado com tratamento (solução de NaLS em banho de ultrassom/1h) (BCT).

\begin{tabular}{c|c|c|c|c|c} 
FIBRAS & $\gamma_{\mathbf{S}}^{\mathbf{d}}\left(\mathrm{mJ} \mathrm{m}^{-2}\right)$ & $\mathbf{A N}_{\mathrm{S}}$ & $\mathbf{D N}_{\mathrm{S}}$ & AN $_{\mathrm{S}} / \mathbf{D N}_{\mathrm{S}}$ & CARÁTER \\
BCNQ & 42 & 1433 & 1211 & 1,2 & Ácido \\
\hline BCQ & 45 & 991 & 1026 & 0,9 & Básico \\
\hline BCQT & 42 & 5518 & 4488 & 1,2 & Ácido \\
\hline
\end{tabular}

As informações de energia dispersiva $\left(\gamma_{\mathrm{S}}^{\mathbf{d}}\right)$ apresentadas na tabela 9 para as fibras de bagaço de cana de açúcar estão condizentes aos valores de energia dispersiva encontrados na 
literatura para fibras lignocelulósicas em geral $\left(38,41-52,39 \mathrm{~mJ} \mathrm{~m}^{-2}\right)$. Cordeiro et al. (2011) estudou a propriedade de diversas fibra naturais (sisal, linho, banana, entre ouras) afirmando que os resultados de energia dispersiva das fibras naturais pode variar tanto pelas condições de análise quanto pela composição química das fibras. Estes componentes estão diretamente ligados às condições e localização de cultivo destas fibras (GUIMARÃES, 2009).

Outro estudo realizado por Cordeiro et al. (2011a) apresenta resultados de energia de superfície de fibras obtidas de diferentes tipos de plantas. Neste estudo, Cordeiro et al. (2011a) divide as fibras analisadas em três grupos, fibras de plantas frutíferas (assai e coco), liberianas (rami e juta) e fibras de folhas (sisal e curauá). Mostrando que a retenção das sondas, consequentemente os resultados de IGC, pode ser influenciada por parâmetros como a cristalinidade, o arranjo e orientação dos grupos químicos na superfície.

As fibras do bagaço não queimado apresenta valor de $\mathrm{DN}_{\mathrm{S}}$ próximo ao da fibra queimada, mas pelo valor de $\mathrm{AN}_{\mathrm{S}}$ ser bem maior para o bagaço não queimado, predomina assim seu caráter ácido. Este resultado pode ser um indicativo da presença de grupos hidroxilas (sítios ácidos) mais disponíveis nas fibras de bagaço de cana não queimado, quando comparado ao bagaço de cana queimado.

A fibra de bagaço não queimada (BCNQ) apesar de possuir o mesmo caráter ácido que a fibra de bagaço queimada e tratada $(\mathbf{B C Q T}), \mathrm{AN}_{\mathrm{S}} / \mathrm{DN}_{\mathrm{S}}=1,2$, a quantidade de sítios doadores e aceptores são bem menores que o disponível nas fibras tratadas, como mencionado na tabela 9.

Os resultados, na tabela 9, mostram que o tratamento (com solução de lignossulfonato de sódio em banho de ultrassom) das fibras de bagaço de cana queimadas altera seu caráter de básico para ácido. O caráter ácido resultante das fibras tratadas deve-se ao aumento de sítios ácidos disponíveis (grupos hidroxilas) como consequência do tratamento.

Comparando os valores de $\mathrm{AN}_{\mathrm{S}}$ e $\mathrm{DN}_{\mathrm{S}}$ observa-se o aumento considerável de sítios ativos quando as fibras são tratadas com o lignossulfonato de sódio, que pode ser resultante da 
introdução de grupos hidroxilas e sulfonatos na superfície das fibras. Observa-se também a predominância dos sítios ativos aceptores $\left(\mathrm{AN}_{\mathrm{S}}\right)$.

\section{1. 4. Análise Térmica das fibras}

Foram realizadas as análises de Termogravimetria (TG, Figura 20) e Calorimetria Exploratória Diferencial (DSC) para as fibras (Figura 21).

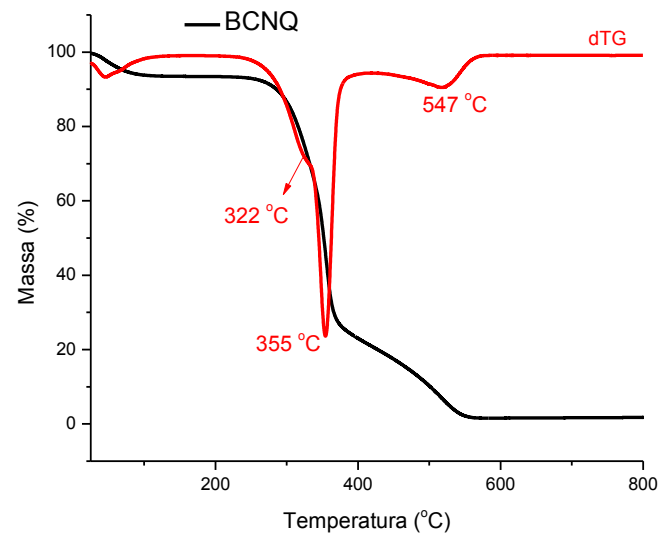

(a)

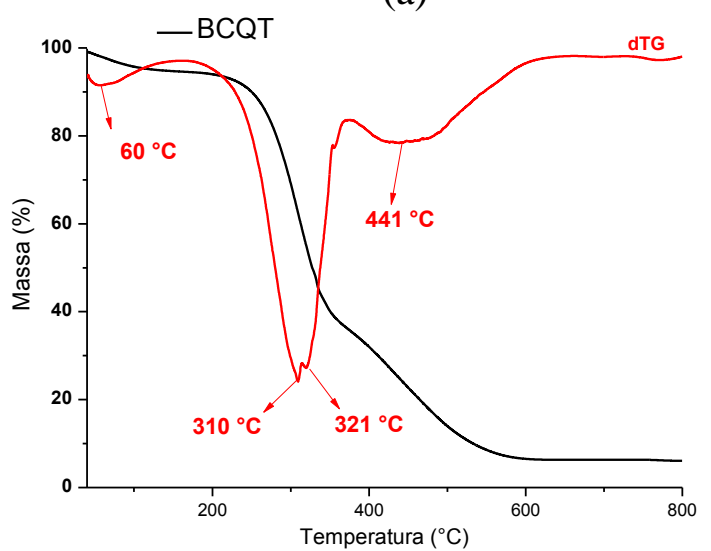

(c)

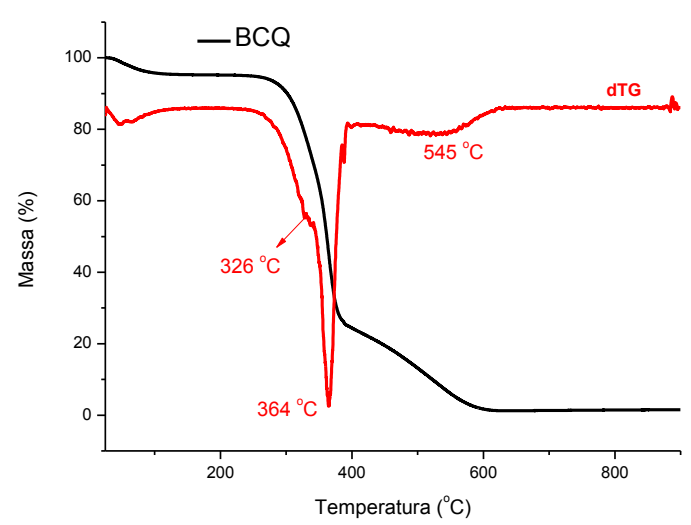

(b)

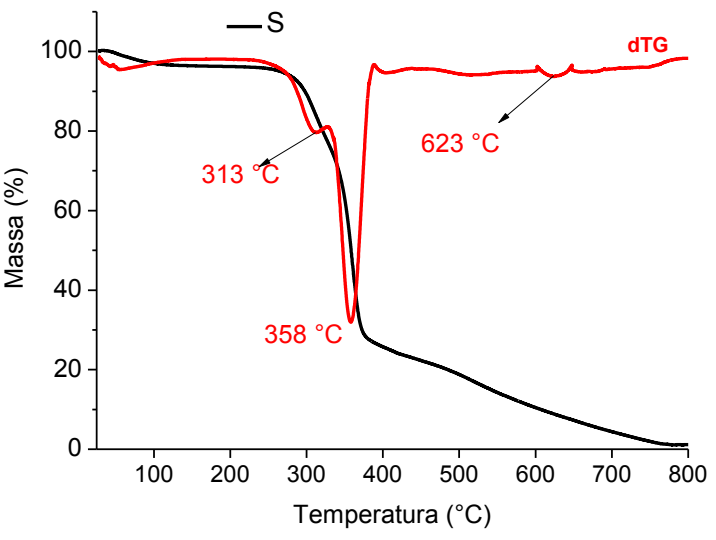

(d)

Figura 20: Curva Derivada Primeira da TG (dTG) fibra de bagaço de cana (a) não queimada (FBCNQ); (b) queimada (FBCQ); (c) queimada e tratada (FBCQT); (d) fibra de sisal (FS), em atmosfera de $\mathrm{N}_{2} 20 \mathrm{~mL} \min ^{-1}$ e $10{ }^{\circ} \mathrm{C} \mathrm{min}^{-1}$.

O pico em $45{ }^{\circ} \mathrm{C}$ (Figura 20a) representa provavelmente a perda de água de superfície da amostra, sendo esta de aproximadamente $6,0 \%$, próximo do teor de umidade encontrado para estas fibras (Tabela 6). A volatilização a baixa temperatura indica que se trata de água “livre”, ou seja, não fortemente aderida à fibra. 
Nas curvas dTG observa-se um "ombro" em 322, 326, 310 e $313{ }^{\circ} \mathrm{C}$ das figuras $20 \mathbf{a}, \mathbf{b}$, c e d, respectivamente, referente à decomposição das polioses (hemicelulose). No caso da fibra tratada (Figura 20c) este pico pode incorporar também a decomposição de grupos laterais do NaLS, presente na superfície. A decomposição da celulose é indicada pelos picos nas curvas dTG em $355,364,321$ e $358{ }^{\circ} \mathrm{C}$ das figuras $20 \mathbf{a}, \mathbf{b}$, c e d, respectivamente. Em temperaturas mais elevadas (acima de $400{ }^{\circ} \mathrm{C}$ ) inicia o estágio de decomposição térmica da lignina, iniciada pela desidratação com geração de cadeias laterais insaturadas. Outro estágio envolve a decomposição de anéis aromáticos e quebra de ligações $\mathrm{C}-\mathrm{C}$ presentes na estrutura da lignina, com perda de água, $\mathrm{CO}$ e $\mathrm{CO}_{2}$ seguido de rearranjos estruturais (Trindade, 2005; Ramires, 2010).

Após o tratamento das fibras com lignossulfonato de sódio, foi possível observar o deslocamento de temperatura para os eventos de decomposição, assim como a intensificação do pico de decomposição da lignina (Figura 20c). A influência do tratamento da fibra de bagaço de cana queimada (com solução de lignossulfonato em banho de ultrassom) é evidenciado pelo alargamento do pico da curva dTG (Figura 20c), quando comparada à curva da fibra bagaço de cana queimada sem tratamento. Embora a amostra tenha sido previamente seca em estufa $\left(105^{\circ} \mathrm{C}\right)$, observa-se um primeiro estágio de perda de massa de água de $2,1 \%$ em $60{ }^{\circ} \mathrm{C}$ (Figura 20), sendo este valor menor que para as fibras de bagaço não tratadas. Em $100{ }^{\circ} \mathrm{C}$, a perda de massa de água é decorrente das moléculas de água ligadas à estrutura de hemicelulose, por ser não-cristalina é mais hidrofílica que a celulose. A perda de massa de água à temperatura de $100{ }^{\circ} \mathrm{C}$ foi de $4,3 \%$.

Para a fibra de sisal, nas curvas TG e dTG (Figura 20d), os eventos de decomposição dos componentes majoritários da fibra (decomposição da celulose, hemicelulose e lignina) são similares aos observados para as fibras de bagaço de cana e ocorrem na mesma faixa de temperatura. Destaca-se que o baixo teor de lignina (Tabela 6) presente na fibra de sisal leva a uma pequena variação de perda de massa $(3,2 \%)$, e a uma temperatura mais alta $\left(623{ }^{\circ} \mathrm{C}\right)$ de 
decomposição, quando comparado às fibras de bagaço de cana (não queimada (18\%), queimada (19\%) e queimada e tratada (22\%)).

Para as fibras estudadas neste trabalho foram realizadas a análise de DSC (Figura 21).

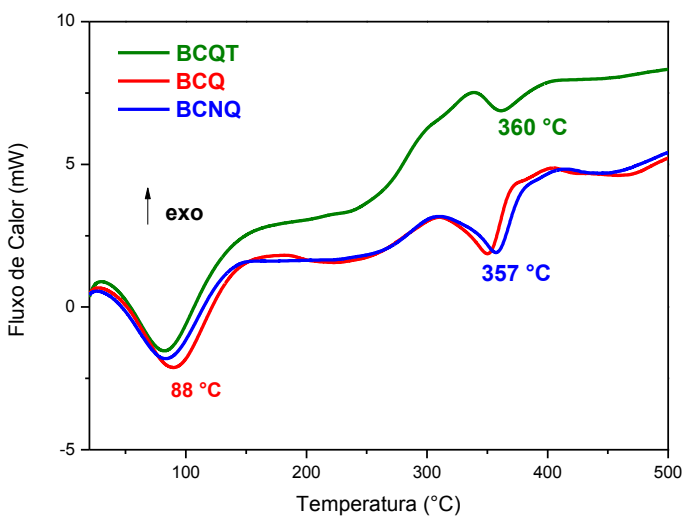

(a)

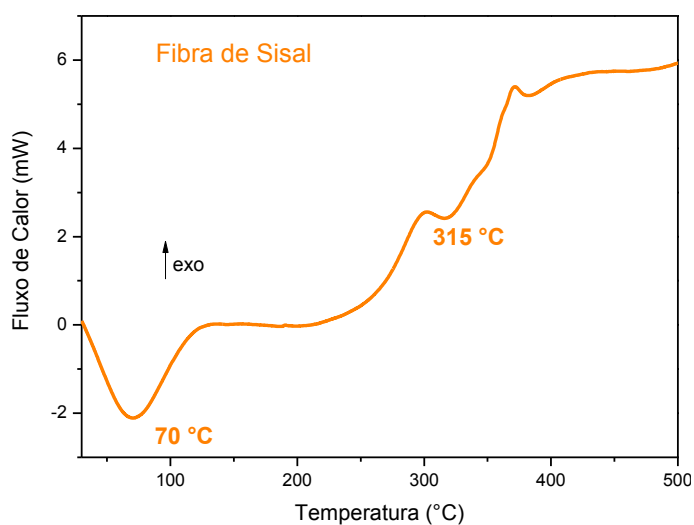

(b)

Figura 21: Curva DSC (a) fibras de bagaço de cana-de-açúcar não queimada, queimada, queimada e tratada (lignossulfonato de sódio+ ultrassom/1h); (b) fibra de sisal, em atmosfera de $\mathrm{N}_{2}$ com $20 \mathrm{~mL}$ $\min ^{-1}$ e $10{ }^{\circ} \mathrm{C} \min ^{-1}$.

Observa-se para todas as fibras em torno de $70-90{ }^{\circ} \mathrm{C}$ um pico endotérmico, na curva DSC (Figura 21), decorrente da volatilização de água. Os demais eventos que ocorrem acima da temperatura de $300{ }^{\circ} \mathrm{C}$ são referentes ao estágio de decomposição térmica de polissacarídeos (celulose e hemicelulose) presentes nas fibras lignocelulósicas. Eventos paralelos, como a liberação de voláteis gerados pela decomposição, geram picos endotérmicos acima de $350{ }^{\circ} \mathrm{C}$. Os eventos observados, de perda de água e decomposição térmica das fibras, apresentados na figura 20 (TG e dTG) estão coerentes com os resultados apresentados na figura 21 (DSC).

\section{2. Caracterização de ligninas}

5. 2. 1. Separação e caracterização da lignina a partir do bagaço de cana de açúcar queimado (LBC)

A partir do bagaço de cana de açúcar queimado, frações de lignina (LBC) foram isoladas, pelo método $\mathrm{NaOH} / \mathrm{AQ}$, e caracterizadas, conforme descrito anteriormente 
(Experimental), sendo posteriormente o mesmo bagaço utilizado como reforço nos compósitos.

Conforme a tabela 6 , o teor de lignina encontrado na fibra deste bagaço foi de $25,3 \%$.

O cozimento das fibras foi feito, sendo que para cada $100 \mathrm{~g}$ de fibra de bagaço obteve-se 11,1g de lignina. A fração de lignina isolada do bagaço de cana (LBC) e a lignina organossolve (LO) foram analisadas por UV-visível, também para determinação do teor de pureza. Os resultados estão descritos na tabela 10.

Tabela 10: Porcentagem de lignina Klason, coeficiente de extinção molar a $280 \mathrm{~nm}$ e rendimento da fração de lignina isolada das fibras de bagaço de cana (LBC) e lignina organossolve (LO).

\begin{tabular}{cccc} 
Ligninas & Lignina Klason \% & $\boldsymbol{\varepsilon} \mathrm{L} \mathrm{g}^{-1} \mathrm{~cm}^{-1}$ & Rendimento \% \\
\hline LBC & 70,3 & 33,9 & 30,8 \\
\hline LO & 95,0 & 30,6 & - \\
\hline
\end{tabular}

A lignina de bagaço de cana queimada (LBC) apresenta 30\% de hidratos de carbono que foram analisados sob a forma de açúcares simples por HPLC, após hidrólise ácida $\left(\mathrm{H}_{2} \mathrm{SO}_{4}\right.$ 72\%). Os resultados estão descritos na tabela 11.

Tabela 11: Análise do teor de açúcares nas frações de lignina nas fibras de bagaço de cana (LBC).

\begin{tabular}{cccccccc}
$\begin{array}{c}\text { Açúcares } \\
(\% \text { massa })\end{array}$ & Celobiose & Glicose & Xilose & Galactose & Arabinose & Manose & Total \\
LBC & 2,6 & 5,6 & 23,2 & 0,9 & 1,9 & 1,5 & 35,7 \\
\hline
\end{tabular}

Os resultados indicam uma forte presença de xilose e de glicose, resultante da presença de hidratos de carbono residuais (FENGEL E WEGENER, 1989) oriundos principalmente de frações de hemicelulose, unidos por ligação covalente às ligninas. A soma da lignina purificada $(70,5 \%)$ com hidratos de carbono $(35,7 \%)$ resulta em $106,0 \%$ para a lignina do bagaço de cana o que se situa dentro da margem de erro de medida de $\pm 7 \%$.

As análises de absorção UV-visível para as ligninas (LBC e LO) foram realizadas em solução de uma mistura de dioxano/água (9:1; v:v). LBC apresentou bandas de absorção clássicas de anéis fenólicos das ligninas (FENGEL; WEGENER, 1989), enquanto que a 
lignina organossolve apresenta absorção significativa em $300 \mathrm{~nm}$, característica da presença de estruturas de carbonila que são geralmente formadas em meio ácido (FENGEL; WEGENER, 1989), lembrando que a lignina organossolve (LO) foi obtida industrialmente por hidrólise ácida em meio etanóico (RAMIRES et al., 2010). O conhecimento do coeficiente de extinção molar em $280 \mathrm{~nm}\left(\varepsilon_{280}\right)$ permite determinar a pureza das ligninas sem passar pela etapa de determinação da lignina Klason. A pureza da lignina extraída foi de $70 \%$ para o LBC e $95 \%$ para LO.

Na figura 22 estão indicados os espectros de FT-IR das ligninas organossolve (LO) e bagaço de cana queimada (LBC), acetiladas $\left(22^{a}\right)$ e não acetiladas (22b).

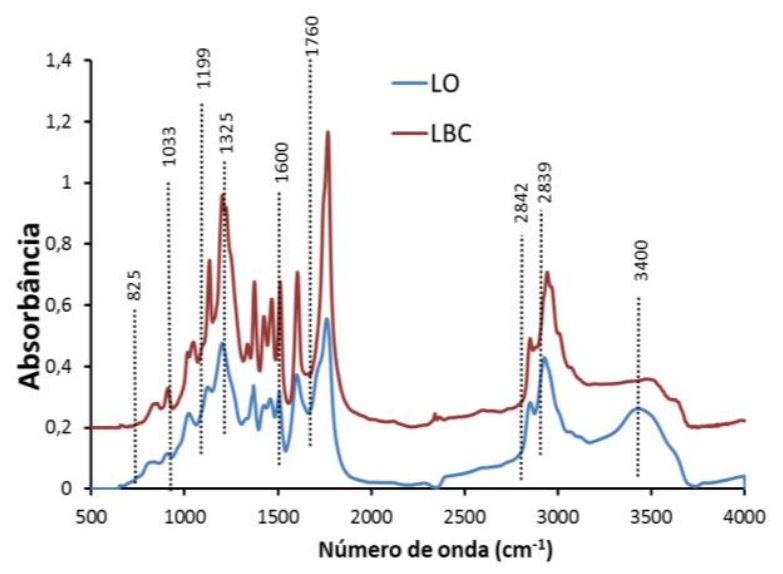

(a)

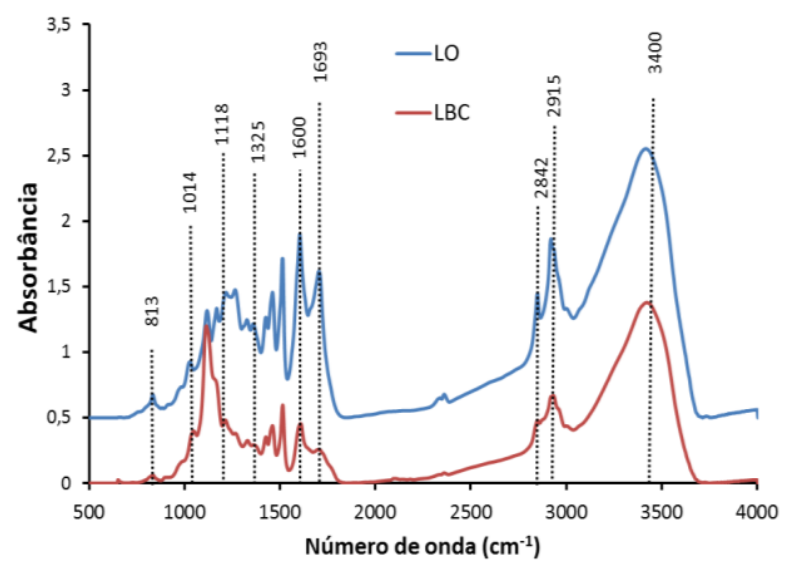

(b)

Figura 22: Espectros de absorção FT-IR das ligninas organossolve (LO) e do bagaço de cana queimado (LBC), (a) acetiladas e (b) não acetiladas.

As bandas observadas em $3400 \mathrm{~cm}^{-1}$ são características de vibrações de elongação de ligações O-H (Figura 22). As ligninas acetiladas apresentam uma banda de baixa intensidade, o que corresponde à uma acetilação incompleta, provavelmente ligações $\mathrm{O}-\mathrm{H}$ de álcoois benzílicos situados no carbono $\mathrm{C} \alpha$ das cadeias propano das unidades aromáticas típicas de ligninas. As absorções entre 2840 e $3100 \mathrm{~cm}^{-1}$ são características de vibrações de elongação C-H das estruturas alifáticas e aromáticas. Os espectros apresentam também bandas características do esqueleto aromáticos $\left(1600,1515\right.$ e $\left.1470 \mathrm{~cm}^{-1}\right)$ de ligninas. 
As bandas de grupos siringilas e guaiacilas condensadas são observadas em torno de $1330 \mathrm{~cm}^{-1}$. A banda de absorção próxima a $825 \mathrm{~cm}^{-1}$ corresponde a vibrações de deformação das unidades $p$-hidroxifenilas. As ligninas apresentam bandas de absorção típicas de ligninas HGS, em torno de 1200 e $825 \mathrm{~cm}^{-1}$ (FENGEL; WEGENER, 1989).

As figuras 23 e 24 mostram os espectros de RMN de próton $\left({ }^{1} \mathrm{H}\right)$ das ligninas LO e LBC acetiladas.

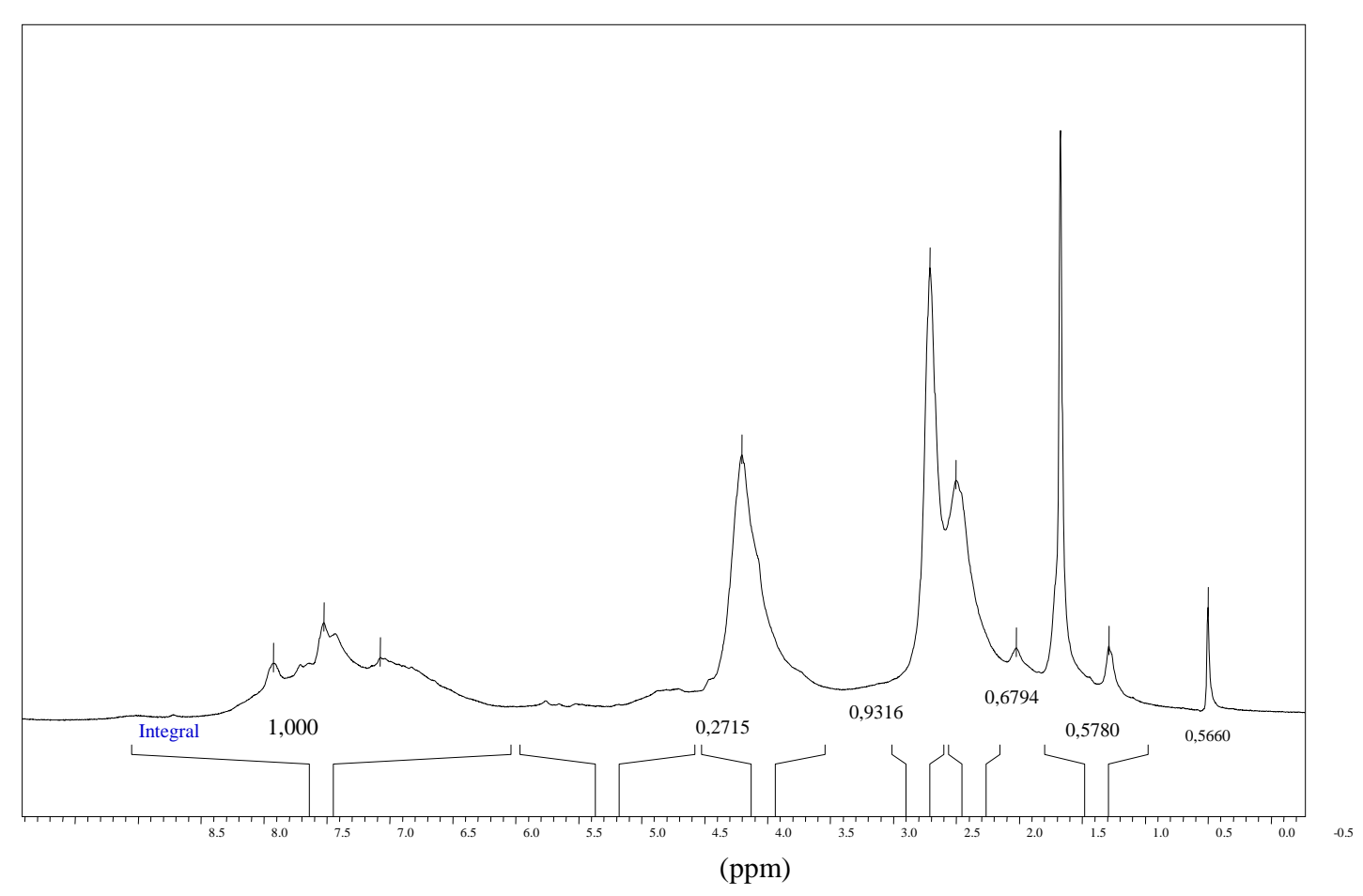

Figura 23: Espectro de $\mathrm{RMN}{ }^{1} \mathrm{H}$ da lignina organossolve (LO) acetilada. 


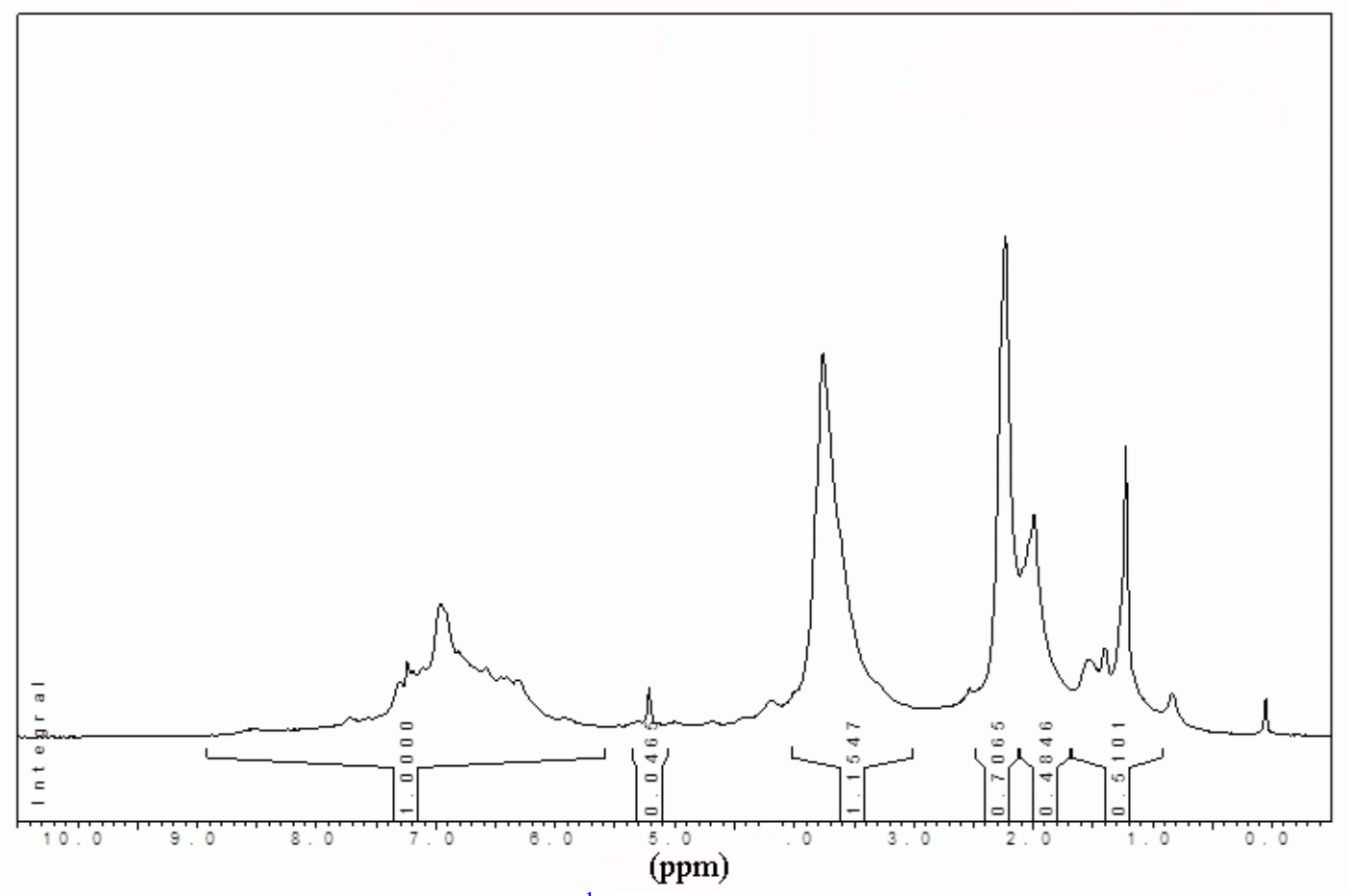

Figura 24: Espectro de RMN ${ }^{1} \mathrm{H}$ da lignina do bagaço de cana acetilada.

A tabela 12 descreve as atribuiçõoes dos picos para as ligninas acetiladas. Os espectros de RMN ${ }^{1} \mathrm{H}$ das duas ligninas são similares e apresentam um sinal em 3,7ppm correspondente aos grupos metoxilas. Os sinais entre 6,2 e 7,6ppm correspondem aos prótons aromáticos. Os sinais entre 1,7-2,1 e 2,1-2,5ppm correspondem aos prótons do grupo acetila alifáticos e aromáticos, respectivamente. Através da integração dos sinais correspondentes, obtém-se a relação entre os grupos alifáticos e aromáticos iguais à: 0,85 para a lignina organossolve; 0,69 para a lignina do bagaço de cana. 
Tabela 12: Atribuições para os picos observados nos espectros de $\mathrm{RMN}{ }^{1} \mathrm{H}$ das ligninas acetilas.

\begin{tabular}{|c|c|}
\hline $\begin{array}{c}\text { Deslocamento químico } \\
(\mathbf{p p m})\end{array}$ & $\begin{array}{c}\text { Atribuições } \\
7,6-7,4\end{array}$ \\
\hline 7,3 et 7,26 & $\begin{array}{c}\text { Protons aromaticos e etilênicos } \\
\text { Prótons aromáticos de ácidos p-cumárico e ferúlico }\end{array}$ \\
\hline $7,2-6,8$ & Solventes residuais: piridina e clorofórmio \\
\hline $6,8-6,2$ & Ar-H (unidades guaiacila) \\
\hline $6,2-5,8$ & Ar-H (unidades siringila e guaiacila condensadas) \\
\hline $5,8-5,2$ & $\mathrm{H} \alpha$ em unidades $\beta-O-4$ e Prótons etilênicos \\
\hline $4,95-4,6$ & $\mathrm{H} \alpha$ em benzil-aril éteres \\
\hline $4,6-4,1$ & $\mathrm{H} \beta$ em unidades $\beta-\mathrm{O}-4$ \\
\hline $4,1-3,3$ & $\mathrm{H} \gamma$ em diferentes estruturas \\
\hline $2,6-2,2$ & $\mathrm{H} \alpha$ em estruturas condensadas \\
\hline $2,2-2,5$ & Prótons metoxílicos \\
\hline $1,5-0,7$ & Acetatos aromáticos \\
\hline & Acetatos alifáticos \\
\hline & Contaminantes alifáticos \\
\hline
\end{tabular}

As figuras 25a e $25 \mathrm{~b}$ apresentam os espectros de $\mathrm{RMN}$ de fosforo $31\left({ }^{31} \mathrm{P}\right)$ para as ligninas LO e LBC, após derivatização com 2-cloro-4,4,5,5-tetrametil-1,3,2-dioxafosfolano, segundo o procedimento descrito por Argyropoulos (1994a,b). Esta análise teve como finalidade de quantificar os diferentes grupos hidroxilas presente a partir dos sinais apresentados no espectro e número de mols da referência interna. Na figura 24 estão indicadas as atribuições correspondentes às diversas estruturas da lignina (Esquema 10).

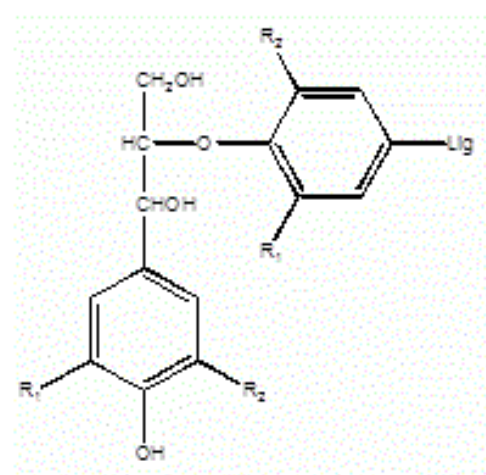

$R_{1}=R_{2}=H$; unidades p-hidroxifenil

$\mathrm{R}_{1}=\mathrm{OCH}_{3} ; \mathrm{R}_{2}=\mathrm{H}$; unidades guaiacil $(\mathrm{G})$

$\mathrm{R}_{1}=\mathrm{OCH}_{3} ; \mathrm{R}_{2}=\mathrm{OCH}_{3}$; unidades siringil (S)<smiles>COc1cc(Br)cc(-c2cc(Br)cc(OC)c2Cl)c1O</smiles><smiles>COc1cc(Cl)cc(Cc2cc(Cl)cc(OC)c2O)c1O</smiles>

unidades fenois condensados

Esquema 10: Diferentes unidades que constituem a lignina. 
A quantificação dos diferentes grupos hidroxilas é apresentada na tabela 13. Análises realizadas por Ramires et al. (2010) para a lignina organossolve indicam valores ligeiramente diferentes: $\mathrm{OH}$ alifático: $0,8 \mathrm{mmol} \mathrm{g} \mathrm{g}^{-1}$; $\mathrm{S}-\mathrm{OH}:$ 0,6; G-OH: 0,5; HO-H: 0,5; OH fenóis condensados 0,3; ácidos carboxílicos: 0,2. Estas diferenças são atribuídas à diferente natureza dos lotes das duas amostras de lignina.

Os valores de $\mathrm{OH}$ alifáticos/OH fenólicos, obtidos a partir dos resultados de $\mathrm{RMN}$ de ${ }^{31} \mathrm{P}$, são de 0,3 e 0,2 para as ligninas organossolve e bagaço de cana (Figura 25), respectivamente. Os valores obtidos a partir de integração dos picos do espectro de RMN de ${ }^{31} \mathrm{H}$ das ligninas acetiladas para $\mathrm{OH}$ alifáticos/OH fenólicos são de 0,9 e 0,7 para as ligninas organossolve (Figura 23) e bagaço de cana (Figura 24), respectivamente. Esta diferença provém da dificuldade de separação dos picos alifáticos/aromáticos acetilados no espectro de RMN ${ }^{1} \mathrm{H}$, mas também devido as diferenças inerentes a uma derivatização por acetilação e por fosforilação. Os valores obtidos por $\mathrm{RMN}{ }^{31} \mathrm{P}$ podem ser considerados mais representativos. 


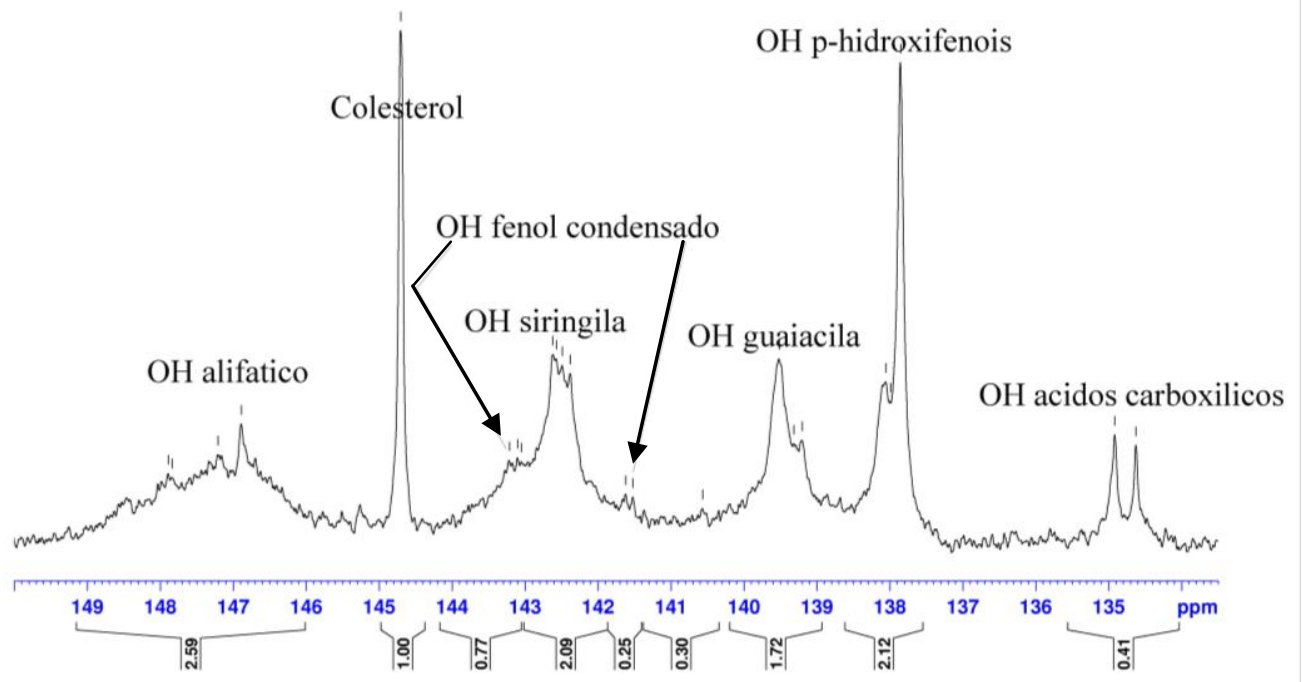

(a)

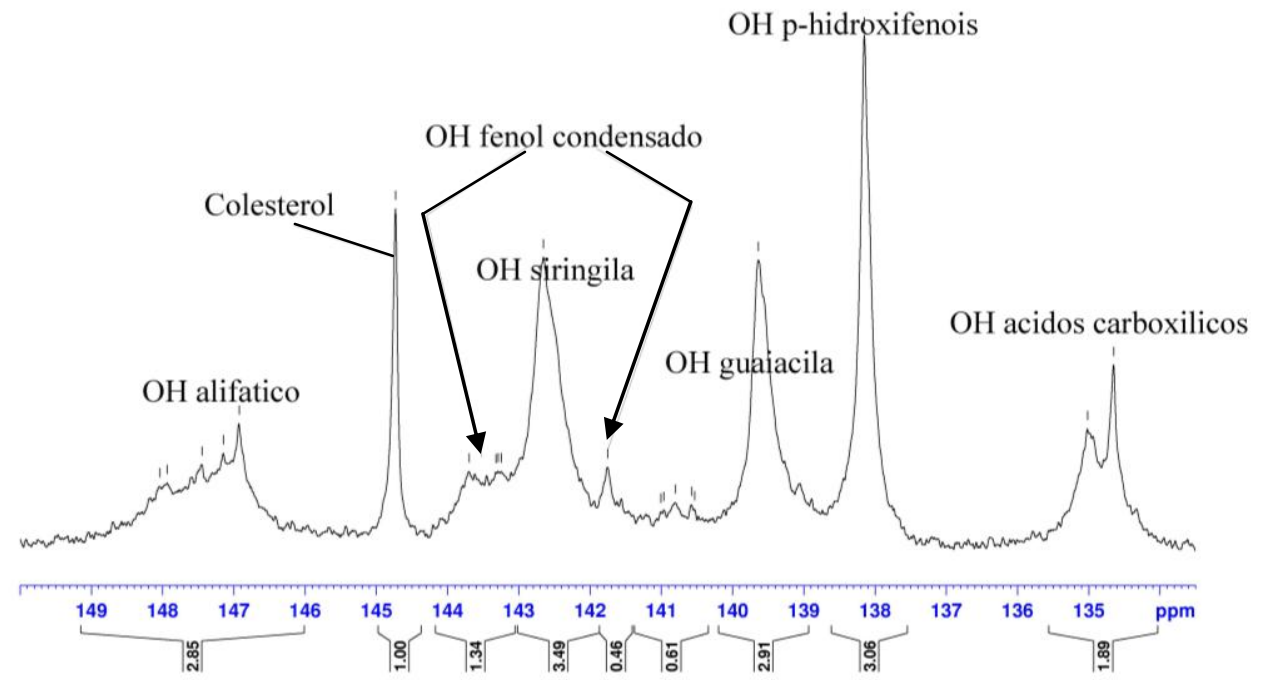

(b)

Figura 25: Espectro de RMN ${ }^{31} \mathrm{P}$ das (a) lignina organossolve (LO), (b) lignina do bagaço de cana queimado (LBC).

Tabela 13: Quantificação dos grupos hidroxilas por $\mathrm{RMN}{ }^{31} \mathrm{P}\left(\mathrm{mmol}^{-1}{ }^{-1}\right.$ de lignina) ligninas organossolve (LO) e lignina do bagaço de cana queimado (LBC).

\begin{tabular}{|c|c|c|c|c|c|c|c|}
\hline Ligninas & OH Alifático & S-OH* & G-OH & H-OH & $\begin{array}{c}\text { OH- } \\
\text { Condensado }\end{array}$ & $\begin{array}{l}\text { Total } \\
\text { fenol }\end{array}$ & Ácido \\
\hline LO & 1,0 & 0,8 & 0,6 & 0,8 & 0,4 & 3,8 & 0,2 \\
\hline LBC & 1,1 & 1,4 & 1,2 & 1,2 & 0,7 & 6,6 & 0,8 \\
\hline
\end{tabular}

*S-OH: grupo fenólico presente na unidade siringila; G-OH: grupo fenólico presente na unidade guaiacila; H-OH: grupo fenólico presente na unidade hidroxifenila; 5,5-condensado: $\mathrm{OH}$ fenólico em unidades condensadas. 
As amostras acetiladas foram usadas para análise por cromatografia de exclusão por tamanho (SEC). Os valores de massa molar média $(\mathrm{Mw})$ e a polidispersividade (Mw/Mn) estão na tabela 14.

Tabela 14: Massa molar média $\left(\mathrm{g} \mathrm{mol}^{-1}\right.$ ) das ligninas organossolve (LO)e bagaço de cana queimada (LBC).

\begin{tabular}{cccc}
\hline Ligninas & Mw & Mn & Mw/Mn \\
\hline LO & 4020 & 325 & 12,4 \\
\hline LBC & 1220 & 134 & 9,1 \\
\hline
\end{tabular}

Os resultados mostram que a lignina LBC, obtida em meio alcalino, é mais despolimerizada que a lignina organossolve, obtida em meio ácido. Ambas as ligninas são provenientes do bagaço de cana queimado, sendo diferenciadas pelo método de extração e pela pureza.

\section{3. Caracterização de resinas, termorrígidos e materiais de partida}

\section{3. 1. Termogravimetria (TG) e Calorimetria exploratória diferencial (DSC)}

\section{3. 1. 1. Resina e termorrígido fenólico}

Análises de termogravimetria e calorimetria exploratória diferencial foram realizadas para elucidar eventos de perda de massa, decomposição e estabilidade térmica dos prépolímeros e termorrígidos utilizados no preparo dos compósitos.

A tabela 15 apresenta os valores de perda de massa acumulativos do pré-polímero, polímero termorrígido fenólico, correspondentes a curva da figura 26. 


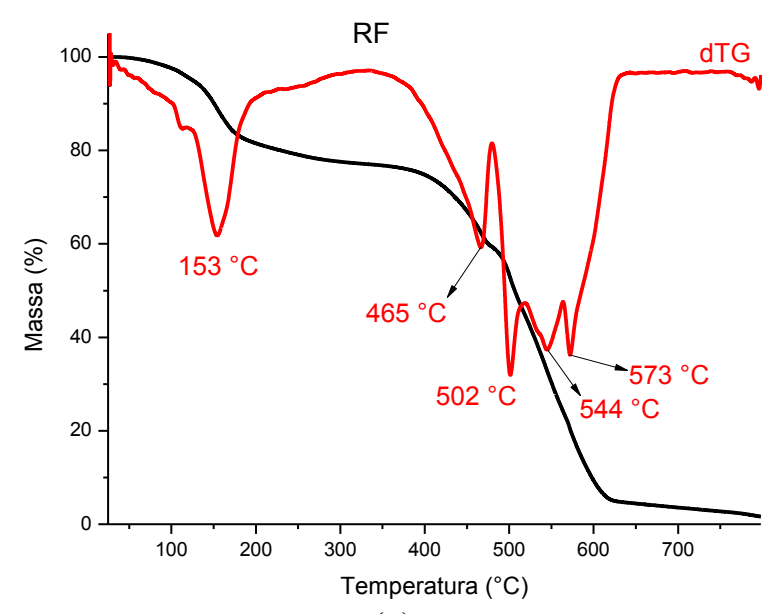

(a)

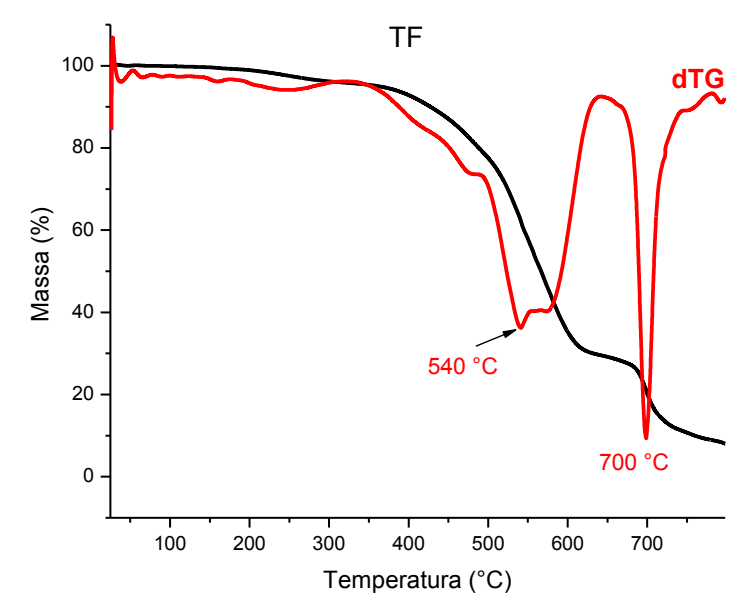

(b)

Figura 26: Curva TG e derivada primeira em atmosfera de ar $\left(20 \mathrm{~mL} \mathrm{~min}^{-1}\right)$ e taxa de aquecimento 10 ${ }^{\circ} \mathrm{C} \min ^{-1}$ para resina (RF) e termorrígido fenólico (TF).

Tabela 15: Perdas de massa (\%) da resina (RF) e termorrígido fenólico (TF).

\begin{tabular}{ccccccc} 
Material & \multicolumn{7}{c}{ Temperatura $\left({ }^{\circ} \mathbf{C}\right)$} \\
& $\mathbf{1 0 0}$ & $\mathbf{2 0 0}$ & $\mathbf{3 0 0}$ & $\mathbf{4 0 0}$ & $\mathbf{5 0 0}$ & $\mathbf{8 0 0}$ \\
\hline $\mathbf{R F}$ & $2,4 \%$ & $18,5 \%$ & $22,4 \%$ & $25,2 \%$ & $46,6 \%$ & $99,0 \%$ \\
\hline $\mathbf{T F}$ & $0 \%$ & $1,1 \%$ & $3,8 \%$ & $7,1 \%$ & $22,3 \%$ & $92,4 \%$ \\
\hline
\end{tabular}

A resina, ou pré-polímero fenólico (RF), apresenta perda de massa até $100{ }^{\circ} \mathrm{C}$ (Figura 26), em decorrência da vaporização de água não eliminada do meio. De $100^{\circ} \mathrm{C}$ a $200{ }^{\circ} \mathrm{C}$, a perda de massa é decorrente de volatilização de água formada como sub-produto das etapas de condensação (cura) que ocorrem durante a varredura. Durante a varredura podem ocorrer reações de entrecruzamento da resina (RF), seguido do início da decomposição do termorrígido que é gerado, originando os picos observados na figura 26a.

Pelos resultados apresentados na tabela 15, obtidos a partir da curva TG do termorrígido fenólico (TF, sem fibras), observa-se que este não apresenta perda de massa até a temperatura de $100{ }^{\circ} \mathrm{C}$, indicando a ausência de umidade na amostra. Para temperaturas até $200{ }^{\circ} \mathrm{C}$, o termorrígido apresenta pequena perda de massa $(1,1 \%)$ provavelmente pela liberação de água como resultado de etapa residual de cura (condensação) que pode ocorrer durante a varredura (COSTA et al,1997; PAIVA, 2006). 
Até a temperatura de $300^{\circ} \mathrm{C}$, a perda de massa do termorrígido ainda é de apenas $3,8 \%$, enquanto para o pré-polímero (RF) é de $22,4 \%$. A partir de $400{ }^{\circ} \mathrm{C}$, a perda de massa é considerável devido ao início das reações de decomposição do material (Tabela 15). A decomposição dos anéis aromáticos ocorre no intervalo de temperatura entre 400 e $500{ }^{\circ} \mathrm{C}$ (Paiva, 2006).

Na figura 27, são apresentadas as curvas DSC para resina ou pré-polímero fenólico (Figura 27a) e o termorrígido fenólico (Figura 27b).

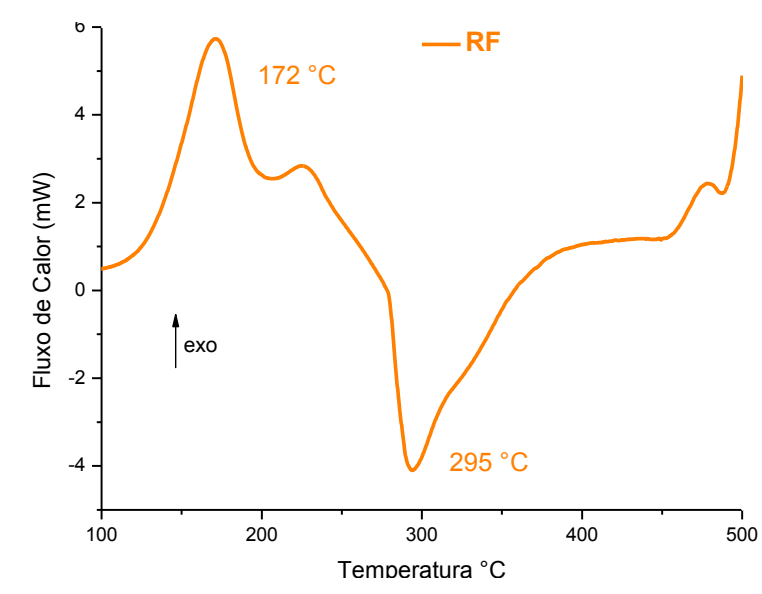

(a)

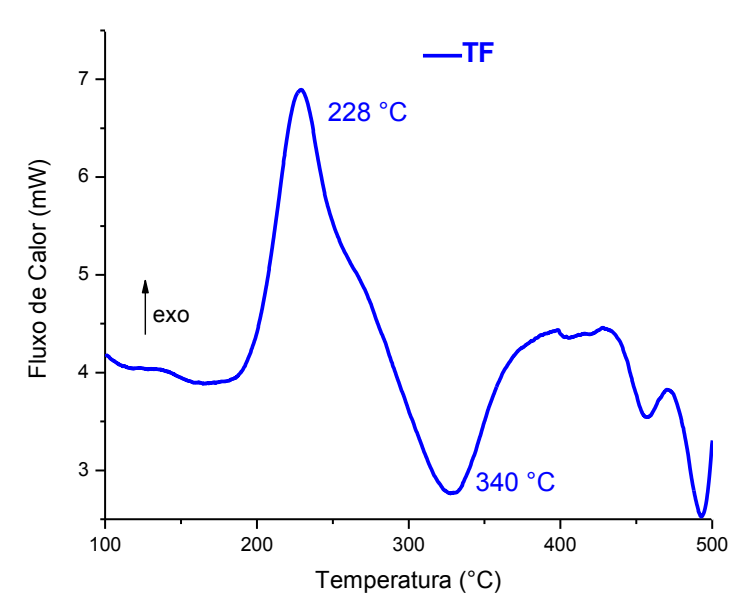

(b)

Figura 27: Curvas DSC do (a) resina fenólica (RF); (b) termorrígido fenólico (TF) em atmosfera de ar sintético, $20 \mathrm{~mL} \min ^{-1}$ e $10{ }^{\circ} \mathrm{C} \mathrm{min}^{-1}$.

A figura 27 mostra a curva DSC da resina fenólica (RF). Os picos exotérmicos observados entre 100 e $200{ }^{\circ} \mathrm{C}$, e em torno de $220^{\circ} \mathrm{C}$, referem-se a reações de condensação que ocorrem durante a varredura. Como nestas reações ocorre formação de água, a volatilização desta (endotérmica) pode, em alguns casos, mascarar o pico exotérmico referente à reação. Estes picos são coerentes com os eventos detectados na curva TG e dTG, embora com alguns deslocamentos nas temperaturas. Ainda, na curva DSC, se observa um pico endotérmico em torno de $300{ }^{\circ} \mathrm{C}$, o qual pode estar relacionado a reação de condensação que leva a formação de ligações do tipo difenil-éter, com liberação de água ou a reações de oxidação (decomposição) que levam a formação de grupos carboxílicos, os quais geram $\mathrm{CO}_{2}$, 
devido descarboxilação. A volatilização de água e $\mathrm{CO}_{2}$ leva a picos endotérmicos. Eventos exotérmicos acima de $400{ }^{\circ} \mathrm{C}$ correspondem a reações de decomposição do material entrecruzado formado durante a varredura (PAIVA, 2006).

Para o termorrígido (TF), observa-se um pico exotérmico em $227{ }^{\circ} \mathrm{C}$, o qual provavelmente corresponde à cura residual (entrecruzamento) que pode ocorrer durante a varredura, pois este termorrígido muito provavelmente ainda possui grupos entre as cadeias poliméricas que não reagiram. Este pico se encontra deslocado em relação à resina (RF), pois neste caso (TF) tem-se uma reação no estado sólido, que requer maior energia térmica para ocorrer, quando comparado ao pré-polímero, o qual é um líquido viscoso, levando então ao deslocamento observado (RAMIRES, 2009).

Acima de $350^{\circ} \mathrm{C}$ eventos exo e endotérmicos, relacionados à cura, liberação de voláteis e processos de decomposição (fibra e polímero), podem se sobrepor.

5. 3. 1. 2. Lignossulfonato de sódio, resinas e termorrígidos baseados em lignossulfonato de sódio

O lignossulfonato de sódio e as resinas baseadas nele, e em formaldeído e glutaraldeído, foram analisadas por TG e DSC. A figura 28 apresenta as curvas TG e dTG (derivada primeira da TG) e DSC.

A decomposição do lignossulfonato de sódio (Figura 28a) inicia em torno de $303{ }^{\circ} \mathrm{C}$, que pode estar relacionado à cisão do grupo sulfonato. 


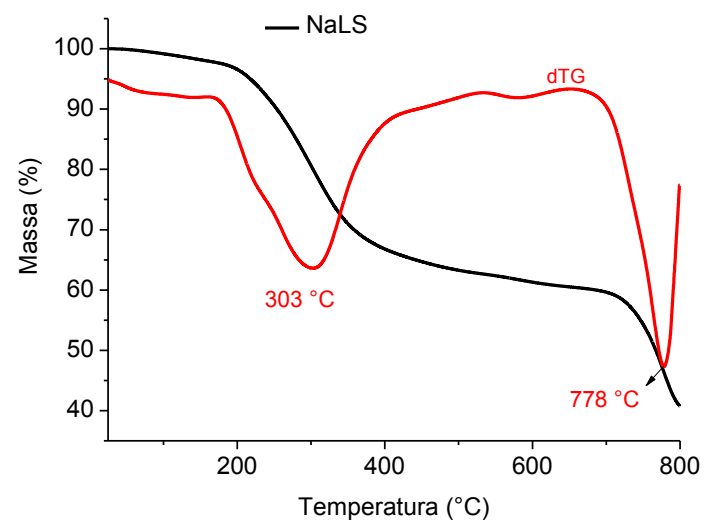

(a)

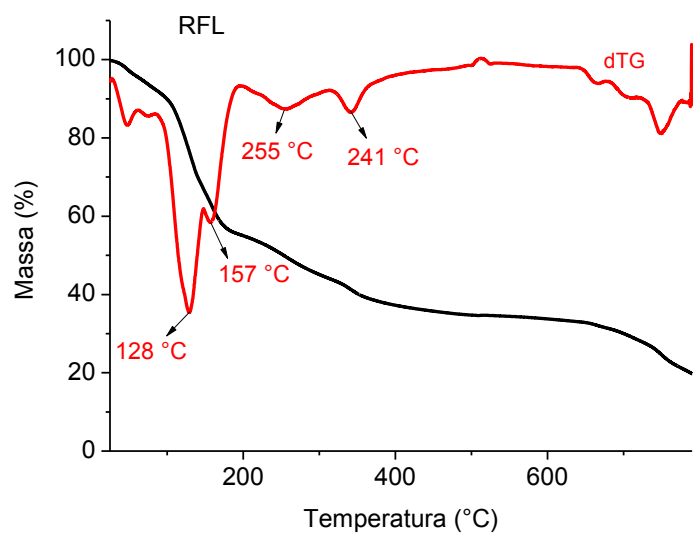

(c)

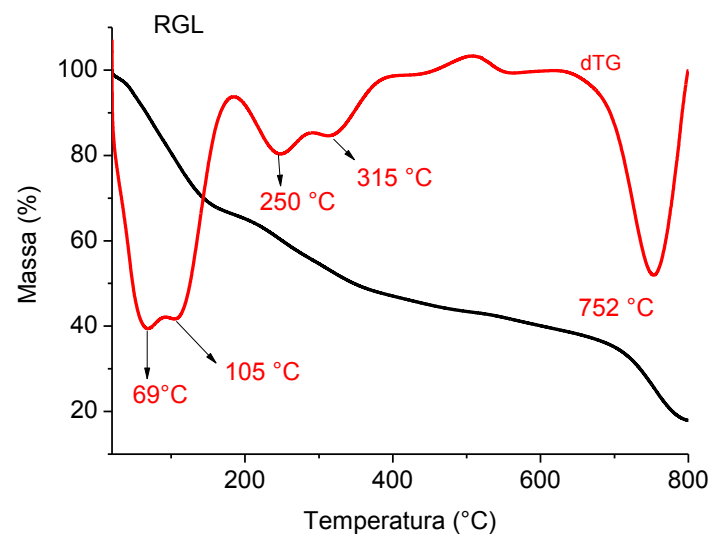

(e)

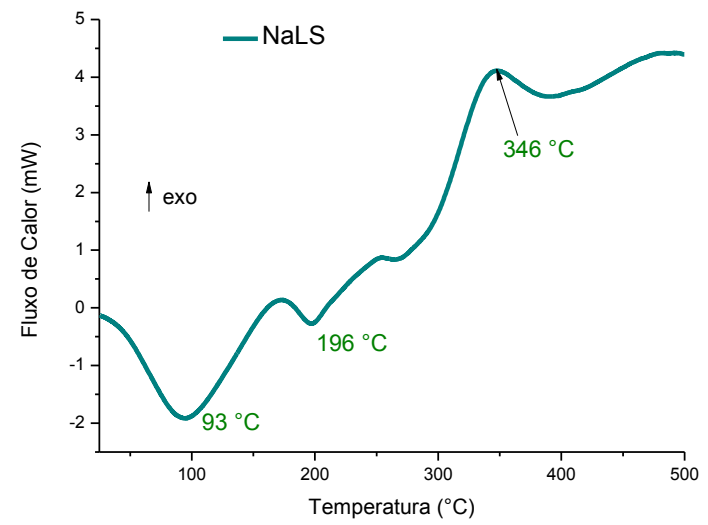

(b)

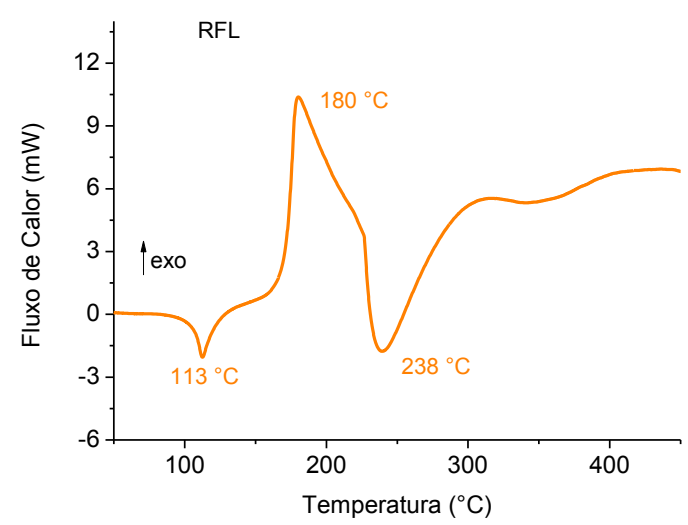

(d)

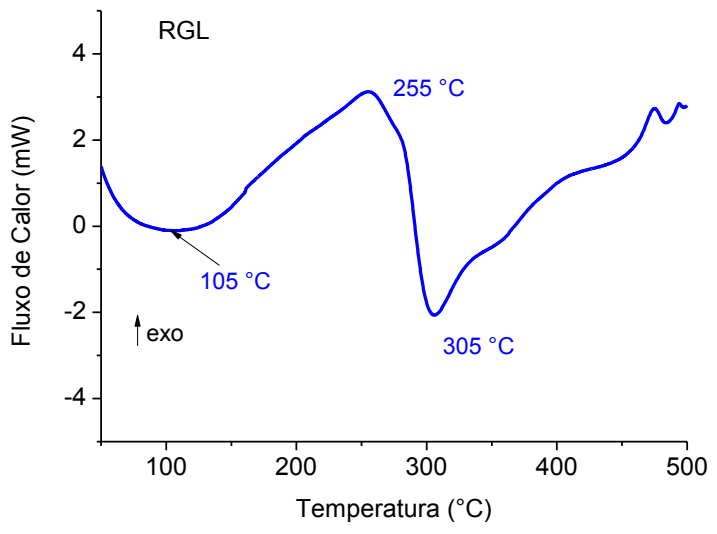

(f)

Figura 28: Curva TG e dTG (Derivada Primeira) e DSC: (a, b) Lignossulfonato de sódio; (c, d) Resina formaldeído-lignossulfonato de sódio (RFL) e (e, f) Resina glutaraldeído-lignossulfonato de sódio (RGL), em atmosfera de $\mathrm{N}_{2}$ com $20 \mathrm{~mL} \min ^{-1}$ e $10{ }^{\circ} \mathrm{C} \min ^{-1}$.

As resinas de formaldeído-lignossulfonato de sódio (RFL) e glutaraldeídolignossulfonato de sódio (RGL) (Figura 28) durante a análise passam pelo estágio de condensação (cura) do pré-polímero com a liberação de moléculas de água, além da água 
residual presente (picos entre 100 e $200{ }^{\circ} \mathrm{C}$ ). Os picos referentes à cura residual no termorrígido aparecem deslocados para temperaturas em torno de $250{ }^{\circ} \mathrm{C}$ e $350{ }^{\circ} \mathrm{C}$ (Figura 29a). Os picos das curvas DSC das resinas aparecem na mesma faixa de temperatura observadas nas curvas TG.

Os termorrígidos formaldeído-lignossulfonato de sódio (TFL), figura 29, apresentam picos de perda de massa na curva dTG em $252{ }^{\circ} \mathrm{C}$ e $340{ }^{\circ} \mathrm{C}$ referente ao inicio da decomposição dos grupos sulfonatos, e de frações típicas da estrutura de lignina, respectivamente. O termorrígido glutaraldeído-lignossulfonato de sódio (TGL) teve o inicio da decomposição deslocada para temperatura mais elevada (acima de $300{ }^{\circ} \mathrm{C}$ ), quando comparado às resinas (Figura 28), apresentando ainda outro pico de decomposição residual de lignina em torno de $500{ }^{\circ} \mathrm{C}$. Estes picos de perda de massa são também identificados na curva dTG da figura 29. 


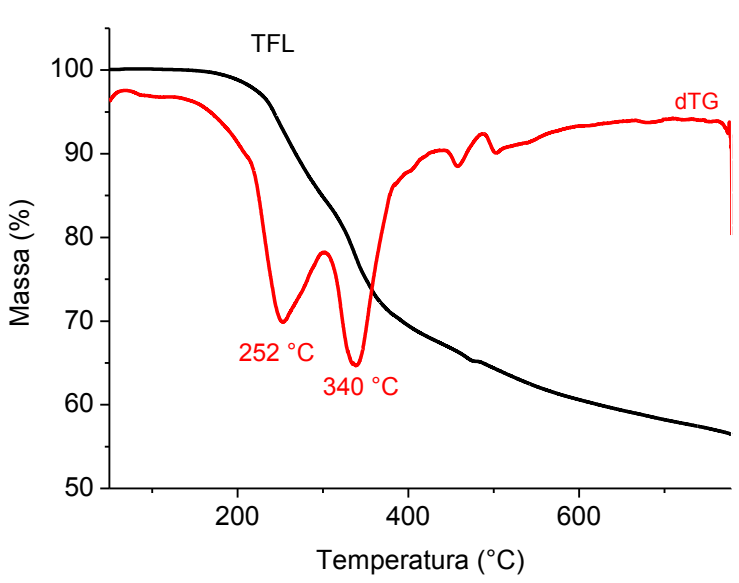

(a)

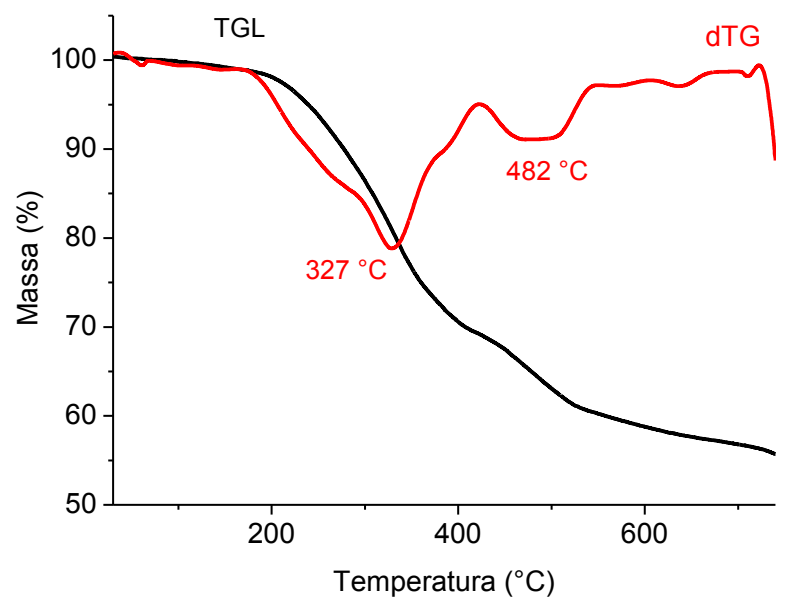

(c)

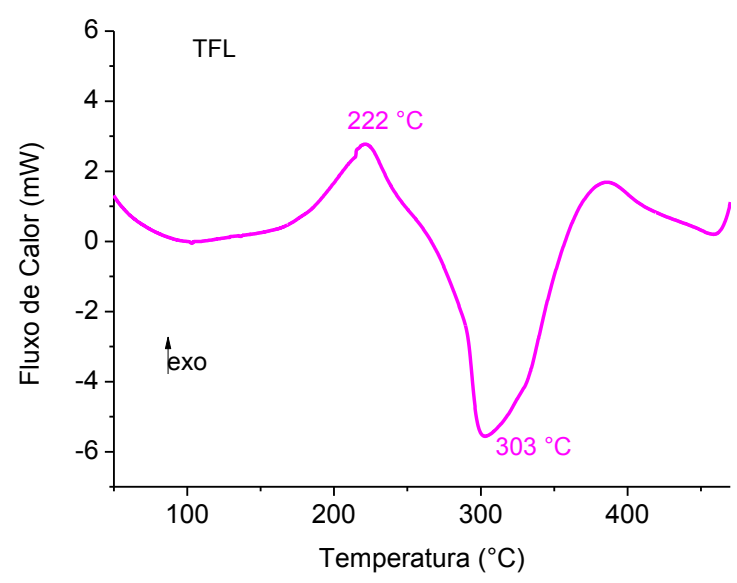

(b)

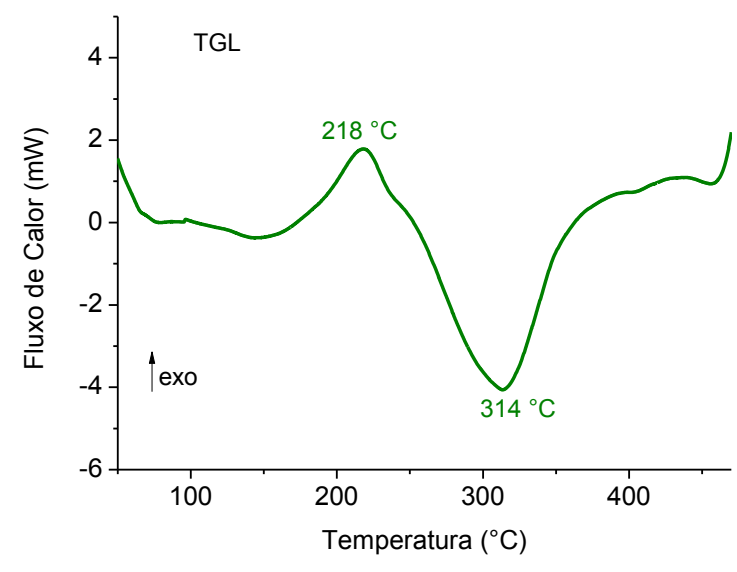

(d)

Figura 29: Curva TG e dTG e DSC: (a, b) termorrígido formaldeído-lignossulfonato (TFL); (c, d) termorrígido glutaraldeído-lignossulfonato (TGL), em atmosfera de $\mathrm{N}_{2} \operatorname{com} 20 \mathrm{~mL} \mathrm{~min}^{-1}$ e $10^{\circ} \mathrm{C} \mathrm{min}^{-1}$.

Os termorrígidos formaldeído-lignossulfonato de sódio (TFL) e glutaraldeídolignossulfonato de sódio (TGL) apresentaram comportamento semelhante nas curvas DSC (Figura 29b, 29d). A cura residual dos termorrígidos é indicada pelos picos exotérmicos em $220{ }^{\circ} \mathrm{C}$, seguido de um pico endotérmico em $300{ }^{\circ} \mathrm{C}$ (TFL) e $313{ }^{\circ} \mathrm{C}$ (TGL), referente a reações de ligninas livres ou crescimento de cadeias. O pico largo em torno de $400{ }^{\circ} \mathrm{C}$ pode estar relacionado à decomposição de frações típicas de lignina presente no termorrígido. Acima desta temperatura os eventos observados são de decomposição total da amostra. 
5. 3. 1. 3. Lignina organossolve, resinas e termorrígidos baseados em lignina organossolve

Resinas baseadas em lignina organossolve (LO) foram preparadas com formaldeído e glutaraldeído, segundo reações já descritas. A lignina organossolve, resinas e termorrígidos (matriz sem reforço) foram analisadas por TG e DSC (Figura 30).

A lignina organossolve apresenta eventos na curva dTG (Figura 30a) referentes a perda de massa de água residual até $100{ }^{\circ} \mathrm{C}$ e em temperaturas mais elevadas $\left(400{ }^{\circ} \mathrm{C}\right.$ ) ocorre a decomposição de anéis aromáticos presentes na estrutura. Na figura 30b observa-se um pico exotérmico em torno de $400{ }^{\circ} \mathrm{C}$ referente à decomposição da macromolécula. $\mathrm{O}$ pico em torno de $200{ }^{\circ} \mathrm{C}$ pode ser referente os resíduos de hemicelulose na amostra, que provavelmente não foram eliminados completamente durante o processo de purificação.

Na curva DSC das resinas com formaldeído (Figura 30d) e glutaraldeído (Figura 30f) é possível observar um pico exotérmico em torno de $200{ }^{\circ} \mathrm{C}$ referente ao processo de cura térmica das resinas. $\mathrm{O}$ pico endotérmico (em torno de $300{ }^{\circ} \mathrm{C}$ ), visto nas curvas das resinas, podem ser relativos a processos reacionais de grupos que ainda não reagiram. Eventos exotérmicos acima de $400{ }^{\circ} \mathrm{C}$ estão relacionados ao processo de decomposição total de frações típicas de lignina presentes nas resinas. 


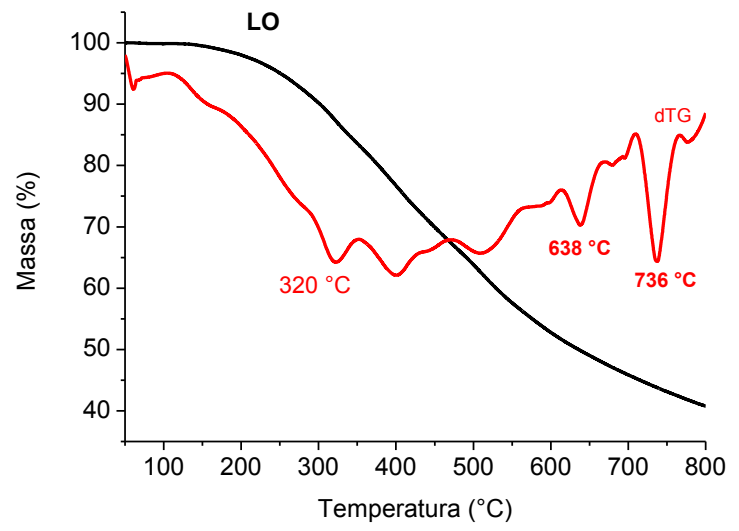

(a)

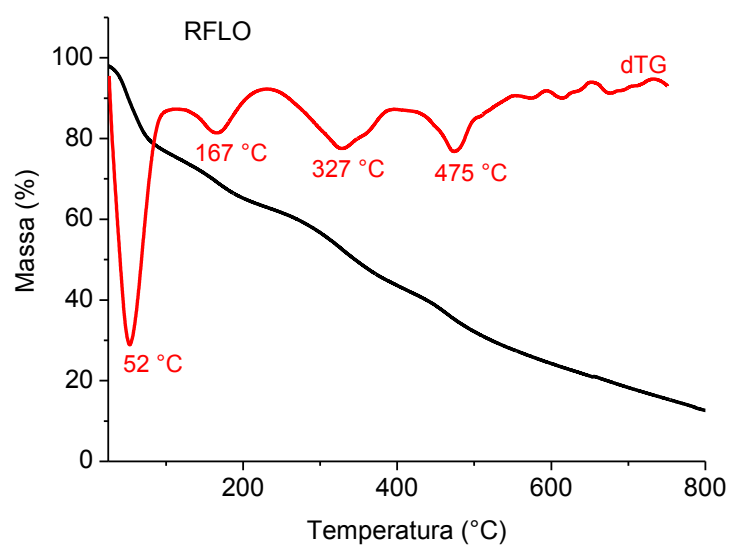

(c)

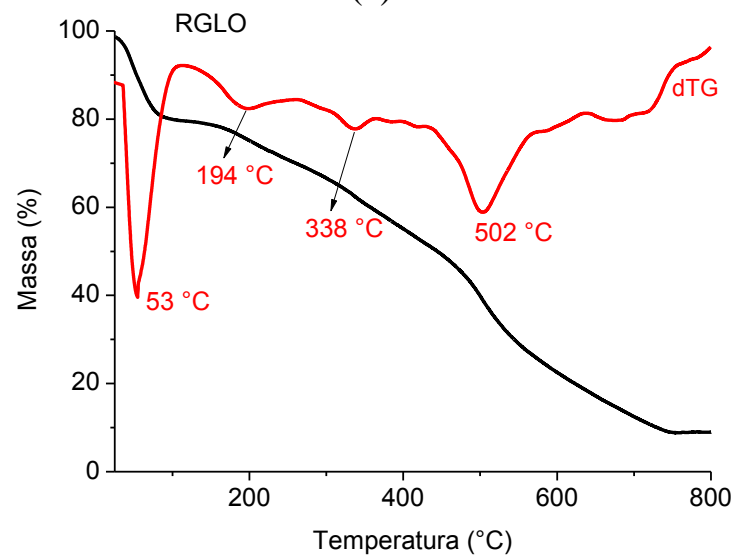

(e)

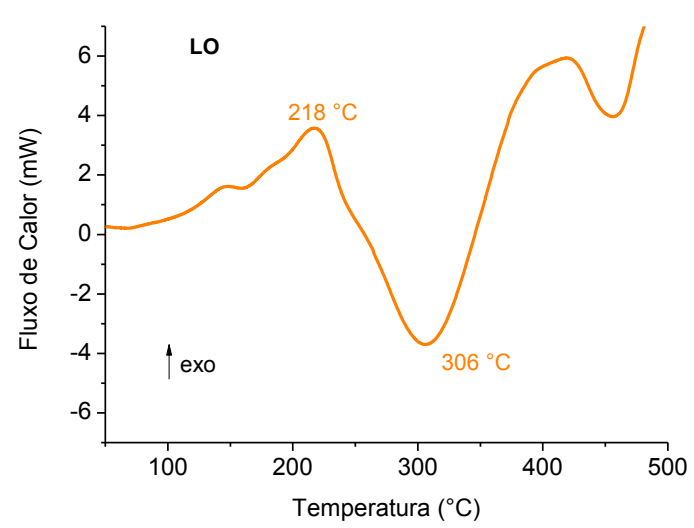

(b)

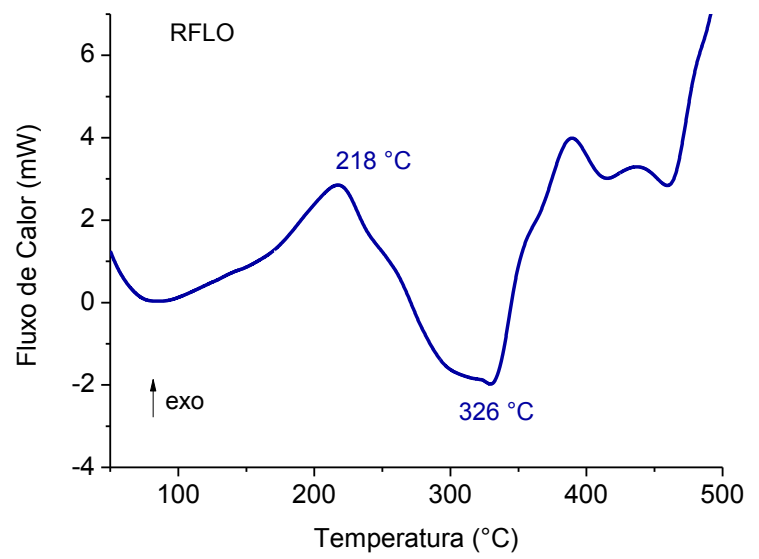

(d)

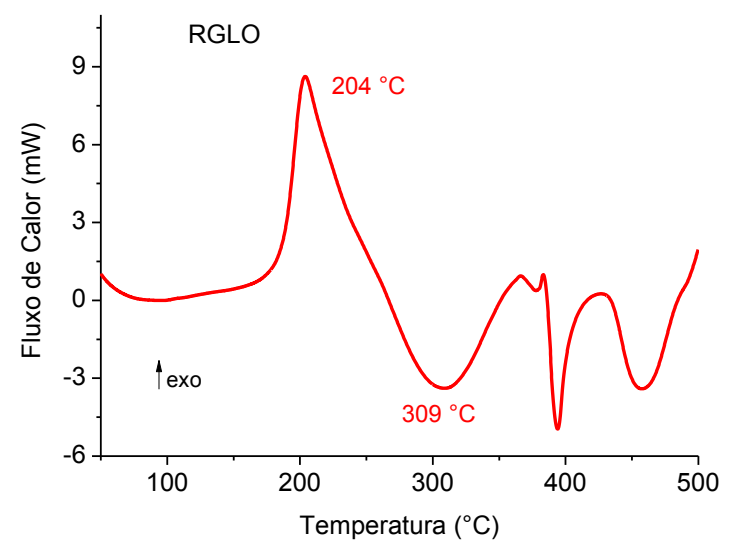

(f)

Figura 30: Curva TG e dTG para (a, b) lignina organossolve (LO), (c, d) resina formaldeído-lignina organossolve (RFLO); (e, f) resina glutaraldeído-lignina organossolve (RGLO), em atmosfera de ar $\left(20 \mathrm{~mL} \mathrm{~min}^{-1}\right)$ e taxa de aquecimento $10^{\circ} \mathrm{C} \mathrm{min}^{-1}$.

As resinas preparadas passaram pelo processo de cura térmica sob pressão obtendo-se assim os termorrígidos correspondentes. Estes termorrígidos foram analisados por TG e DSC (Figura 31). 
Nas curvas dTG (Figura 31a, 31c) dos os termorrígidos são observados picos em torno de $180{ }^{\circ} \mathrm{C}$ para o termorrígido formaldeído-lignina organossolve (TFLO) e $220{ }^{\circ} \mathrm{C}$ para o termorrígido glutaraldeído-lignina organossolve (TGLO) relativos a cura térmica residual e picos em $376{ }^{\circ} \mathrm{C}$ (TFLO) e $368{ }^{\circ} \mathrm{C}$ (TGLO) relativos a processo de entrecruzamento de grupos das cadeias que não reagiram na etapa de preparação do termorrígido. Os picos em temperaturas mais elevadas, em $482{ }^{\circ} \mathrm{C}$ (TFLO) e $590{ }^{\circ} \mathrm{C}$ (TGLO), são referentes à etapa de decomposição de anéis aromáticos.

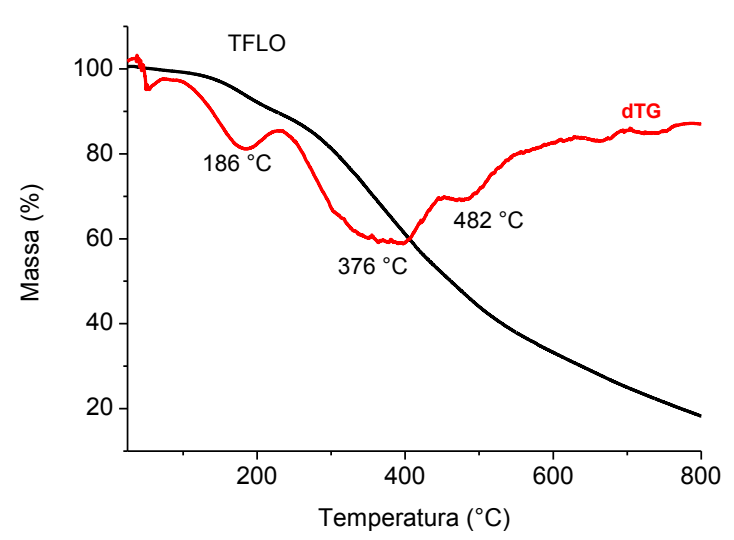

(a)

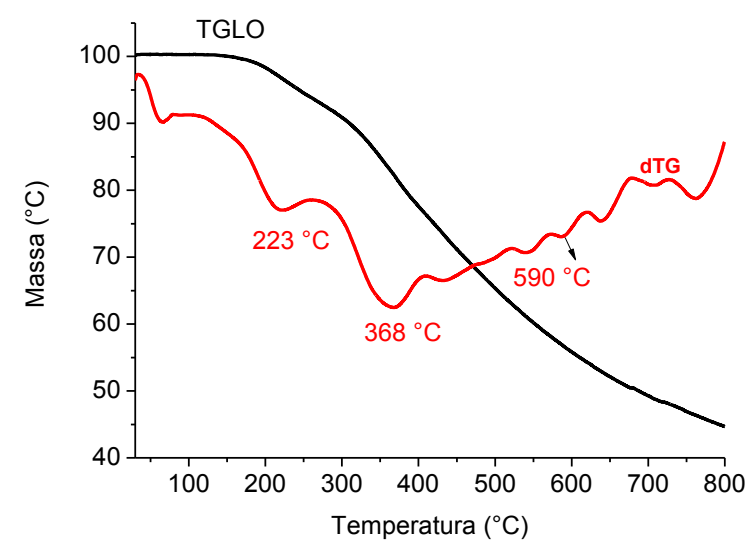

(c)

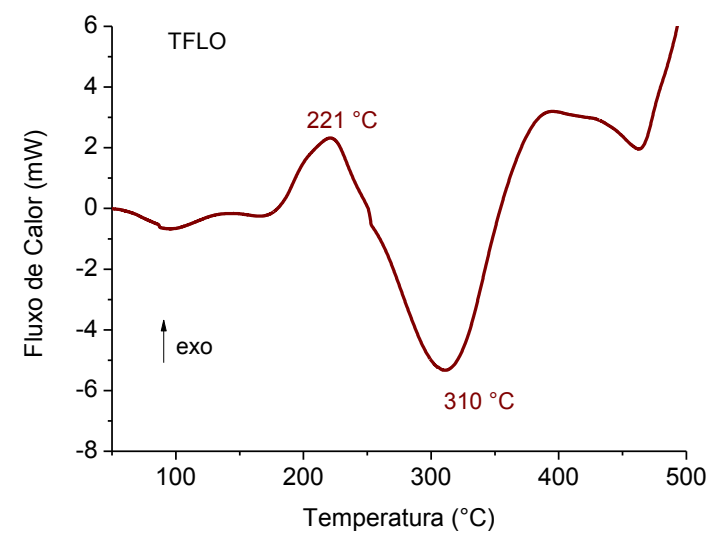

(b)

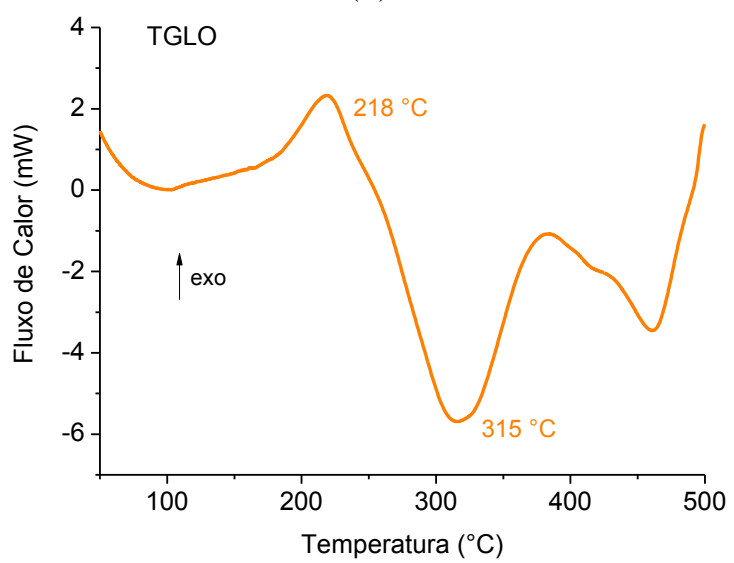

(d)

Figura 31: Curva TG e dTG para (a, b) termorrígido formaldeído-lignina organossolve (TFLO); (c, d) termorrígido glutaraldeído-lignina organossolve (TGLO), em atmosfera de ar $\left(20 \mathrm{~mL} \mathrm{~min}^{-1}\right)$ e taxa de aquecimento $10^{\circ} \mathrm{C} \mathrm{min}^{-1}$.

Observa-se os picos referentes a estes eventos nas curvas DSC para os termorrígidos (Figura 31c, 31d), com um pico exotérmico, em torno de $220^{\circ} \mathrm{C}$, relacionado à cura residual com eliminação de moléculas pequenas voláteis, como a água. Os picos endotérmicos em 310 ${ }^{\circ} \mathrm{C}$ podem estar relacionados a processos reacionais de sítios do termorrígido que ainda não 
haviam reagido. O mesmo comportamento é observado nas curvas DSC (Figura 30), dos prépolímeros.

\section{4. Espectroscopia na região do Infravermelho (IV)}

Lignossulfonato de sódio e lignina organossolve foram analisadas por espectroscopia na região do infravermelho (Figura 32).

As bandas da região entre 1700 e $500 \mathrm{~cm}^{-1}$ mostram as principais diferenças entre o lignossulfonato de sódio e lignina organossolve. A presença de grupos sulfonatos no lignossulfonato é indicada no espectro pelas bandas em 1207 e $1041 \mathrm{~cm}^{-1}$.

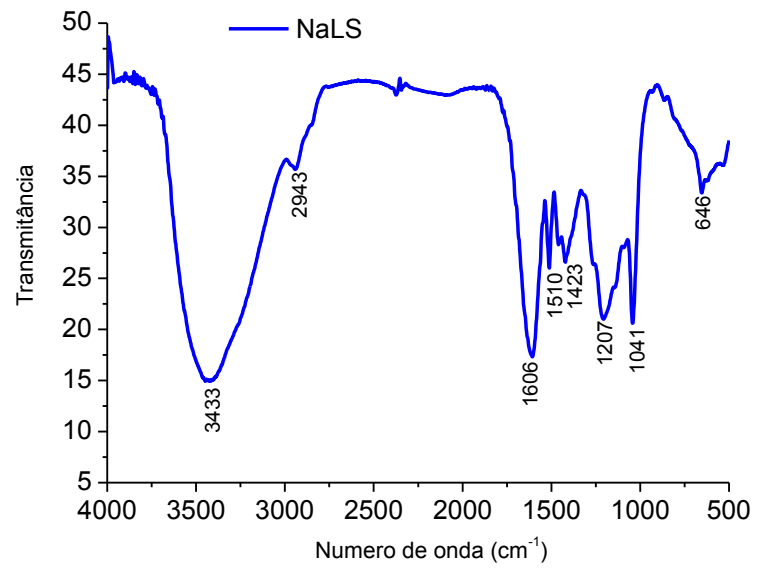

(a)

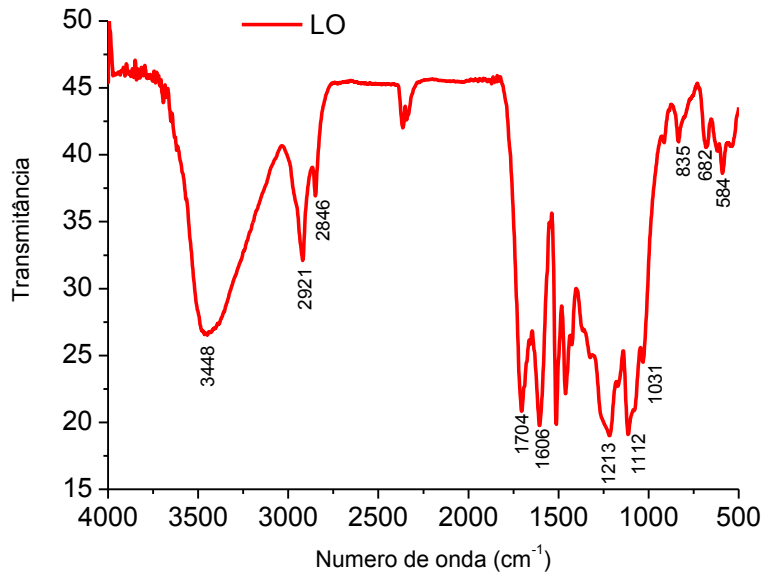

(b)

Figura 32: Espectro na região de infravermelho da (a) lignossulfonato de sódio (NaLS); (b) lignina organossolve (LO).

A lignina organossolve possui bandas características relativas às suas unidades básicas: para-hidroxifenila $(\mathbf{H})$, guaiacila $(\mathbf{G})$ e siringila $(\mathbf{S})$, segundo o modelo de Faix (1991), o que permite a classificação da lignina. No espectro (Figura 32b) são observadas bandas em 1166 e $834 \mathrm{~cm}^{-1}$ devido à vibração de ligações do tipo $\mathrm{C}=\mathrm{O}$ de ésteres e ligações do tipo $\mathrm{C}-\mathrm{H}$ do esqueleto aromático fora do plano em unidades para-hidroxifenilas, respectivamente, que caracterizam ligninas do tipo HGS. 
As possíveis atribuições das principais bandas, referentes ao lignossulfonato de sódio e lignina organossolve, estão descritas na tabela 16 e 17, respectivamente.

Tabela 16: Bandas de absorção na região do infravermelho característica de lignossulfonato de sódio, (OLIVEIRA, 2010).

\begin{tabular}{|c|c|}
\hline $\begin{array}{c}\text { Número de onda }\left(\mathrm{cm}^{-1}\right) \\
\text { 3360-3330 }\end{array}$ & $\begin{array}{c}\text { Possíveis atribuições } \\
\text { Deformação axial simétrica das hidroxilas (-OH) dos grupos } \\
\text { alcoólicos e fenólicos }\end{array}$ \\
\hline $\mathbf{2 9 4 0 - 2 8 9 0}$ & Deformação axial da ligação C-H em grupos metileno \\
\hline $\mathbf{1 6 0 6}$ & Vibração do esqueleto aromático e da ligação C=O \\
\hline $\mathbf{1 4 6 0 - 1 4 2 1}$ & Estiramento C-O em lignina e lignossulfonato \\
\hline $\mathbf{1 2 1 3 - 1 2 0 7}$ & Estiramento C-O em lignina e lignossulfonato \\
\hline $\mathbf{1 0 4 1}$ & Estiramento C-O grupos sulfonatos \\
\hline $\mathbf{6 4 6}$ & Vibração em C-S do grupo sulfônico \\
\hline
\end{tabular}

Tabela 17: Bandas de absorção na região de infravermelho características da lignina organossolve (RAMIRES, 2009).

\begin{tabular}{|c|c|}
\hline Número de onda $\left(\mathrm{cm}^{-1}\right)$ & Possíveis Atribuições \\
\hline $3400-3450$ & $\begin{array}{c}\text { Deformação axial simétrica das hidroxilas (-OH) dos grupos } \\
\text { alcoólicos e fenólicos }\end{array}$ \\
\hline $3000-2846$ & Alongamento da ligação C-H dos grupos metila e metileno \\
\hline 1704 & $\begin{array}{l}\text { Alongamento da ligação } \mathrm{C}=\mathrm{O} \text { de cetonas não conjugadas, ésteres } \\
\text { ou ácidos carboxílicos }\end{array}$ \\
\hline 1606 & Vibração do esqueleto aromático e da ligação $\mathrm{C}=\mathrm{O}$ \\
\hline 1514 & Vibrações dos esqueletos aromáticos \\
\hline 1460 & Deformações assimétricas da ligação $\mathrm{C}-\mathrm{H}$ dos grupos $\mathrm{CH}_{2} \mathrm{e} \mathrm{CH}_{3}$ \\
\hline $1421-1423$ & $\begin{array}{l}\text { Vibrações do esqueleto aromático combinado com as } \\
\text { deformações da ligação C-H no plano }\end{array}$ \\
\hline 1323 & Unidades siringilas e guaiacilas condensadas \\
\hline 1207 & Unidades guaiacilas combinadas com elongação da ligação $\mathrm{C}=\mathrm{O}$ \\
\hline 1166 & $\begin{array}{c}\text { Alongamento da ligação } \mathrm{C}=\mathrm{O} \text { de grupos éster, característica da } \\
\text { lignina do tipo HGS }\end{array}$ \\
\hline 1108-1112 & $\begin{array}{l}\text { Deformação da ligação C-O de álcool secundário } \\
\text { Deformação da ligação C-H dos núcleos aromáticos }\end{array}$ \\
\hline 1031 & $\begin{array}{l}\text { Deformação da ligação C-O de álcool primário } \\
\text { Deformação de C-H do esqueleto aromático no plano } \\
\text { Alongamento da ligação } \mathrm{C}=\mathrm{O}\end{array}$ \\
\hline 834-584 & $\begin{array}{l}\text { Vibração da ligação C-H fora do plano nas unidades } \\
\qquad p \text {-hidroxifenila }\end{array}$ \\
\hline
\end{tabular}


Resinas foram preparadas com lignina organossolve e lignossulfonato de sódio com formaldeído e glutaraldeído, e foram analisadas por espectroscopia na região do infravermelho (Figura 33).

As resinas apresentam bandas similares àquelas dos reagentes a partir dos quais foram preparados, lignina organossolve e lignossulfonato de sódio (NaLS), como pode ser observados nos espectros da figura 32.

A tabela 18 lista as principais absorções na região de IV relacionadas às bandas características das resinas e termorrígidos fenólicos (TF) (espectros apresentados na figura $33)$.

Na figura 33, tem-se o espectro de absorção da resina fenólica (RF) onde, em todos os espectros é observada uma banda intensa na região de 3500 a $3300 \mathrm{~cm}^{-1}$ característicos de estiramento ou deformação axial de grupo $\mathrm{OH}$ alcoólico e fenólico.

Tabela 18: Principais atribuições de absorção na região do IV da resina e termorrígido fenólico (SILVERSTEIN; BASSLER,1994).

\begin{tabular}{|c|c|}
\hline $\begin{array}{l}\text { Comprimento de } \\
\text { onda }\left(\mathrm{cm}^{-1}\right)\end{array}$ & Atribuições \\
\hline 3500-3300 & Estiramento ou deformação axial de O-H alcoólico e fenólico. \\
\hline$\sim 2900$ & Estiramento da ligação C-H em grupos metilenos. \\
\hline $2400-2300$ & Absorção referente a ligação C-O \\
\hline $1600-1400$ & Estiramento (deformação axial) das ligações $\mathrm{C}=\mathrm{C}$ do anel aromático. \\
\hline $1250-1200$ & Absorções referentes ao modo de estiramento da ligação C-O-H de fenóis. \\
\hline$\sim 1100$ & Estiramento -C-O-C- da ligação - $\mathrm{CH}_{2}-\mathrm{O}-\mathrm{CH}_{2}$ - em éteres. \\
\hline$\sim 1000$ & Estiramento -C-O- de grupo hidroximetil $-\mathrm{CH}_{2} \mathrm{OH}$. \\
\hline $830-820$ & $\begin{array}{l}\text { Deformação angular da ligação - } \mathrm{CH} \text { fora do plano em anéis unidos por ligações } \\
\qquad o-p .\end{array}$ \\
\hline$\sim 750$ & $\begin{array}{l}\text { Deformação angular - } \mathrm{CH} \text { fora do plano da ligação - } \mathrm{CH} \text { em anéis unidos por } \\
\text { ligações } o-o .\end{array}$ \\
\hline
\end{tabular}




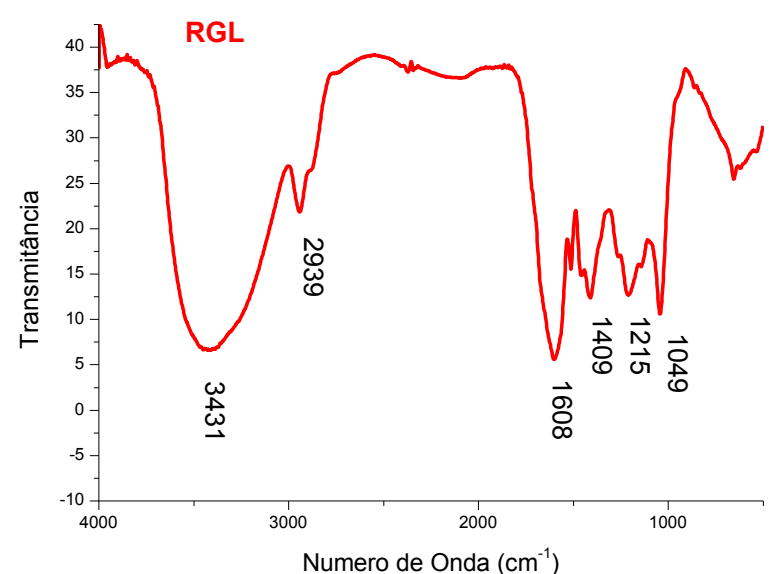

(a)

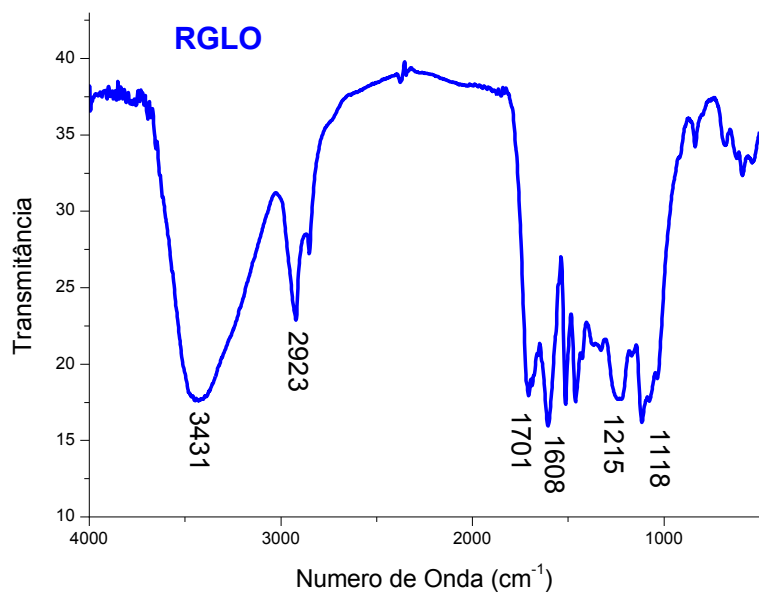

(c)

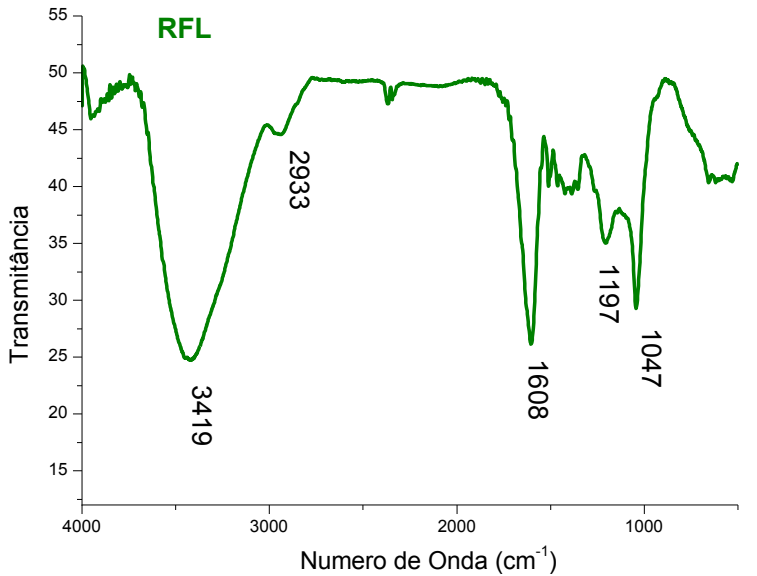

(b)

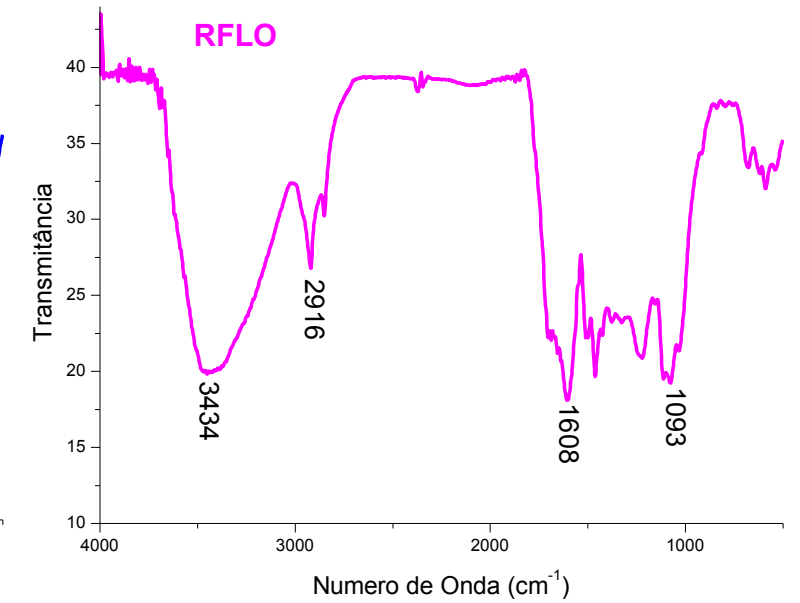

(d)

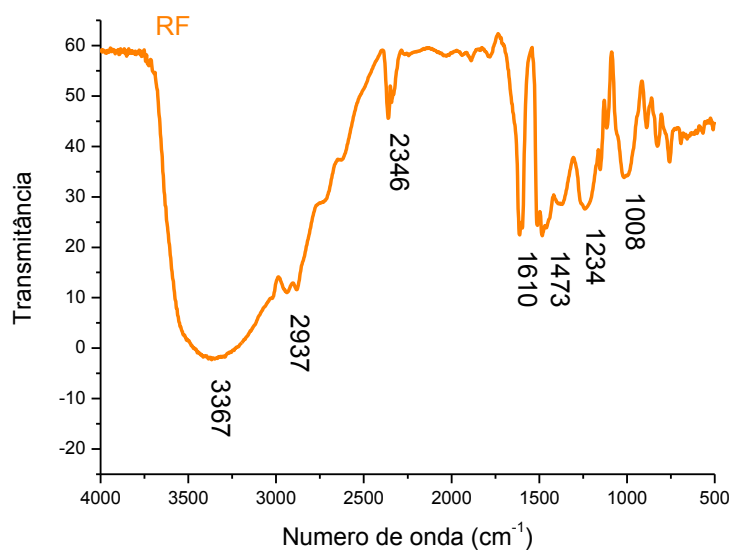

(e)

Figura 33: Espectros na região de infravermelho das resinas de (a) glutaraldeído-lignossulfonato (RGL); (b) formaldeído-lignossulfonato (RFL); (c) glutaraldeído-lignina organossolve (RGLO); (d) formaldeído-lignina organossolve (RFLO); (e) resina fenólica (RF). 
Em torno de $1100 \mathrm{~cm}^{-1}$ tem-se a banda de absorção referente ao estiramento C-O-C da ligação de éteres (Figura 33). A mesma banda é observada no espectro do termorrígido, figura 34 (pré-polímero entrecruzado). Provavelmente, a diminuição de intensidade desta banda no termorrígido se deve a diminuição da quantidade de pontes etéreas, após o entrecruzamento, e formação de metileno quinona relacionada à ruptura das ligações de éter. Em torno de 1000 $\mathrm{cm}^{-1}$, tem-se o estiramento $(\mathrm{C}-\mathrm{O})$ referente ao grupo hidroximetila $\left(\mathrm{CH}_{2} \mathrm{OH}\right)$.

A região de $842 \mathrm{~cm}^{-1}$ é referente à deformação angular da ligação $-\mathrm{CH}$ fora do plano em anéis unidos por ligações orto-para, e em $754 \mathrm{~cm}^{-1}$ tem-se a banda de absorção referente à deformação angular - $\mathrm{CH}$ fora do plano de ligações em anéis, unidos por ligações orto-orto (Figura 34).

Na região entre 820 e $754 \mathrm{~cm}^{-1}$, observa-se no polímero termorrígido uma diminuição na intensidade da banda em $754 \mathrm{~cm}^{-1}$, com relação à resina fenólica (Figura 33). Devido o crescimento das cadeias poliméricas predominam as ligações orto-orto e, no processo de entrecruzamento, formam-se ligações orto-para, identificadas na absorção em $840 \mathrm{~cm}^{-1}$. 


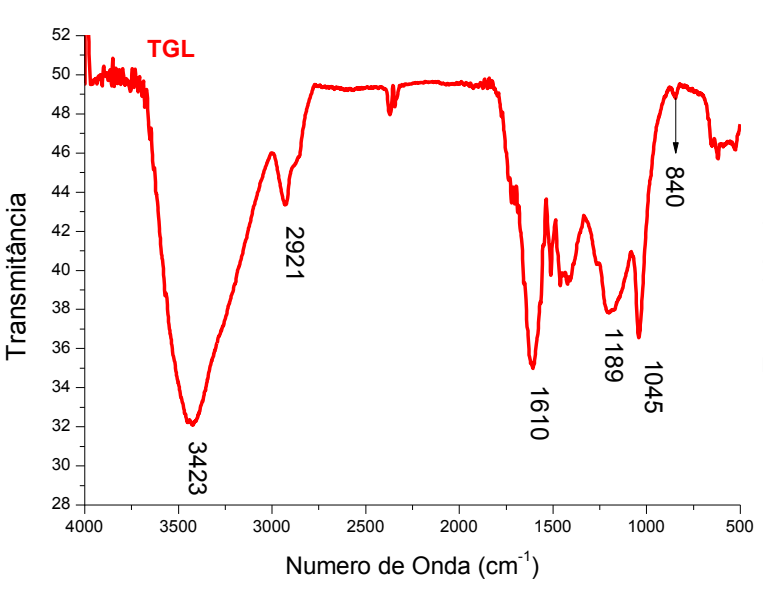

(a)

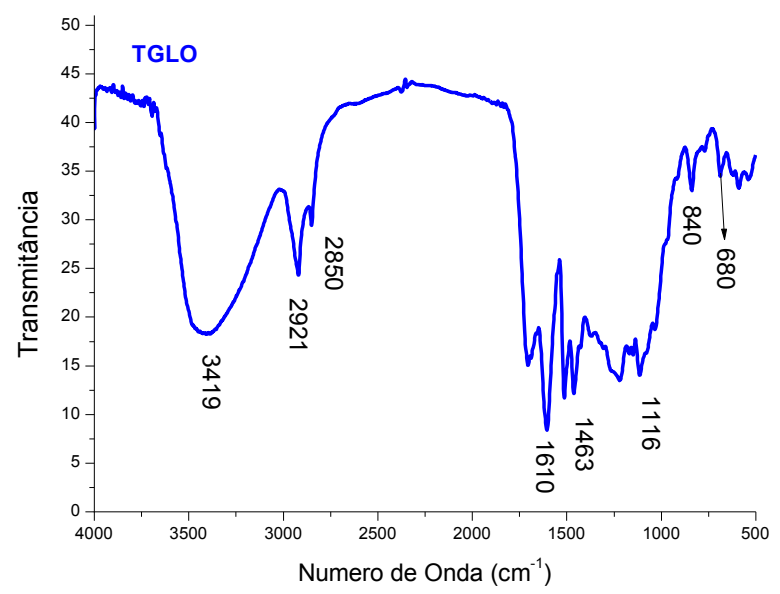

(c)

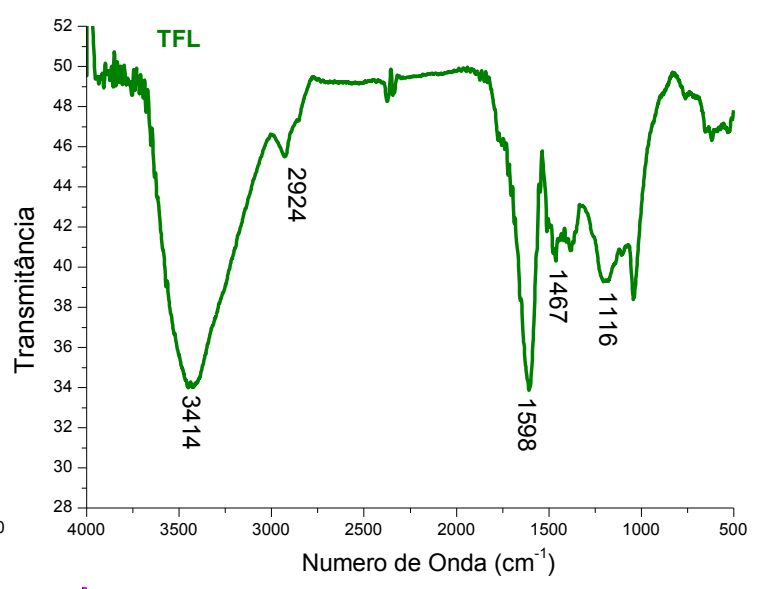

(b)

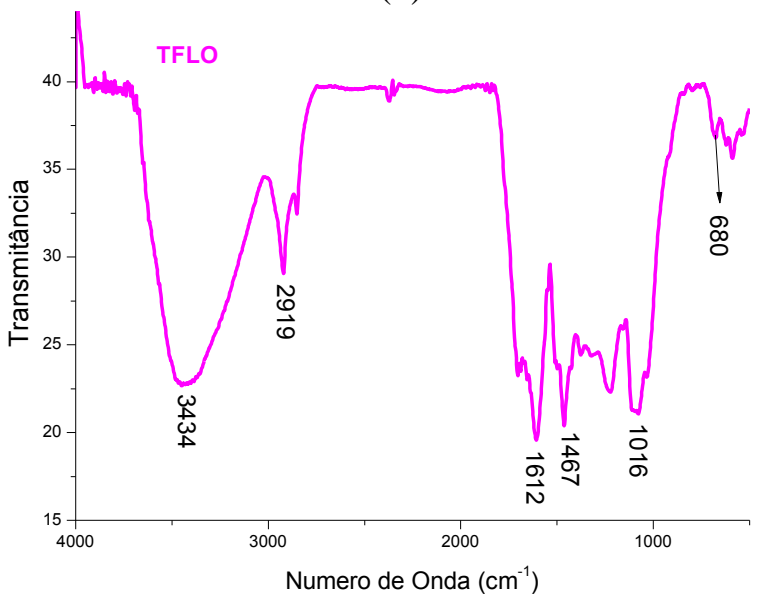

(d)

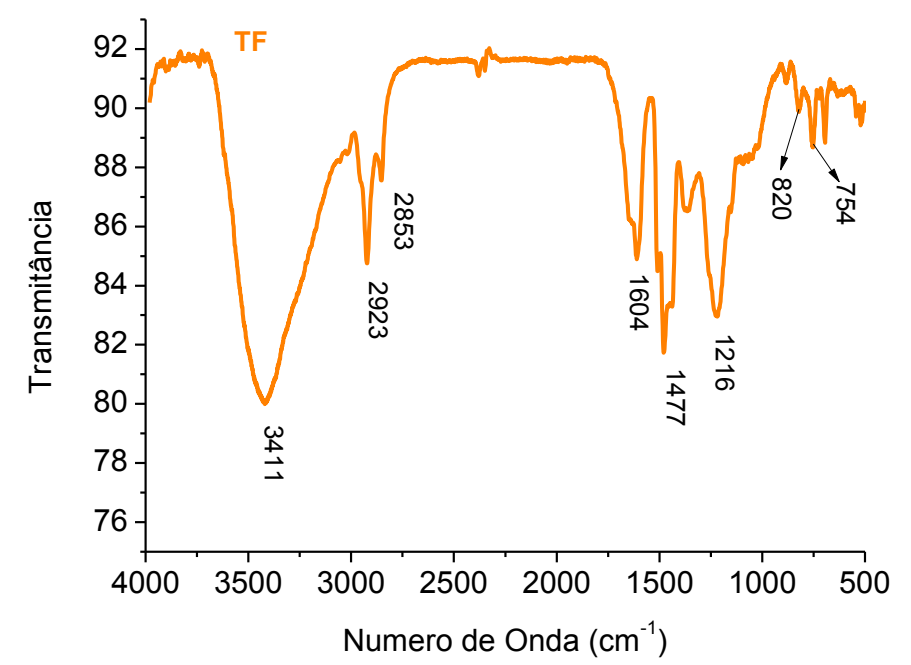

(e)

Figura 34: Espectros na região de infravermelho dos termorrígidos de (a) glutaraldeídolignossulfonato (TGL); (b) formaldeído-lignossulfonato (TFL); (c) glutaraldeído-lignina organossolve (TGLO); (d) formaldeído-lignina organossolve (TFLO); (e) termorrígido fenólico (TF).

Comparando os espectros das resinas (Figura 33) e termorrígidos (Figura 34) observa-se deslocamento dos picos, o qual pode estar relacionado ao processo de entrecruzamento do 
pré-polímero para a formação do termorrígido. Por exemplo, o consumo de grupos hidroximetila, que leva a diminuição da concentração de grupos $\mathrm{OH}$, o consumo de grupos OH alcoólico e fenólico, assim como formação de metileno quinona.

\section{5. Cromatografia por Exclusão de Tamanho - (Size Exclusion Chromatography} - SEC)

5. 5. 1. Resinas: glutaraldeído-lignina organossolve (RGLO), glutaraldeído-lignina extraída do bagaço de cana queimado (extração soda/AQ) (RLBC) e glutaraldeídolignossulfonato de sódio (RGL)

Um estudo foi realizado para a substituição do formaldeído por glutaraldeído na reação de polimerização leva às resinas baseadas em lignina. Os pré-polímeros (resinas) foram analisados por SEC, RMN ${ }^{1} \mathrm{H}$ e ${ }^{31} \mathrm{P}$ e UV-visível. Para a análise de SEC e RMN ${ }^{1} \mathrm{H}$, a resina foi previamente acetilada.

Os resultados de SEC das resinas estão apresentados na figura 35 e tabela 19, respectivamente.

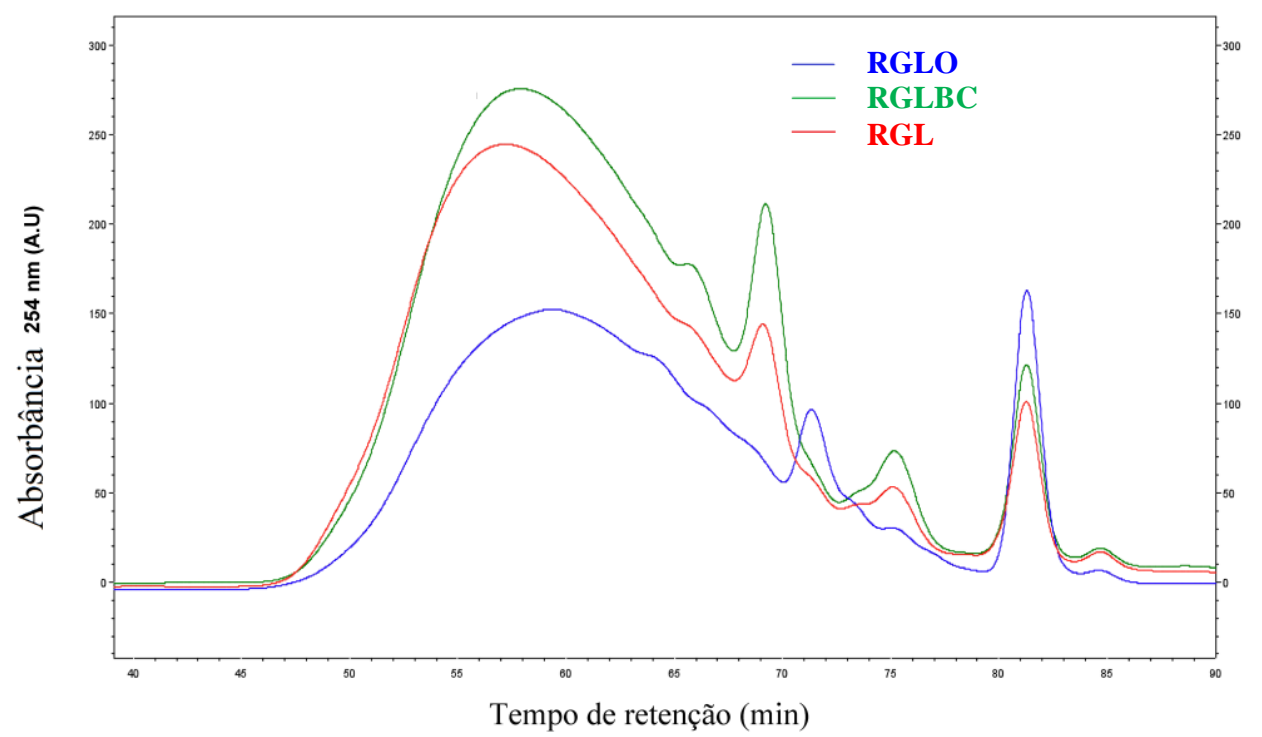

Figura 35: Curvas de eluição SEC das resinas preparadas a partir de glutaraldeído e acetiladas: (匹) lignina do bagaço de cana queimado (extração soda/antraquinona (AQ)) (RGLBC); (ロ) lignina organossolve (RGLO); ( $\mathbf{- 1}$ ) lignossulfonato de sódio (RGL). 
Tabela 19: Análise de massa molecular por SEC das resinas acetiladas: glutaraldeído-lignina do bagaço de cana queimado (extração soda/AQ) (RLBC); glutaraldeído-lignina organossolve (RGLO); glutaraldeído-lignossulfonato de sódio (RGL).

\begin{tabular}{c|c|c|c} 
resinas & Mw & Mn & Mw/Mn \\
RGLO & 2038 & 1099 & 1,8 \\
\hline RLBC & 2324 & 1636 & 1,4 \\
\hline RGL & 2522 & 1726 & 1,5 \\
\hline
\end{tabular}

As curvas (Figura 35) e os resultados da tabela 19 indicam uma mudança na distribuição de massa molar para tempos de eluição menores, quando comparado aos resultados de massa molecular das ligninas não polimerizadas (Tabela 14), o que corresponde a um aumento significativo de massa molecular devido à polimerização da lignina pelo glutaraldeído.

As figuras 36 e 37 apresentam os espectros de RMN de fosforo $31\left({ }^{31} \mathrm{P}\right)$ dos prépolímeros após derivatização com o 2-cloro-4,4,5,5-tetrametil-1,3,2dioxafosfolano, segundo o procedimento descrito por Argyropoulos (1994a,b). A quantificação dos diferentes grupos hidroxilas é apresentada na tabela 20.

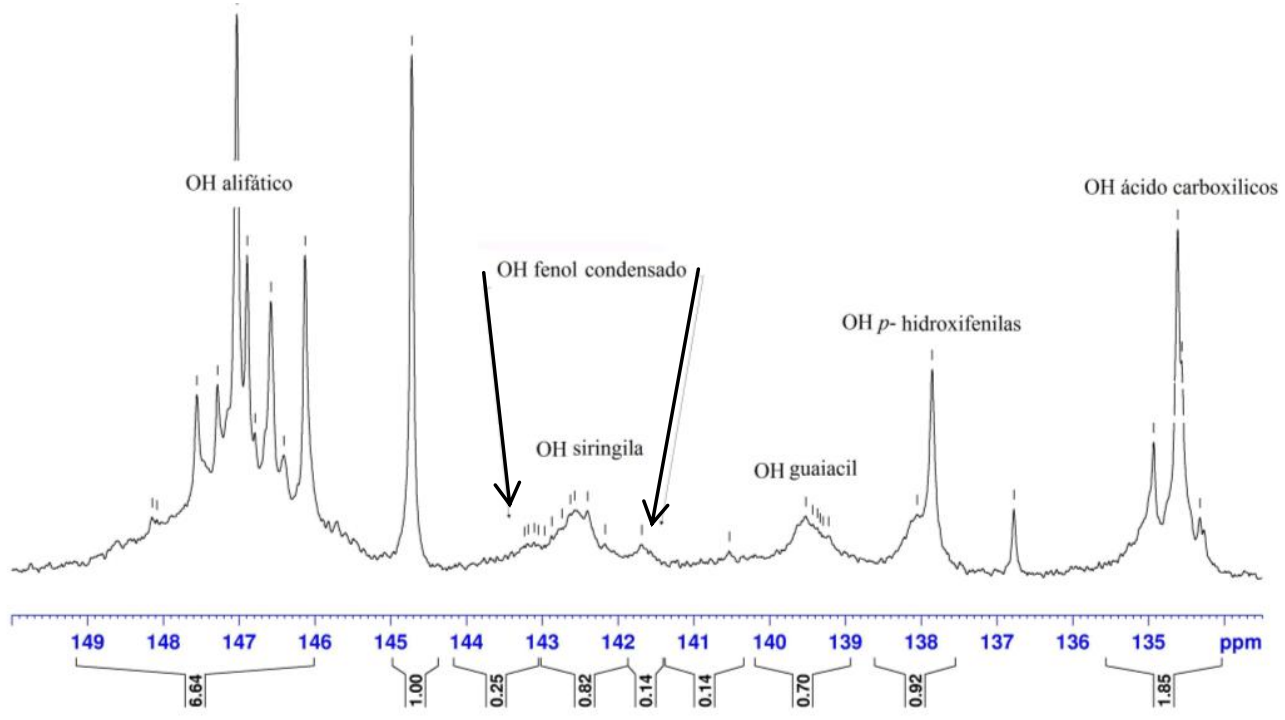

(a)

Figura 36: Espectro de RMN ${ }^{31} \mathrm{P}$ da resina glutaraldeído-lignina organossolve (RGLO).

Os picos foram assinalados no espectro (Figura 36) de acordo com os grupos $\mathrm{OH}$ alifáticos, tanto para ligações do tipo $\beta-\mathrm{O}-4$ como de $\mathrm{OH}$ primários. Os picos de baixa 
intensidade correspondem aos grupos $\mathrm{OH}$ fenólicos em unidades condensadas, indicados na figura 36. Também os grupos fenólicos presentes em unidades básicas siringila (S), guaiacila (G) e p-hidroxifenila (H) estão indicados em 143,5ppm, 139,5ppm e 138ppm, respectivamente. Os picos por volta de 135,5ppm corresponde as hidroxilas presentes em ácidos carboxílicos (ARGYROPOULOS, 1994). O pico intenso em aproximadamente 145ppm é referente à referência interna, colesterol.

O número de mols da referência interna e as integrais dos sinais possibilitaram quantificar os grupos hidroxilas presentes nas ligninas (Figura 36 e 37), como mostra a tabela 20. 


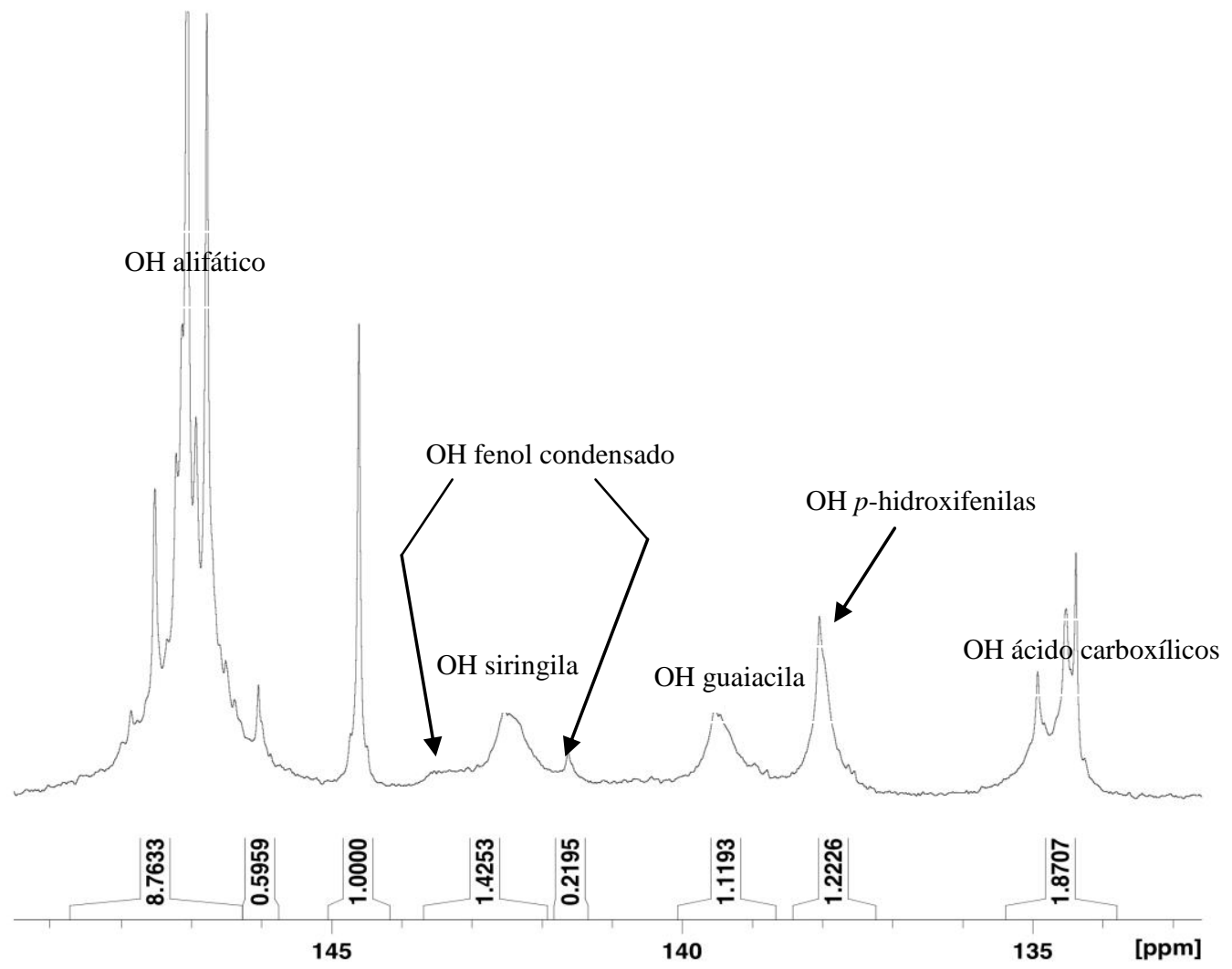

(b)

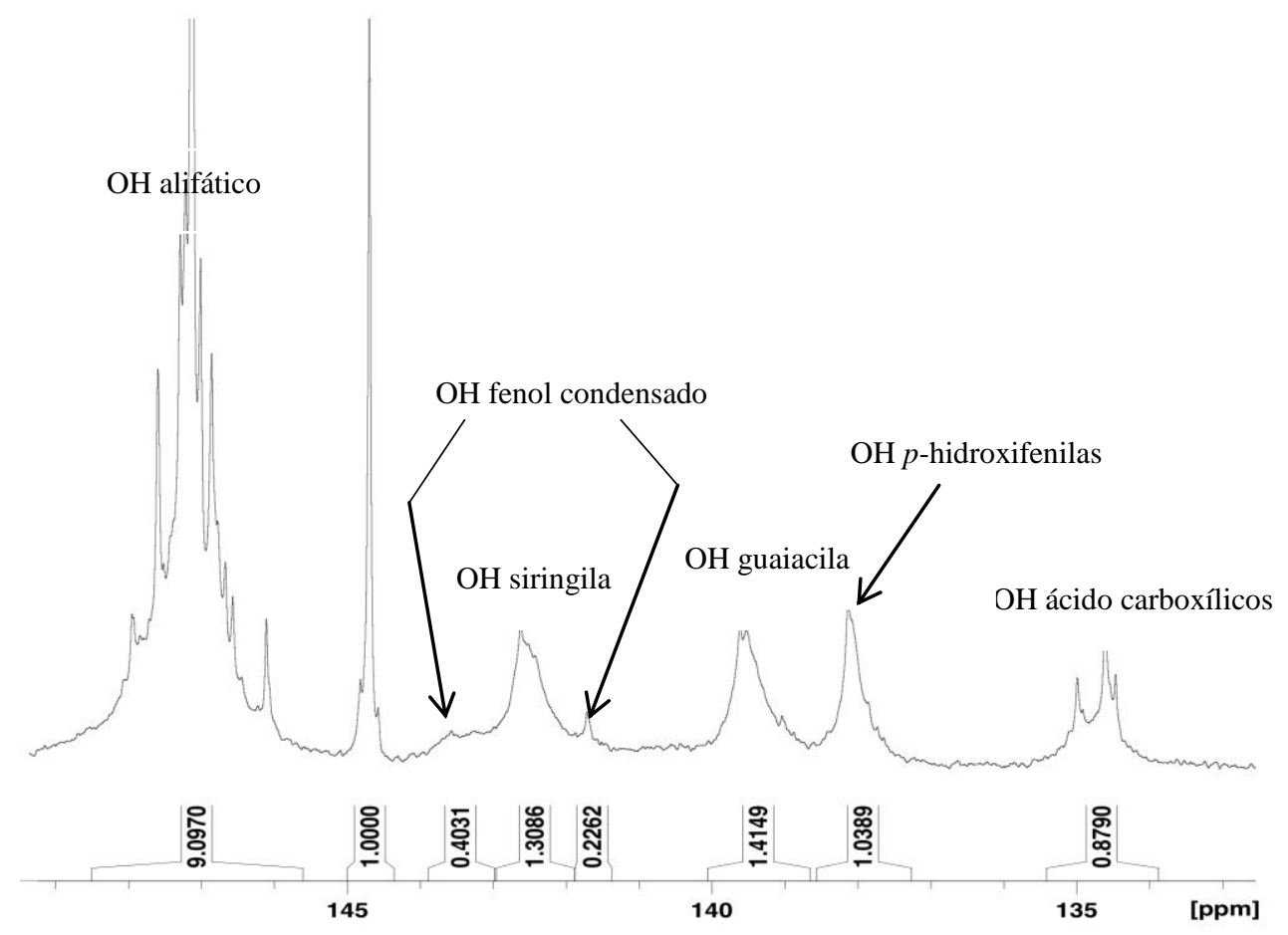

(c)

Figura 37: Espectro de $\mathrm{RMN}{ }^{31} \mathrm{P}$ da resina de (a) glutaraldeído-lignina do bagaço de cana queimado (extração soda/AQ) (RGLBC); (b) glutaraldeído-lignossulfonato de sódio (RGL). 
Comparando os espectros da figura 37 (RGLBC e RGL) com o da figura 36 ( lignina organossolve) pode-se observar a aparição de muitos picos na região de hidroxilas alifáticas, estando de acordo com o produto da reação de grupos aldeídos com grupos fenóis em meio alcalino (Esquema 7 e 8). Mesmo assim, uma acentuada diminuição na taxa da função fenol (70\%) foi observada. Provavelmente este último se encontra em equilíbrio com as funções acetona do equilíbrio ceto-enólico, limitando também sua detecção (Ramires, 2009).

Tabela 20: Quantificação dos grupos hidroxilas obtidos por $\mathrm{RMN}{ }^{31} \mathrm{P}$ ( $\mathrm{mmol} \mathrm{g}^{-1}$ de lignina) das resinas preparadas a partir do glutaraldeído com: lignina organossolve (RGLO); lignina do bagaço de cana queimado (RGLBC); lignossulfonato de sódio (RGL).

\begin{tabular}{c|c|c|c|c|c|c|c}
\multicolumn{2}{c}{$\begin{array}{c}\text { OH Alifáticos } \\
\text { resinas }\end{array}$} & S-OH* & G-OH & H-OH & $\begin{array}{c}\text { OH- } \\
\text { Condensados }\end{array}$ & $\begin{array}{c}\text { Total } \\
\text { fenol }\end{array}$ & Ácidos \\
RGLO & 1,85 & 0,23 & 0,19 & 0,26 & 0,11 & 0,68 & 0,51 \\
\hline RGLBC & 2,36 & 0,32 & 0,31 & 0,33 & 0,12 & 1,08 & 0,50 \\
\hline RGL & 2,48 & 0,29 & 0,39 & 0,28 & 0,13 & 1,09 & 0,24 \\
\hline
\end{tabular}

*S-OH: grupo fenólico presente na unidade siringila; $\mathrm{G}-\mathrm{OH}$ : grupo fenólico presente na unidade guaiacila; H-OH: grupo fenólico presente na unidade hidroxifenila; 5,5-condensado: $\mathrm{OH}$ fenólico em unidades condensadas.

Os resultados obtidos indicam que é possível o preparo do pré-polímero a partir de dialdeídos (glutaraldeído) e ligninas, visando a elaboração de compósitos.

\section{6. Cromatografia gasosa inversa (IGC) - ligninas e termorrígidos}

Através da técnica de IGC, que avalia a superfície dos materiais, realizou-se neste trabalho a caracterização dos materiais utilizados no preparo das matrizes, lignossulfonato de sódio e dos respectivos termorrígidos.

A partir dos resultados de injeções das sondas da série de n-alcanos, e do método proposto pro Schultz et al. (Equação 9) tem-se o gráfico da figura 38: 


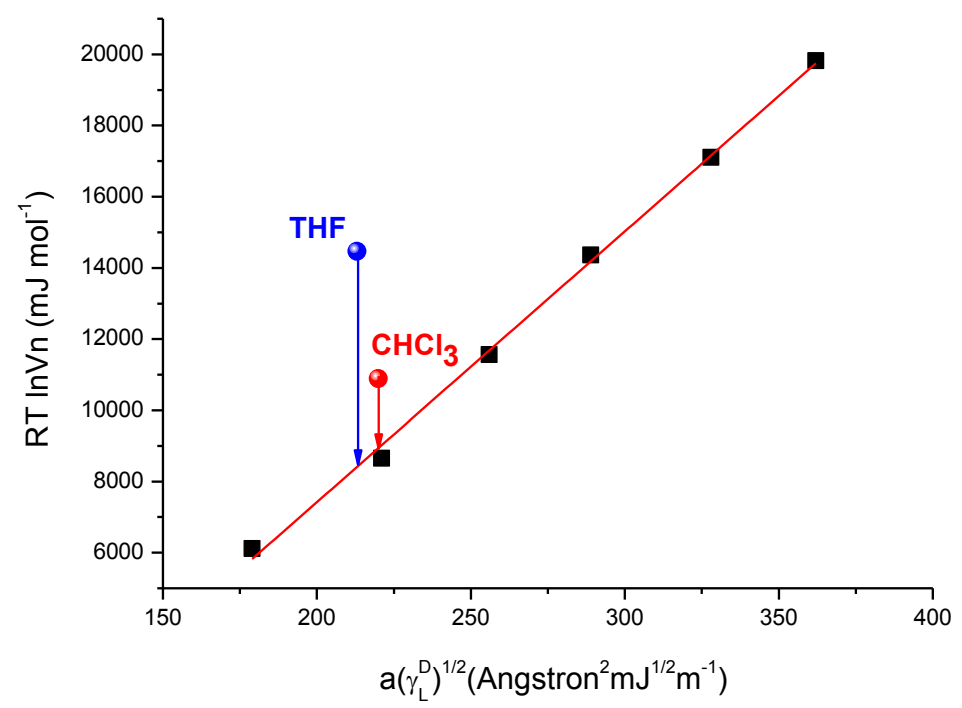

Figura 38: Cromatograma referente à coluna preenchida com termorrígido formaldeídolignossulfonato de sódio (TFL).

Este (Figura 38) e outros (Figuras não mostradas) gráficos obtidos possibilitaram o cálculo da energia dispersiva e o caráter ácido/base para termorrígidos (Tabela 21).

Tabela 21: Componentes de energia de dispersiva e caráter ácido/base da superfície dos termorrígidos.

\begin{tabular}{|c|c|c|c|c|c|}
\hline Amostras & $\gamma_{\mathrm{S}}^{\mathrm{d}}\left(\mathrm{mJ} \mathrm{m}^{-2}\right)$ & $\mathbf{A} \mathbf{N}_{\mathbf{S}}$ & $\mathbf{D N}_{\mathbf{S}}$ & $\mathbf{A N}_{\mathrm{S}} / \mathbf{D N _ { S }}$ & CARÁTER \\
\hline Fenol-formaldeído ${ }^{12}$ & 34 & 3074 & 2276 & 1,4 & Ácido \\
\hline Lignossulfonato de sódio & 31 & 3490 & 2931 & 1,2 & Ácido \\
\hline $\begin{array}{c}\text { Formaldeído- } \\
\text { lignossulfonato de sódio }\end{array}$ & 34 & 4585 & 3282 & 1,4 & Ácido \\
\hline $\begin{array}{c}\text { Glutaraldeído- } \\
\text { lignossulfonato de sódio }\end{array}$ & 42 & 4830 & 3585 & 1,4 & Ácido \\
\hline
\end{tabular}

Os dados obtidos para o termorrígido fenólico (fenol/formaldeído) na análise de IGC (MEGIATTO, 2008) foi próximo ao encontrado por Ramires (2009), que obteve valores de energia de superfície para o termorrígido de $34,2 \mathrm{~mJ} \mathrm{~m}^{-2}$ e caráter ácido $\left(\mathbf{A N}_{\mathrm{S}} / \mathbf{D N}_{\mathbf{S}}=1,5\right)$. $\mathrm{O}$ mesmo valor de energia de superfície para a resina formaldeído-lignossulfonato de sódio foi obtido.

\footnotetext{
${ }^{12}$ MEGIATTO Jr, J.D.; SILVA, C.G.; ROSA, D.S.; FROLLINI, E. Sisal chemically modified with lignins: Correlation between fibers and phenolic composites properties. Polymer Degradation and Stability, 93, 1109-121, 2008.
} 
No presente trabalho o fenol foi substituído pelo lignossulfonato de sódio para o preparo de matrizes termorrígidas. Os resultados mostram que o caráter ácido dos termorrígidos é mantido $\left(\mathrm{AN}_{\mathrm{S}} / \mathrm{DN}_{\mathrm{S}}\right)$, como o do termorrígido fenólico (MEGIATTO, 2008), embora a disponibilidade de sítios ativos aceptores e doadores sejam alterados. O termorrígido lignossulfonato de sódio-formaldeído apresentou um alto valor de $\mathbf{A} \mathbf{N}_{\mathbf{S}}$, sítios aceptores disponíveis. Este valor se mantém acima dos valores dos demais termorrígidos e do lignossulfonato de sódio. Este resultado pode ser atribuído ao fato de maior disponibilidade de sítios ativos aceptores do que doadores na superfície deste material.

Quando o formaldeído é substituído pelo glutaraldeído na reação para obtenção do termorrígido, o caráter do material obtido $\left(\mathrm{AN}_{\mathrm{S}} / \mathrm{DN}_{\mathrm{S}}\right)$ não é alterado. Os sítios aceptores $\left(\mathbf{A N}_{\mathbf{S}}\right)$ e doadores $\left(\mathbf{D N}_{\mathbf{S}}\right)$ disponíveis aumentam, quando comparado ao termorrígido lignossulfonato de sódio-formaldeído. Também, a energia de superfície deste termorrígido (42

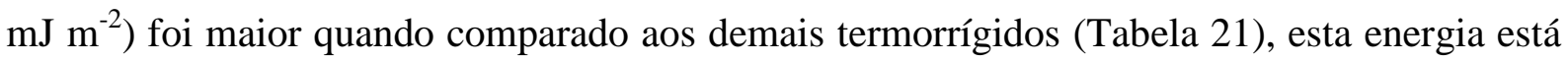
diretamente ligada ao mecanismo de interação do material em análise com as sondas, por isso quanto maior a interação da sonda com o material de análise maior o volume de retenção, resultando em uma maior energia de superfície. Estes fatos podem estar relacionados às características do arranjo estrutural do produto obtido da reação entre o glutaraldeído e lignossulfonato, possibilitando que os sítios aceptores, presentes na estrutura, estejam mais disponíveis que nos demais materiais.

Comparando os valores de $\mathbf{D} \mathbf{N}_{\mathbf{S}}$ dos termorrígidos em que o lignossulfonato de sódio está presente com o valor de $\mathbf{D N}_{\mathbf{S}}$ do termorrígido fenólico observa-se um aumento o destes valores, indicando maior caráter ácido dos termorrígidos com lignossulfonato. Este fato se deve provavelmente à maior acessibilidade das sondas aos sítios ácidos, principalmente aos grupos hidroxilas (-OH). Esta maior acessibilidade aos grupos polares pode ser decorrente ao menor entrecruzamento das cadeias deste termorrígido obtido a partir de lignossulfonato de sódio. 
Comparando os valores das tabelas 9 e 21, para fibras e termorrígidos respectivamente, observa-se os valores de $\mathbf{A} \mathbf{N}_{\mathbf{S}}$ e $\mathbf{D N}_{\mathbf{S}}$ para as fibras de bagaço de cana queimada e tratada, são os que mais se aproximam dos valores dos termorrígidos (Tabela 21), sugerindo que as interações entre as fibras e a matriz nos compósitos, preparados com estes materiais, podem ser mais favorecidas. As interações mais intensas que podem ocorrer entre os sítios aceptores e doadores correspondem ao estabelecimento de ligações hidrogênios na interface (fibra/matriz). Como será visto nos resultados de resistência ao impacto, os compósitos preparados com fibras de bagaço de cana queimada e tratadas, com matriz de lignossulfonato de sódio/formaldeído, apresentaram maior valor de resistência, quando comparado aos compósitos preparados com fibras de bagaço de cana sem tratamento.

\section{7. Compósitos fenólicos reforçados com fibras naturais}

Diversos tipos de resinas foram preparadas e utilizadas como matrizes no preparo de compósitos. Fibras de bagaço de cana não queimadas e queimadas foram utilizadas como reforço. Os compósitos foram caracterizados para avaliar as propriedades de estabilidade térmica, mecânicas (ensaios de impacto Izod, resistência à flexão, DMTA) e absorção de água.

\section{3. 1. Caracterização dos compósitos}

\section{3. 1. 1. Espectroscopia na região de infravermelho}

Análises de infravermelho foram realizadas para os compósitos preparados com os diferentes tipos fibras e resinas cujos espectros foram apresentados nos itens 5.1.2 e 5.4, respectivamente.

A figura 39 mostra o espectro de infravermelho do compósito fenólico reforçado com fibras lignocelulósicas (bagaço de cana não queimado e queimado), são observadas bandas de absorção relativas aos modos de vibração já citados para o polímero fenólico, acrescidas das bandas de absorção referentes às fibras lignocelulósicas (Tabelas 16, 17 e 18). 


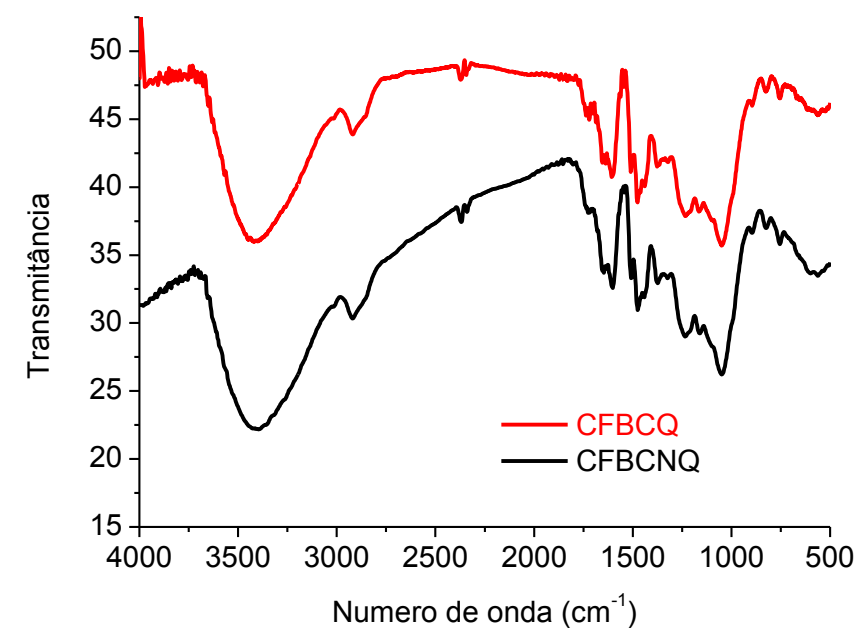

Figura 39: Espectro na região de infravermelho dos compósitos fenólico reforçados com fibras de bagaço de cana queimada (CFBCQ) e não queimada (CFBCNQ).

Espectros similares foram observados para os demais dos compósitos analisados (mostrados em Anexo).

\section{3. 1. 2. TG e DSC}

Todos os compósitos foram analisados por TG e DSC com a finalidade de avaliar a estabilidade térmica, observando os estágios de perda de massa (curva dTG) e eventos de decomposição dos componentes (curvas DSC).

No compósito fenólico reforçado com fibra de bagaço de cana queimado (Figura 40c) a curva dTG (derivada primeira da TG) apresenta uma pequena porcentagem de perda de massa referente a volatilização de água $(0,3 \%)$.

A curva dTG mostra picos de decomposição referente a fibra lignocelulósica e matriz. Os picos de decomposição das fibras de bagaço de cana sobrepõem os picos de decomposição da matriz fenólica. Até $200{ }^{\circ} \mathrm{C}$, a matriz apresenta perdas de massa provavelmente resultante da liberação de água, como resultado da etapa de cura residual do polímero (condensação), ocorrido durante a varredura. Perdas de massa consideráveis da matriz, ocorrem em 
temperaturas acima de $400{ }^{\circ} \mathrm{C}$. Eventos similares são observados para o compósito com fibras não queimadas, pois como visto nas figuras 20a, 20b os eventos de decomposição das fibras bagaço de cana, queimadas e não queimadas, se apresentam em temperaturas bem próximas (em $364{ }^{\circ} \mathrm{C}$ e $355^{\circ} \mathrm{C}$, respectivamente).

A figura 40 mostra as curvas DSC obtidas para compósitos de matriz fenólica reforçados com fibras de bagaço de cana queimados (CFenBCQ) e não queimados (CFenBC). Nesta curva, também ocorre a sobreposição dos eventos de degradação térmica da fibra e da matriz. Vale relembrar que, para a fibra (Figura 21a) observa-se eventos térmicos decorrentes da decomposição de polissacarídeos (celulose e hemicelulose) a partir de aproximadamente $200{ }^{\circ} \mathrm{C}$, e da degradação da lignina acima de $350{ }^{\circ} \mathrm{C}$. Para os compósitos fenólicos reforçados com bagaço de cana os picos endotérmicos em torno de $310^{\circ} \mathrm{C}$ (Figura 40b) e em torno de $340{ }^{\circ} \mathrm{C}$ (Figura 40d), devem estar relacionados ao processo de cura residual da matriz que pode ocorrer durante a varredura. Um pico exotérmico, por volta de $370{ }^{\circ} \mathrm{C}$, é observado devido reações de decomposição e a consequente liberação de voláteis, tanto da fibra quanto da matriz. 


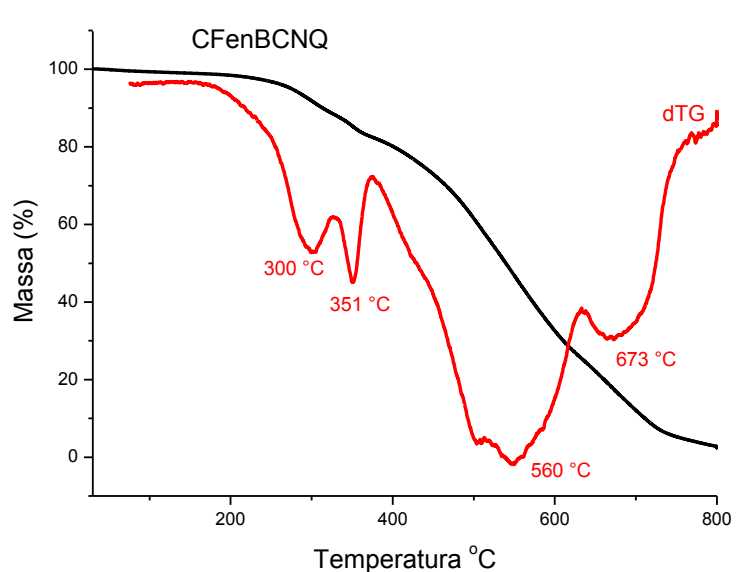

(a)

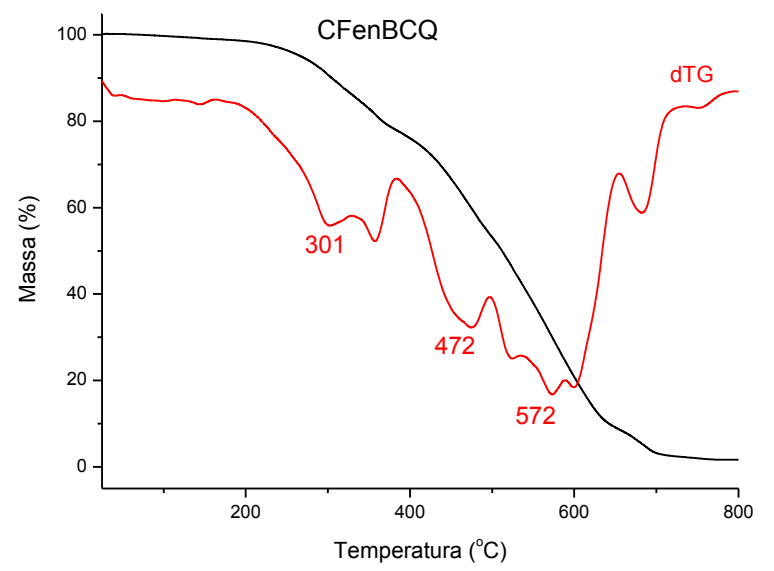

(c)

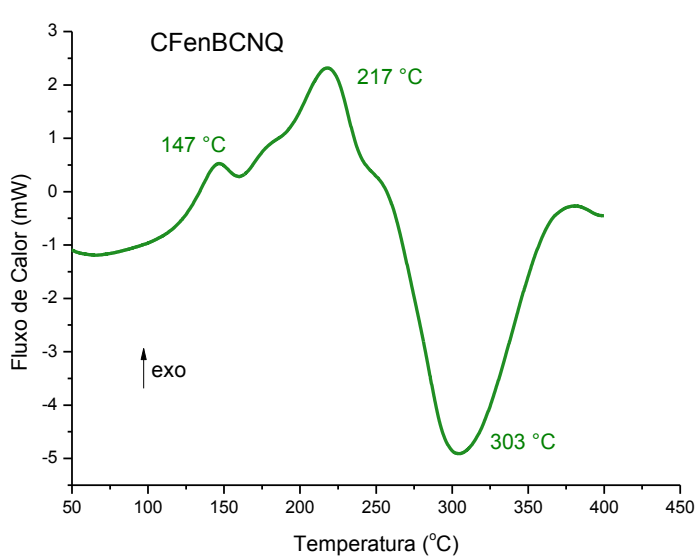

(b)

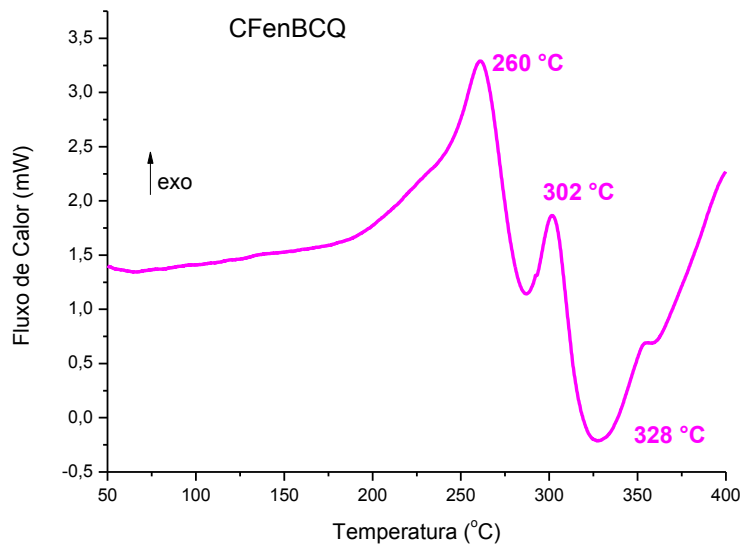

(d)

Figura 40: Curva TG e dTG para o compósito fenólico reforçado com fibras de bagaço de cana-deaçúcar queimada (CFenBCQ) e não queimada (CFenBCNQ), em atmosfera de $\mathrm{N}_{2}$ com $20 \mathrm{~mL} \mathrm{~min}^{-1} \mathrm{e}$ $10{ }^{\circ} \mathrm{C} \min ^{-1}$.

Comparando as curvas dTG dos compósitos da figura 40 com a do termorrígido (Figura 26), observa-se que o termorrígido (pré-polímero curado) apresenta o primeiro pico de decomposição térmica em $540{ }^{\circ} \mathrm{C}$. Quando este termorrígido é reforçado com as fibras lignocelulósicas, a temperatura inicial de decomposição é de aproximadamente $300{ }^{\circ} \mathrm{C}$ (Figura 40a, 40c), pois a decomposição térmica das fibras ocorre em temperaturas menores que do termorrígido. Quando as fibras fazem parte do compósito as temperaturas de início de decomposição podem variar, dependendo da natureza da fibra, tratamento a que a mesma possa ter sido submetida, dentre outros fatores.

A figura 41 apresenta as curvas TG, dTG e DSC para o compósito formaldeídolignossulfonato de sódio reforçado com fibra de bagaço de cana queimado. Nas curvas dTG 
(Figuras 41a, c, e), este compósito apresenta o primeiro pico intenso de perda de massa (26\%) em torno de $300{ }^{\circ} \mathrm{C}$. A presença de frações típicas de lignossulfonato de sódio e fibras de bagaço de cana nos compósitos diminui a temperatura inicial de decomposição.

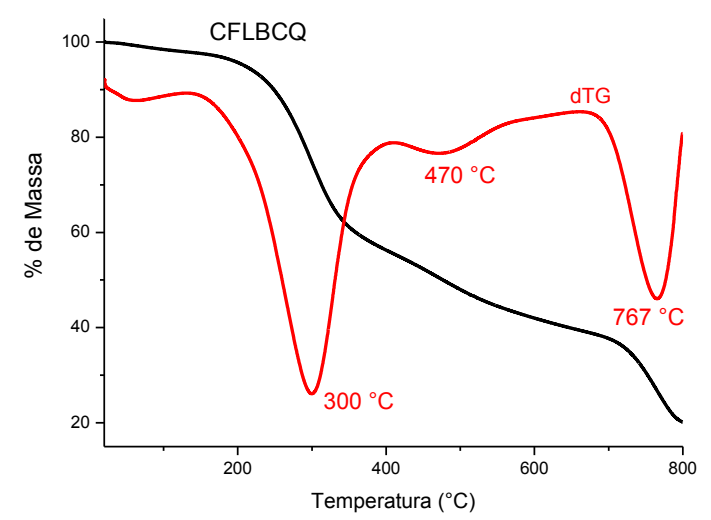

(a)

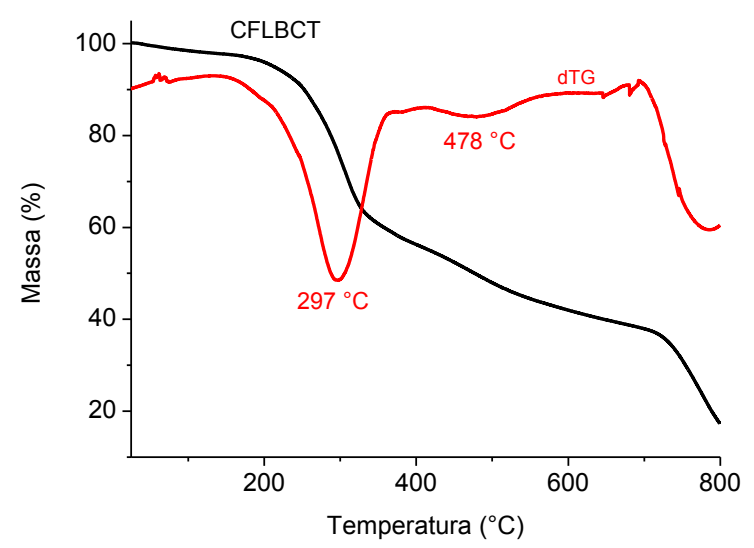

(c)

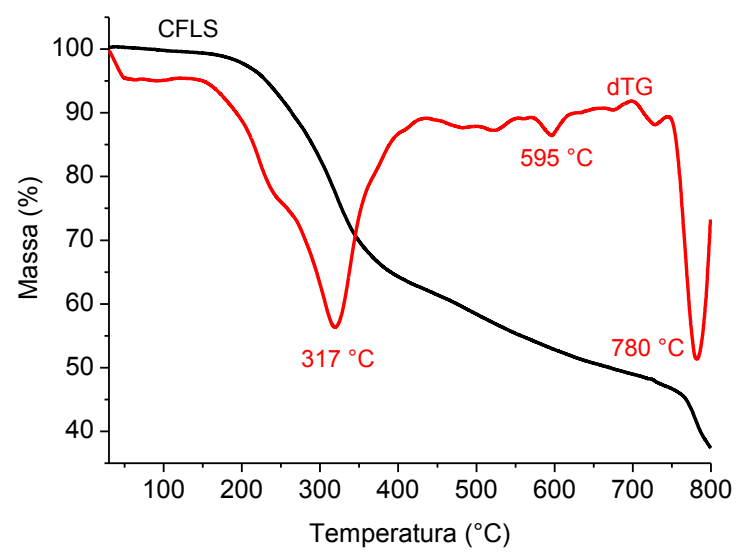

(e)

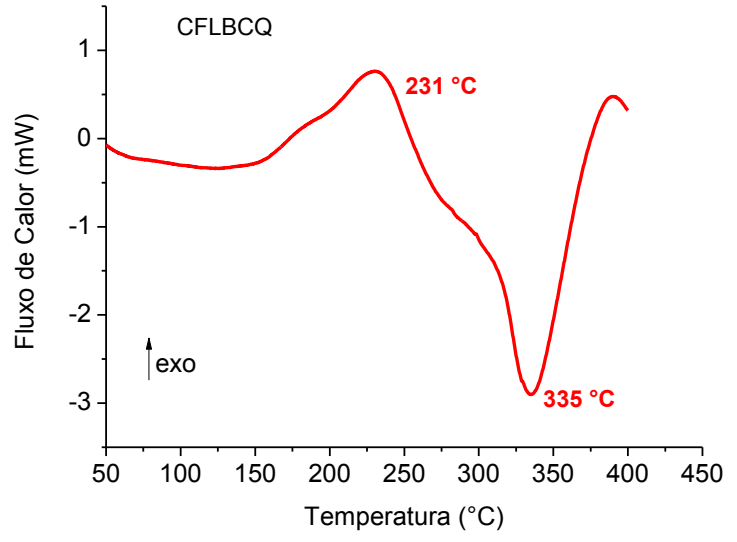

(b)

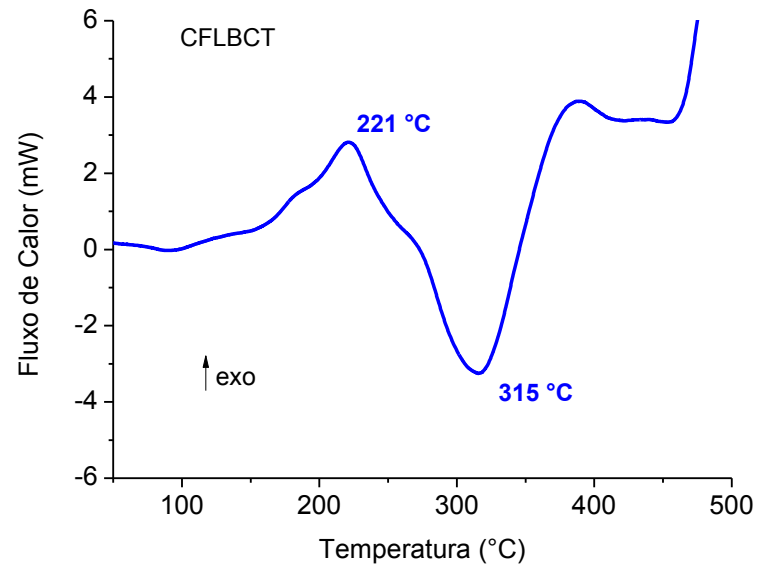

(d)

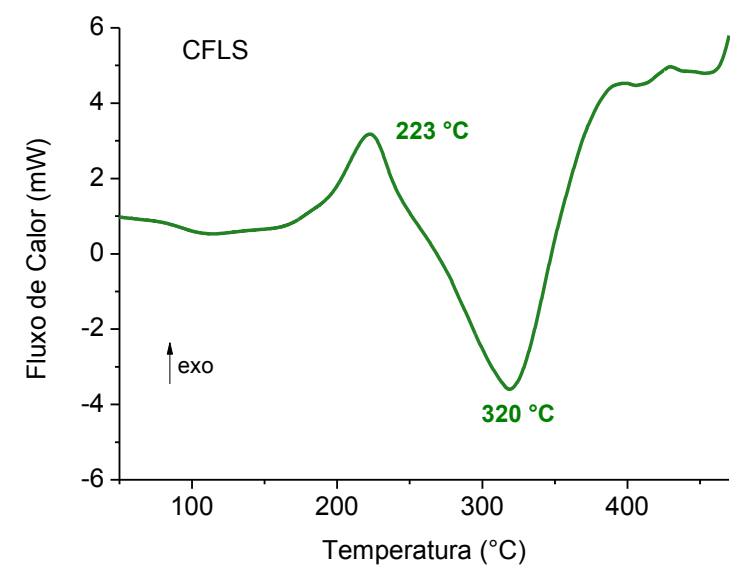

(f)

Figura 41: Curva TG e dTG para o compósito de resina formaldeído-lignossulfonato reforçado com fibras de bagaço de cana queimada (CFLBCQ); queimada e tratada (lignossulfonato de sódio+ ultrassom/1h) (CFLBCT); sisal (CFLS), em atmosfera de $\mathrm{N}_{2}$ com $20 \mathrm{~mL} \mathrm{~min}^{-1}$ e $10{ }^{\circ} \mathrm{C} \mathrm{min}^{-1}$. 
Em $470{ }^{\circ} \mathrm{C}$ observa-se um pico (relativo a perda de massa de 50\%) de decomposição referente às estruturas típicas de lignina (anéis aromáticos). O pico próximo a $765{ }^{\circ} \mathrm{C}$ está relacionado à decomposição final e estruturas características do lignossulfonato de sódio e da matriz do tipo fenólica, também observado na figura 28a.

Para os compósitos CGLBCQ e CGLS (Figura 42), nas curvas TG e dTg, observou-se que em temperaturas superiores a $300{ }^{\circ} \mathrm{C}$ inicia um novo estágio de perda de massa, provavelmente devido à quebra de ligações típicas de frações de lignina presente na matriz. Em temperaturas mais elevadas (em torno de $550{ }^{\circ} \mathrm{C}$ ) ocorre a decomposição dos anéis aromáticos da matriz. Um pico é observado acima de $750{ }^{\circ} \mathrm{C}$, possivelmente decorrente da decomposição dos anéis aromáticos presentes na matriz, devido à presença do lignossulfonato de sódio, pois o mesmo é característico da decomposição do lignossulfonato de sódio tendo sido observado na dTG da figura 28a. 


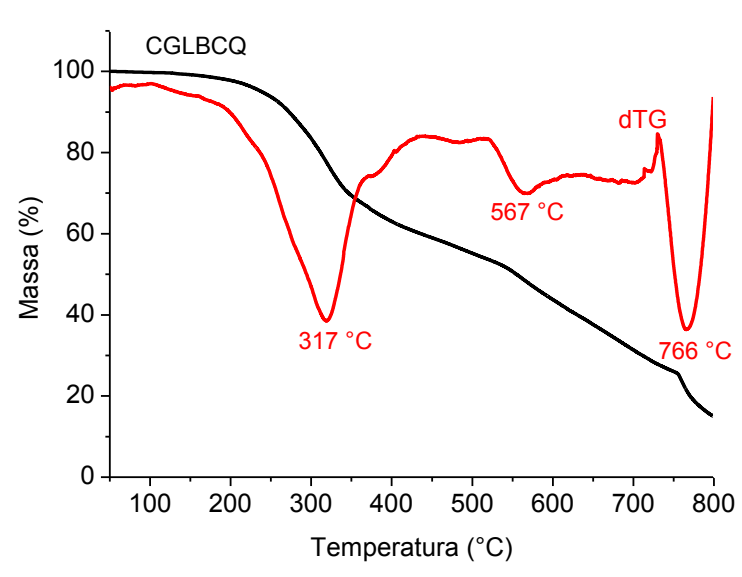

(a)

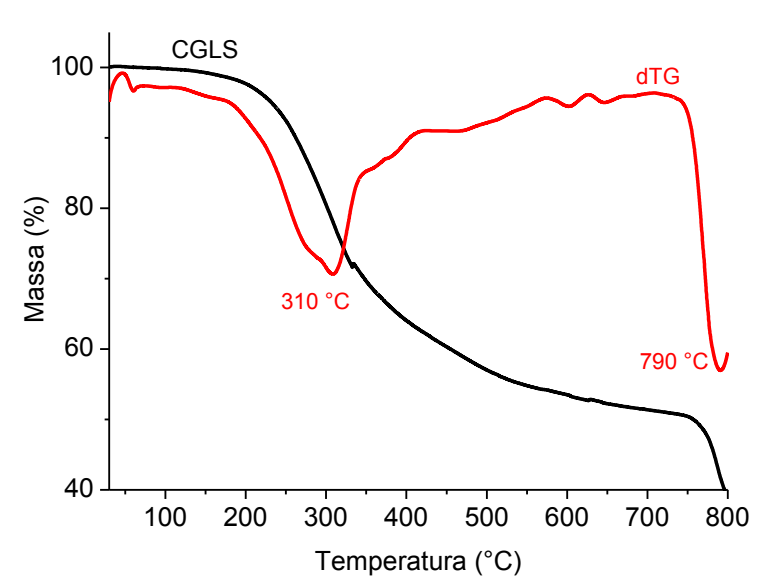

(c)

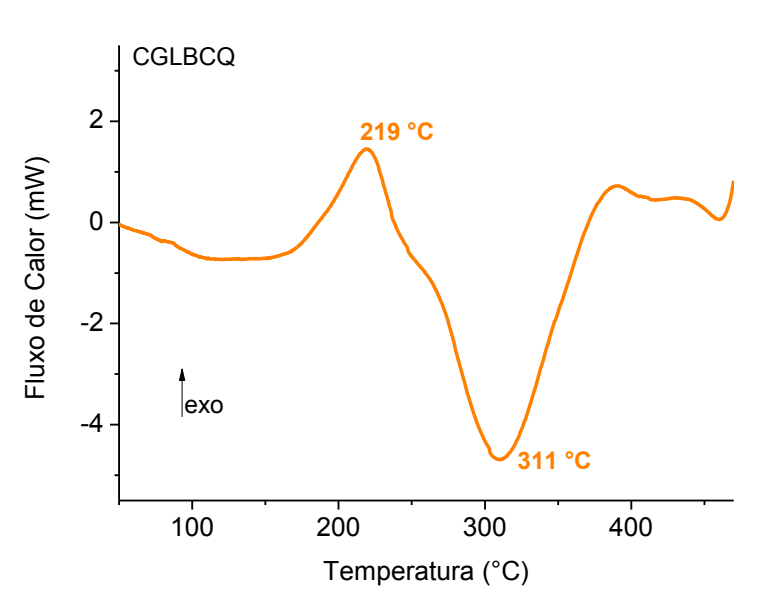

(b)

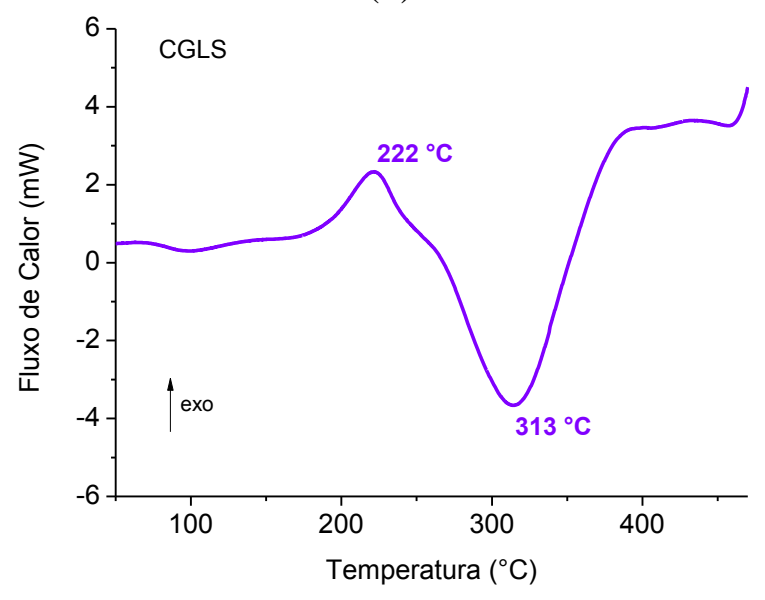

(d)

Figura 42: Curva TG, dTG e DSC para o compósito de resina glutaraldeído-lignossulfonato de sódio reforçado com fibras de bagaço de cana queimada (CGLBCQ); compósito glutaraldeídolignossulfonato sisal (CGLS), em atmosfera de $\mathrm{N}_{2}$ com $20 \mathrm{~mL} \mathrm{~min}^{-1}$ e $10{ }^{\circ} \mathrm{C} \mathrm{min}{ }^{-1}$.

Nos demais compósitos preparados com glutaraldeído (Figuras 42c e 42d) o mesmo comportamento já discutido é observado nas curvas dTG, em toda extensão da análise. A mudança de formaldeído para glutaraldeído no preparo da resina não alterou a estabilidade térmicas dos materiais.

A partir das resinas formaldeído-lignina organossolve e glutaraldeído-lignina organossolve foram preparados os compósitos reforçados com fibras de bagaço de cana queimado e sisal, e os resultados de TG, dTG e DSC estão apresentadas nas figuras 43 e 44, respectivamente. 
As curvas referentes aos compósitos apresentados nas figuras 43a e 43c mostram que os mesmos apresentam pequena perda de massa inicial $(0,5 \%)$ decorrente da umidade absorvida pelos compósitos. As fibras lignocelulósicas contribuem para com a retenção de umidade do material, por possuírem características higroscópicas. Nas análises de TG somente das fibras (Figura 20) observou-se que a perda de massa neste mesmo estágio $\left(100^{\circ} \mathrm{C}\right)$ é de $3,0 \%$, maior que a obtida para os compósitos $(0,5 \%)$, pois nos compósitos as fibras estão protegidas pela matriz polimérica, diminuindo a interação com moléculas de água. A mesma observação feita, de perda de massa inicial, pode ser levada em consideração para os compósitos apresentados na figura 44 (CFLOS e CGLOS).

Os picos da curva TG indicam uma perda de massa acentuada, de 15 e 39\%, no intervalo de temperatura entre 300 e $400{ }^{\circ} \mathrm{C}$, respectivamente. Esta perda de massa é decorrente da decomposição de macromoléculas (celulose, hemicelulose e lignina), presentes nas fibras. Agregado a esta etapa ocorre à decomposição térmica de estruturas típicas de lignina que não reagiram presentes na matriz. Picos apresentados nas curvas dTG acima de $400{ }^{\circ} \mathrm{C}$ estão ligados à perda de massa (mais de 45\%) decorrente da decomposição cadeias poliméricas e anéis aromáticos (típicos da estrutura da lignina) que compõem a matriz. Estes eventos são observados para todos os compósitos apresentados nas figuras 43 e 44 .

Comparando estes compósitos com os compósitos fenólicos (reforçados com o mesmo tipo de fibra) (Figura 43) é observado que a estabilidade térmica diminui devido à presença de estruturas típicas da lignina organossolve (Figura 30a) ou do lignossulfonato de sódio (Figura 28a), embora ainda se mantenha em um intervalo que não prejudique aplicações. 


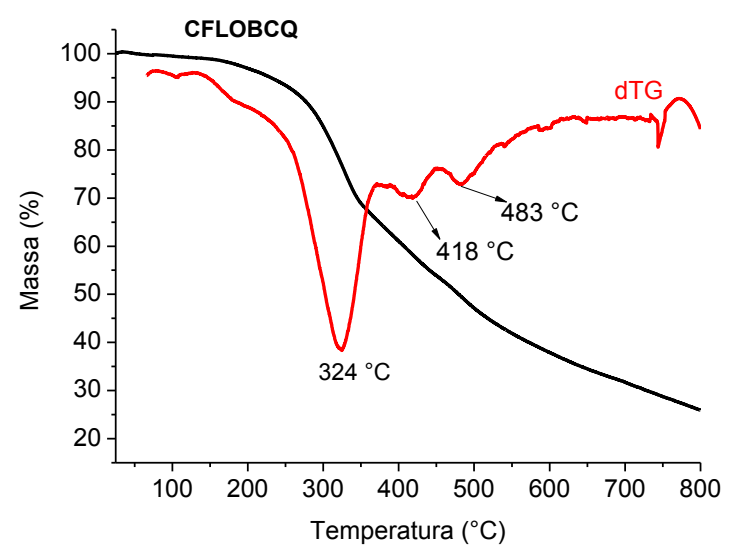

(a)

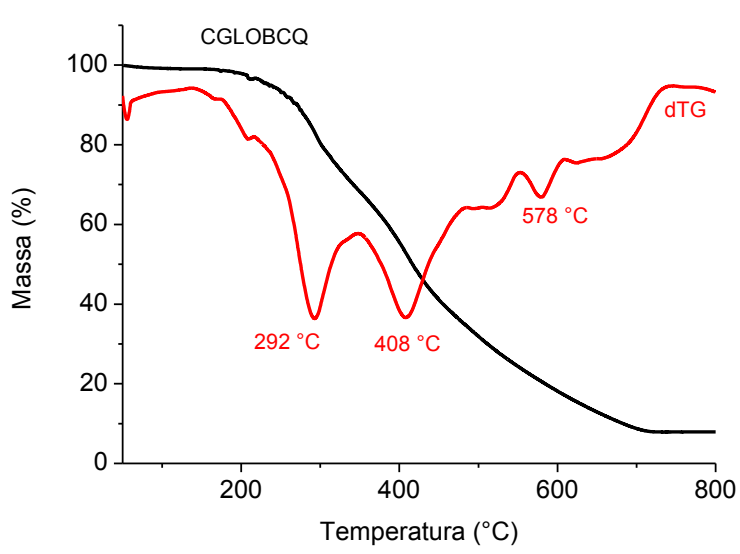

(c)

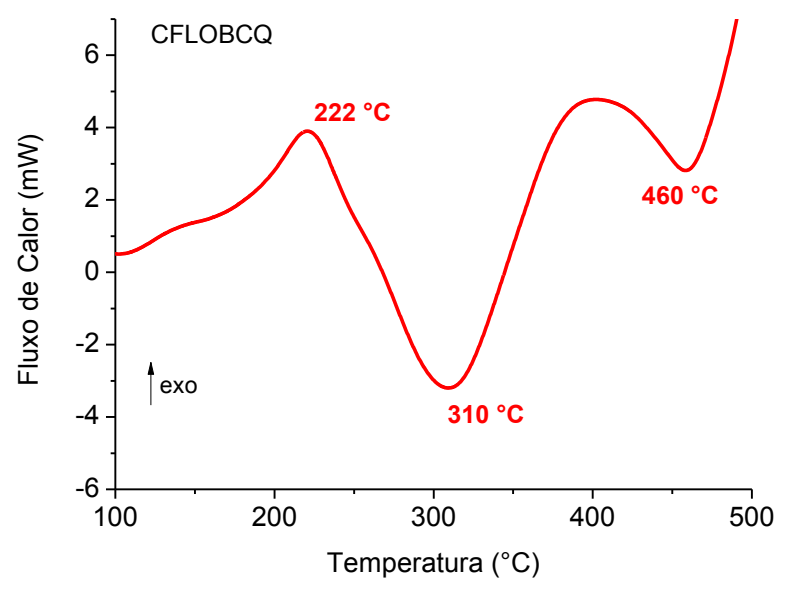

(b)

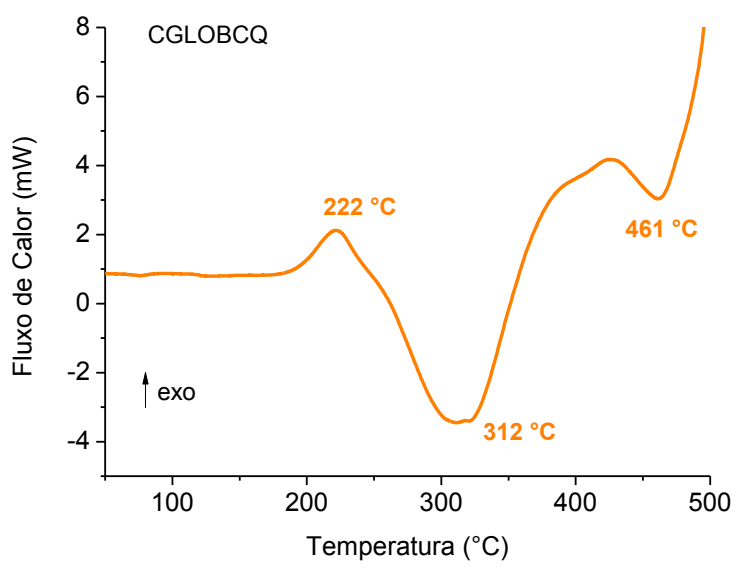

(d)

Figura 43: Curva TG, dTG (Derivada Primeira) e DSC para o compósito de resina formaldeído-lignina organossolve reforçado com fibras de bagaço de cana queimada (CFLOBCQ); compósito glutaraldeído-lignina organossolve reforçado com fibras de bagaço de cana queimada (CGLOBCQ), em atmosfera de $\mathrm{N}_{2}$ com $20 \mathrm{~mL} \mathrm{~min}^{-1}$ e $10{ }^{\circ} \mathrm{C} \mathrm{min}^{-1}$.

O mesmo tipo de matriz foi utilizado (formaldeído-lignina organossolve e glutaraldeído-lignina organossolve) mudando o tipo de reforço, de fibra de bagaço de cana queimado, para fibra de sisal. As fibras de sisal apresentam uma porcentagem menor no teor de lignina em sua composição (Tabela 6). A mudança de fibra como reforço não alterou a estabilidade térmica do material final.

Através das curvas dTG (Figura 44) é possível observar que o pico de maior intensidade, o qual indica o inicio de decomposição do compósito, permanece em torno de $330{ }^{\circ} \mathrm{C}$, sendo referente a uma perda de massa de 19 e $30 \%$ para CFLOS e CGLOS, respectivamente. 


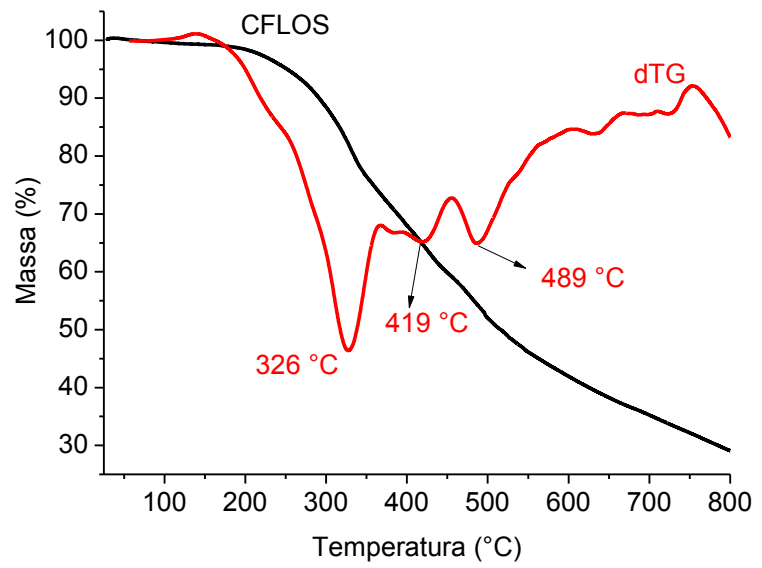

(a)

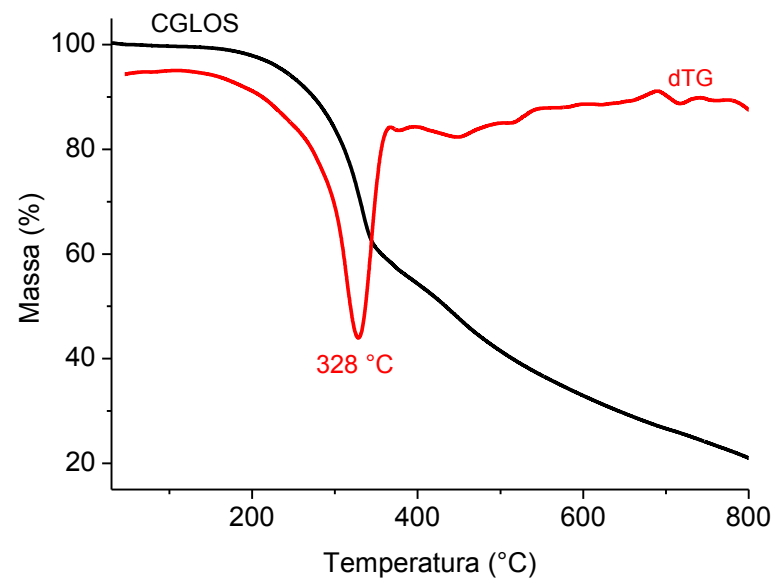

(c)

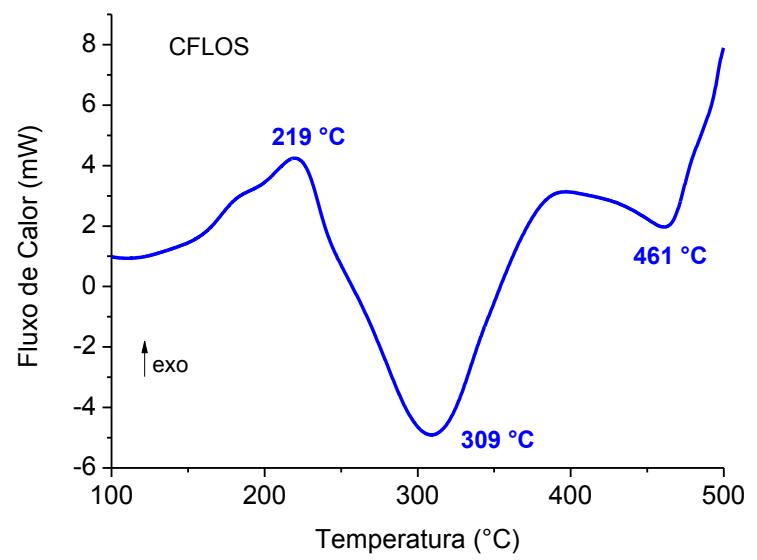

(b)

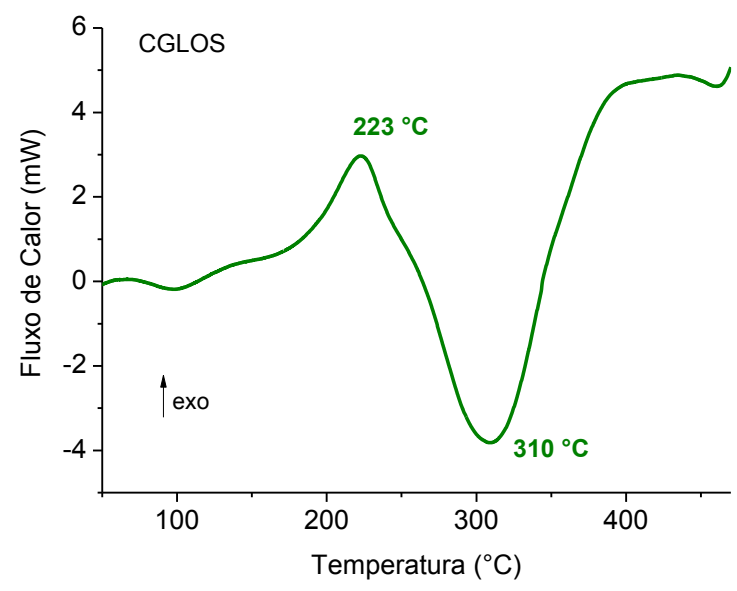

(d)

Figura 44: Curva TG, dTG e DSC para o compósito de resina glutaraldeído-lignina organossolve com fibra de sisal (CGLOS) e formaldeído-lignina organossolve reforçado com fibra de sisal (CFLOS), em atmosfera de $\mathrm{N}_{2} \operatorname{com} 20 \mathrm{~mL} \min ^{-1}$ e $10{ }^{\circ} \mathrm{C} \mathrm{min}^{-1}$.

Os eventos endo e exotérmicos observados nas curvas DSC para os compósitos reforçados com bagaço de cana queimado (Figura 43) são também observados nos compósitos reforçados com fibras de sisal (Figura 44).

$\mathrm{Na}$ figura $44 \mathrm{~b}$ e $44 \mathrm{~d}$ o primeiro evento observado é um pico exotérmico, provavelmente correspondente à etapa de cura residual da matriz, e decomposição de hemicelulose presentes nas fibras de bagaço (Figura 21a) ou de sisal (Figura 21b), que ocorrem em torno de $220{ }^{\circ} \mathrm{C}$.

$\mathrm{O}$ pico endotérmico em torno de $310^{\circ} \mathrm{C}$ (Figura 44) corresponde à volatilização de moléculas de baixa massa molar, como moléculas de água, somado aos voláteis gerados na decomposição da celulose presente nas fibras lignocelulósicas. Em temperaturas acima de 460 
${ }^{\circ} \mathrm{C}$, os picos observados nas curvas DSC são referentes a eventos de decomposição, tanto da fibra quanto da matriz, e estão provavelmente relacionados à decomposição de anéis aromáticos.

\section{8. Propriedades mecânicas dos compósitos}

\section{8. 1. Compósitos de matriz fenólica}

Compósitos de matriz fenólica foram preparados utilizando fibras de bagaço de cana como reforço. Estas fibras são provenientes de duas fontes distintas, conforme já informado anteriormente, sendo que uma delas passou pelo processo de queima antes da colheita.

Esta etapa do trabalho teve como finalidade avaliar se o processo de queima das fibras pode influenciar nas propriedades mecânicas dos compósitos de matriz fenólica preparados. Para estes compósitos, variou-se a porcentagem de fibra no compósito, avaliando-se assim a proporção ideal de fibra para o preparo.

As fibras que não passaram pelo processo de queima são mais longas, sendo assim possível variar o comprimento das fibras (de 1 a $5 \mathrm{~cm}$ ) e avaliar qual o comprimento ideal de fibra para preparo em compósito.

\section{8. 1. 1. Compósitos reforçados com fibras de bagaço de cana queimado}

\section{(CFenBCQ)}

Os compósitos fenólicos foram reforçados com fibras de bagaço de cana queimada variando a porcentagem de fibra (30, 50 e 70\%, em massa) sendo na sequência caracterizados.

\section{8. 1. 1. 1. Ensaio de Impacto Izod}

O ensaio de impacto é um dos testes importantes para avaliar a resistência de novos materiais poliméricos. $\mathrm{O}$ valor de resistência ao impacto representa a capacidade total que o material tem absorver a energia de impacto (HAGE, 2004). 
A resistência ao impacto dos compósitos é determinada pela energia total dissipada no material antes da fratura final ocorrer. A energia total absorvida pelo material é a soma da energia dinâmica dissipada (choque) e a energia consumida durante a deformação plástica, mais a energia para a criação de novas superfícies. Os mecanismos de fratura gerados durante o impacto incluem rachaduras na matriz, descolamento fibra/matriz, quebra da fibra e o mecanismo de pull-out da fibra (PAIVA, 2002).

Os compósitos foram ensaiados segundo a norma ASTM D256 obtendo-se os resultados da figura 48. A resistência ao impacto do termorrígido fenólico foi de $25 \mathrm{Jm}^{-1}$. Os resultados indicam (Figura 45) que a resistência ao impacto dos compósitos aumenta com o aumento da porcentagem de fibra na matriz, indicando que a contribuição das fibras curtas de bagaço de cana é significativa.

Destaca-se a alta porcentagem de fibras naturais (até $70 \%$ em massa) substituindo a matriz, no compósito preparado a partir de fenol e formaldeído, que corresponde a matéria prima não oriunda de fontes renováveis.

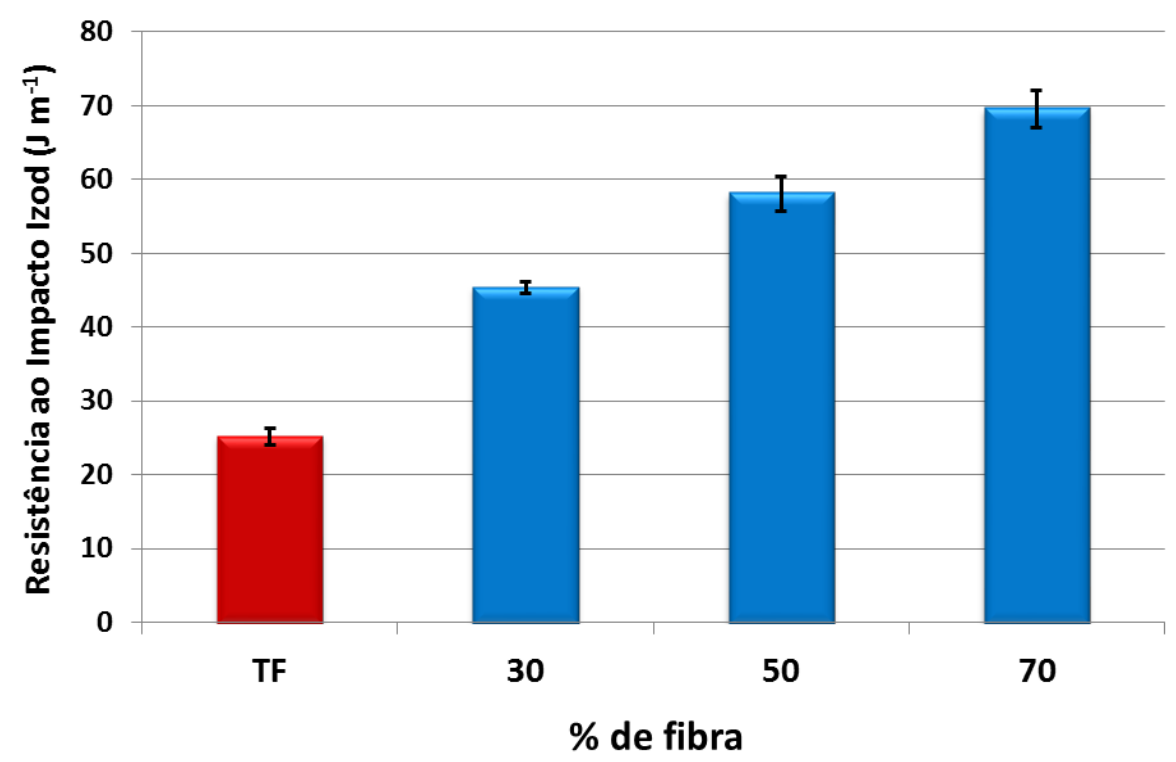

Figura 45: Resistência ao impacto Izod para termorrígido fenólico (TF) e compósitos reforçados com fibras de bagaço de cana queimadas $(\mathbf{C F e n B C Q})(1,5 \mathrm{~cm})$ em função da porcentagem de fibra (em massa) na matriz. 
Como será visto nas imagens de MEV (Figura 46) o aumento na quantidade de fibras praticamente não levou a interação fibra/fibra. A fibra de bagaço apresentou um bom comportamento no que se refere à molhabilidade pela resina. Ainda, o alto teor de lignina (21\%) na fibra, favorece a interação com a matriz, também rica em anéis aromáticos.

Um estudo similar foi realizado por Akesson et al. (2010) sobre compósitos de matriz fenólica reforçados com fibras de linho, tendo como principal objetivo preparar compósitos com alta porcentagem de fibra. Resultados de compósitos reforçados com 57, 62, 70 e 75\% (em massa) de fibra são apresentados, mostrando o aumento de resistência ao impacto até o compósito com $70 \%$ de fibra. O autor atribui o aumento nas propriedades mecânicas como resultado da boa adesão das fibras com a matriz na interface. O compósito com $75 \%$ teve sua propriedade mecânica diminuída drasticamente, o autor atribui a este fato de que a fibra não foi impregnada eficientemente, o que foi comprovado por imagens de MEV.

O tratamento das fibras é aplicado na maioria das vezes com o propósito de tornar o processo de impregnação das fibras mais eficiente, melhorando assim a interface entre a fibra e a resina. O tratamento das fibras de bagaço de cana com lignossulfonato de sódio foi usado neste trabalho, buscando-se melhores resultados de propriedades mecânicas (os resultados serão apresentados posteriormente).

\section{8. 1. 1. 2. $M E V$}

As imagens de microscopia eletrônica de varredura podem revelar o comportamento da região de fratura dos compósitos. As fraturas em compósitos podem ser afetadas por diferentes variáveis, tais como a natureza das fibras e da matriz, a presença de "voids" (vazios), a interação fibra/matriz, propagação de trincas, entre outros. Esta técnica pode revelar possíveis falhas de processamento na obtenção dos materiais.

Os compósitos reforçados com fibras de bagaço de cana queimada também foram analisados na região de fratura (Figura 46), após o ensaio de impacto. Em geral, os 
compósitos, independente da porcentagem de fibras, mostraram uma interação satisfatória das fibras com a matriz, e distribuição homogênea das fibras. Além disso, os compósitos apresentaram bom recobrimento das fibras pela resina polimérica (indicado pela seta azul, Figura 46b), e preenchimento das cavidades das mesmas, indicado pelas setas amarelas (Figura 46a).

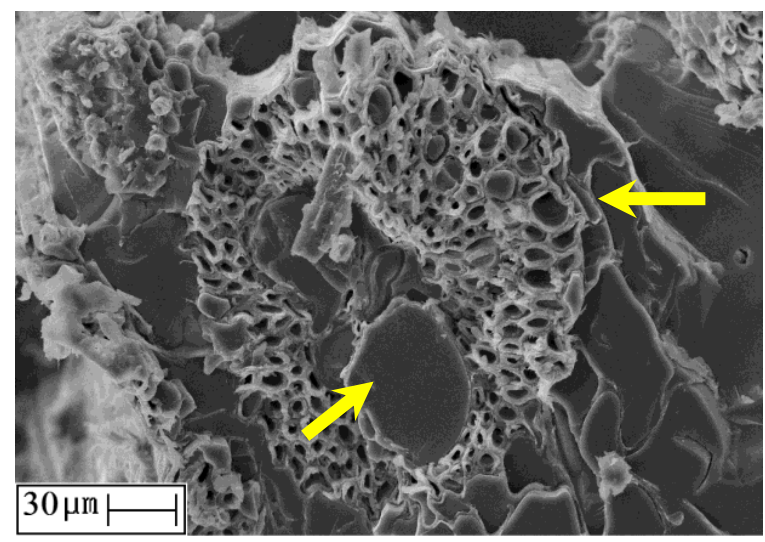

(a)

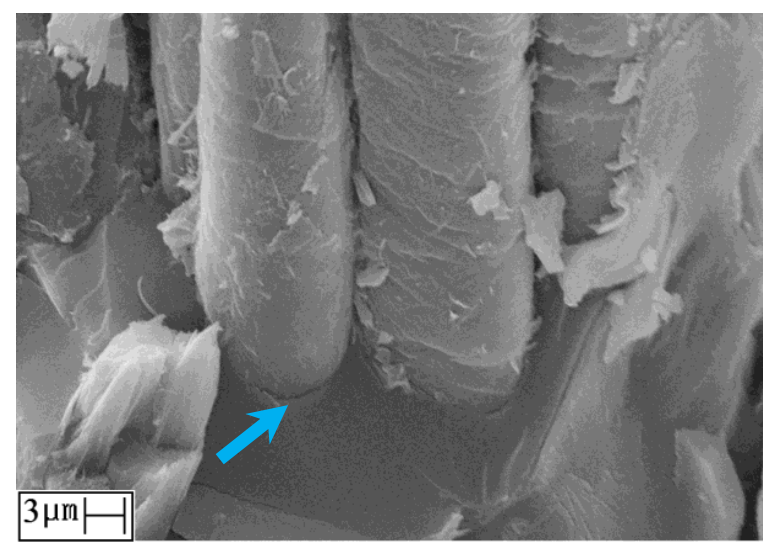

(b)

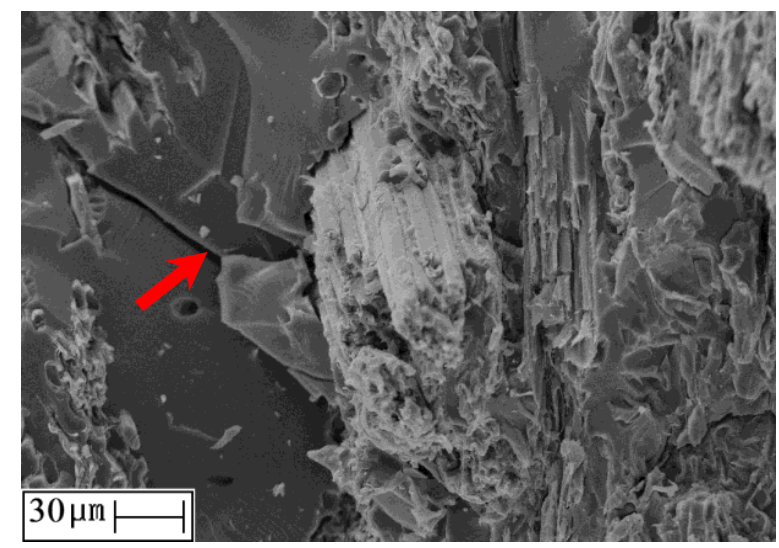

(c)

Figura 46: Micrografias da região de fratura dos compósitos fenólicos reforçados com fibra de bagaço de cana queimada (CFenBCQ), (a) 30\%; (b) 50\%; (c) $70 \%$.

$\mathrm{Na}$ maioria das imagens, observa-se que as fibras romperam no mesmo plano de fratura da matriz ou bem próximo deste, com pouquíssimas fibras arrancadas. Apenas o compósito com $70 \%$ de fibras apresentou poucas regiões de descolamento das fibras da matriz e propagação de trincas em algumas regiões (Figura 46c), indicado pela seta vermelha. 


\section{8. 1. 1. 3. DMTA}

A técnica de DMTA é amplamente utilizada para a caracterização de materiais poliméricos, reforçados ou não. Esta técnica foi utilizada neste trabalho com a finalidade de avaliar as propriedades dos materiais poliméricos reforçados com fibras lignocelulósicas quando sujeito a solicitação dinâmica em relação à temperatura. Alguns parâmetros podem ser avaliados a partir dos resultados obtidos pela análise, tais como, rigidez, grau de entrecruzamento, temperatura de transição vítrea, entre outros. O comportamento de compósitos reforçados foi avaliado por esta técnica e os resultados serão apresentados a seguir.

Os compósitos preparados com fibras de bagaço de cana queimada, variando a porcentagem em massa de fibra na matriz (de 30, 50 e 70\%, em massa) foram analisados por DMTA. Os módulos de armazenamento (E'), perda (E”) e tan $\delta$ estão apresentados na figura 47. 


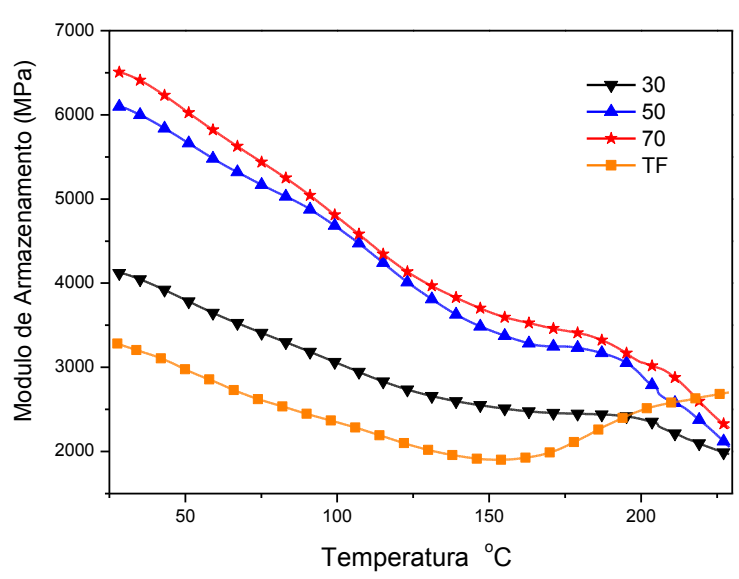

(a)

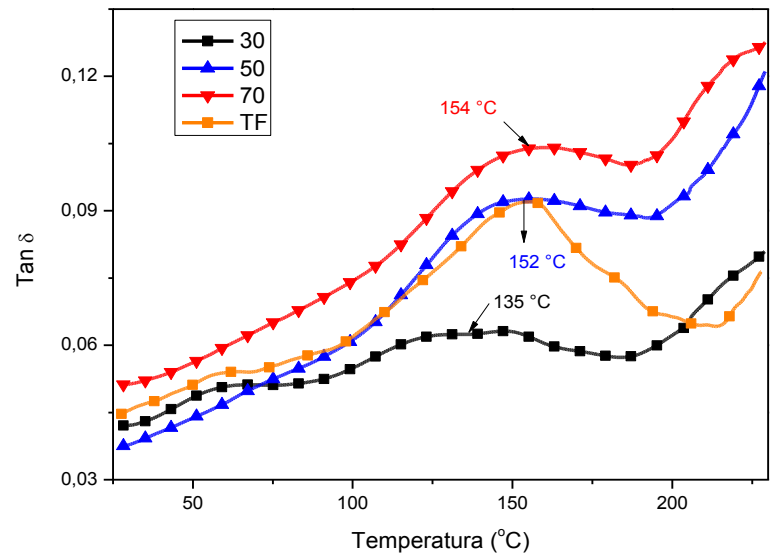

(b)

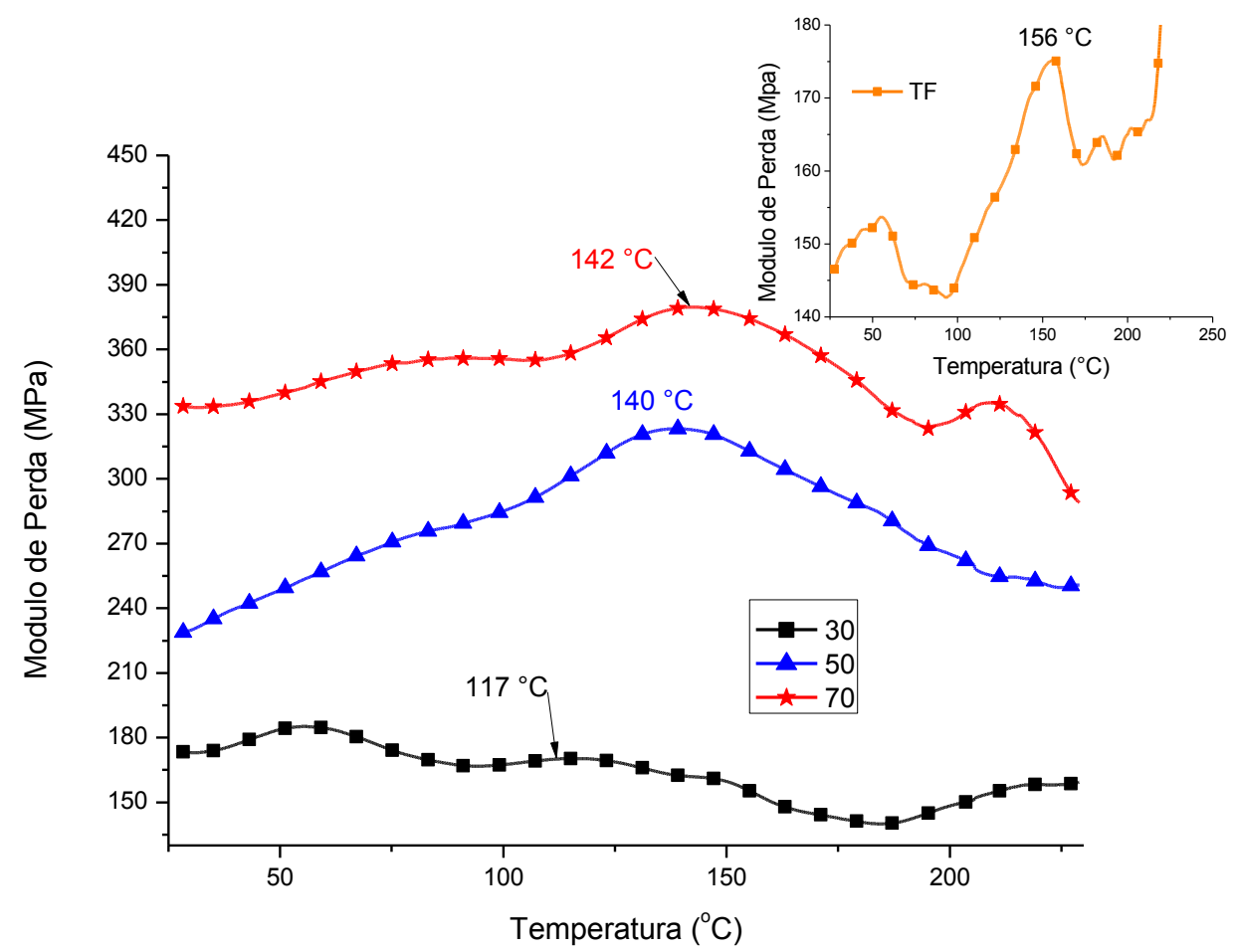

(c)

Figura 47: (a) Módulo de Armazenamento (E’); (b) Módulo de Perda E” e (c) tan $\delta$ em função da temperatura para compósitos fenólicos reforçados com fibras de bagaço de cana queimada (CFenBCQ): 30, 50 e 70\% em massa; comprimento médio de 1,5cm e termorrígido fenólico (TF).

O módulo de armazenamento (E') para estes compósitos aumenta proporcionalmente ao aumento da porcentagem de fibras na matriz. A incorporação de fibras na matriz torna o material mais rígido e quanto maior a porcentagem de material acrescentado, maior a rigidez, maior E'. Valores obtidos a partir da curva E' na temperatura inicial da análise $\left(25^{\circ} \mathrm{C}\right)$ está apresentados na tabela 22 , mostrando o aumento no módulo a $25^{\circ} \mathrm{C}$, conforme aumenta o teor de fibras. 
Tabela 22: Valores de Módulo de Armazenamento (E' em $25^{\circ} \mathrm{C}$ ) para compósitos fenólicos reforçados com fibras de bagaço de cana queimada (CFenBCQ): 30, 50 e 70\% em massa; comprimento médio de $1,5 \mathrm{~cm}$.

\begin{tabular}{c|c}
\multicolumn{2}{|c}{$\mathrm{E}^{\prime}\left(\mathrm{GPa}, \mathbf{2 5}^{\circ} \mathrm{C}\right)$} \\
\hline $\mathbf{3 0 \%}$ & 4,1 \\
\hline $\mathbf{5 0 \%}$ & 6,1 \\
\hline $\mathbf{7 0 \%}$ & 6,5 \\
\hline
\end{tabular}

Na figura 50c observa-se que o módulo de perda aumenta de acordo com o aumento de fibras adicionadas ao compósito. Para porcentagens de fibras mais elevadas o processo de impregnação das fibras pela resina é dificultado, podendo resultar em compósitos com maior número de defeitos. O compósito com maior quantidade de fibra (70\%) apresentou maior módulo de perda, provavelmente devido ao maior número de defeitos gerados por pontas de fibras e microtrincas (visto nas micrografias de MEV). Os defeitos podem contribuir para um maior amortecimento, dissipando energia através do atrito.

A figura 47 mostra a diferença entre os compósitos e o termorrígido fenólico no pico de módulo de perda e $\tan \delta$. O alargamento do pico do módulo de perda, assim como para as curvas de $\tan \delta$, está relacionado à homogeneidade da estrutura do material em questão. Quanto mais estreito for o pico, pode ser considerada mais homogênea a estrutura do material. Os compósitos fenólicos reforçados com fibras de bagaço de cana queimado apresentam picos mais alargados que o termorrígido fenólico, evidenciando que estes possuem uma estrutura mais heterogênea quando comparado ao termorrígido. Este comportamento deve-se ao fato do menor volume de matriz (ou maior volume de fibras) que torna o estabelecimento de ligações entrecruzadas mais difícil, resultando em um material mais heterogêneo. Ainda o comportamento das camadas da matriz mais próximas e mais distantes das fibras é diferenciado, o que também contribui para o alargamento dos picos (Figura 47).

A Tg nos compósitos pode ser determinada a partir da curva de E” versus a temperatura para este conjunto de compósitos, esta ocorre em torno de $117{ }^{\circ} \mathrm{C}, 140{ }^{\circ} \mathrm{C}, 142{ }^{\circ} \mathrm{C}$. Para os compósitos de 30\%, 50\% e 70\%, respectivamente, o que corresponde a um deslocamento para 
maior temperatura, comparativamente ao termorrígido $\left(156{ }^{\circ} \mathrm{C}\right.$, Figura $\left.47 \mathrm{c}\right)$. Para termorrígidos, esta temperatura se refere a movimentação de segmentos entre os pontos de entrecruzamento. Os valores encontrados indicam que a presença de fibras pode ter facilitado a movimentação dos segmentos de camadas mais distantes das fibras, diminuindo a Tg.

\section{8. 1. 1. 4. Resistência à flexão dos compósitos}

A resistência à flexão de um material corresponde à capacidade do material de resistir à força aplicada perpendicularmente ao eixo horizontal.

A figura 48 mostra os resultados de resistência à flexão dos compósitos fenólicos reforçados com fibras de bagaço de cana queimada com porcentagens de fibras de $30 \%, 50 \%$ e $70 \%$.

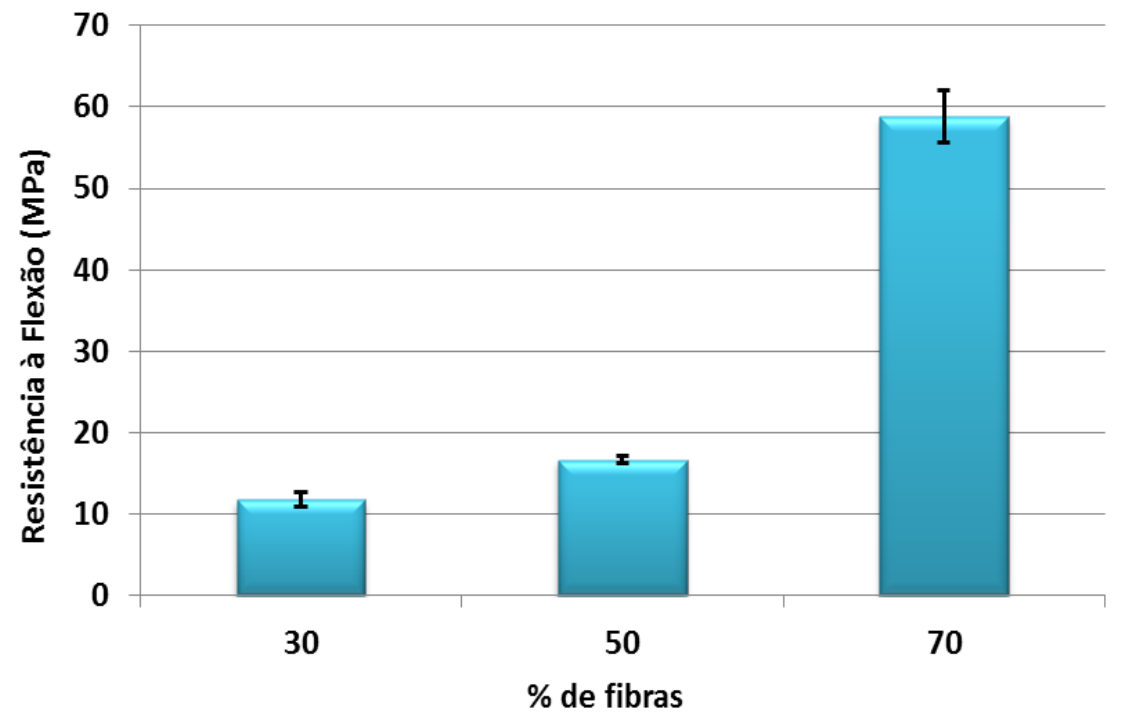

Figura 48: Resultado do ensaio de resistência à flexão (MPa) dos compósitos fenólicos reforçados com fibras de bagaço de cana queimado (CFenBCQ) (30, 50 e 70\%, em massa).

O ensaio mostrou que o aumento gradativo na quantidade de fibras de bagaço de cana como reforço elevou capacidade do compósito em resistir à força aplicada. O ensaio de flexão não foi possível realizar para o termorrígido fenólico (matriz fenólica sem reforço fibroso) neste trabalho. Em ensaios realizados para termorrígido fenólico por Joseph et al. (2002) e 
Oliveira (2010) foram obtidos valores de resistência à flexão de 10 e 16 Mpa, respectivamente. No presente trabalho, a substituição de $70 \%$ (em massa) da matriz, por fibras, elevou consideravelmente a resistência à flexão.

Através do ensaio de flexão também é possível obter informações sobre o módulo de flexão (ou elasticidade) dos materiais (Figura 49). Este módulo avalia a rigidez do material, obtido, a partir do coeficiente angular da porção linear inicial da curva tensão-deformação.

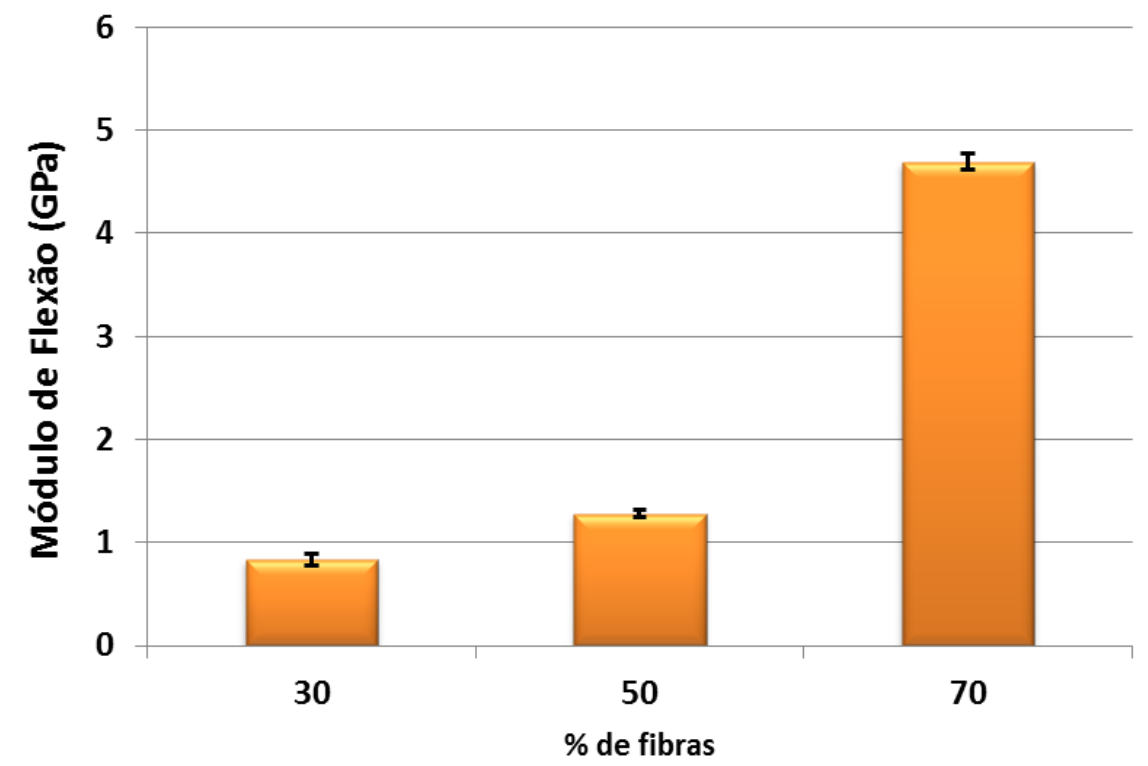

Figura 49: Resultados de módulo de elasticidade (GPa) obtidos a partir do ensaio de resistência à flexão dos compósitos fenólicos reforçados com fibras de bagaço de cana queimado (CFenBCQ) (30, 50 e $70 \%$, em massa).

Um comportamento semelhante à resistência a flexão é observado para o módulo de flexão, com destaque para o resultado do compósito com $70 \%$ de fibra. Vale ressaltar que o mesmo comportamento, de aumento de rigidez no material, é observado nos resultados de DMTA avaliado pelo módulo de armazenamento (E') a $25{ }^{\circ} \mathrm{C}$ (Figura 47), porém o compósito reforçado com 50\% de fibra apresentou módulo de armazenamento próximo àquele reforçado com $70 \%$ de fibra. 


\section{8. 1. 1. 5. Absorção de água}

Os compósitos preparados com resina fenólica e reforçados com fibras de bagaço de cana queimado (30, 50 e 70\%) foram ensaiados com a finalidade de avaliar a afinidade destes materiais por água. A figura 50 apresenta os resultados do ensaio de absorção de água, até o ponto de saturação. O gráfico mostra a porcentagem de absorção de água para o termorrígido fenólico, matriz sem reforço fibroso. A porcentagem de água absorvida pelo termorrígido é extremamente baixa, quando comparado aos compósitos. A adição de fibras à matriz polimérica eleva a porcentagem de água que o material absorve devido ao fato de as fibras possuírem um caráter hidrofílico, devido à presença de grande quantidade de grupos polares em sua estrutura. Deve-se ressaltar que neste ensaio foram usadas condições mais drásticas que aquelas normalmente encontradas nas aplicações, pois corpos de prova sem proteção lateral foral imersos em água. 


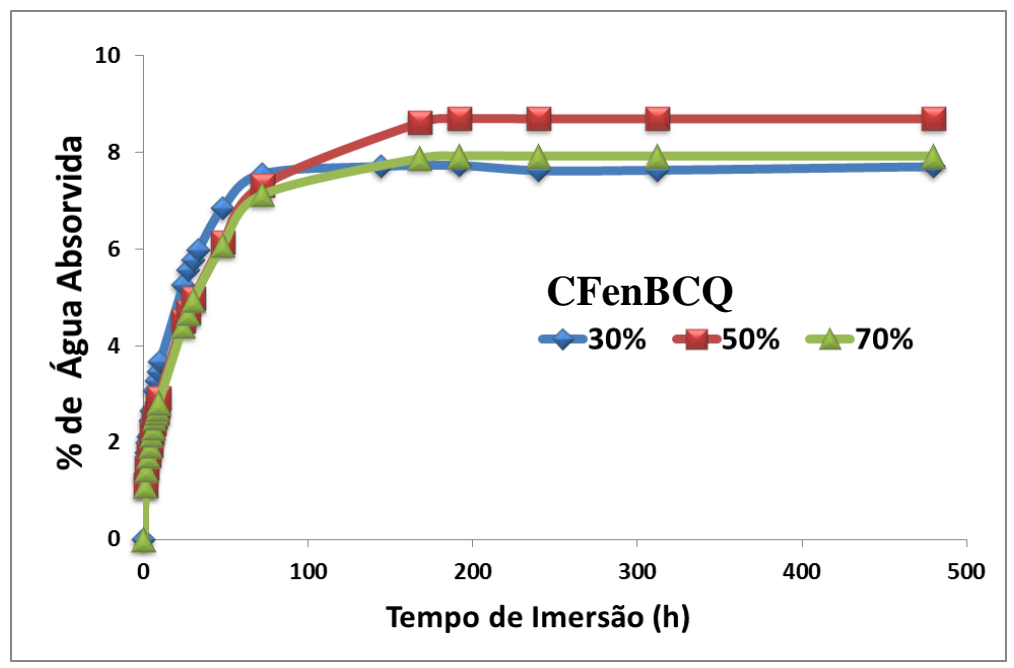

(a)

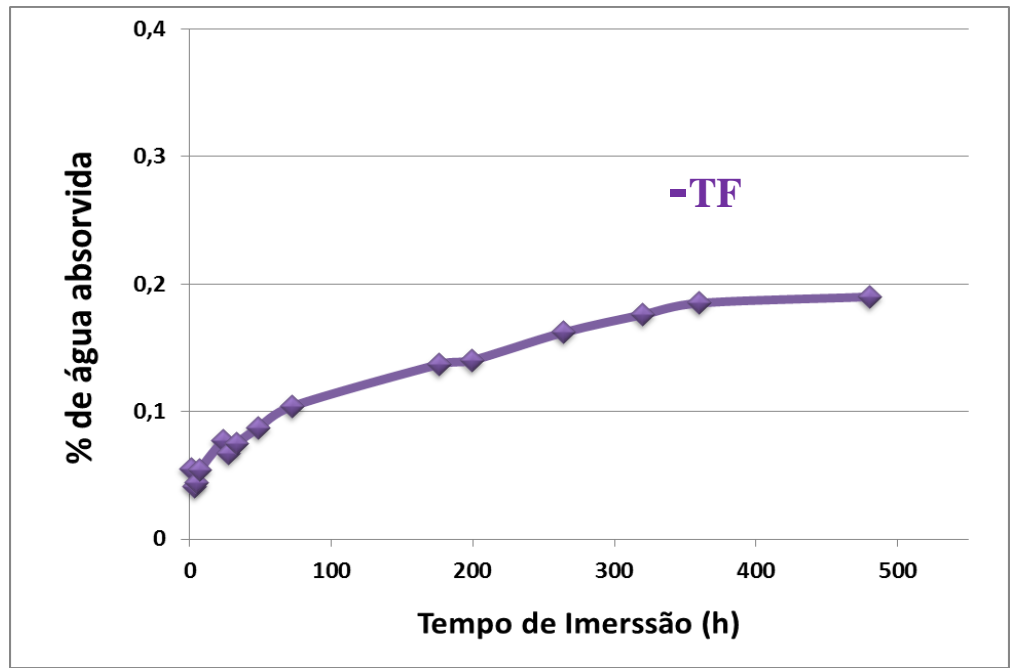

(b)

Figura 50: Resultado do ensaio de absorção de água: (a) compósitos fenólicos reforçados com fibras de bagaço de cana queimado (CFenBCQ) (30, 50 e 70\%, em massa) e (b) termorrígido fenólico (TF).

Nos resultados de absorção de água, seria esperada uma grande diferença na porcentagem de água absorvida pelos compósitos, devido à diferença na quantidade de fibras. No entanto, os resultados mostraram que a quantidade de fibras não exerceu muita influência na quantidade de água absorvida.

5. 8. 1. 2. Compósitos reforçados com fibras de bagaço de cana não queimado

\section{(CFenBCNQ)}

Atualmente dois tipos de bagaço de cana de açúcar podem ser obtidos devido ao processo de coleta realizado pelas usinas produtoras de álcool e açúcar, conforme já 
mencionado. Compósitos reforçados com fibras de bagaço de cana queimados e não queimados foram preparados e ensaiados com a finalidade de comparar as diferenças quanto a suas propriedades físico-químicas e mecânicas.

\section{8. 1. 2. 1. Ensaio de Impacto}

A figura 51 apresenta os resultados dos compósitos fenólicos reforçados com fibras de bagaço de cana de açúcar não queimadas, com comprimento variado. Destaca-se que este estudo só foi possível ser feito usando fibras não queimadas, pois as queimadas apresentaram comprimento médio reduzido (aproximadamente $1,5 \mathrm{~cm}$ ).

Comparando os valores de resistência dos compósitos, ao do termorrígido fenólico (TF, matriz não reforçada com fibras) se observa a ação de reforço destas fibras.

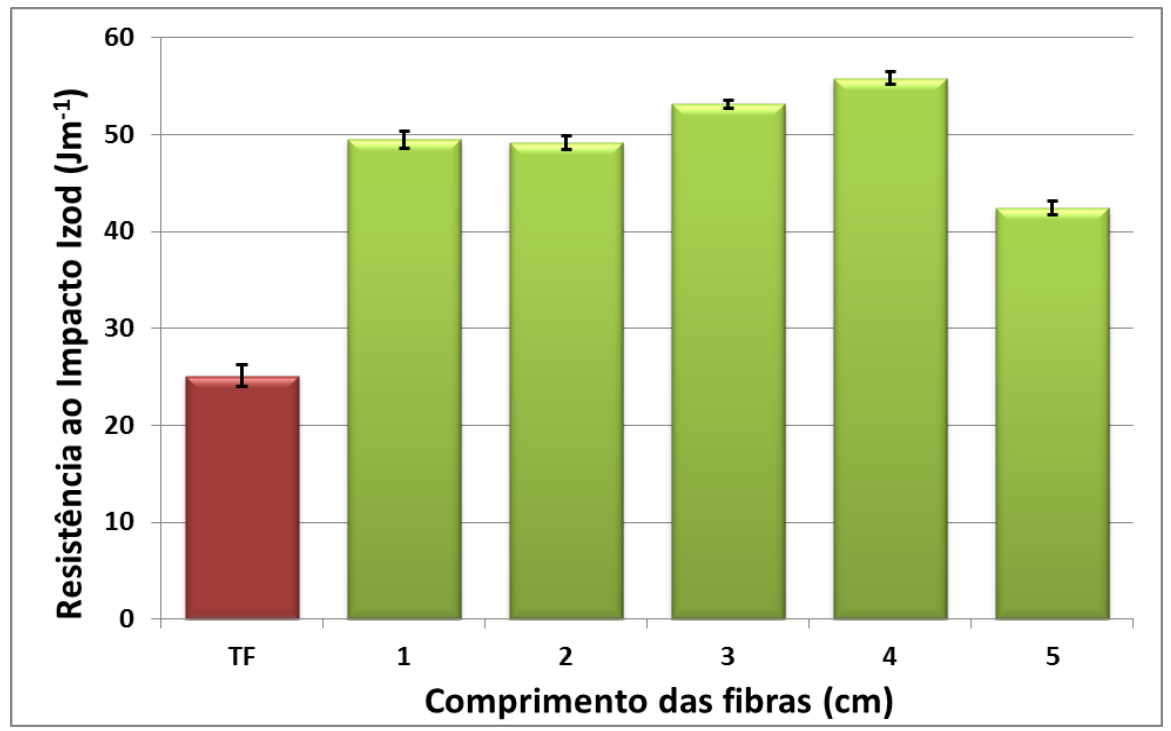

Figura 51: Resistência ao impacto Izod para o termorrígido fenólico (TF) e compósitos fenólicos reforçados com fibras de bagaço de cana não queimada (CFenBCNQ); comprimento: 1, 2, 3, 4 e 5cm (30\% em massa).

Os resultados mostram que o aumento no comprimento das fibras (não queimadas) até $4 \mathrm{~cm}$ leva a uma tendência no aumento de resistência ao impacto dos compósitos $(30 \%$ em massa). A diminuição da resistência do compósito preparado com fibras de comprimento de 
$5 \mathrm{~cm}$ deve-se provavelmente a quebra de partes das fibras durante o processo de mistura, visualmente observado, levando a diminuição média do comprimento, durante o processamento.

Comparando os compósitos reforçados com fibras curtas queimadas (BCQ) e não queimadas (BCNQ) (Tabela 23), nota-se que não há diferenças significativas nos valores de impacto, considerando os valores dos erros.

Tabela 23: Resistência ao Impacto Izod (RI) para compósitos fenólicos reforçados com fibras de bagaço de cana (CFenBCNQ) (30\% em massa).

\begin{tabular}{cc} 
CFen - 30\% & RI $\left(\mathrm{J} \mathrm{m}^{-1}\right)$ \\
$\mathbf{1 , 5} \mathbf{c m}$ (BCQ) & $45,3 \pm 1,6$ \\
\hline $\mathbf{1 , 0} \mathbf{c m}$ (BCNQ) & $49,5 \pm 1,6$ \\
\hline $\mathbf{2 , 0} \mathbf{c m}$ (BCNQ) & $49,1 \pm 1,2$ \\
\hline
\end{tabular}

Considerando estes resultados, a continuidade dos estudos, cujos resultados são discutidos posteriormente, se deu com bagaço de cana queimada, devido a maior disponibilidade atual desta fibra, comparativamente à não queimada.

\section{8. 1. 2. 2. $M E V$}

Após o ensaio de impacto, as regiões de fratura dos compósitos foram analisadas por microscopia eletrônica (MEV).

Em geral, observou-se que para todos os compósitos a distribuição das fibras na matriz foi homogênea, e que houve boa adesão entre as fibras e a matriz fenólica (Figuras 52a, 52e), ou seja, boa interação na interface fibra/matriz. Isto se deve ao eficiente recobrimento das fibras pela matriz, independente do comprimento destas.

Para os compósitos, as imagens mostram poucas regiões em que as fibras foram arrancadas (pull out) (imagens não apresentadas), o que quando ocorre indica fraca adesão fibra/matriz. Majoritariamente, as fibras foram rompidas no mesmo plano de fratura da matriz 
durante o ensaio de impacto, como observados nas figuras 52b e 52c. Estas características indicam que, em geral, o processo de impregnação das fibras pela matriz foi eficiente, e há uma boa interação das fibras com a matriz, devido às características de polaridade da fibra e da matriz, assim como devido à presença de anéis aromáticos em ambas, fibra e matriz.

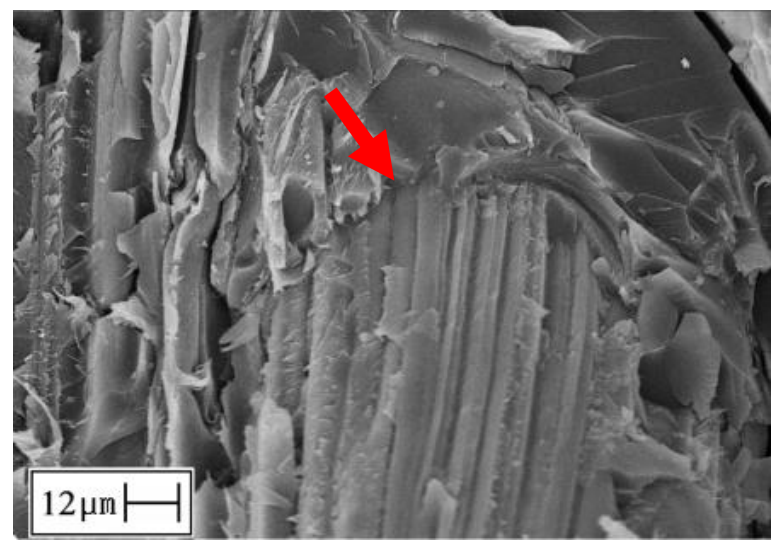

(a)

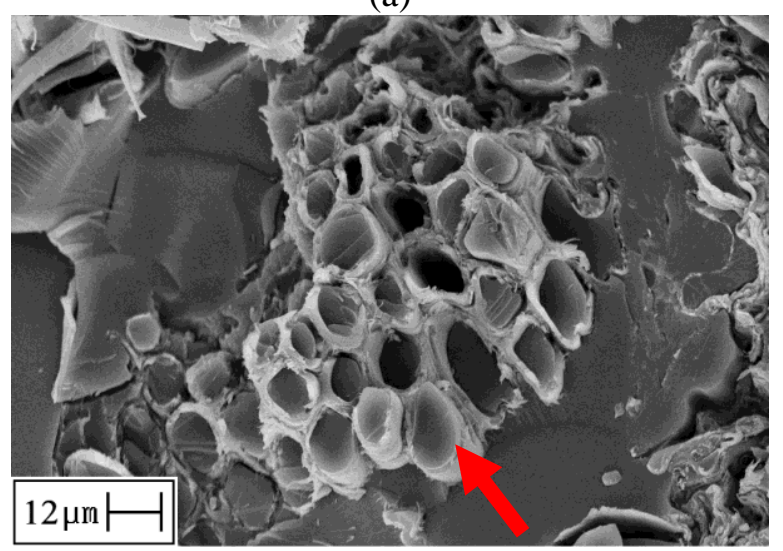

(c)

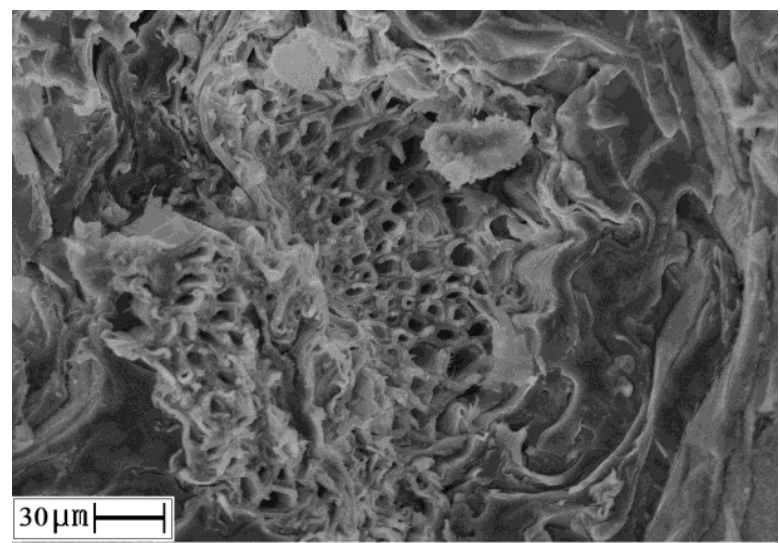

(b)

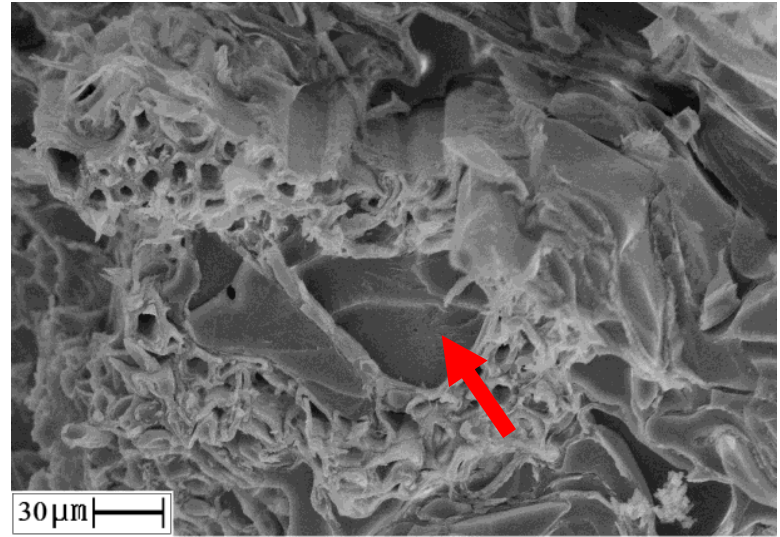

(d)

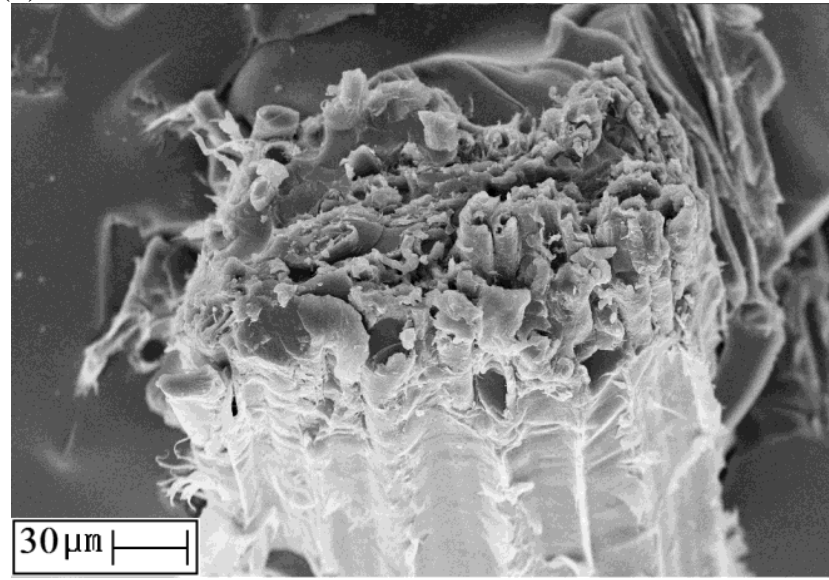

(e)

Figura 52: MEV dos compósitos fenólicos reforçados com fibras de bagaço de cana não queimada (CFenBCNQ); comprimento: (a) 1cm; (b) 2cm; (c) 3cm; (d) 4cm; (e) $5 \mathrm{~cm}$; (30\% em massa). 
Nas figuras 52c nota-se o preenchimento de parte das cavidades das fibras pela resina, favorecendo a boa interação e adesão das fibras com a matriz. Nos compósitos reforçados com fibras de $5 \mathrm{~cm}$ (Figura 52e) observou-se a propagação de trincas na matriz, ao redor de alguns feixes de fibras (figura não apresentada), o que pode ter sido uma das causas da diminuição do valor de resistência ao impacto.

\section{8. 1. 2. 3. DMTA}

Foram realizados ensaios de DMTA para os compósitos reforçados com fibras de comprimentos 1, 2, 3, 4 e 5cm (bagaço de cana não queimado) com 30\% de fibra (em massa). A figura 53 apresenta as curvas resultantes. 


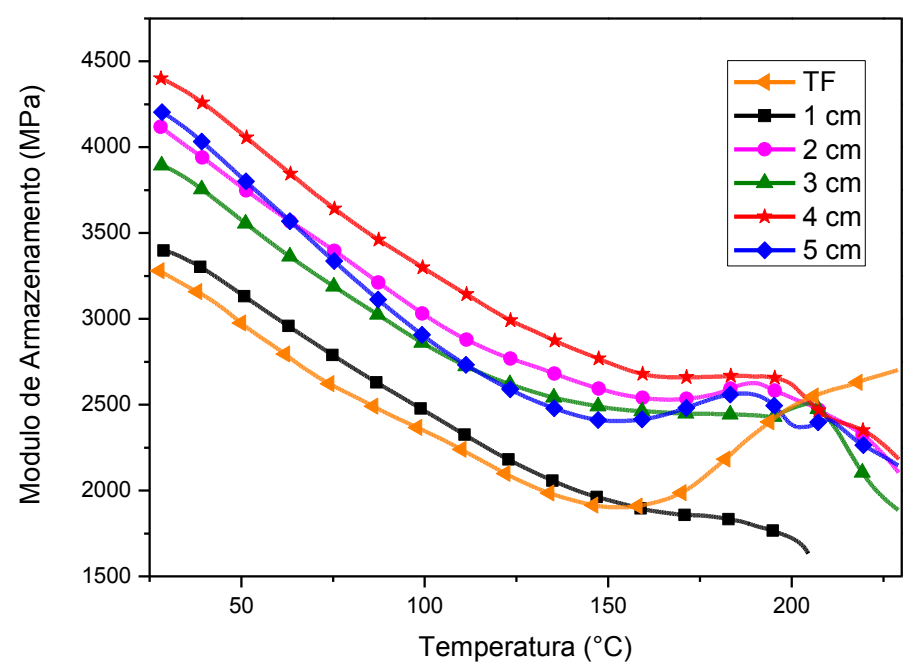

(a)

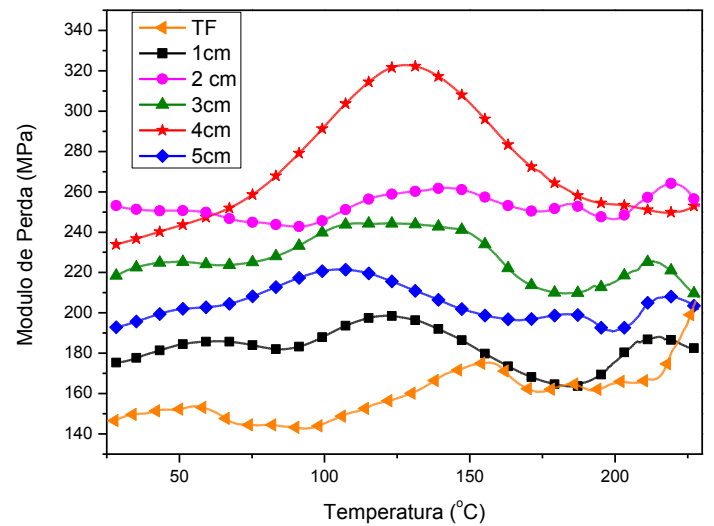

(b)

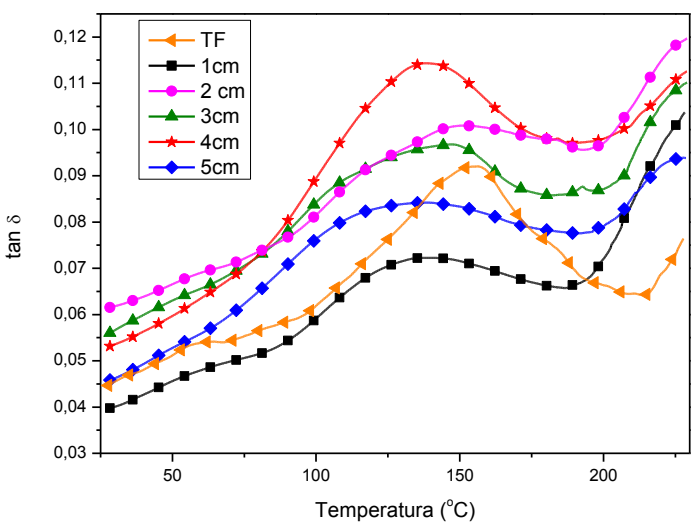

(c)

Figura 53: (a) Módulo de Armazenamento E’ (b) Módulo de Perda E” e (c) Tan $\delta$ em função da temperatura para o termorrígido fenólico (TF) compósitos fenólicos reforçados com fibras de bagaço de cana não queimada (CFenBCNQ): 1, 2, 3, 4 e 5cm (30\% em massa).

De acordo com a figura 53a e dados apresentados na tabela 25 , observa-se que a introdução de fibras na matriz termorrígida fenólica (mantendo-se a proporção constante em $30 \%$ ) leva a uma tendência de aumento da rigidez dos materiais, evidenciado pelos valores de módulo de E' quando comparado ao termorrígido fenólico $\left(25^{\circ} \mathrm{C}\right)$. Quando o comprimento da fibra aumenta de $1 \mathrm{~cm}$ para $2-5 \mathrm{~cm}$, a extensão de camada de matriz envolvida nas interações é maior, e este alongamento das fibras pode dificultar a movimentação de segmentos da matriz, dando a este material característica de maior rigidez, embora não exista uma correlação bem definida entre E' $\left(25^{\circ} \mathrm{C}\right)$ e comprimento da fibra (Tabela 24$)$. 
Tabela 24: Valores de Módulo de Armazenamento (E’) em $25{ }^{\circ} \mathrm{C}$ para o termorrígido fenólico (TF) compósitos fenólicos reforçados com fibras de bagaço de cana não queimadas (CFenBCNQ): 1, 2, 3, 4 e $5 \mathrm{~cm}$ ( $30 \%$ em massa).

\begin{tabular}{ccc} 
& & $\mathbf{E}^{\prime}\left(\mathbf{2 5}{ }^{\circ} \mathbf{C}\right), \mathbf{G P a}$ \\
\hline \multirow{2}{*}{$\begin{array}{c}\text { CFenBCNQ } \\
(\mathbf{c m})\end{array}$} & $\mathbf{1}$ & 3,2 \\
\cline { 2 - 3 } & $\mathbf{2}$ & 3,4 \\
\cline { 2 - 3 } & $\mathbf{3}$ & 4,1 \\
\cline { 2 - 3 } & $\mathbf{4}$ & 3,9 \\
\hline
\end{tabular}

Em temperaturas acima de $150{ }^{\circ} \mathrm{C}$, o termorrígido fenólico apresenta um comportamento diferente dos compósitos (Figura 53a). O termorrígido fenólico é um material parcialmente entrecruzado, e acima da temperatura de $200{ }^{\circ} \mathrm{C}$ é possível observar o comportamento de cura residual (aumento em E'). Este comportamento não é tão evidente nos compósitos, pois a presença de fibras diminui o volume de matriz, modificando o perfil da curva.

Comparando as curvas E" da figura 53b observa-se que o aumento no comprimento das fibras eleva os valores de E", em todo intervalo de temperatura, exceto para o compósito reforçado com fibras normalmente com $5 \mathrm{~cm}$, pois conforme já mencionado, observou-se a quebra das fibras durante o processamento. Em compósitos reforçados com fibras mais longas, estas podem se acomodar de maneira menos eficiente no interior do material, gerando pontos de tensão, fibras arqueadas e a presença de vazios. Quanto maior o número de defeitos presente no material, pior é o desempenho mecânico deste.

A transição vítrea ( $\mathrm{Tg}$ ) para os polímeros termorrígidos este ponto varia de acordo com o grau de entrecruzamento, pois para termorrígidos a $\mathrm{Tg}$ está relacionada à mobilidade molecular dos segmentos existentes entre uma ligação cruzada e outra. Quanto maior a interação das cadeias poliméricas, mais restrita será a movimentação. Quando fibras vegetais são acrescentadas à matriz polimérica outros parâmetros devem ser levados em consideração, pois este polímero (neste caso um termorrígido) será parte do compósito. Uma região de 
interface é inserida ao material, sendo que esta apresenta um comportamento particular, diferente do comportamento das fibras ou da matriz isoladamente. A Tg dos compósitos torna-se resultado de um conjunto de materiais. Para os compósitos apresentados na figura 53b, a Tg para este conjunto de materiais ocorre na faixa de temperatura de 120 a $150{ }^{\circ} \mathrm{C}$.

\section{8. 1. 2. 4. Absorção de água}

Compósitos reforçados com fibras de bagaço de cana não queimados foram preparados e ensaiados, com a finalidade de avaliar se o processo de queima realizada na cana-de-açúcar exerce alguma influência sobre a propriedade de absorção de água dos compósitos reforçados por esta fibra.

A figura 54 mostra os resultados de porcentagem de água absorvida versus o tempo de imersão das amostras em água, até o ponto de saturação.

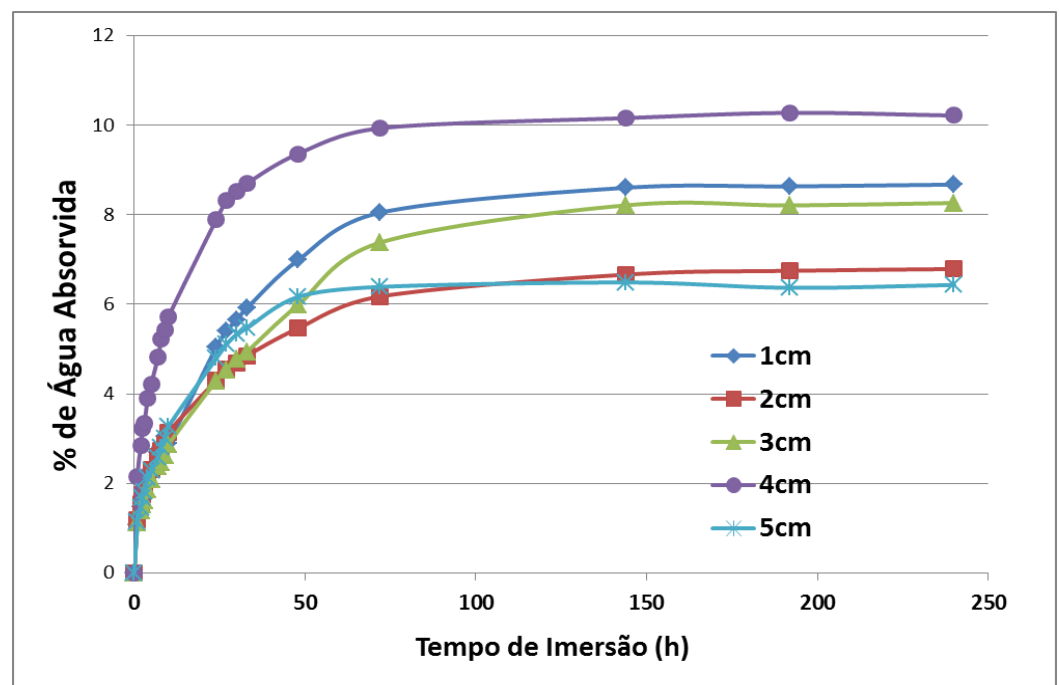

Figura 54: Resultados do ensaio de absorção de água compósitos fenólicos reforçados com fibras de bagaço de cana de não queimada (CFenBCNQ): 1, 2, 3, 4, 5cm (30\% em massa).

Comparando os resultados entre compósitos e termorrígido fenólico (material sem reforço), se observa que a porcentagem de água absorvida pelo termorrígido foi bem menor que a absorvida pelos compósitos. O termorrígido apresentou um máximo de $0,2 \%$ de massa 
de água absorvida, já os compósitos absorvem de 6 a $10 \%$ de água, dependendo do comprimento da fibra.

A variação no comprimento das fibras mostrou uma variação de porcentagem de água absorvida pelos compósitos. O aumento no comprimento não foi inversamente proporcional à diminuição de água absorvida, como esperado, pois quanto mais longas as fibras, menor a quantidade de pontas das fibras, que podem ser consideradas como pontos de descontinuidade do material, e que facilitaria a difusão da água.

Comparando os resultados dos compósitos preparados com $30 \%$ de fibras de bagaço queimadas (comprimento de 1,5cm, Figura 50) e não queimadas (comprimento de $1,0 \mathrm{~cm}$, Figura 54) observa-se que a porcentagem de água absorvida foi aproximadamente a mesma (8\%). Assim, a queima ou não da fibra não interferiu na propriedade do material para este ensaio.

\section{8. 2. Compósitos de matriz formaldeído-lignossulfonato de sódio}

5. 8. 2. 1. Compósitos reforçados com fibras de bagaço de cana queimadas (CFLBCQ)

A matriz preparada à base de lignossulfonato de sódio (NaLS) e formaldeído foi reforçada com fibras de bagaço de cana queimada. A resina preparada apresentou-se como forte candidata a substituição da resina fenólica no preparo de compósitos, devido aos resultados discutidos a seguir.

\section{8. 2. 1. 1. Ensaio de Impacto}

Foram preparados compósitos de matriz baseada em formaldeído-lignossulfonato de sódio (100\% de fenol substituído) reforçados com fibras de bagaço de cana de açúcar queimada (comprimento médio de 1,5cm). Para estes compósitos a porcentagem de fibra foi variada em 30, 50 e 70\% (em massa) (Figura 55). O termorrígido preparado com 
lignossulfonato de sódio (NaLS) se mostrou muito frágil, sendo impossível submetê-lo ao ensaio de impacto. Por este motivo, o termorrígido fenólico (TF) foi usado para fins comparativos (Figura 55).

Compósitos preparados com matriz polimérica baseada em lignossulfonato de sódio (NaLS), quando reforçados com fibras de bagaço de cana, resultaram em materiais mais resistentes quando comparados aos compósitos de matriz fenólica (Figura 45 e 51). Isto se deve provavelmente ao aumento no teor de grupos polares na matriz, presente na macromolécula de NaLS, os quais interagem com as fibras de bagaço de cana, melhorando a interface fibra/matriz.

Os resultados de IGC para a matriz de formaldeído-lignossulfonato de sódio e as fibras de bagaço de cana queimada, reforçam o favorecimento da compatibilidade entre ambos os componentes, a partir dos valores obtidos para a razão entre os sítios disponíveis aceptores e doadores, $\mathrm{AN}_{\mathrm{S}} / \mathrm{DN}_{\mathrm{S}}$, o qual determina o caráter do material em questão (Tabela 9 e 21). A análise de IGC mostrou que a matriz apresenta grande quantidade de sítios aceptores disponíveis para interagir com os sítios doadores das fibras de bagaço de cana queimado, pois estes materiais apresentam caráter ácido e básico, respectivamente. 


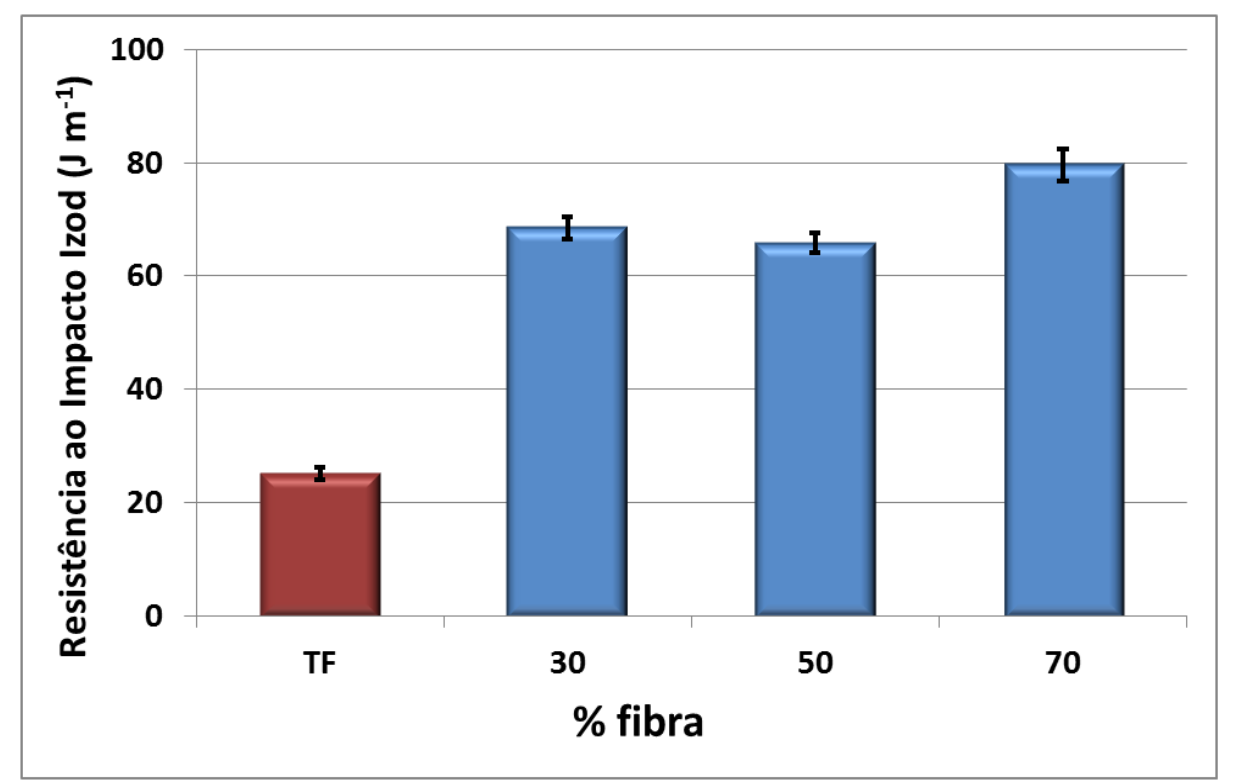

Figura 55: Ensaio de resistência ao impacto Izod para o termorrígido fenólico (TF) e os compósitos de formaldeído-lignossulfonato reforçados com fibras de bagaço de cana queimado em função da porcentagem de fibra na matriz (CFLBCQ) (30, 50 e $70 \%$ em massa).

Para estes compósitos de matriz baseada em NaLS, o melhor resultado de impacto foi obtido com $70 \%$ de fibras $\left(79 \mathrm{~J} \mathrm{~m}^{-1}\right.$ ), o qual corresponde a substituição de uma grande fração de matriz pelas fibras naturais (Figura 55).

Paiva e Frollini (2002) realizaram um estudo com fibras de bagaço de cana queimadas em matriz fenólica e lignofenólica avaliando as propriedades mecânicas dos compósitos preparados. Os resultados mostraram que a lignina organossolve também pode substituir o fenol no preparo de resinas termorrígidas, sem perda de propriedades mecânicas.

\section{8. 2. 1. 2. $M E V$}

Compósitos preparados com matriz de lignossulfonato e reforçados com fibras de bagaço de cana, nas proporções de 30, 50 e 70\% (em massa) após ensaio de impacto tiveram suas superfícies de fratura analisadas por microscopia eletrônica de varredura (MEV). O conjunto de imagens (Figura 56) indica que as fibras de bagaço de cana apresentaram boa interação com a matriz de lignossulfonato, pois o rompimento destas fibras ocorreu no mesmo plano de fratura da matriz, e com poucas propagações de trincas ao redor das fibras. 
Para o compósito com $70 \%$ de fibras, o aumento na quantidade de fibras descoladas da matriz, e a propagação de trincas, foram mais acentuados quando comparados aos demais compósitos. É possível que estes eventos tenham ocorrido devido ao alto teor de fibra presente. Levando em consideração os resultados de impacto (Figura 55) os valores obtidos para os compósitos de 30 e 50\% apresentam valores próximos, destacando-se o compósito com $70 \%$ de fibra, pela quantidade de material natural presente.

As micrografias do interior das fibras (Figura 56b, 56c) mostram o preenchimento das cavidades pela resina (indicado pelas setas vermelhas). Esta difusão da resina no interior das cavidades é um indicativo da boa molhabilidade e interação das fibras pela resina. 


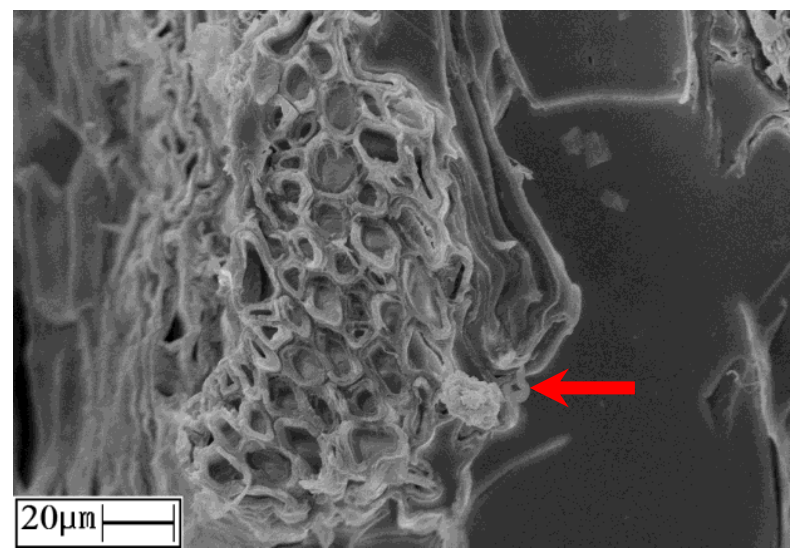

(a)

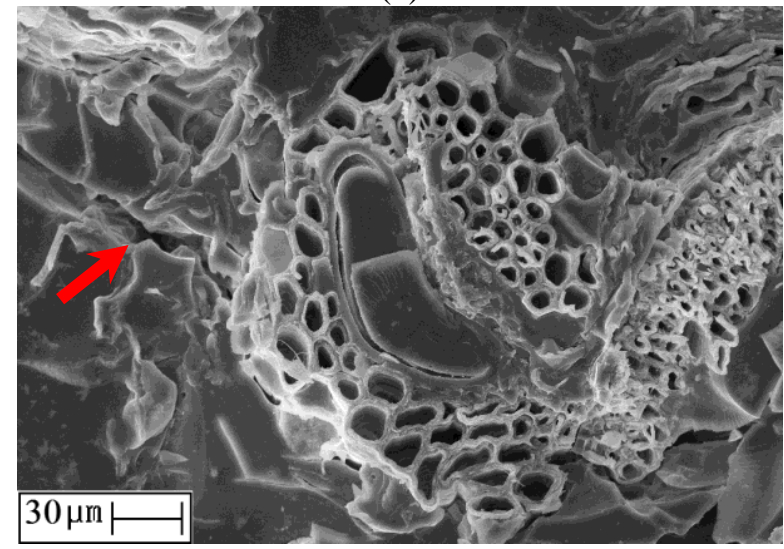

(c)

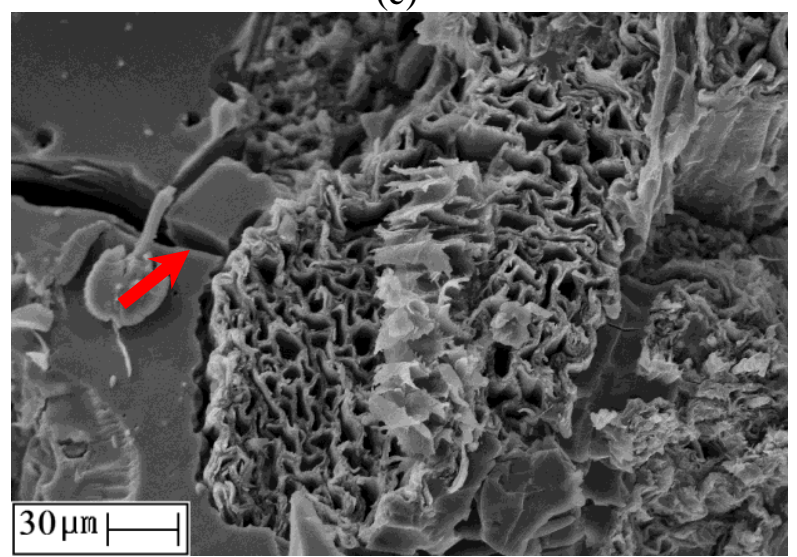

(e)

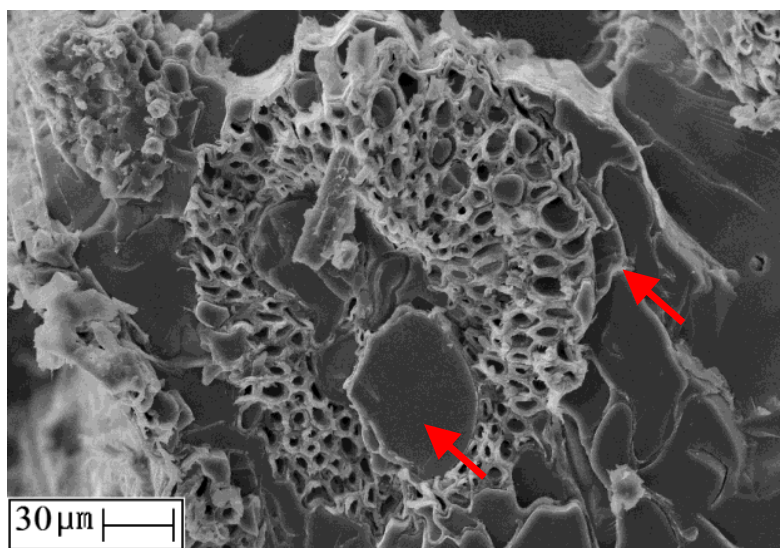

(b)

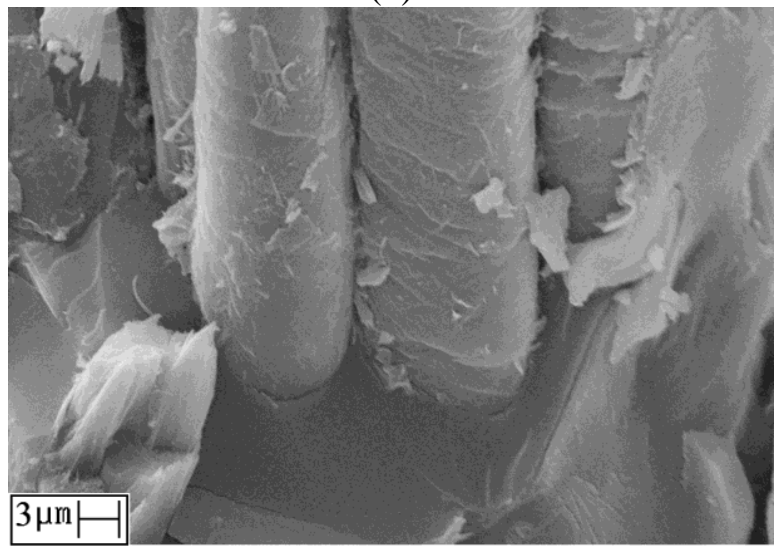

(d)

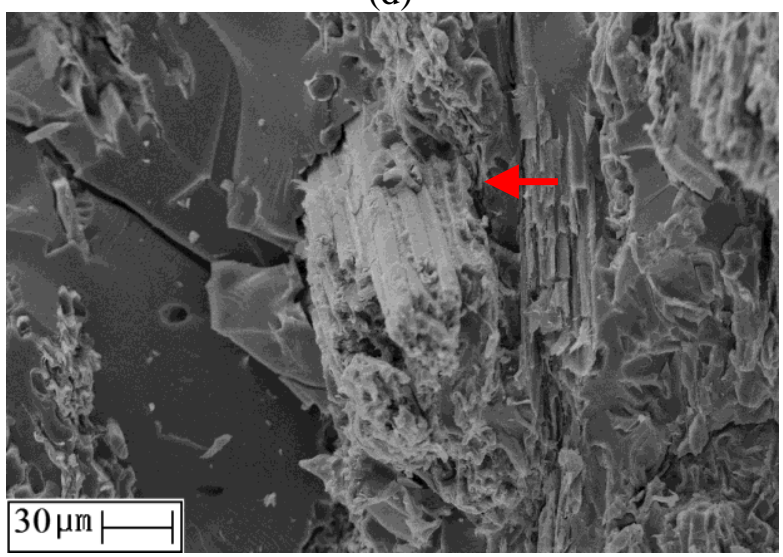

(f)

Figura 56: Microscopia eletrônica de varredura para compósitos de formaldeído-lignossulfonato reforçados com fibras de bagaço de cana queimado em função da porcentagem de fibra na matriz: (a, b) $30 \%$; (c, d) $50 \%$; (e, f) $70 \%$ (em massa) (CFLBCQ).

A propagação de trincas na matriz (ao redor de alguns feixes de fibras, figura 56c) pode ter sido uma das causas da diminuição do valor de resistência ao impacto do compósito com $50 \%$ de fibra, comparativamente ao de $30 \%$, embora os desvios aproximem os valores. 


\section{8. 2. 1. 3. DMTA}

Compósitos preparados com matriz baseada em NaLS e reforçados com fibras de bagaço de cana queimadas (sem tratamento, CFLBCQ) foram ensaiados, obtendo-se os resultados apresentados na figura 57. Os compósitos de matriz baseada em NaLS apresentaram comportamento semelhante aos de matriz fenólica. O aumento no módulo de armazenamento foi proporcional ao aumento na quantidade de fibras na matriz.

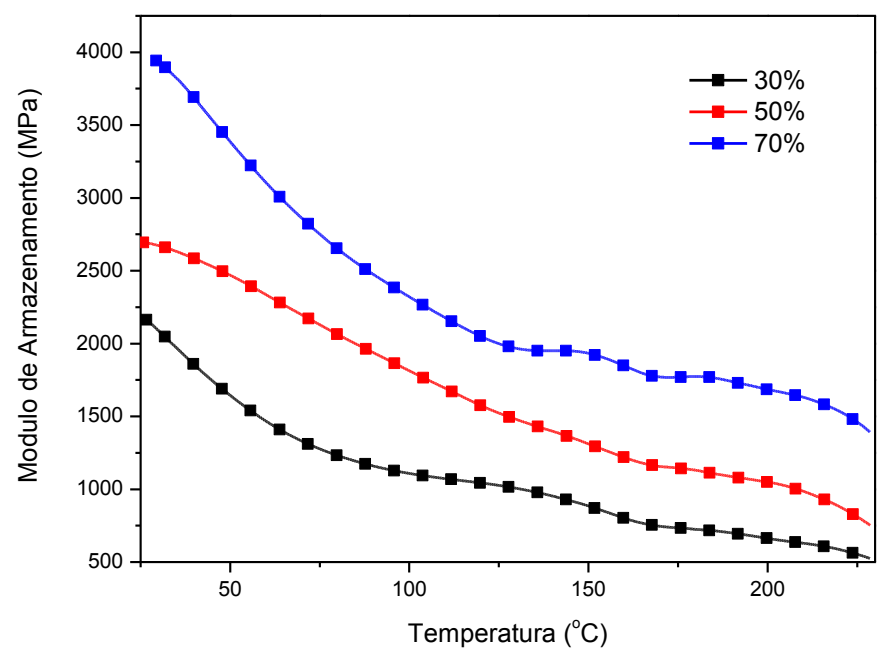

(a)

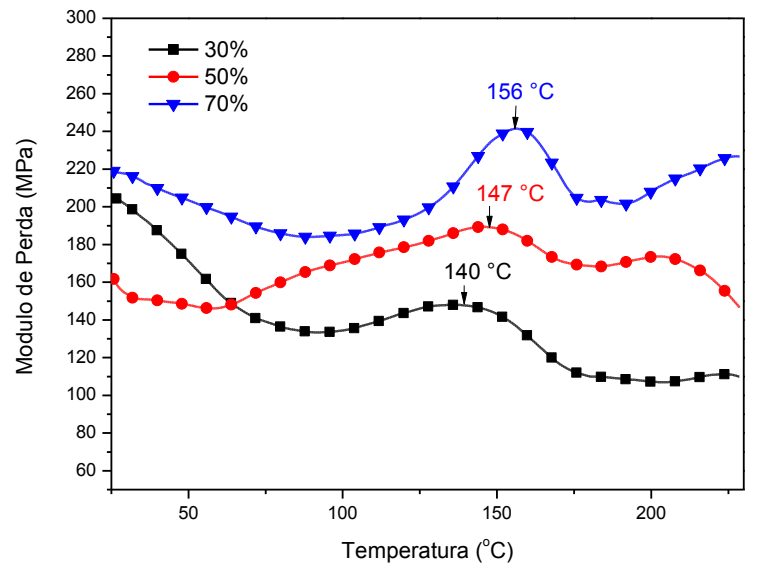

(b)

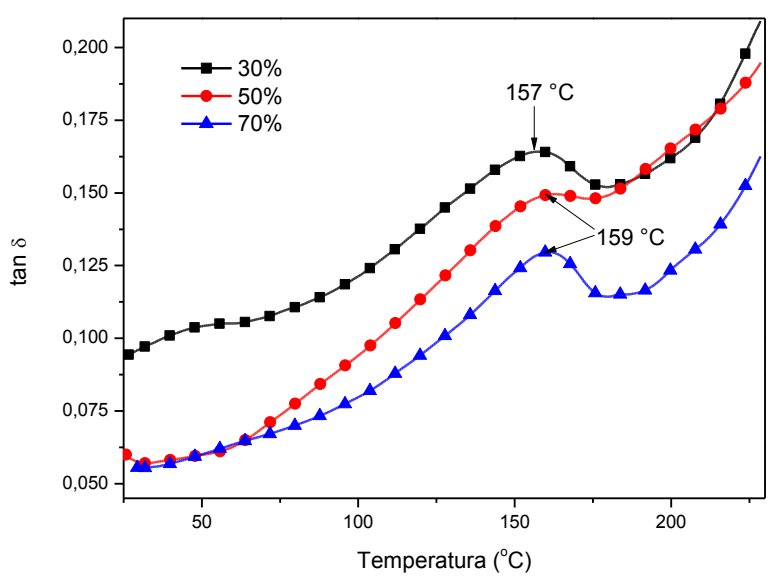

(c)

Figura 57: (a) Módulo de Armazenamento E'; (b) Módulo de Perda E” e (c) $\tan \delta$ em função da temperatura para compósitos de formaldeído-lignossulfonato reforçados com fibras de bagaço de cana queimado em função da porcentagem de fibra na matriz (CFLBCQ) (30, 50 e 70\% em massa).

O aumento da rigidez do material deve-se a diminuição na mobilidade nas cadeias poliméricas da matriz ocasionada pela presença das fibras. 
A tabela 25 mostra o módulo de armazenamento dos compósitos de matriz fenólica e matriz de lignossulfonato de sódio. Neste caso, os compósitos com matriz de lignossulfonato de sódio apresentam menor módulo de armazenamento, ou seja, são menos rígidos. $\mathrm{O}$ lignossulfonato, usado como "macromonômero", em substituição do fenol, apresenta uma estrutura rica em anéis aromáticos e grupos hidroximetila, esta estrutura mais volumosa pode levar a menor entrecruzamento e proporcionar a diminuição da rigidez do material.

Tabela 25: Valores de Módulo de Armazenamento (E', em $25{ }^{\circ} \mathrm{C}$ ) para compósitos fenólicos (CFenBCQ) e formaldeído-lignossulfonato (CFLBCQ) reforçados com fibras de bagaço de cana queimadas: 30,50 e $70 \%$ em massa.

\begin{tabular}{ccc}
\multicolumn{3}{c}{ E' $^{\prime}\left(\mathbf{G P a}, \mathbf{2 5}^{\circ} \mathrm{C}\right)$} \\
\% de fibra & CFLBCQ & CFenBCQ \\
\hline 30 & 2,1 & 4,1 \\
\hline 50 & 2,7 & 6,1 \\
\hline 70 & 3,9 & 6,5 \\
\hline
\end{tabular}

O comportamento similar para os demais compósitos, de módulo de perda e tan $\delta$, também é observado para os compósitos de matriz a base de NaLS, visto na figura 57b e 57c. O aumento do módulo de perda está diretamente ligado ao aumento da quantidade de fibras na matriz, ou seja, ao aumento de rigidez do material. A temperatura de transição vítrea (Tg) para este conjunto de compósitos foi de $140^{\circ} \mathrm{C}, 147^{\circ} \mathrm{C}$ e $156^{\circ} \mathrm{C}$ para os compósitos de 30,50 e $70 \%$, respectivamente.

A incorporação de fibras na matriz polimérica causa um incremento no módulo de perda (E") indicando que há um aumento na dissipação de calor pelos compósitos, quando comparado aos termorrígidos (RAZERA, 2006; GEETHAMM et al., 2005). Este efeito é observado nas curvas E" da figura 57b. Conforme mencionado anteriormente, o aumento da quantidade de fibras restringe a mobilidade de segmentos das cadeias poliméricas próximas às fibras, como consequência a transição vítrea do material poderá ocorrer em uma faixa ampla de temperatura. Este comportamento também se reflete nas curvas $\tan \delta$. $\mathrm{O}$ 
alargamento no pico da curva $\tan \delta$ é indicativo de que o material apresenta uma estrutura mais heterogênea, com regiões de densidade de entrecruzamento diversificada (COOK, 2004).

\section{8. 2. 1. 4. Ensaio de Flexão}

O termorrígido formaldeído-lignossulfonato de sódio foi preparado, mas não foi possível obter corpos de prova nas dimensões especificadas na norma deste ensaio (ASTM D790) devido sua fragilidade.

A figura 58 mostra o aumento nos valores de resistência à flexão destes compósitos, quando a porcentagem de fibra aumenta, assim como ocorre com o módulo de elasticidade destes materiais (Figura 59).

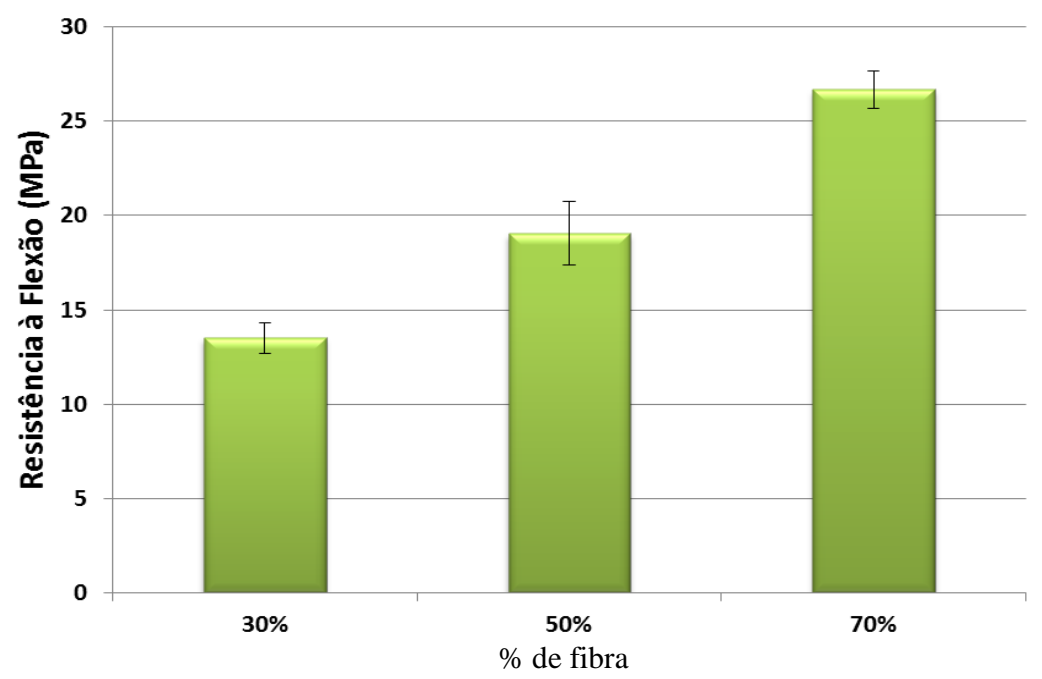

Figura 58: Resultados de resistência à flexão os compósitos de formaldeído-lignossulfonato reforçados com fibras de bagaço de cana queimada em função da porcentagem de fibra na matriz (CFBCQ) (30, 50 e 70\% em massa).

Os resultados do ensaio de flexão para os compósitos seguiram a mesma tendência dos resultados obtidos por DMTA, pois o módulo de elasticidade aumenta com a porcentagem de fibra adicionada ao compósito. 


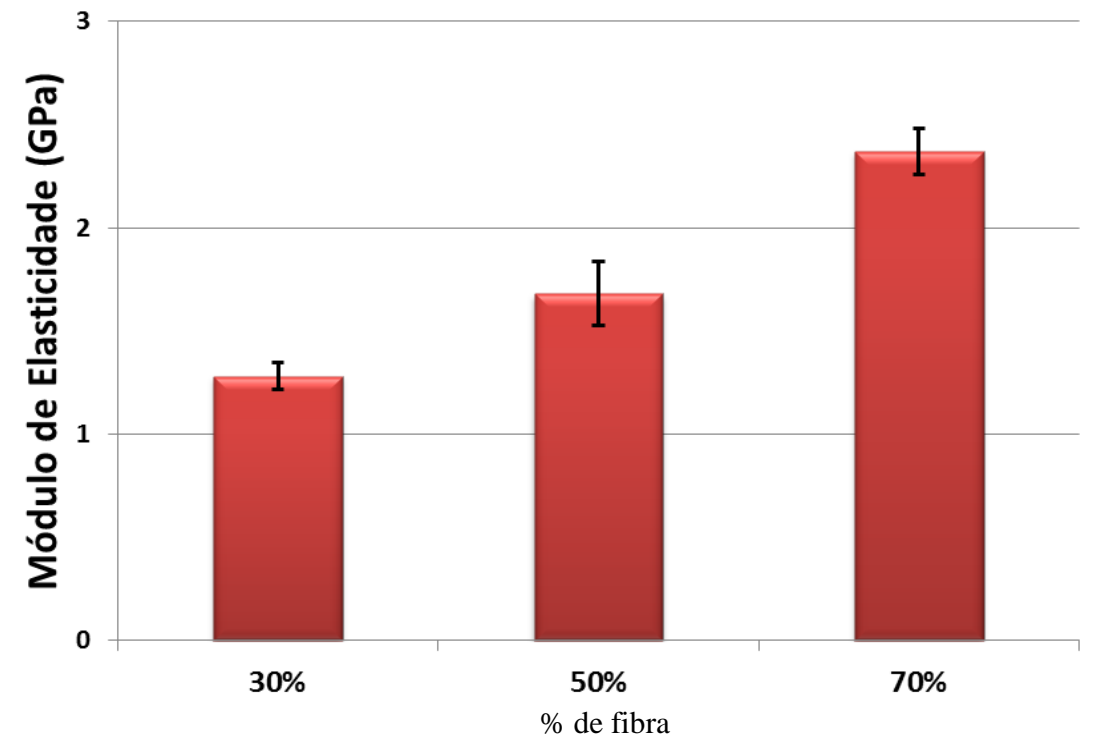

Figura 59: Resultados de módulo de elasticidade para os compósitos de formaldeído-lignossulfonato reforçados com fibras de bagaço de cana queimada em função da porcentagem de fibra na matriz (CFBCQ) (30, 50 e $70 \%$ em massa).

Tabela 26: Resultados de resistência à flexão e módulo de flexão para os compósitos fenólicos reforçados com bagaço de cana queimada (CFenBCQ) e compósitos de formaldeído-lignossulfonato reforçados com fibras de bagaço de cana queimada (CFLBCQ) em função da porcentagem de fibra na matriz.

\begin{tabular}{c|c|c|c|c|c|c}
\hline & \multicolumn{3}{|c}{ Resistência à flexão (Mpa) } & \multicolumn{3}{c}{ Módulo de flexão (Gpa) } \\
\hline & $\mathbf{3 0 \%}$ & $\mathbf{5 0 \%}$ & $\mathbf{7 0 \%}$ & $\mathbf{3 0 \%}$ & $\mathbf{5 0 \%}$ & $\mathbf{7 0 \%}$ \\
\hline CFenBCQ & 11,8 & 16,7 & 58,8 & 0,8 & 1,3 & 4,7 \\
\hline CFLBCQ & 13,5 & 19,1 & 26,7 & 1,3 & 1,7 & 2,4 \\
\hline
\end{tabular}

Comparando os resultados dos compósitos fenólicos (Tabela 26) e compósitos formaldeído-lignossulfonato de sódio (Tabela 26), é observado que estes últimos, com 30 e $50 \%$ de fibra, apresentam valores de resistência à flexão maior que o respectivo compósito fenólico. No entanto, para o compósito com 70\% de fibra, ocorre uma inversão. Os valores evidenciam que a substituição do fenol pela macromolécula de lignossulfonato de sódio favorece esta propriedade até 50\% de fibras. Um alto teor de fibras (70\%) parece ser o fator que leva à diminuição dos valores de resistência e módulo. 


\section{8. 2. 1. 5. Absorção de água}

Compósitos de matriz baseada em lignossulfonato de sódio foram reforçados com 30, 50 e $70 \%$ de fibras de bagaço de cana e mantidos em água para avaliar sua capacidade de absorção. A figura 60 apresenta os resultados de porcentagem de água absorvida pelos compósitos em função do tempo de imersão destes. Neste caso, quanto maior o teor de fibras maior foi porcentagem de água absorvida (Figura 60). Este comportamento está ligado principalmente às fibras lignocelulósicas, que apresentam características hidrofílicas por disponibilizar grande quantidade de grupos polares em sua superfície.

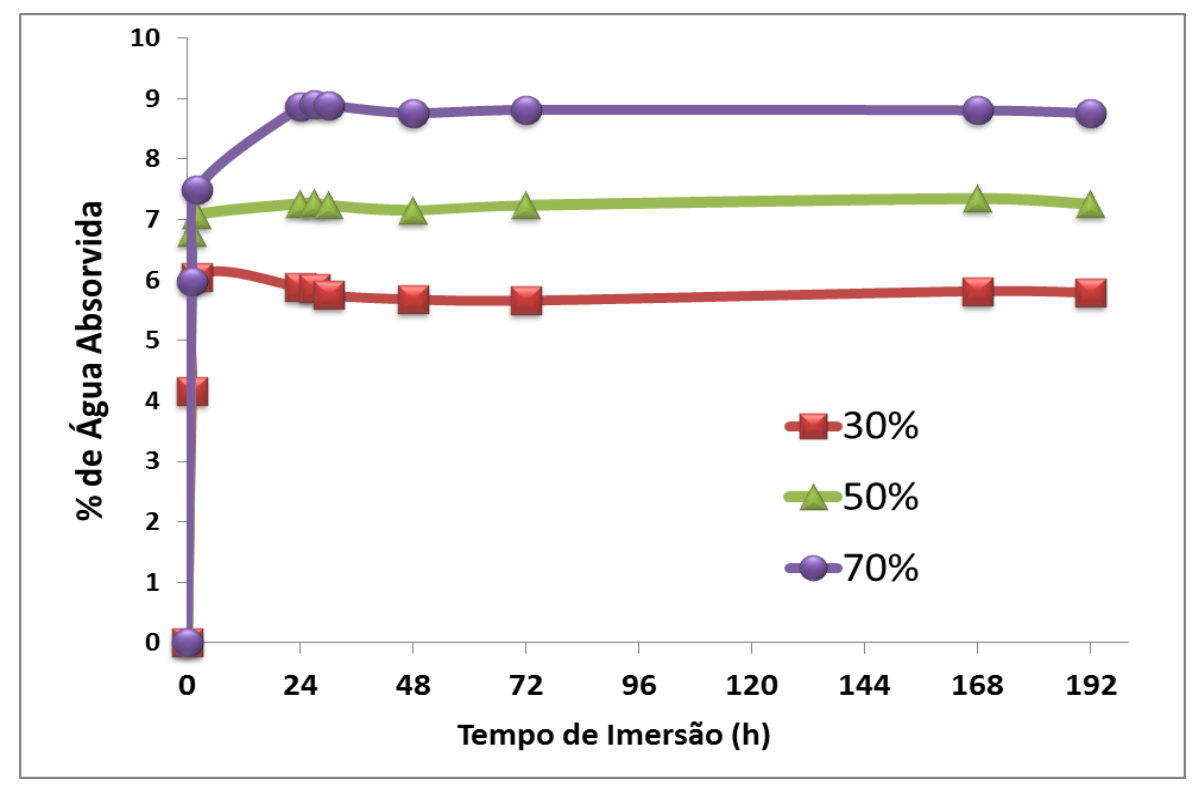

Figura 60: Resultados do ensaio de absorção de água compósitos de formaldeído-lignossulfonato reforçados com fibras de bagaço de cana queimado em função da porcentagem de fibra na matriz (CFLBCQ) (30, 50 e $70 \%$ em massa).

Os resultados mostram que a substituição do fenol pelo lignossulfonato de sódio no preparo da matriz não altera o comportamento dos compósitos, quando submetidos ao ensaio de absorção de água. Comparando os resultados, pode-se notar que a porcentagem de massa de água absorvida pelos compósitos, apresentados até este momento, foi aproximadamente a mesma. A porcentagem de água absorvida se manteve no intervalo de 6 a 10\% (Figura 50, 54 e 60). 


\section{8. 2. 2. Compósitos reforçados com fibras de bagaço de cana queimado e tratado}

\section{(CFBCQT)}

\section{8. 2. 2. 1. Ensaio de Impacto}

Compósitos de matriz baseada em NaLS e reforçados com fibra de bagaço de cana queimado e tratado (NaLS/ultrassom) (30, 50 e 70\%, em massa) foram ensaiados, obtendose os resultados apresentados na figura 61 .

Os resultados (Figura 61) mostram a melhora na resistência ao impacto dos compósitos quando as fibras são tratadas com solução de NaLS saturada, destacando os compósitos com 50 e $70 \%$ de fibras onde os desvios aproximam os valores. Os resultados são indicativos que o aumento no teor de NaLS tanto na matriz quanto nas fibras melhora e interação entre estes dois componentes, devido a intensificação da afinidade fibra/matriz, por ambas conterem estruturas típicas de NaSL.

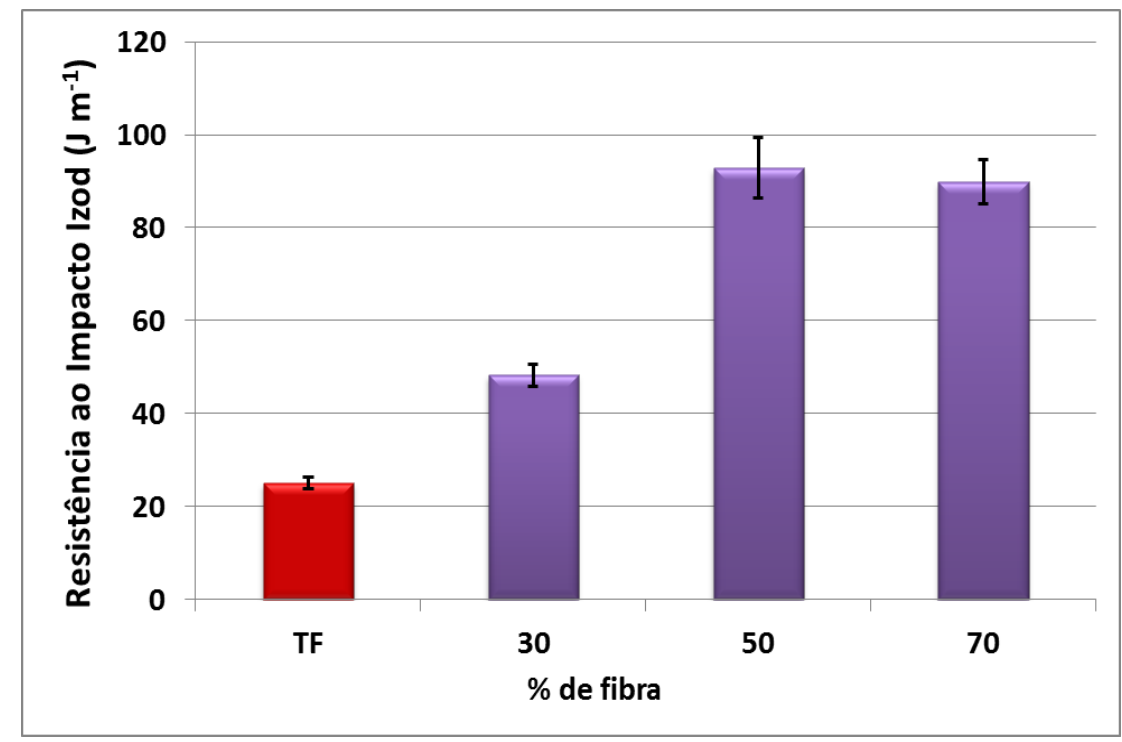

Figura 61: Resultados de resistência ao Impacto Izod para os compósitos de formaldeídolignossulfonato reforçados com fibras de bagaço de cana queimado e tratado (lignossulfonato de sódio+ultrassom/1h) em função da porcentagem de fibra na matriz (30, 50 e $70 \%$ em massa) (CFBCQT), termorrígido fenólico (TF). 
O lignossulfonato de sódio (presente na matriz) e as fibras de bagaço de cana apresentam grupos polares que interagem resultando em uma interface mais intensa. Esta interação é intensificada quando as fibras de bagaço são tratadas com o lignossulfonato, exercendo este um papel de agente compatibilizante entre as fibras e a matriz. O lignossulfonato pode estabelecer interações com os componentes da fibra (lignina e polissacarídeos) e com grupos presentes na estrutura da matriz (como hidroxilas e anéis aromáticos). Destaca-se que o fato de o tratamento das fibras ter ocorrido via adsorção é relevante, pois a modificação química das fibras pode comprometer suas propriedades mecânicas, devido à degradação parcial que pode ocorrer durante o tratamento (MEGIATTO et al., 2007).

\section{8. 2. 2. 2. $M E V$}

As fibras de bagaço de cana que foram tratadas com lignossulfonato de sódio apresentaram interação mais intensa com a matriz comparativamente a fibra não tratada, como pode ser comprovado pelos resultados de resistência ao impacto (Figura 61) e as micrografias apresentadas a seguir (Figura 62). Nas imagens de MEV das fibras, nota-se que após o tratamento a rugosidade na superfície destas fibras (Figura 62 a e 62d, veja setas azuis) aumentou, sendo possível que este seja um dos fatores que contribuiu para a melhora na interação fibra-matriz. 


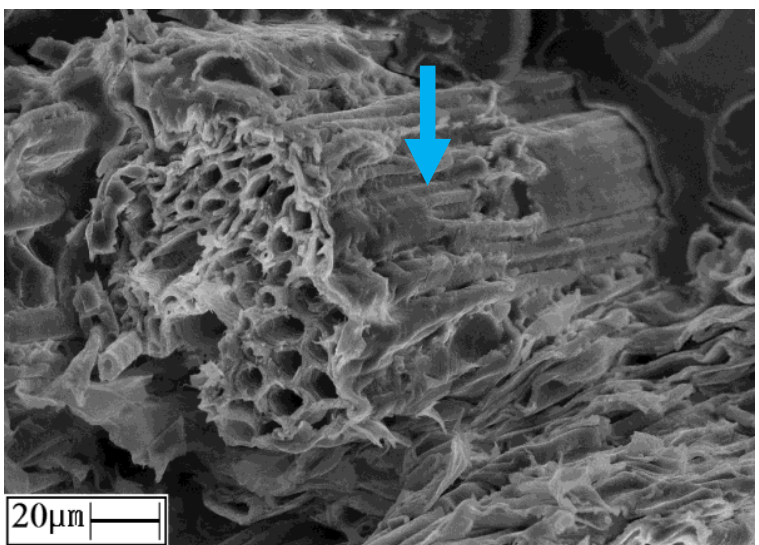

(a)

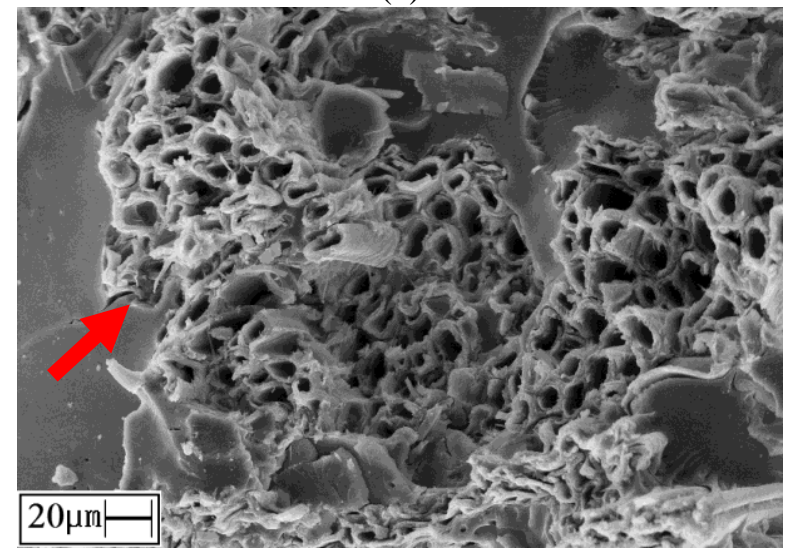

(c)

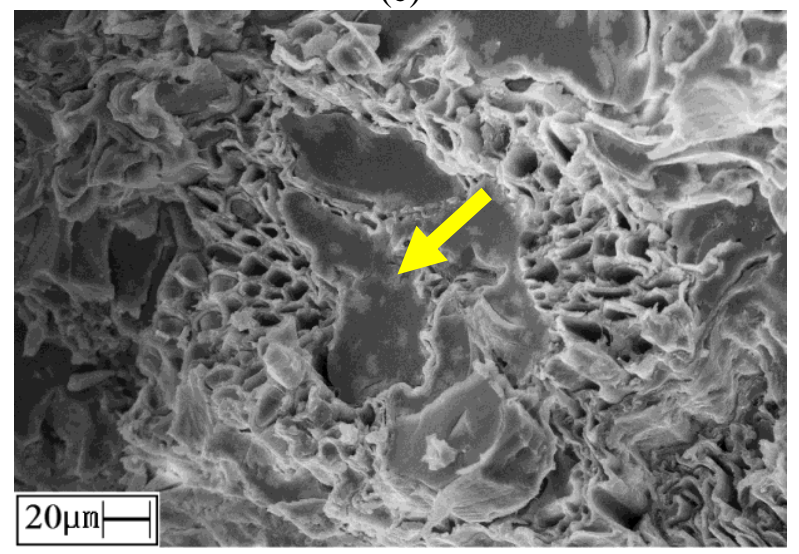

(e)

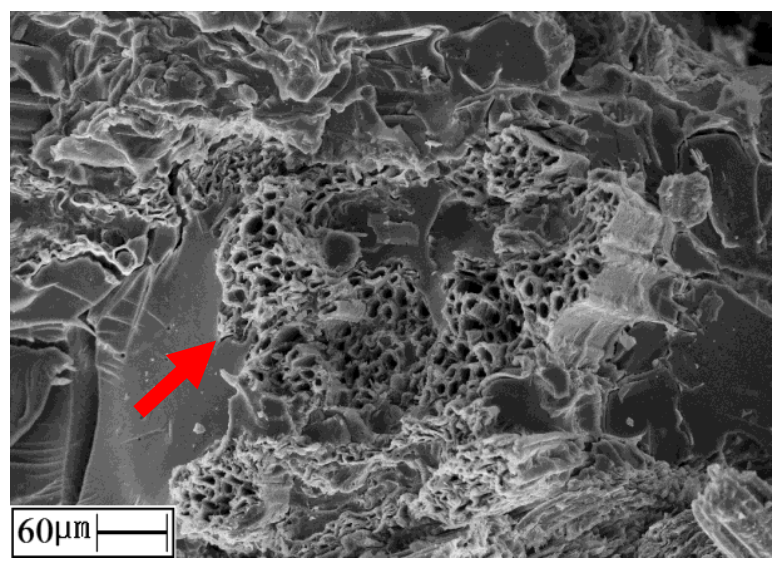

(b)

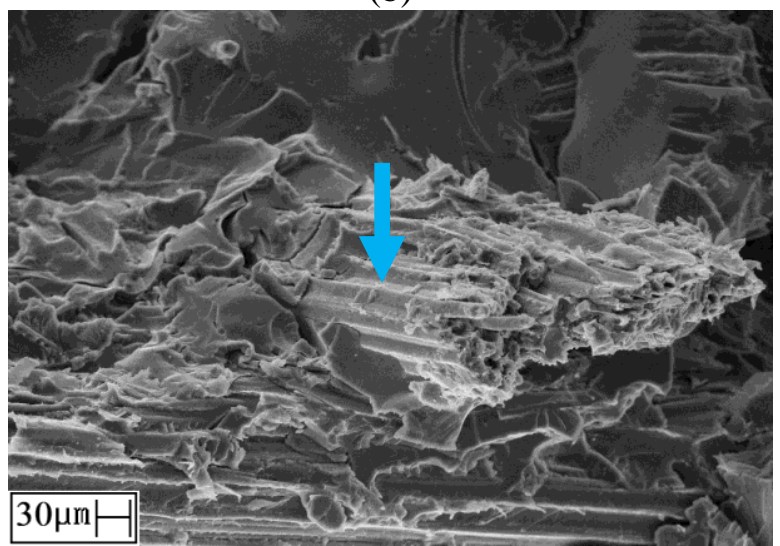

(d)

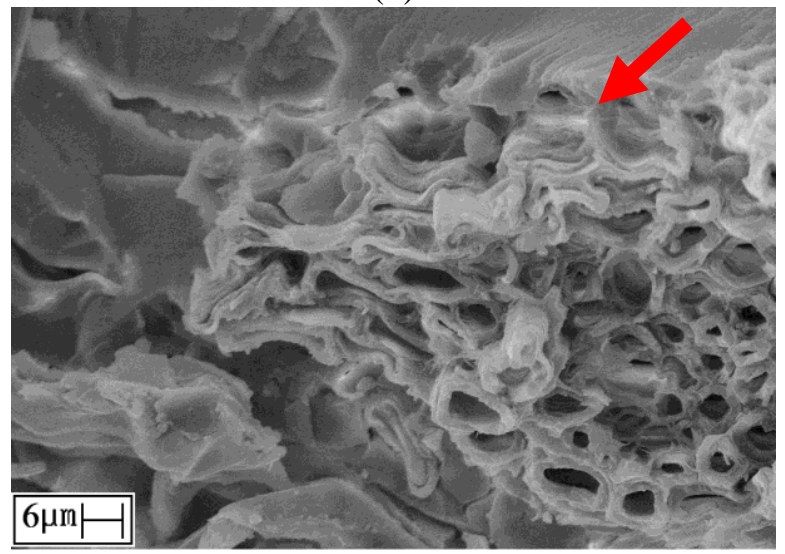

(f)

Figura 62: Microscopia eletrônica de varredura para compósitos reforçados com fibras de bagaço de cana queimado e tratado (lignossulfonato de sódio+ ultrassom/1h), em matriz de formaldeídolignossulfonato: (a, b) 30\%; (c, d) 50\%; (e, f) 70\% (em massa).

A quantidade de lignina depositada sobre as fibras, como resultado do tratamento, aumentou a quantidade de grupos polares disponíveis na fibra, facilitando as interações fibra/matriz, já que esta última foi preparada usando NaLS como reagente. As intensas interações fibras/matriz levaram a excelente adesão na interface (Figura 62c, indicado pela 
seta vermelha), preenchimento dos dutos da fibra pela matriz (Figura 62e, indicado pela seta amarela) e ótimo recobrimento da fibra pela matriz (Figura 62f, indicado pela seta vermelha).

\section{8. 2. 2. 3. DMTA}

Na figura 63 são apresentados as curvas de módulo de armazenamento (E') versus temperatura dos compósitos de matriz baseada em NaLS-formaldeído reforçados com fibras de bagaço de cana queimadas, que passaram pelo tratamento em banho de solução de NaLS/ultrassom (durante 1h).

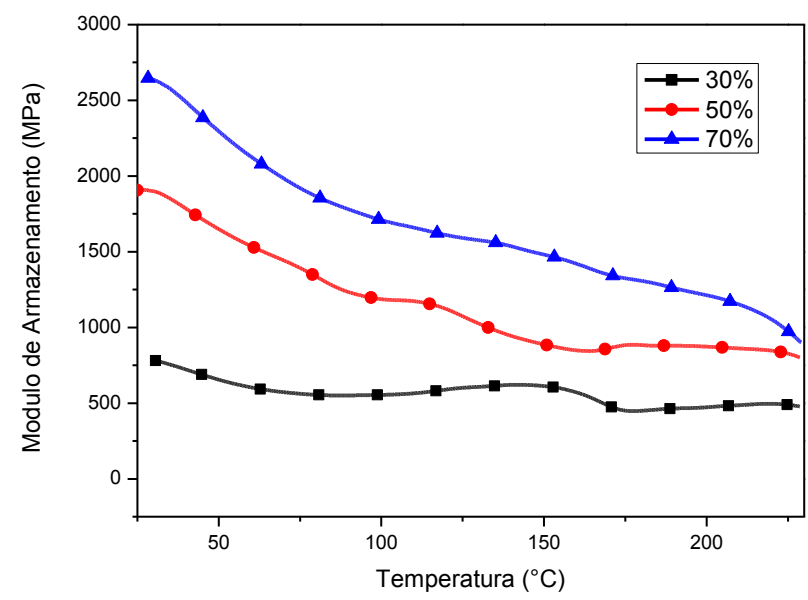

(a)

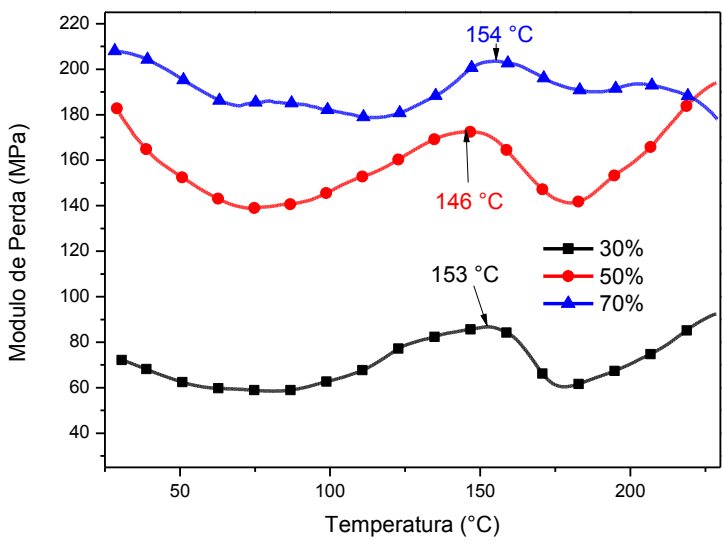

(b)

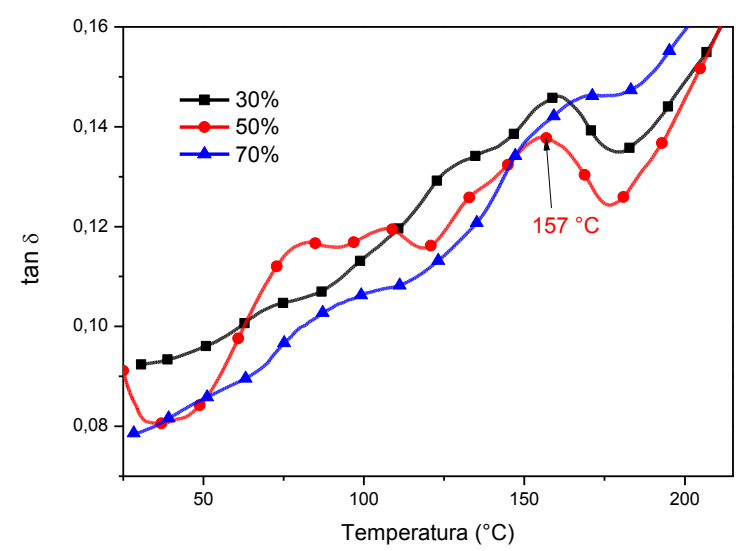

(c)

Figura 63: (a) Módulo de Armazenamento E', (b) Módulo de Perda E" e (c) Tan $\delta$ em função da temperatura para compósitos formaldeído-lignossulfonato reforçados com fibras de bagaço de cana queimado e tratado (lignossulfonato de sódio+ ultrassom/1h) (CFLBCQT): 30\%, 50\% e 70\% (em massa). 
A figura 63a mostra as curvas de módulo de armazenamento (E') para os compósitos. As curvas apresentaram mesmo comportamento, quando comparadas aos demais compósitos já apresentados. O módulo E' aumenta à medida que a quantidade de fibra é acrescentada ao compósito. O compósitos com $70 \%$ de fibra apresentou E’ inicial (à $25{ }^{\circ} \mathrm{C}$ ) maior que os demais (Tabela 27).

Tabela 27: Valores de Módulo de Armazenamento (E’) em $25{ }^{\circ} \mathrm{C}$ para compósitos lignossulfonatoformaldeído reforçados com fibras de bagaço de cana queimado tratado (NaLS+ultrassom/1h) (CFLBCQT) e compósitos lignossulfonato-formaldeído reforçados com fibras de bagaço de cana (CFLBCQ) (30, 50 e 70\%, em massa).

\begin{tabular}{c|c|c}
\multirow{2}{*}{$\%$ de fibra } & \multicolumn{2}{|c}{ E' $^{\prime}\left(\mathrm{GPa}, 2 \mathbf{~}^{\circ} \mathrm{C}\right)$} \\
\hline $\mathbf{3 0}$ & 0,8 & CFLBCQ \\
\hline $\mathbf{5 0}$ & 1,9 & 2,1 \\
\hline $\mathbf{7 0}$ & 2,6 & 2,7 \\
\hline
\end{tabular}

Comparando o conjunto de resultados dos compósitos de matriz baseada em formaldeído-lignossulfonato e reforçados com fibras de bagaço de cana queimadas não tratadas e tratadas (CFLBCQT), nota-se que os compósitos reforçados com fibras tratadas são os que apresentam menores valores de módulo de armazenamento (em $25{ }^{\circ} \mathrm{C}$ ), ou seja, menor rigidez que todos os demais conjuntos de resultados apresentados.

O tratamento das fibras pode ter influenciado nas características dos compósitos como um todo como mostram os valores de E' (tabela 27). Quanto menor o valor de E' mais flexível é o material. Os valores de E’ mostram que compósitos reforçados com fibras tratadas são mais flexíveis quando comparado aos compósitos com fibras não tratadas, para compósitos com mesma porcentagem de fibra.

Comparando os compósitos fenólicos com os compósitos formaldeído-lignossulfonato de sódio (NaLS), o módulo de armazenamento $\left(25^{\circ} \mathrm{C}\right)$ dos compósitos fenólicos é maior, conforme mostram as tabelas 24 e 25 . Esta mudança de comportamento pode ser atribuída à substituição do fenol pela macromolécula de NaLS no preparo da matriz. O grande volume 
ocupado pelo NaLS, quando comparado ao fenol, pode ter dificultado o entrecruzamento entre os segmentos das cadeias poliméricas, justificando menores valores de E' para estes compósitos preparados com matriz baseada em NaLS.

No trabalho apresentado por Barbosa et al. (2010) sobre compósitos reforçados com fibras de coco em matriz tanino-fenólica, o pré-polímero tanino-fenólico foi preparado utilizando o tanino, macromolécula obtida de fonte natural, como substituto de $50 \%$ do fenol com fibras de coco, as quais apresentam características próximas as do bagaço de cana (como o teor de celulose: $43,5 \%$ e índice de cristalinidade: $44 \%$ ). O mesmo comportamento e valores foram observados nos resultados de DMTA com relação ao módulo de armazenamento (E'). Os valores de E' aumentam conforme a quantidade de fibra aumenta no compósito e são da mesma ordem de grandeza que os compósitos de matriz baseada em NaLS reforçados com fibras de bagaço de cana, quando comparados aos compósitos fenólicos reforçados com bagaço de cana (apresentados neste trabalho).

No que se refere a E” e $\tan \delta$, os compósitos reforçados com as fibras tratadas, apresentam comportamento similar aos demais compósitos apresentados até aqui. O aumento no módulo de perda está diretamente ligado à quantidade de fibras presente na matriz. $\mathrm{O}$ aumento na quantidade de fibras levou ao incremento nos valores de módulo da perda dos compósitos, pois a mobilidade dos segmentos das cadeias poliméricas foi dificultado . Os máximos da curva E” podem ser usados para estimar a faixa de temperatura de transição vítrea, Tg, que para estes compósitos ocorreu em torno de $140-150{ }^{\circ} \mathrm{C}$, não havendo correlação clara com a porcentagem de fibras (Figura 63).

\section{8. 2. 2. 4. Ensaio de Flexão}

Fibras de bagaço de cana foram tratadas (solução de lignossulfonato de sódio em banho de ultrassom) e utilizadas como reforço na matriz de formaldeído-lignossulfonato de 
sódio de porcentagem de fibra de 30, 50 e 70\%, em massa. Os compósitos obtidos foram caracterizados quanto à resistência à flexão.

Nos compósitos, a quantidade de fibras utilizadas como reforço é relevante, pois o alto teor de fibra pode ocasionar regiões de aglomerados de fibras prejudicando o desempenho mecânico da amostra. Neste caso o alto teor de fibra não prejudicou o desempenho do material com $70 \%$ de fibra (Figura 61), pois este material apresenta resistência à flexão superior aos demais.

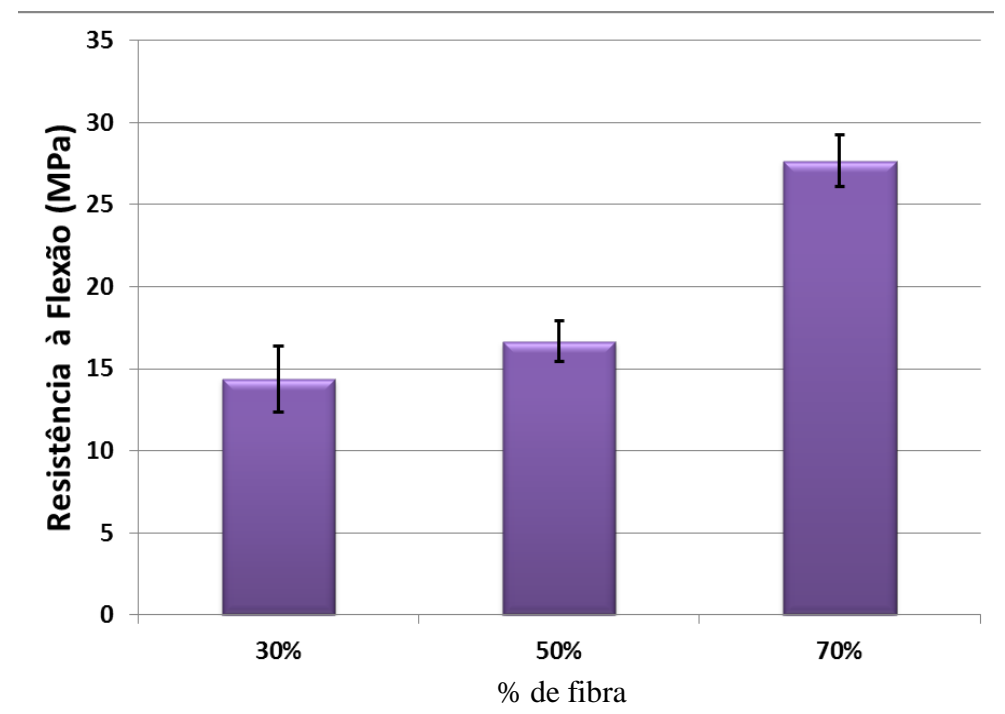

Figura 64: Resultados de resistência à flexão para os compósitos de formaldeído-lignossulfonato reforçados com fibras de bagaço de cana queimado e tratado (lignossulfonato de sódio+ultrassom/1h) (CFLBCQT) em função da porcentagem de fibra na matriz (30, 50 e 70\%, em massa).

O módulo de elasticidade (Figura 65) do compósito reforçado com $70 \%$ de fibra também apresentou módulo de elasticidade consideravelmente maior que os demais compósitos com 30 e $50 \%$ de fibra. 


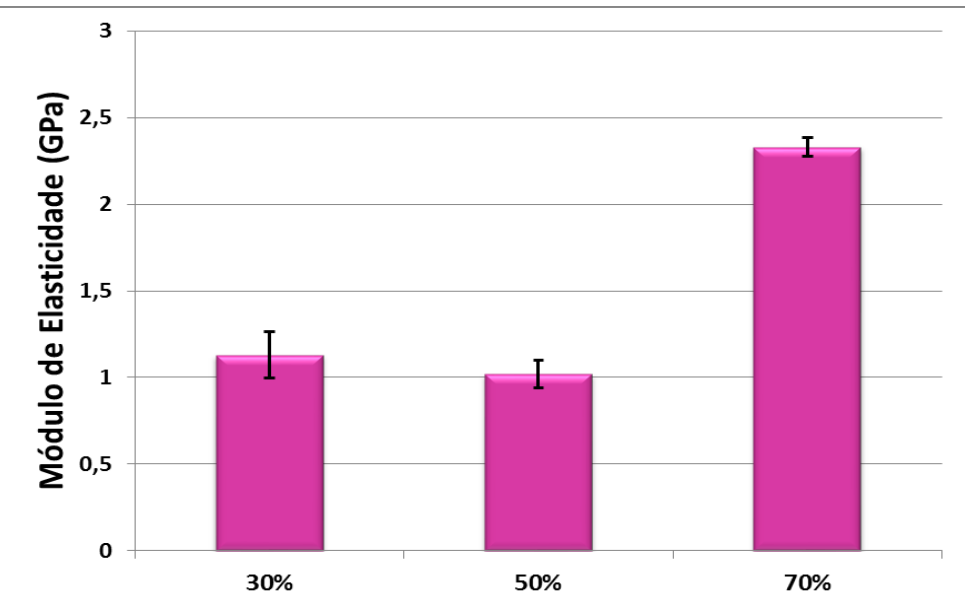

Figura 65: Resultados módulo de elasticidade para os compósitos de formaldeído-lignossulfonato reforçados com fibras de bagaço de cana queimado e tratado (lignossulfonato de sódio+ultrassom/1h) em função da porcentagem de fibra na matriz (30, 50 e $70 \%$ em massa).

O tratamento nas fibras de bagaço queimadas não alterou a propriedade de resistência à flexão, quando comparada a compósitos de mesma matriz (formaldeído-lignossulfonato), permanecendo com valores de resistência à flexão inferiores aos compósitos de matriz fenólica (Figura 48).

\section{8. 2. 2. 5. Absorção de água}

A figura 66 mostra os resultados de porcentagem de absorção de água versus o tempo de imersão (h) dos compósitos. O compósito com 50\% de fibra tratada apresentou menor porcentagem de água absorvida, quando comparado aos demais compósitos deste conjunto. Conforme mostrado na discussão dos resultados de resistência ao impacto, o compósito com $50 \%$ de fibra apresentou desempenho no ensaio comparável ao de $70 \%$ de fibras, provavelmente devido à boa distribuição das fibras na matriz e bom revestimento das fibras pela matriz. O revestimento das fibras pela resina diminuiu a interação destas com as moléculas de água. Para o compósito com $70 \%$ de fibra é provável que tenha ocorrido o contato fibra-fibra, devido o alto teor das mesmas e, portanto, menor quantidade de resina, prejudicando o recobrimento destas fibras. 


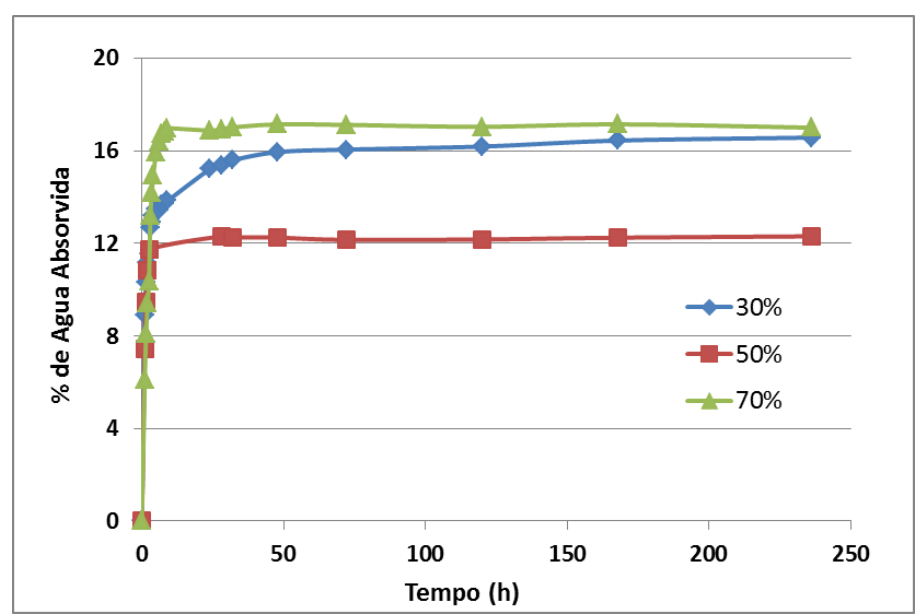

Figura 66: Resultado do ensaio de absorção de água para os compósitos de formaldeídolignossulfonato reforçados com fibras de bagaço de cana queimado e tratado (lignossulfonato de sódio+ultrassom/1h) em função da porcentagem de fibra na matriz (30, 50 e 70\% em massa)(CFLBC).

As características da interação fibra/matriz, na região de interface, são refletidas na porcentagem de água absorvida pelo compósito, quando exposto a um ambiente de alta umidade, ou imersos em água, como no presente trabalho.

Intensificar a interação de grupos polares nas fibras com os grupos polares na matriz, melhora a interface e o recobrimento das fibras, disponibilizando menor quantidade de grupos polares para interagir com moléculas de água, e assim a porcentagem de água absorvida pelo material é menor.

No entanto, os compósitos reforçados com fibras de bagaço de cana tratada absorveram uma porcentagem de água maior quando comparado aos demais compósitos já apresentados (Figuras 51, 58 e 63). Estruturas típicas de lignossulfonato que se adsorveram na superfície das fibras, ricas em grupos polares, além de interagir com sítios polares da matriz podem interagir com moléculas de água durante o ensaio, contribuindo para o aumento de massa de água absorvida. 
5. 8. 3. Compósitos de matriz formaldeído-lignina organossolve (FLO), glutaraldeído-lignina organossolve (GLO) e glutaraldeído-lignossulfonato de sódio (GL)

\section{8. 3. 1. Compósitos reforçados com fibras bagaço de cana queimado}

Resinas foram preparadas com lignina organossolve (macromolécula de origem natural) com formaldeído e glutaraldeído, como discutido anteriormente. A partir destas resinas os compósitos reforçados com fibras de bagaço de cana queimado foram preparados e ensaiados com a finalidade de avaliar a influência das diferentes resinas nas propriedades do produto final.

\section{8. 3. 1. 1. Ensaio de Impacto}

Compósitos reforçados com fibras de bagaço de cana foram preparados com cinco diferentes tipos de matrizes. O processo que levou ao compósito de matriz fenol-formaldeído foi utilizado como base para a preparação dos demais.

A figura 67 mostra os corpos de prova após o ensaio de impacto. Observa-se que as fibras não apresentaram o fenômeno "fiber bridging" por serem fibras curtas, diferentes das amostras que foram preparadas com fibras de sisal (Figura 74), discutidas posteriormente. Este fenômeno de "fiber bridging" é geralmente observado em compósitos preparados com fibras, como, sisal e coco, que apresentam características de maior rigidez e resistência. Geralmente, são utilizadas em comprimentos iguais ou maior que $3 \mathrm{~cm}$, como reforço em compósitos (OLIVEIRA, 2010; RAZERA, 2006). 


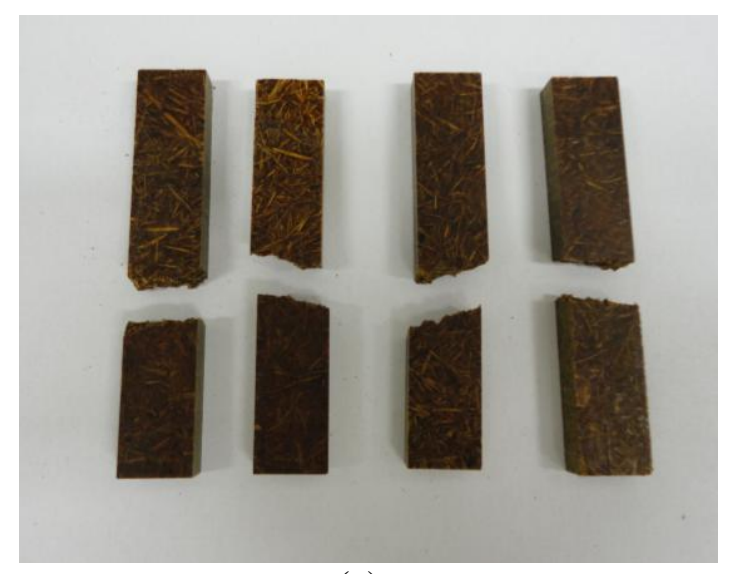

(a)

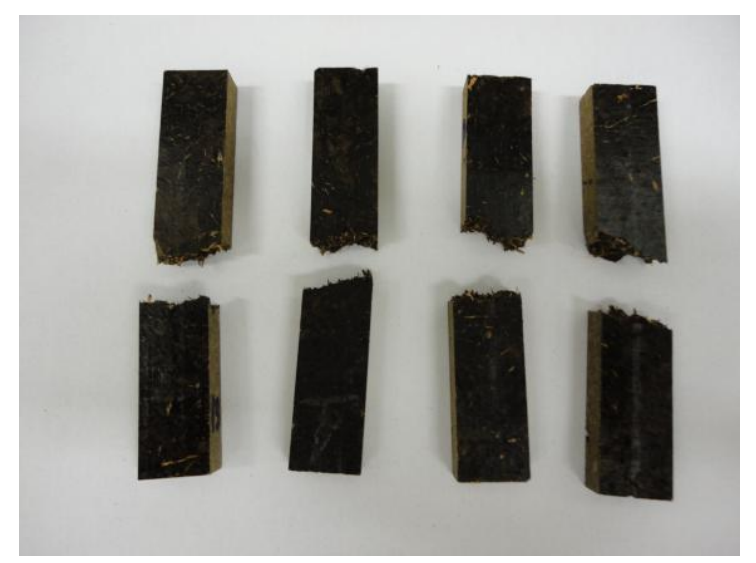

(b)

Figura 67: Corpos-de-prova pós-fratura de compósitos: (a) formaldeído-lignossulfonato de sódio; (b) formaldeído-lignina organossolve, reforçados com fibras de bagaço de cana queimado $(30 \%$ em massa; comprimento médio: $1,5 \mathrm{~cm})$.

A figura 68 mostra o baixo valor de resistência ao impacto do termorrígido fenólico, usado em termos de comparação. Quando reforçado com fibras de bagaço de cana queimadas (CFen), observa-se uma melhora considerável resistência, embora ainda seja o de menor valor de resistência com relação aos demais deste conjunto.

Quando o fenol é substituído pela lignina organossolve (CGLO), no preparo da resina, este valor aumenta consideravelmente (de 45,31 $\mathrm{Jm}^{-1}$ para $73,81 \mathrm{Jm}^{-1}$ ). Um aumento significativo no valor de resistência ao impacto é gerado pela substituição do formaldeído pelo glutaraldeído (CGLO, Figura 68).

Com relação às ligninas utilizadas, os compósitos onde a lignina organossolve foi usada na formulação da matriz, apresentaram valores superiores de resistência, quando comparado aos compósitos preparados com matriz baseada em NaLS. 


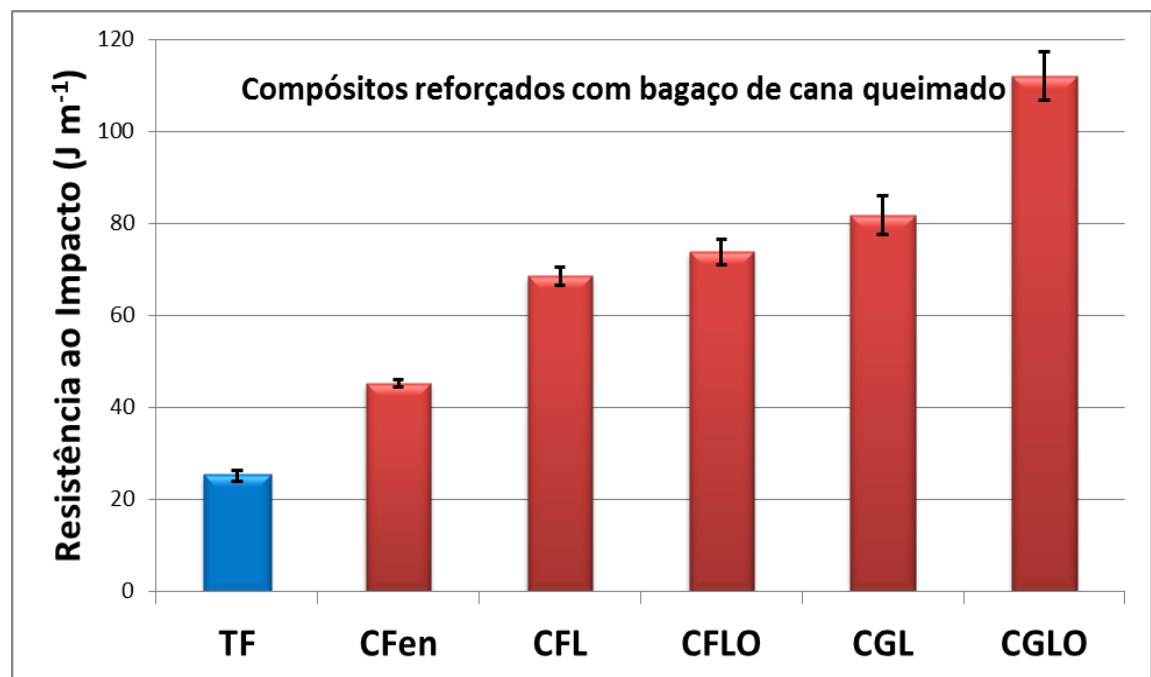

Figura 68: Resistência ao impacto Izod dos compósitos com diferentes tipos de matrizes: compósito fenólico (CFen); compósito glutaraldeído-lignina organossolve (CGLO); compósito formaldeídolignina organossolve (CFLO); compósito formaldeído-lignossulfonato de sódio (CFL); compósito glutaraldeído-lignossulfonato (CGL) reforçados com fibras de bagaço de cana queimado (BCQ, $30 \%$ em massa).

Dentre os compósitos reforçados com fibras de bagaço de cana, o que apresentou melhor resultado de resistência ao impacto foi o compósito preparado com resina do tipo glutaraldeído-lignina organossolve. Os resultados de resistência ao impacto (Figura 68) podem estar relacionados aos resultados de IGC da matriz glutaraldeído- lignina organossolve, destacando que esta apresentou maior valor de energia de superfície, assim como alto teor de sítios ácido/base disponíveis, quando comparada as demais matrizes analisadas (Tabela 21). Conforme discutido anteriormente, o uso do glutaraldeído como substituto do formaldeído no preparo da resina pode ter levado a um produto em que o arranjo estrutural disponibilizou maior número de sítios aceptores/doadores, comparada as demais matrizes. As características da matriz CGLO associadas às da fibra de bagaço queimada, resultaram em fortes interações na interface (fibra/matriz), favorecendo a transferência de carga da matriz para a fibra. 


\section{8. 3. 1. 2. $M E V$}

Para obter maiores informações sobre o feito da mudança de matriz com relação às fibras de bagaço de cana queimado, logo após o ensaio de impacto das amostras (item 5.8.3.1.2) foram obtidas microscopias da superfície das regiões de fratura (Figura 69).

Os compósitos, em que a matriz foi preparada a partir de lignina organossolve, apresentaram características semelhantes aos compósitos com matriz baseada em NaLS, quando reforçados com fibras de bagaço de cana queimado (Figura 69), apresentando fibras rompidas no mesmo plano de fratura da matriz, com poucas regiões em que as fibras foram arrancadas da matriz (figura não apresentada).

Na região de interface (fibra/matriz), após o ensaio de impacto, há uma quantidade maior de fibras que são descoladas da matriz baseada em lignina organossolve, CFLOBC (Figuras 69a, b, c, d). Para os compósitos de matriz baseada em NaLS observa-se, na região de interface, que o descolamento não ocorre e as fibras permanecem aderidas à matriz (Figura 69e, 69f).

O compósito CGLOBC apresentou o melhor resultado de resistência ao impacto, quando comparado aos demais compósitos deste conjunto, e também as imagens mostraram a boa compatibilidade entre a matriz glutaraldeído-lignina organossolve com as fibras de bagaço de cana. Esta adesão fibra/matriz é evidenciada pela figura 69a e 69b, na região de interface (indicada pelas setas azuis). 


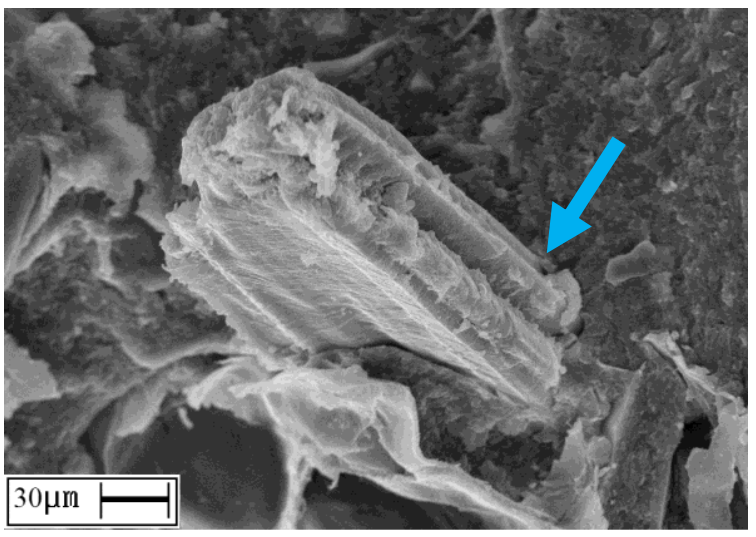

(a)

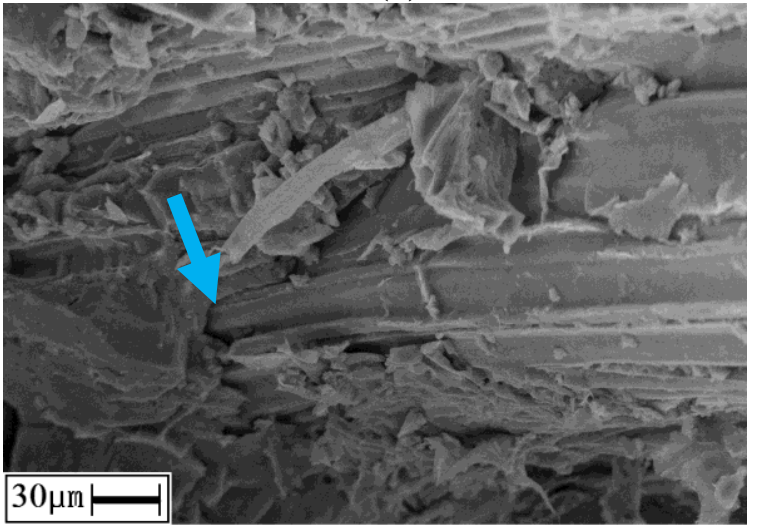

(c)

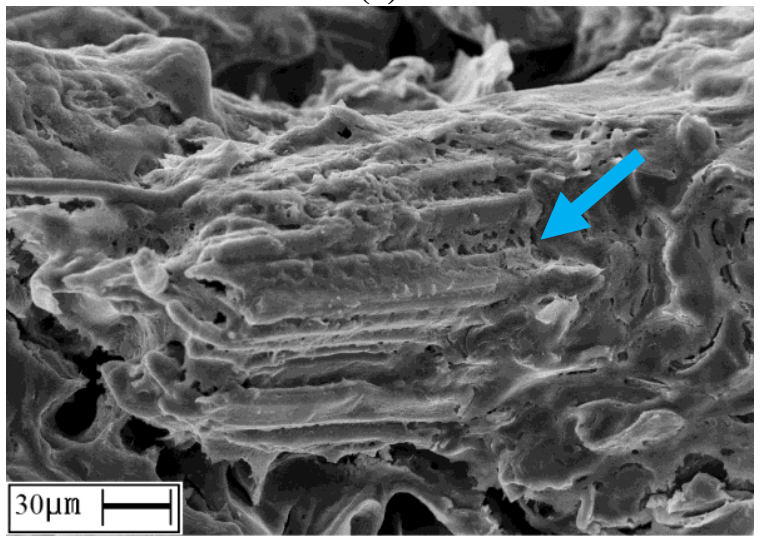

(e)

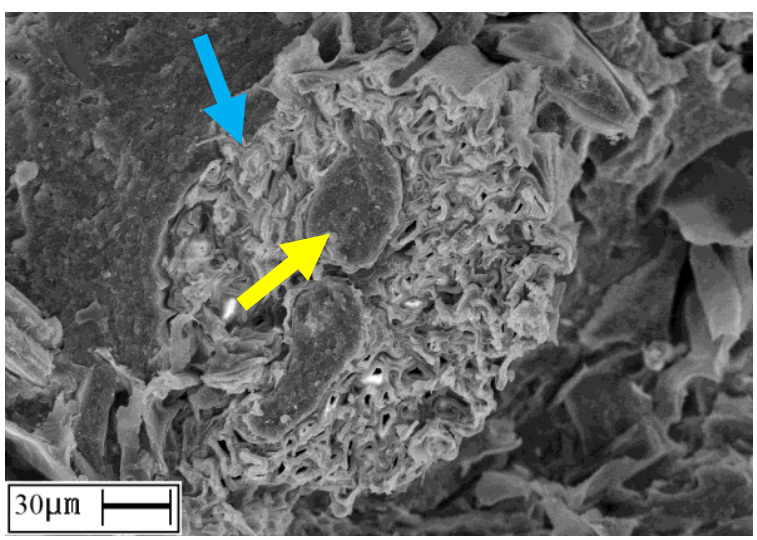

(b)

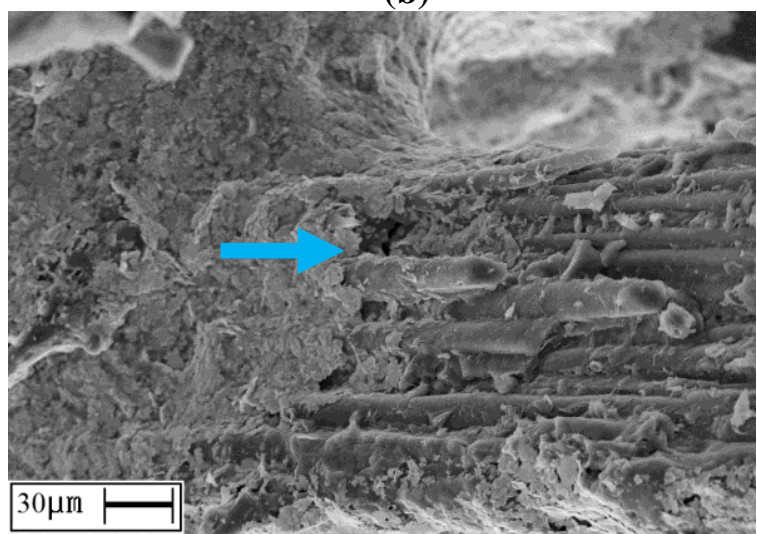

(d)

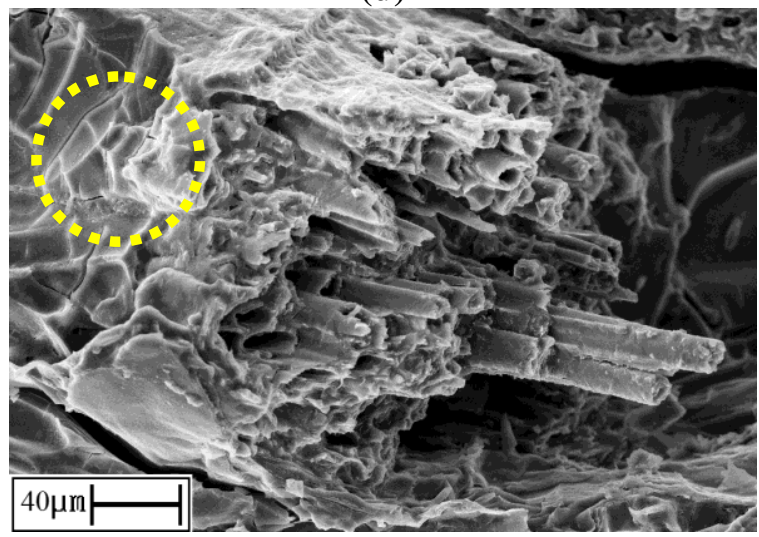

(f)

Figura 69: Microscopia eletrônica de varredura dos compósitos de reforçados com fibras de bagaço de cana queimado reforçados com fibras de bagaço de cana queimado (30\% em massa) com diferentes tipos de matrizes; (a, b) compósito glutaraldeído-lignina organossolve (CGLOBC); (c, d) compósito formaldeído-lignina organossolve (CFLOBC); (e, f) compósito glutaraldeídolignossulfonato de sódio (CGLBC).

A resina, além de recobrir a superfície das fibras, também penetrou nos "canais" internos destas (Figuras 69b, indicado pela seta amarela). Este fato mostra que o processo de impregnação das fibras pela resina foi eficiente (indicado pela seta azul). 
Para todos os compósitos reforçados com fibras de bagaço de cana, independente do tipo de matriz e quantidade de fibras, a distribuição das fibras foi sempre homogênea. Esta boa distribuição permite que a transferência de carga fibra/matriz ocorra de maneira mais eficiente, pois a presença de aglomerados leva ao contato fibra/fibra prejudicando principalmente as propriedades mecânicas do compósito.

Na figura 69f é possível observar a presença de microtrincas ao redor da fibra (circulo amarelo), mostrando que houve o efeito de transferência de carga sofrida pela matriz e levada à fibra, durante o ensaio de impacto. Este processo é indicado pela propagação da trinca, através da matriz, até encontrar a fibra. Ao encontrar a fibra, a trinca se propaga ao redor desta. Desta maneira, a energia envolvida no processo é distribuída através da trinca e absorvida pela fibra. A energia absorvida pela fibra leva ao rompimento parcial das interações presentes na interface, provocando assim o descolamento destas.

\section{8. 3. 1. 3. Ensaio de Flexão}

Compósitos baseados em diferentes tipos de matrizes foram reforçados com fibras de bagaço de cana queimada, passaram também pelo ensaio de flexão. Os valores obtidos para este conjunto de compósitos são observados na figura 70.

Os resultados indicam uma tendência de aumento nos valores de resistência à flexão quando o fenol foi substituído pela lignina organossolve e lignossulfonato de sódio.

Neste ensaio, os compósitos preparados com matriz baseada em formaldeído apresentaram valores maiores que os preparados com matriz baseada em glutaraldeído, apesar de os desvios aproximarem os valores, como indicado na figura 70 pelas linhas vermelhas. 


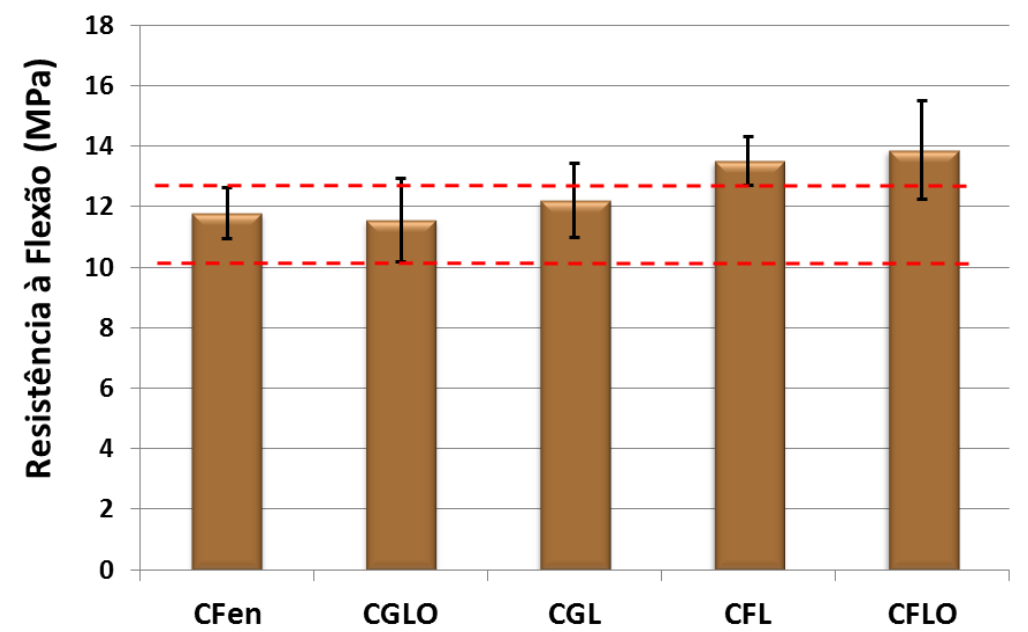

Figura 70: Resistência à flexão Izod dos compósitos de reforçados com fibras de bagaço de cana queimado (30\% em massa) com diferentes tipos de matrizes; compósito fenólico (CFen); compósito glutaraldeído-lignina organossolve (CGLO); compósito formaldeído-lignina organossolve (CFLO); compósito formaldeído-lignossulfonato de sódio (CFL); compósito glutaraldeído-lignossulfonato (CGL).

Os compósitos CGLO e CGL, preparado com matriz baseada em glutaraldeído, apresentam resultados de módulo de elasticidade maior que os demais compósitos, como mostrado na figura 71

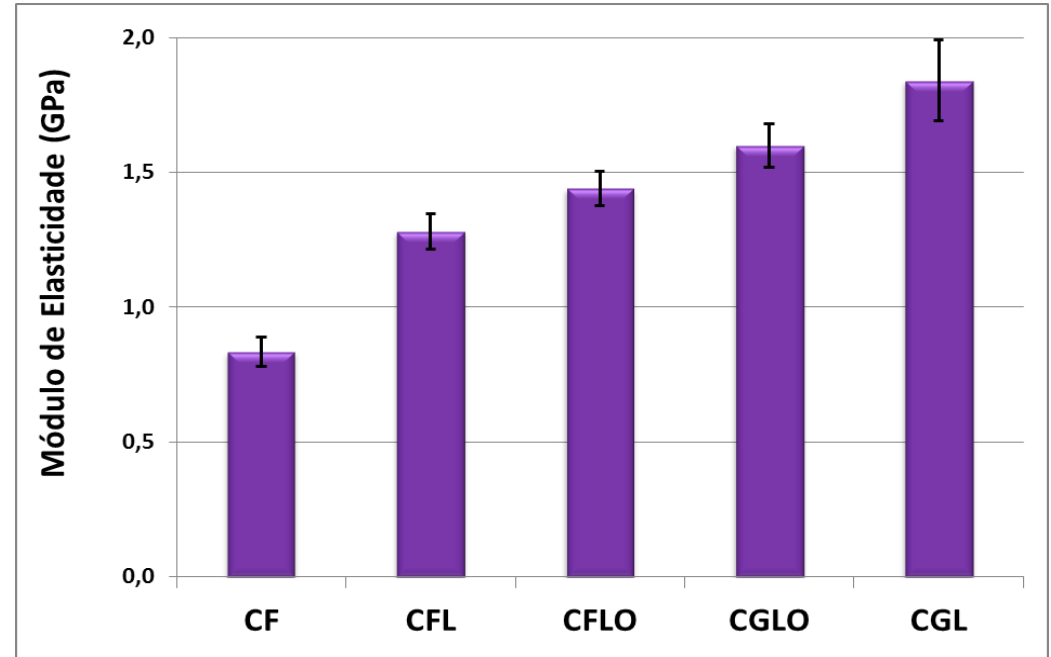

Figura 71: Resultados de módulo de elasticidade dos compósitos de reforçados com fibras de bagaço de cana queimado (30\% em massa) com diferentes tipos de matrizes; compósito fenólico (CFen); compósito glutaraldeído-lignina organossolve (CGLO); compósito formaldeído-lignina organossolve (CFLO); compósito formaldeído-lignossulfonato de sódio (CFL); compósito glutaraldeídolignossulfonato (CGL). 
O grau de rigidez dos materiais está ligado ao grau de entrecruzamento das cadeias poliméricas e a distância entre estas cadeias. Grupos provenientes do glutaraldeído podem ter influenciado nestes parâmetros físico-químicos tornando a matriz menos rígida.

\section{8. 3. 1. 4. Absorção de água}

Os compósitos preparados com fibras de bagaço de cana queimada com diferentes tipos de matriz, conforme explicado anteriormente, foram ensaiados segundo as normas de absorção de água, obtendo-se os resultados mostrados na figura 72.

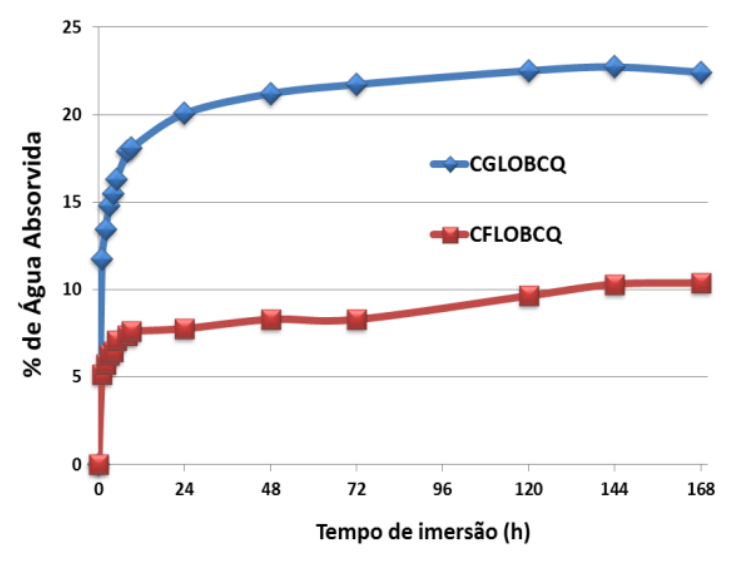

(a)

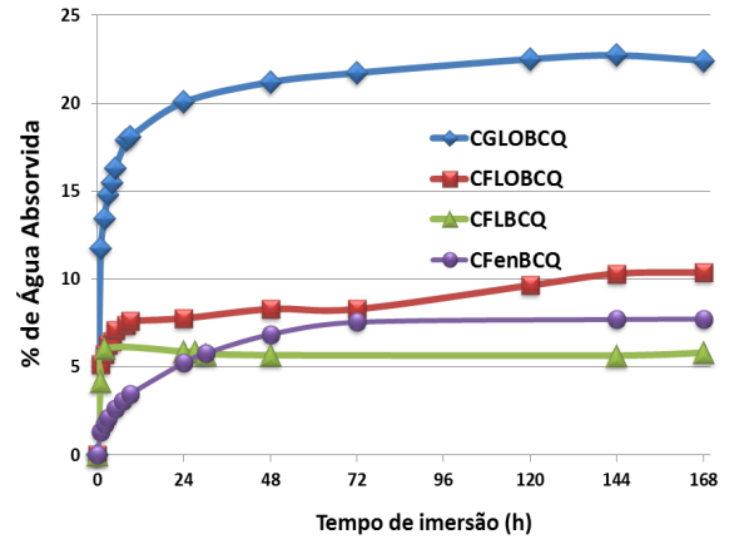

(b)

Figura 72: Ensaio de absorção de água dos compósitos de reforçados com fibras de bagaço de cana queimado (30\% em massa) com diferentes tipos de matrizes; (a, b) compósito glutaraldeído-lignina organossolve (CGLOBCQ); compósito formaldeído-lignina organossolve (CFLOBCQ); (b) compósito formaldeído-lignossulfonato bagaço de cana queimado (CFLBCQ); compósito fenólico bagaço de cana queimado (CFenBCQ).

Estes resultados mostram que o compósito CFLOBCQ apresentou melhor resultado quando comparado ao compósito CGLOBCQ no ensaio de absorção de água (Figura 72), sendo possível que as fibras no compósito CFLOBCQ tenham sido melhor revestidas pela matriz.

$\mathrm{Na}$ figura $72 \mathrm{~b}$ podem ser observadas as diferenças de porcentagem de massa de água absorvida pelos compósitos quando o fenol é substituído pelas ligninas organossolve (LO) e 
lignossulfonato de sódio (NaLS), sendo que praticamente o comportamento do material para este ensaio foi não alterado. Porém, quando o formaldeído é substituído pelo glutaraldeído, a porcentagem de água absorvida é bem maior quando comparado aos demais compósitos.

\section{8. 3. 2. Compósitos reforçados com fibras de sisal}

Estudos realizados em outros trabalhos, inseridos no mesmo grupo de pesquisa do atual (Grupo de Macromoléculas e Fibras Lignocelulósicas), mostraram que a fibra de sisal é umas das fibras lignocelulósicas que mais se destacam quando aplicadas como reforço em compósitos (SILVA, 2006; RAMIRES, 2009; MEGIATTO, 2006; OLIVEIRA, 2010).

Neste contexto, desenvolveu-se o estudo dos compósitos reforçados com fibras de sisal (30\% em massa, comprimento de $3 \mathrm{~cm}$ ) variando a composição da matriz, de acordo com os reagentes usados:

1. lignina organossolve e formaldeído;

2. lignossulfonato de sódio e formaldeído;

3. lignina organossolve e glutaraldeído;

4. lignossulfonato de sódio e glutaraldeído.

Os parâmetros de massa $(30 \%)$ e comprimento $(3 \mathrm{~cm})$ da fibra foram baseados em estudos anteriores (SILVA, 2006; PAIVA, 2002; MEGIATTO, 2006; OLIVEIRA, 2010; RAMIRES, 2009). Mesmo usando diferentes comprimentos de fibra, pretendeu-se também um estudo comparativo com as fibras de bagaço de cana queimadas. 


\section{8. 3. 2. 1. Ensaio de Impacto}

Compósitos reforçados com fibras de sisal foram preparados em diferentes tipos de matrizes a base de lignina (organossolve e lignossulfonato de sódio) usando glutaraldeído ou formaldeído como reagente no preparo das resinas.

Os resultados de impacto dos compósitos estão apresentados na figura 73. O preparo de termorrígidos a partir destas resinas não foi possível, pois estes se apresentaram mais frágeis que o termorrígido fenólico, não sendo possível a realização de ensaios mecânicos. Resultados excelentes de resistência foram obtidos com a adição das fibras de sisal a estas resinas, para o preparo de placas de compósitos.

A figura 73 mostra claramente que a substituição do fenol pelo lignossulfonato de sódio (CGLS e CFLS) foi mais eficiente, do que quando substituído pela lignina organossolve. Resultados obtidos de resistência ao impacto foram excelentes, principalmente o que se refere ao compósito CFLS (1029 J m $\left.{ }^{-1}\right)$.

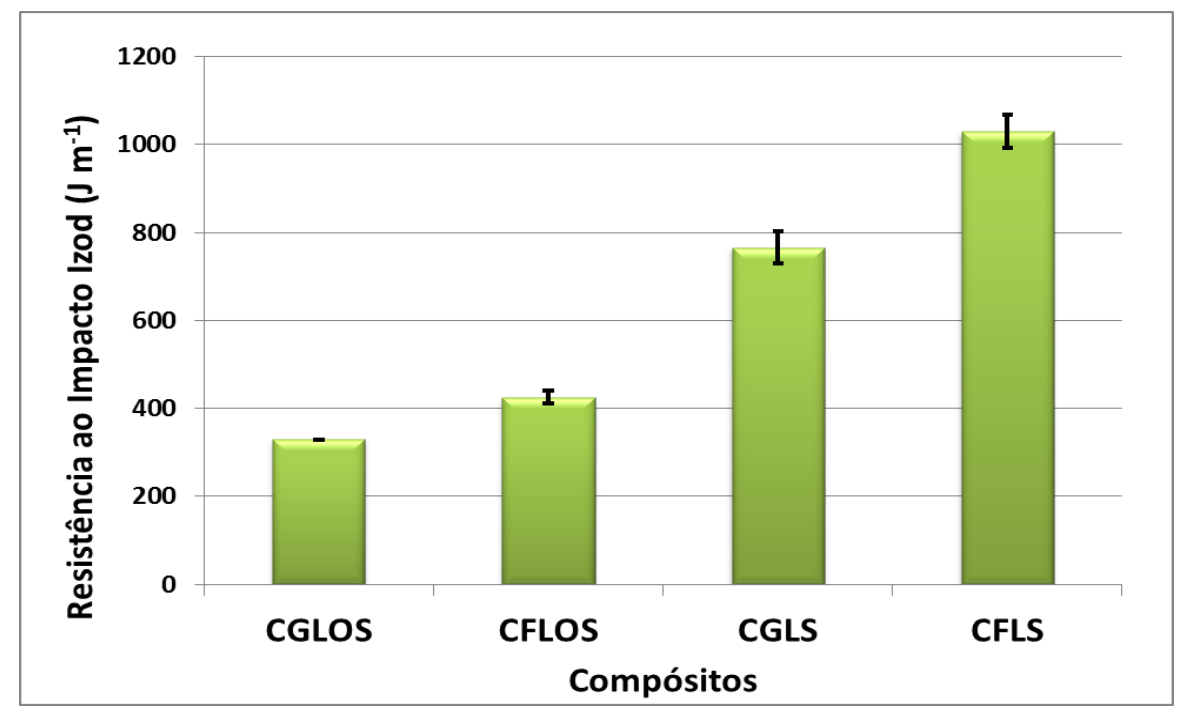

Figura 73: Ensaio de resistência ao impacto Izod para os compósitos de reforçados com fibras de sisal (30\% em massa) com diferentes tipos de matrizes; compósito glutaraldeído-lignina organossolve (CGLOS); compósito formaldeído-lignina organossolve (CFLOS); compósito formaldeídolignossulfonato de sódio (CFLS); compósito glutaraldeído-lignossulfonato (CGLS). 
Os resultados mostram que a resina preparada com formaldeído resultou em compósitos mais resistentes, quando comparado ao compósito preparado com resina baseada em glutaraldeído. Grupos polares (sulfonatos e hidroxilas) presentes nas resinas, RFL e RFLO, devem ter interagido de maneira mais eficiente com grupos polares presentes na superfície das fibras de sisal resultando em excelentes valores de resistência ao impacto (Figura 73).

A interação eficientemente das resinas com as fibras de sisal, a qual apresenta superfície rica em hidroxilas disponível para interação com a resina, intensificou a adesão fibra/matriz na interface. Todos estes compósitos apresentaram o fenômeno "fiber bridging" (Figura 74) indicativo de boa adesão na interface fibra/matriz.

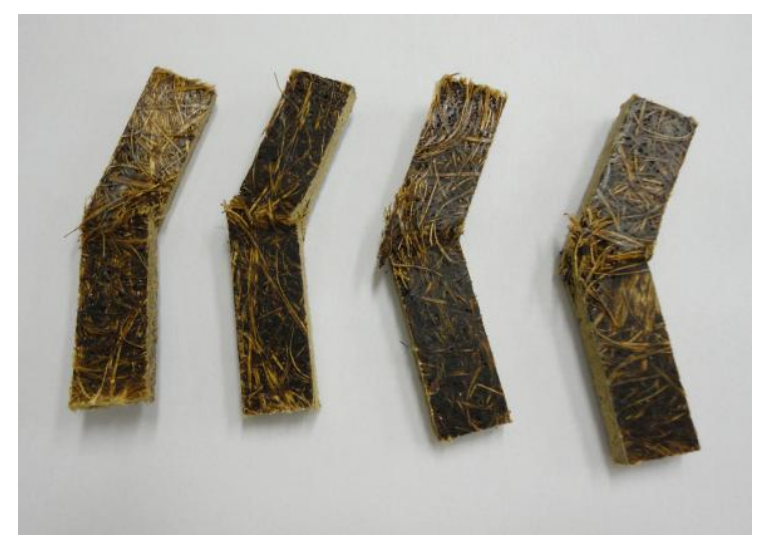

(a)

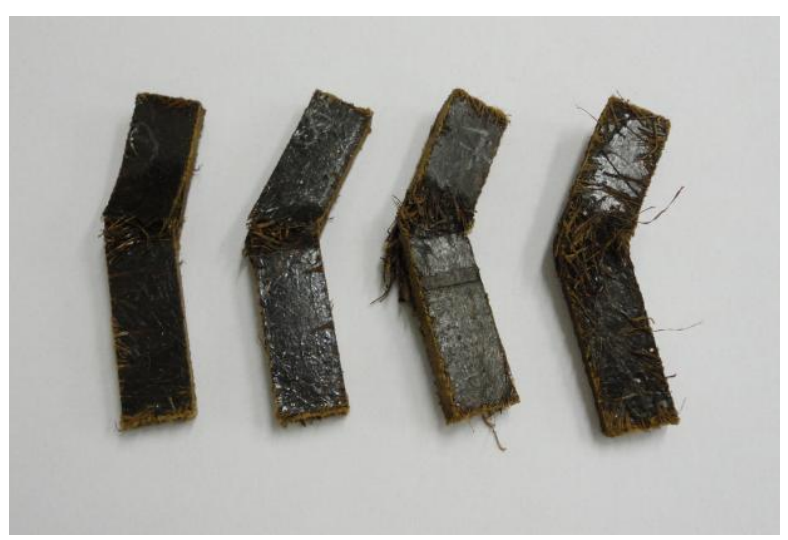

(b)

Figura 74: Corpos-de-prova após o ensaio de Impacto Izod: (a) glutaraldeído-lignossulfonato de sódio/sisal (CGLS); (b) glutaraldeído-lignina organossolve/sisal (CGLOS).

Pode-se afirmar que os resultados de todos os compósitos reforçados com fibras de sisal são promissores, pois estes apresentam valores de resistência ao impacto maior que os encontrados na literatura.

No geral, os trabalhos inseridos neste grupo de pesquisa apresentaram em média valores de resistência ao impacto entre 340 e $512 \mathrm{Jm}^{-1}$, para compósitos com 30\% (em massa) de fibra de sisal em matriz fenólica (PAIVA, 2001, MEGIATTO, 2006, RAMIRES, 2009). O 
resultado obtido para o compósito CFLS está condizente ao apresentado por Oliveira (2010) com valor de resistência ao impacto de $1000 \mathrm{Jm}^{-1}$.

Diferentes resultados foram obtidos para os compósitos de mesma matriz, quando as fibras de bagaço de cana foram substituídas pela fibra de sisal. Os ensaios mostraram que o mesmo tipo de matriz pode apresentar comportamentos distintos quando reforçados com tipos de fibras distintas. Características das fibras devem ser levadas em consideração, como o teor de seus componentes, cristalinidade, resistência à tração, entre outros fatores que podem influenciar na interação e na adesão das fibras com a matriz e na capacidade de resistência da fibra.

\section{8. 3. 2. 2. $M E V$}

Os compósitos preparados para o ensaio de impacto foram analisados por microscopia eletrônica de varredura para avaliar a região de fratura das amostras (Figura 75).

Para estes compósitos, diferentemente dos compósitos com fibras de bagaço de cana, não foi possível observar com clareza a interface das fibras com a matriz tão facilmente, como foi observado para os demais compósitos. Isso ocorreu devido ao fato estes compósitos apresentarem o efeito "fiber briging" (Figura 74). 

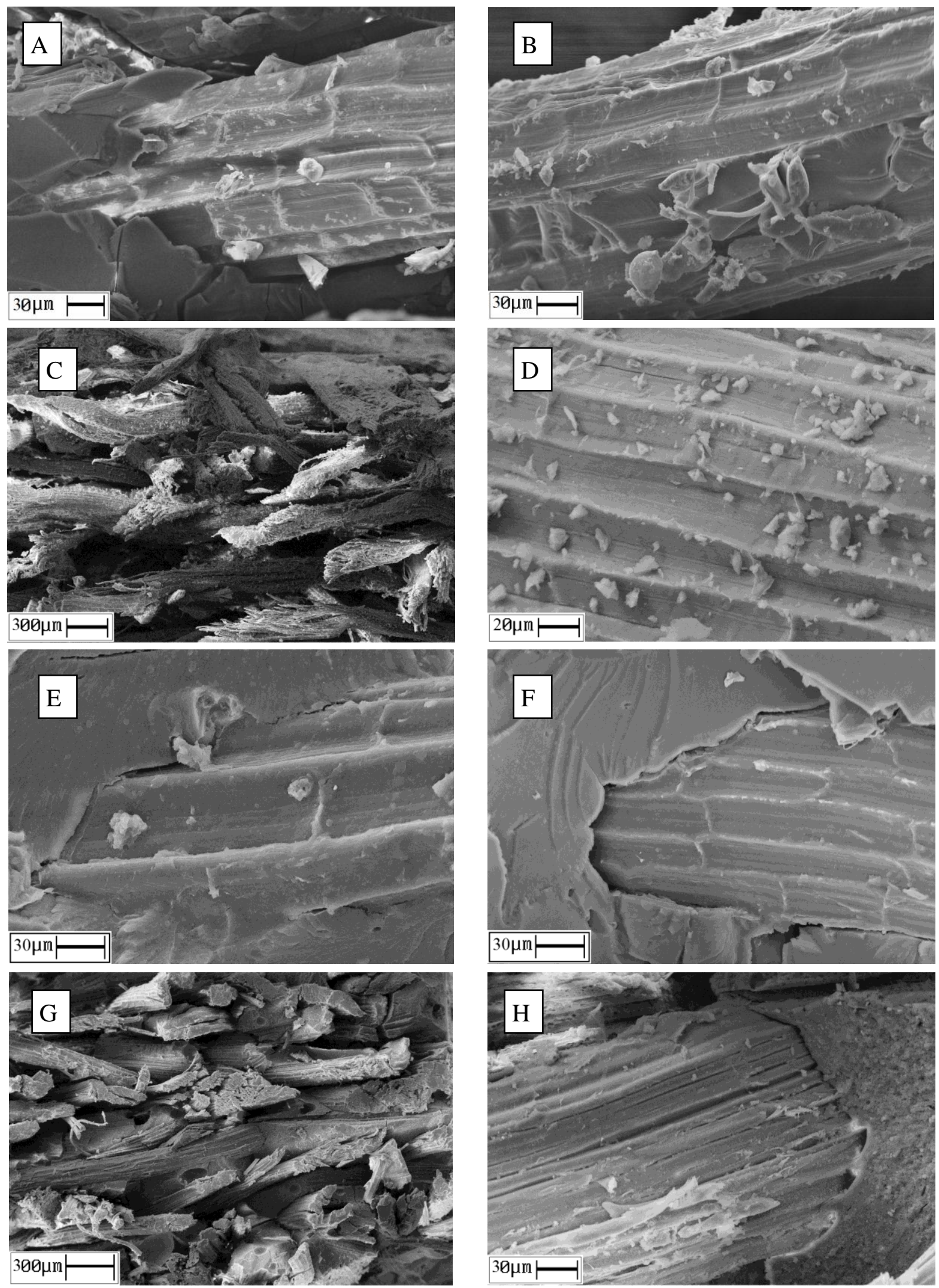

Figura 75: Microscopia eletrônica de varredura para os compósitos de reforçados com fibras de sisal

(30\% em massa) com diferentes tipos de matrizes: $(\mathrm{a}, \mathrm{b})$ compósito glutaraldeído-lignossulfonato (CGLS); (c, d) compósito glutaraldeído-lignina organossolve (CGLOS); (e, f) compósito formaldeído-lignossulfonato de sódio (CFLS); (g, h) compósito formaldeído-lignina organossolve (CFLOS). 
Durante a análise não foram observados sinais de arrancamento de fibras (mecanismo de "pull out") da matriz devido o ensaio de impacto, indicando que a fibra de sisal é um bom reforço para estas matrizes. Também a boa interação na interface das fibras com a matriz justifica os elevados valores de resistência ao impacto.

Regiões ao redor de algumas fibras, como por exemplo, para o compósito CGLS (Figura 75a) apresentaram propagações de trincas, indicando a transferência de carga para as fibras durante o ensaio de impacto.

As imagens de microscopia mostram que no geral as fibras se apresentaram bem distribuídas pela matriz e recobertas pela resina, justificando os excelentes resultados obtidos no ensaio de impacto. Diversos fatores podem influenciar no desempenho dos materiais reforçados. Analisando o conjunto de resultados observa-se que as características das fibras, assim como da matriz, são de grande importância para as propriedades finais do compósito. A substituição de qualquer material (fibras) ou reagente (formaldeído ou glutaraldeído) no preparo do compósito pode alterar as propriedades finais.

Estes efeitos podem ser verificados tanto nos ensaio mecânicos (impacto e flexão) quanto nas micrografias obtidas. Para um mesmo tipo de matriz foi observado comportamento distinto, quando o tipo de fibra foi alterado. Esta diferença foi notada quando compara-se as micrografias da figura 69 com a figura 75. O comportamento das fibras é diferente nas regiões de interface com a matriz, pois a composição química e teor de grupos polares presentes na superfície são diferentes.

\section{8. 3. 2. 3. Ensaio de Flexão}

As fibras de sisal foram utilizadas como reforço em diferentes tipos de matrizes conforme descrito no item 2 (Experimental).

Este trabalho e em diversos outros encontrados na literatura, mencionados anteriormente, evidenciam que as fibras de sisal quando utilizadas como reforço levam a 
compósitos com bons resultados de resistência ao impacto (Figura 73). O ensaio de resistência à flexão foi utilizado para também avaliar as propriedades mecânicas destes materiais.

A figura 76 mostra os resultados de resistência à flexão quando o formaldeído é substituído pelo glutaraldeído, e quando o lignossulfonato de sódio é substituído pela lignina organossolve no preparo da matriz.

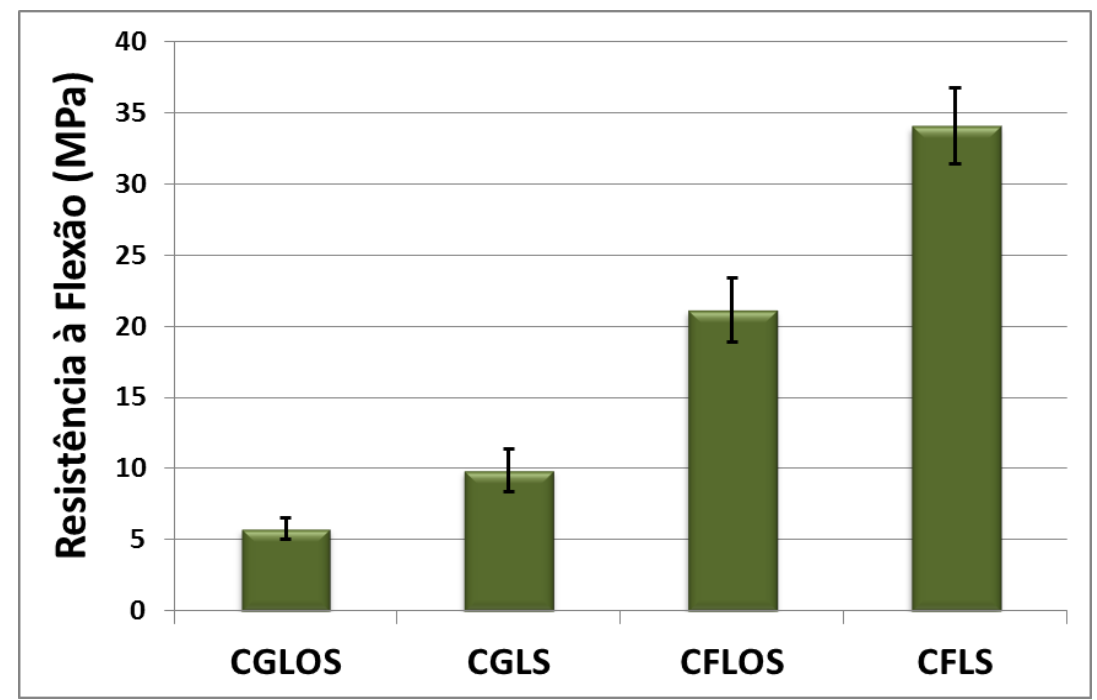

Figura 76: Resultados de resistência à flexão dos compósitos de reforçados com fibras de sisal (30\% em massa) com diferentes tipos de matrizes; compósito glutaraldeído-lignina organossolve (CGLOS); compósito formaldeído-lignina organossolve (CFLOS); compósito formaldeído-lignossulfonato de sódio (CFLS).

Comparando os compósitos CGLOS e CFLOS observa-se que a troca de aldeído, glutaraldeído pelo formaldeído, no preparo de resinas resultou em um o valor de resistência à flexão quatro vezes maior para o compósito preparado com formaldeído. Ainda, para os compósitos CGLOS e CGLS, observa-se que a troca da lignina organossolve pelo lignossulfonato de sódio no preparo de resinas com glutaraldeído, dobrou o valor de resistência à flexão.

Os compósitos que foram preparados a partir de formaldeído (CFLOS e CFLS) apresentaram melhores desempenhos no ensaio de flexão, conforme mostra a figura 76. 
Vale a pena ressaltar que o compósito CFLS apresentou melhor desempenho tanto nos ensaios de impacto quanto de flexão. Também sua resistência à elasticidade (ou flexibilidade) se mantém acima dos demais compósitos (Figura 77). As micrografias de MEV comprovam que as fibras de sisal apresentam uma boa capacidade de absorção de energia durante ensaios mecânicos, evidenciado pela presença de trincas que se propagam pela matriz ao redor das fibras (Figura 75).

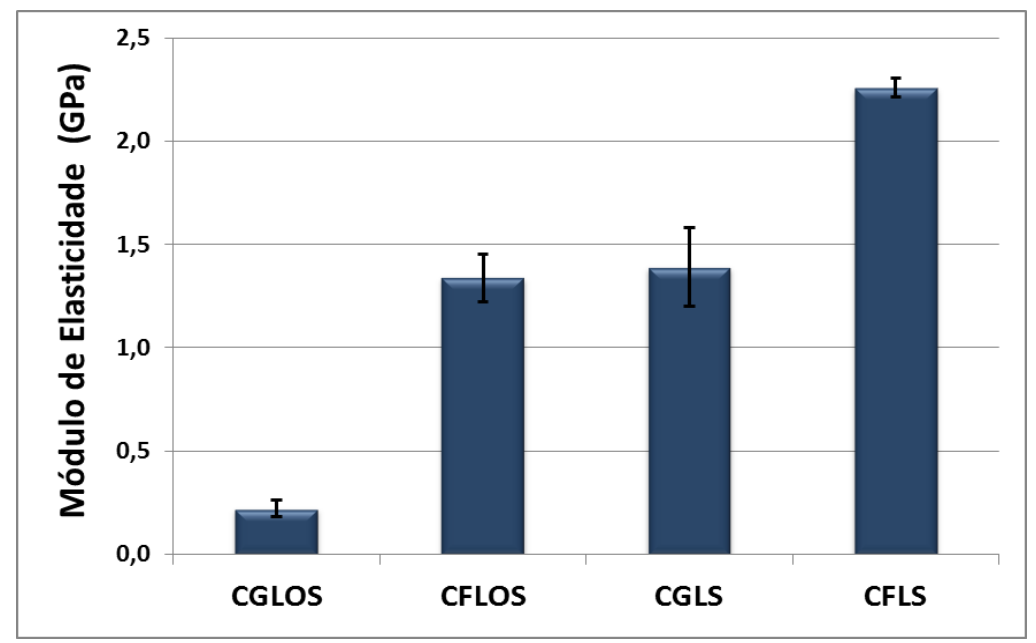

Figura 77: Resultados de módulo de elasticidade dos compósitos de reforçados com fibras de sisal (30\% em massa) com diferentes tipos de matrizes; compósito glutaraldeído-lignina organossolve (CGLOS); compósito formaldeído-lignina organossolve (CFLOS); compósito formaldeídolignossulfonato de sódio (CFLS).

Os compósitos baseados em matriz de lignossulfonato de sódio apresentaram melhores propriedades mecânicas durante os ensaios, quando comparado aos compósitos baseados em matriz de lignina organossolve, indicando que os grupos polares presentes nesta resina podem estar mais disponíveis à interação com os grupos polares das fibras.

Características intrínsecas das resinas preparadas com glutaraldeído, associadas às características das fibras de bagaço de cana (mais curtas e mais flexíveis, comparadas ao sisal) fizeram com que o compósito apresentasse um módulo de elasticidade inferior ao demais compósitos, tanto os reforçados com fibras de sisal (Figura 76) quanto de bagaço de cana (Figura 71). 
Ressalta-se que neste trabalho as fibras de bagaço de cana utilizadas foram de comprimento médio de $1,5 \mathrm{~cm}$ enquanto para as fibras de sisal foram de $3 \mathrm{~cm}$. O comprimento das fibras também é um dos fatores que podem ter influenciado em melhores valores de módulo de flexão e módulo de elasticidade para compósitos reforçados com sisal. Estudos apresentados por Razera (2006) sobre compósitos fenólicos reforçados com fibras de coco e bananeira variando o comprimento das fibras, evidenciam que nos compósitos reforçados com fibras de coco mais longas $(6 \mathrm{~cm})$ a porcentagem de fibras ideal utilizada como reforço é no máximo de 50\% (em massa), enquanto que para as fibras de bananeira o comprimento ideal é de $4 \mathrm{~cm}$, chegando à $90 \%$ de fibra na matriz. Estas proporções podem variar de acordo com as características das fibras, para uma matriz especifica.

\section{8. 3. 2. 4. Absorção de água}

Compósitos foram preparados utilizando fibras de sisal (de comprimento de $3 \mathrm{~cm}$ e $30 \%$ em massa) como reforço em diferentes tipos de matrizes, conforme explicado anteriormente. A afinidade destes materiais por água foi avaliada.

A figura 78 mostra os resultados de porcentagem de água absorvida versus o tempo de imersão das amostras em água. O compósito CFLS (compósito formaldeído-lignossulfonato de sódio reforçado com fibra de sisal, $30 \%$ em massa, comprimento de $3 \mathrm{~cm}$ ) foi a amostra que apresentou o melhor resultado deste conjunto com fibras de sisal, pois com poucas horas de ensaio a massa de água absorvida se mantém constante e menor que $5 \%$. 


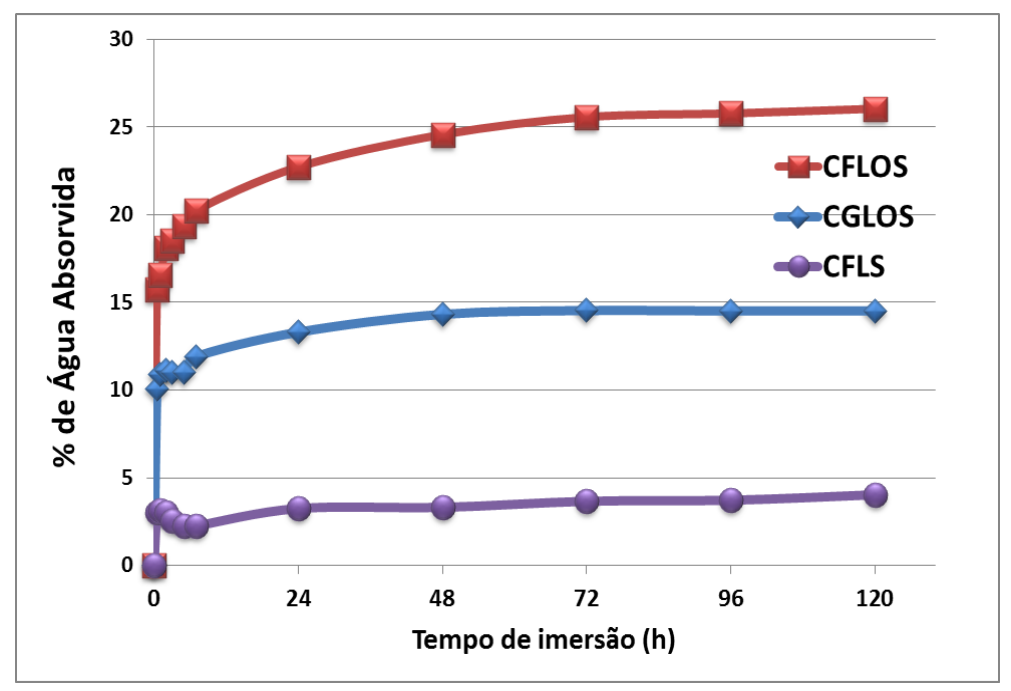

(a)

Figura 78: Absorção de água dos compósitos de reforçados com fibras de sisal (30\% em massa) com diferentes tipos de matrizes: (a) compósito glutaraldeído-lignina organossolve (CGLOS); compósito formaldeído-lignina organossolve (CFLOS); compósito formaldeído-lignossulfonato de sódio (CFLS).

Os compósitos CFLOS e CGLOS preparados com lignina organossolve apresentaram resultados de absorção de água dentro da faixa de porcentagem esperada, como visto anteriormente para os compósitos reforçados com fibras de bagaço de cana. $\mathrm{O}$ estudo feito por Ramires (2010) mostrou um comportamento no mesmo patamar para compósitos de matriz formaldeído-lignina organossolve reforçado com fibras de sisal $(3 \mathrm{~cm}, 30 \%$ em massa), em que $18 \%$ de água foi absorvida (até o ponto de saturação). Destaca-se novamente que neste ensaio, foram usadas condições mais drásticas que aquelas normalmente encontradas na aplicação deste tipo de material, pois corpos de prova sem proteção lateral foram imersos em água. Na aplicação, normalmente os materiais são protegidos por revestimentos (as fibras não ficam expostas nas laterais), e são sujeitas à umidade do ar, e não imersos em água. 


\section{Conclusões}

Os termorrígidos preparados com formaldeído-lignossulfonato de sódio e lignina organossolve apresentaram grande fragilidade, não sendo possível preparar amostras com dimensões adequadas para os ensaios de impacto. Mas, quando as fibras foram adicionadas à matriz, compósitos com propriedades promissoras foram obtidos, conforme indicado pelos resultados de impacto e flexão.

Compósitos de matriz fenólica reforçados com fibras de bagaço de cana queimado e não queimado não mostraram diferenças significativas nos ensaios aplicados, indicando que ambas as fibras podem ser utilizadas como reforço, dependendo da disponibilidade.

A adsorção do lignossulfonato de sódio às fibras de bagaço de cana, através do tratamento, pode ser avaliada pela análise de IGC, mostrando que houve um aumento de sítios ácidos (ANs) e básicos (DNs) disponíveis na superfície da fibra, quando comparado aos resultados da fibra não tratada. Este tratamento também resultou na alteração de básico para ácido, quanto ao caráter da fibra. O tratamento refletiu nos resultados de resistência ao impacto dos compósitos, pois a resistência do compósito com $50 \%$ de fibra não tratada era de $66 \mathrm{Jm}^{-1}$ e, após o tratamento, o valor foi elevado para $93 \mathrm{Jm}^{-1}$. O tratamento das fibras pode ter levado à melhora de adesão na região de interface fibra/matriz, devido à intensificação das interações entre ambos.

Para compósitos de matriz fenólica e formaldeído-lignossulfonato reforçados com fibras de bagaço de cana, observou-se que o aumento na proporção de fibras $(30,50$ e $70 \%$, em 
massa) resultou em um aumento gradativo nos valores de resistência ao impacto. O aumento de até $70 \%$ de fibra no compósito não alterou o desempenho deste no ensaio de absorção de água. Compósitos com alto teor de fibras naturais são fortes candidatos à substituição de materiais sintéticos, principalmente pela disponibilidade do bagaço de cana de açúcar pela agroindústria em grande escala.

Compósitos reforçados com fibras de bagaço de cana (30\%, em massa) em diferentes tipos de matriz, apresentaram bons resultados nos ensaios mecânicos, resistência ao impacto e flexão, destacando-se o compósito de matriz baseada em glutaraldeído-lignina organossolve (CGLOBC) resistência ao impacto de $112 \mathrm{Jm}^{-1}$. Os resultados mostraram que glutaraldeído pode ser utilizado como substituto do formaldeído no preparo de resinas baseadas em lignina organossolve.

Compósitos reforçados com fibras de sisal, conforme esperado, apresentaram excelente desempenho nos ensaios mecânicos, variando a propriedade de acordo com o tipo de matriz empregada. No geral, excelentes resultados foram obtidos para compósitos nos ensaios mecânicos, com destaque para o compósito preparado com a resina formaldeídolignossulfonato de sódio com excelente desempenho em todos os ensaios, alto valor de resistência ao impacto $\left(1029 \mathrm{Jm}^{-1}\right)$, resistência à flexão e baixa absorção de água.

O conjunto de resultados dos compósitos correspondentes ao ensaio de absorção de água mostrou que, principalmente, os compósitos preparados com matriz baseada em lignossulfonato de sódio, apresentaram rápida estabilização e baixos valores de massa de água absorvida. Esta característica também é um importante fator para a aplicação dos compósitos.

Os resultados obtidos mostraram que compósitos podem ser preparados a partir de alto teor de matéria prima obtida de fonte renovável, tanto na matriz quanto no reforço, com indicação para aplicações não estruturais. 


\section{Referências Bibliográficas}

ACHA, B. A.; MARCOVICH, N. E.; REBOREDO, M. M. Lignin in Jute FabricPolypropylene Composites. Journal of Applied Polymer Science, v. 113, p. 1480-1487, 2009.

ALAM, M. MD.; AHMED, T.; HAQUE, MD. M.; GAFUR, M. A.; KABIR, A. N. M. H. Mechanical Properties of Natural Fiber Containing Polymer Composites. Polymer-Plastics Technology and Engineering, v. 48, p. 110-113, 2009.

ALONSO, M.V.; OLIET, M.; PÉREZ, J.M.; RODRIGUEZ, F.; ECHEVERRIA J. Determination of curing kinetic parameters of lignin-phenol-formaldehyde resol resins by several dynamic differential scanning Calorimetry methods. Thermochimica Acta v. 419, p. 161-167, 2004.

ALVAREZ, V.A.; VÁZQUEZ, A. Influence of fiber chemical modification procedure on the mechanical properties and water absorption of Mater $\mathrm{Bi}-\mathrm{Y} /$ sisal fiber composites. Composites: A. v. 38, p. 1672-1680, 2005.

ARGYROPOULOS, D.S. Quantitative Phosphorus 31 NMR analysis of lignins; a new tool for the lignin chemist. Journal Wood Chemistry Technology, v. 14, p. 45-63, 1994a.

ARGYROPOULOS, D.S. Quantitative Phosphorus 31 NMR analysis of six soluble lignins. J. Journal Wood Chemistry Technology, v.14, p. 65-82, 1994b.

ASHORI, A. Wood-plastic composites as promising green-composites for automotive industries! Bioresource Technology, v. 99, p. 4661-4667, 2008.

ASTM International; Designation: D790 - 02; Standard Test Methods for Flexural Properties of Unreinforced and Reinforced Plastics and Electrical Insulating Materials.

BAKARE, I. O.; OKIEIMEN, F. E.; PAVITHRAN, C.; ABDUL KHALIL, H. P. S.; BRAHMAKUMAR, M. Mechanical and thermal properties of sisal fiber-reinforced rubber seed oil-based polyurethane composites. Materials and Design. 31 (2010) 4274-4280.

BARBOSA Jr, Vilmar. Taninos como macromonômero na síntese de polímeros fenólicos visando a preparação de compósitos reforçados com material de origem vegetal. 2007. $106 \mathrm{f}$. Dissertação (Mestrado em Físico-Química) - Instituto de Química de São Carlos, Universidade de São Paulo, São Carlos, 2007. 
BARBOSA, V. JR.; RAMIRES, E. C.; RAZERA, I. A. T.; FROLLINI, E. Biobased composites from tannin-phenolic polymers reinforced with coir fibers. Industrial Crops and Products. v. 32, p. 305-312, 2010.

BELGACEM, M. N. R, BLAYO, A., GANDINI, A. Surface Characterization of Polysaccharides, Lignins, Printing Ink Pigments, and Ink Fillers by Inverse Gas Chromatography. Journal of Colloid and Interface Science v.182, p.431-436, 1996.

BELGACEM, M. N., GANDINI, A. The surface modification of cellulose fibres for use as reinforcing elements in composite materials. Composite Interfaces, v. 12, p. 41-75, 2005.

BELGACEM, M. N.; BLAYO, A.; GANDINI, A. Surface characterization of polysaccharides, lignins, printing ink pigments, and ink fillers by inverse gas chromatography. Journal of colloid and Interface Science, v. 182, p. 431-436, 1996.

BELGACEM, M. N.; CZEREMUSZKIN, G.; SAPIEHA, S.; GANDINI, A. Surface characterization of cellulose fibres by XPS and inverse gas chromatography. Cellulose, v. 2, p. $145-157,1995$.

BELGACEM, M. N.; GANDINI, A. Inverse gas chromatography as a tool to characterize dispersive and acid-base properties of the surface of fibers and powders. In: Interfacial Phenomena in Chromatography. New York: Marcel Dekker, p. 41-124, 1999.

BELGACEM, M. N.; GANDINI, A. Monomers, Polymers and Composites from Renewable Resources, Oxford, Elsevier, 2008.

BELGACEM, M. N.; GANDINI, A. The surface modification of cellulose fibres for use as reinforcing elements in composite materials. Composite Interfaces, v. 12, p. 41-75, 2005. BELLMANN, C.; CASPARI, A.; ALBRECHT, V.; LOAN DOAN, T.T.; MÄDER, E.; LUXBACHER, T.; KOHL, R. Electrokinetic properties of natural fibres Colloids Surface, A, p. 1-5, 2005.

BEPPU, M. M., ARRUDA E. J., SANTANA, C. C. Síntese e Caracterização de Estruturas Densas e Porosas de Quitosana. Polímeros: Ciência e Tecnologia - Out/Dez 1999.

BLEDZKI, A. K.; GASSAN, J. Composites reinforced with cellulose based fibres. Progress in Polymer Science, v. 24, p. 221-274, 1999.

BLEDZKI, A. K.; GASSAN, J. Composites reinforced with cellulose based fibres. Progress in Polymer Science, v. 24, p. 221-274, 1999.

BRAS, J.; HASSAN, M. L.; BRUZESSE, C.; HASSAN, E. A.; EL-WAKIL, N. A.; DUFRESNE, A. Mechanical, barrier, and biodegradability properties of bagasse cellulose whiskers reinforced natural rubber nanocomposites. Industrial Crops and Products, v. 32, p. 627-633, 2010.

BROWN, M. E. Introduction to Thermal Analysis. Techniques and applications. Second Editon. Kluwer Academic Publishers, p.1-17, 2001. 
BUSCHILLER-DILLER, G.; ZERONIAN, S. H. Enhancing the reactivity and strength of cotton fibers, Journal Applied Polymer Science, v. 45, p. 967-979, 1992.

CALLISTER, W. D.; RETHWISCH, D. G. Fundamentals of materials science and engineering: an integrated approach. Editor John Wiley \& Sons, p. 882, 2007.

CAMPBELL, D., Polymer Characterization: physical techniques. London, New York, Chapman and Hall, 1989.

CANEVAROLO JR, S. Ciência dos Polímeros: Um Texto Básico para Tecnólogos e Engenheiros, Artliber, 2002a.

CANEVAROLO JR, S. V. Técnicas de Caracterização de Polímeros, Artliber, 2002b.

CANTO, L. B.; PESSAN, L. A. Resistência à tração, flexão e compressão. In: Canevarolo Jr., S. V. ed. Técnicas de Caracterização de Polímeros, Artliber, p.341-360, 2004.

CASTRO, D.O. Biocompósitos a partir de biopolietileno de alta densidade reforçado por fibras de curauá. 2010. Dissertação (Mestrado, Físico-Química). Instituto de Química de São Carlos, Universidade de São Paulo, São Carlos, 2010.

CHAND, N. AND FAHIM, M. Tribology of natural fiber polymer composite. Cambridge, Woodhead Publishing and Maney Publishing Limited, 2008.

CHAWLA, K. K. Composites Materials. New York: Springer, 1998.

COMYN, J. Polymer Permeability. New York: Springer, 1985. p. 1-35.

CORDEIRO, N., GOUVEIA, C., JOHN, M. J. Investigation of surface properties of physicochemically modified natural fibres using inverse gas chromatography. Industrial Crops and Products, 33, 108-115, 2011.

CORDEIRO, N., GOUVEIA, C., MORAES, A.G.O., AMICO, S.C. Natural fibers characterization by inverse gas chromatography. Carbohydrate Polymers v. 84, p. 110-117, 2011a.

COSTA, L. DI MONTEleRA, R., CÁRMinO, G., WEIL, E. D., PEARCE, E. M. Polymer Degradation and Stability, v. 56, p. 23, 1997.

DEL CORRAL, J.M.M., CASTRO, M. A. G., MARHIQUES, M., SAN FELICIANO, A., GARCIA-GARVALOS, D. Further antineoplastic terpenylquinones and terpenylhydroquinones. Bioorganic \& Medicinal Chemistry v.6, p.31-41, 1998.

DIMMEL, D.R., ANDERSON, S., IZSAK, P. A study aimed at understanding the AQ/Polysulfide synergistic effect in alkaline pulping. Journal of Wood Chemistry Technology, v. 23, p. 141-159, 2003.

DIMMEL, D.R., PERRY, L., PALASZ, P., CHUM, H.L. Chemistry of AQ pulping is uniqueSET, Journal of Wood Chemistry Technology, v. 5, p. 15-36, 1985. 
DIMMEL, D.R., SCHULLER, L.F. Structural / reactivity studies (I): soda reactions of lignin model compounds, Journal of Wood Chemistry Technology, v. 6, p. 535-564, 1986.

DIMMEL, D.R., SCHULLER, L.F., APFELD, P.B. Electron transfer reaction in pulping systems (III): a study of steric effects in lignin model / AQ reaction, Journal of Wood Chemistry Technology v.7, p. 97-113, 1987.

DORRIS G. M., GRAY D. G. J. Colloid Interface Sci. v.77, p.353, 1980. apud BELGACEM M. N.; GANDINI A. Inverse gas chromatography as a tool to characterize dispersive and acid-base properties of the superface of fibers and powders. In: Interfacial Phenomena in Chromatography. New York, Marcel Dekker, p. 56, 1999.

DUARTE-ALMEIDA, J. M.; SALATINO, A.; GENOVESE, M. I.; LAJOLO, F. M. Phenolic composition and antioxidant activity of culms and sugarcane (Saccharum officinarum L.) products. Food Chemistry, v.125, p.660-664, 2011.

E.C. RAMIRES, J. D. MEGIATTO JR, C. GARDRAT, A. CASTELLAN, E. FROLLINI. Biobased composites from glyoxal-phenolic resins and sisal fibers. Bioresource Technology. v. 101, p. 1998-2006, 2010.

EL HAGE, R., BROSSE, N., CHRUSCIEL, L., SANCHEZ, C., SANNIGRAHI, P., RAGAUSKAS, A. Characterization of milled wood lignin and ethanol organosolv lignin from miscanthus. Polymer Degradation and Stability. v. 94, p. 1632-1638, 2009.

ESPERT, A.; VILAPLANA, F.; KARLSSON, S. Comparison of water absorption in natural cellulosic fibres from wood and one-year crops in polypropylene composites and its influence on their properties. Composite: A, v. 35, p. 1267-1276, 2004.

FENGEL, D, WEGENER, G. Wood: Chemistry, Ultrastructure, Reactions, New York, Walter de Gruyter, 1989.

FENGEL, D., WEGENER, G. Wood Chemistry Ultrastructure, Reactions. Ed: Walter de Gruyter. Berlin, 1989.

FREDHEIM, G. E.; BRAATEN, S. M.; CHRISTENSEN, B. E. Molecular weight determination of lignosulfonates by size-exclusion chromatography and multi-angle laser light scattering. Journal of Chromatography A, v. 942, n. 1-2, p. 191-199, 2002.

FRIED, J. R. Polymer Science and Technology. Prentice Hall PTR, New Jersey, 1995.

FROLLINI, E. Lignina como Substituta Parcial do Fenol em Espumas e Compósitos Reforçados com Fibras Lignocelulósicas. 2002. Tese (Livre Docência) - Instituto de Química de São Carlos, Universidade de São Paulo, São Carlos, 2002.

FURTADO, A. T.; SCANDIFFIO, M. I. G.; CORTEZ, L. A. B. The Brazilian sugarcane innovation system. Energy Policy, v. 39, p. 156-166, 2011.

HUANG, G.L.; SHI, J.X.; Langrrish, T.A.G. Environmentally friendly bagasse pulping with $\mathrm{NH}_{4} \mathrm{OH}-\mathrm{KOH}-\mathrm{AQ}$. J. Cleaner Production. v. 16, p.1287-1293, 2008. 
GASSAN, J.; BLEDZKI, A. K. Alkali treatment of jute fibres: relationship between structure and mechanical properties. Journal of Applied Polymer Science, v.71, p.623-629,1999.

GAUDER, M., GRAEFF-HÖNNINGER, S., CLAUPEIN, W. The impact of a growing bioethanol industry on food production in Brazil. Applied Energy v.88, p.672-679, 2011.

GHOSH, P.; DAS, D. Modification of jute by some low molecular weight glycols and a polyol under thermal treatment, Europe Journal Polymer. v.36, p.2147-2157, 2000.

GIANCASPRO, J.; PAPAKONSTANTINOU, C.; BALAGURU P. Mechanical behavior of fire-resistant biocomposite. Composites: Part B, v.40, p.206-211, 2009.

GIRIFALCO L. A.; GOOD R. J. J. Phys. Chem. v.61, p.904. 1957. apud BELGACEM M. N.; GANDINI A. Inverse gas chromatography as a tool to characterize dispersive and acid-base properties of the superface of fibers and powders. In: INTERFACIAL Phenomena in Chromatography. New York, Marcel Dekker, p.56, 1999.

GOETZ, L.; MATHEW, A.; OKSMAN, K.; GATENHOLM, P.; RAGAUSKAS, A. Journal of Carbohydrate Polymer, v.75, p.85, 2009.

GRANATA, A., ARGYROPOULOS, D.S. 2-Chloro-4,4,5,5-tetramethyl-1,3,2dioxaphospholane, a reagent for the accurate determination of the uncondensed and condensed phenolic moieties in lignins. Journal of Agriculture and Food Chemistry, v.43, p.1538-1544, 1995.

GUIMARÃES, J.L., E. FROLLINI, C.G. DA SILVA, F. WYPYCH, K.G. SATYANARAYANA. Characterization of banana, sugarcane bagasse and sponge gourd fibers of Brazil. Industrial Crops and Products. v. 30, p.407-415, 2009.

GUTIERREZ, M.C., RUBIO, J., RUBIO, F.; OTEO, J.L. Inverse gas chromatography: a new approach to the estimation of specific interactions. Journal of Chromatography A, v.845, p.53-66, 1999.

GUTIÉRREZ, M.C.; OSUNA, S.; BARÁIBAR, I. Solid surface mapping by inverse gas chromatography. Journal of Chromatography, A. v. 1087, p. 142, 2005.

HAENSEL, T.; COMOUTH, A.; LORENZ, P.; AHMED, S. I.-U.; KRISCHOK, S.; ZYDZIAK, N.; KAUFFMANN, A.; SCHAEFER, J. A. Pyrolysis of cellulose and lignin. Applied Surface Science, v.255, p.8183-8189, 2009.

HANDBOOK OF THERMOSET PLASTICS. 2nd Ed. by Sidney W. Goodman ISBN $9780815514213,1988$.

HATAKEYAMA, T.; QUINN, F. X. Thermal Analysis - Fundamentals and Applications to Polymer Science. Chichester, John Wiley \& Sons, p. 1-105, 1994.

HEBEISH, A.; SHARAF, S.; ABD EL-HADY, M. M. Ultrasound aided KMnO4-acid systems for bleaching linen fabric. Carbohydrate Polymers. v.83, p.1370-1376, 2011.

HERAKOVICH, C. T., Mechanics of Fibrous Composites. John Wiley \& Sons; New York, 1998. 
HERRERA-FRANCO, P. J.; GONZALES, A. V. A study of the mechanical properties of short natural-fiber reinforced composites. Composite B. v. 36, p.597-608, 2005.

HOAREAU, W.; OLIVEIRA, F. B. ; GRELIER, S.; SIEGMUND, B.; FROLLINI, E.; CASTELLAN, A. Fiberboards Based on Sugarcane Bagasse Lignin and Fibers, Macromolecular Materials Engineering, v.291, p.829-839, 2006.

HOAREAU, W.; Trindade, W. G.; Siegmund, B.; Castellan, A.; Frollini E. Sugar cane bagasse and curaua lignins oxidized by chlorine dioxide and reacted with furfuryl alcohol: characterization and stability. Polymer Degradation and Stability. v. 86, p. 567, 2004.

JACOB, M.; THOMAS, J.; VARUGHESE, K. T. Mechanical properties of sisal/oil palm hybrid fiber natural rubber composites. Composite Science and Technology, v.64, p.955-965, 2004.

JOHN, M. J.; THOMAS, S. Biofibres and biocomposites. Carbohydrate Polymers, v.71, p.343-364, 2008.

JOHNSON, R. K.; ZINK-SHARP, A.; RENNECKAR, S. H.; GLASSER, W. G. Mechanical properties of wetlaid lyocell and hybrid fiber-reinforced composites with polypropylene. Composites: Part A, v.39, p.470-477, 2008.

JOSEPH, S.; SREEKALA, M. S.; OOMMEN, Z; KOSHY, P; THOMAS, S. A comparison of the mechanical properties of phenol formaldehyde composites reinforced with banana fibres and glass fibres. Composites Science and Technology. v.62, p. 1857-1868, 2002.

KHRISTOVA, P., KORDSACHIA, O., PATT, R., KARAR, I., KHIDER, T. Environmentally friendly pulping and bleaching of bagasse. Industrial Crops Products, v.23, p.131-139, 2006.

KLASIN, P.S. Spectroscopy of Organic Compounds. Sixth Edition. New Age International Publisher. p.65-68, 2004.

KNOP, A; PILATO, L. A. Phenolic Resins, Berlin, Springer-Verlag, 1985.

KU, H.; ROGERS, D.; DAVEY, R.; C., FRANCISCO; T., MOHAN. Fracture Toughness of Phenol Formaldehyde Composites: Pilot Study. Journal of Materials Engineering and Performance, v.17, p.85-90, 2008.

KUMAR, P., CHANDRA, R., SINGH, S. P. Interphase Effect on Fiber-Reinforced Polymer Composites. Composite Interfaces, v.17, p.15-35, 2010.

KUSAK, S.G.; HILTZ, J.A.; WAITKUS, P.A. Impact Performance of Phenolic Composites Following Thermal Exposure, Journal of Applied Polymer Science, v.67, p.349-361, 1998.

MANSOUR, O., EL-HADY, B. A., IBRAHIM, S. K., GODA, M. Lignocellulose-Polymer Composites-V, Polymer Plastics Technology Engineering, v.40, p.311-320, 2001. 
MARTIN, A. R.; MARTINS, M. A.; DA SILVA, O.R.R.F.; MATTOSO, L. H.C. Studies on the thermal properties of sisal fiber and its constituents. Thermochimica Acta, v.506, p.14-19, 2010.

MATTHEWS, F. L.; RAWLINGS, R.D. Composites Materials: engineering and Science. New York: Chapman\&Hall, 1994.

MEGIATTO JR, J.D., OLIVEIRA, F. B., ROSA, D. S., GARDRAT, C., CASTELLAN, A., FROLLINI, E. Renewable resources as reinforcement of polymeric matrices: composites based on phenolic thermosets and chemically modified sisal fibers. Macromolecular Bioscience. v.7, p.1121-1131, 2007.

MEGIATTO Jr, J.D.; SILVA, C.G.; ROSA, D.S.; FROLLINI, E. Sisal chemically modified with lignins: Correlation between fibers and phenolic composites properties. Polymer Degradation and Stability, v.93, p.1109- 121, 2008.

MEGIATTO Jr., J. D. Fibras de sisal: estudo de propriedades e modificações químicas visando aplicação em compósitos de matriz fenólica. 2006. 262f. Tese (Doutorado em FísicoQuímica) - Instituto de Química de São Carlos, Universidade de São Paulo, São Carlos, 2006.

MEGIATTO, J. D., CAZEILS, E., GRELIER, S., GARDRAT, C., HAM-PICHAVANT F., CASTELLAN, A. Synthesis of a lignin polymer model consisting of only phenolic $\beta-\mathrm{O}-4$ linkages and testing its reactivity under alkaline conditions, Holzforschung, v.63, p.681-689, 2009.

MISHRA, S.; MOHANTY, A. K.; DRZAL, L. T.; MISRA, M.; HINRICHSEN, G. A rewiew on Pineapple leaf fibers, sisal fibers and their composites. Macromolecular Materials Engineering, v.289, p.955-974, 2004.

MOHANTY, A. K.; MISRA, M.; DRZAL, L. T. Natural fibers, biopolymers, and biocomposites/ edited byTaylor and Francis Group, USA, 2005.

MOHANTY, A.K.; WIBOWO, A.; MISRA, M.; DRZAL, L.T. Effect of process enngineering on the performance of natural fiber reinforced cellulose acetate biocomposites. Composites: Part A, v. 35, p. 363-370, 2004.

MOUSAVIOUN, P., DOHERTY, W.O.S., Chemical and thermal properties of fractionated bagasse soda lignin. Industrial Crops and Products. v.31, p.52-58, 2010.

MU, Q., WEI, C., FENG, S. Studies on Mechanical Properties of Sisal Fiber/Phenol Formaldehyde Resin In-Situ Composites. Polymer Composites v.30, p.131-137, 2009.

MUKHOPADHYAY, S.; FANGUEIRO, R. Physical Modification of Natural Fibers and Thermoplastic Films for Composites - A Review. Journal of Thermoplastic Composite Materials, v. 22, p. 135-162, 2009.

MURAYAMA, T., Dynamic Mechanical Analysis of Polymeric Material, Elsevier Scientific Publishing Company, Amsterdam - Oxford - New York, 1978. 
NAIK, P.V. Principles of Physical. 4th edition. Published by Asoke K. Ghosh, PHI Learning Private Limited, 2010.

NBR9656-ABNT- ASSOCIAÇÃO BRASILEIRA DE NORMAS TÉCNICAS. Determinação de Umidade por Secagem em Estufa. São Paulo, 1986.

Norma ASTM International; Designation: D790 - 02; Standard Test Methods for Flexural Properties of Unreinforced and Reinforced Plastics and Electrical Insulating Materials.

OLIVEIRA, F. Lignossulfonato de sódio como agente de modificação da superfície de fibras lignocelulósicas e da formulação de termorrígido fenólico. 2010. Dissertação (Mestrado, Físico-Química). Instituto de Química de São Carlos, Universidade de São Paulo, São Carlos, 2010.

ONESIPPE, C., PASSE-COUTRIN, N., TORO, F., DELVASTO, S., BILBA, K., ARSENE, M. Sugar cane bagasse fibres reinforced cement composites: Thermal considerations. Composites: Part A, v.41, p.549-556, 2010.

PAIVA, J. M. F.; FROLLINI E. Unmodified and modified surface sisal fibers as reinforcement of phenolic and lignophenolic matrices composites: Thermal analyses of fibers and composites. Macromolecules Material Engineering, v. 291, p. 405-417, 2006.

PAIVA, J. M. F.; FROLLINI, E. Sugarcane Bagasse Reinforced Phenolic and Lignophenolic Composites. Journal of Applied Polymer Science, v. 83, p.880-888, 2002.

PEREIRA, A.A., MARTINS, G.F., ANTUNES, P.A., CONRRADO, R., PASQUINI, D., JOB, A.E., Curvelo, A.A.S., Ferreira, M., Riul Jr., A., Constantino, C.J.L. Lignin from sugar cane bagasse: Extraction, fabrication of nanostructured films, and application. Langmuir. v.23, p.6652-6659, 2007.

PETINAKIS, E.; YU, ;L. EDWARD, G.; DEAN, K.; LIU, H.; SCULLY, A. D. Effect of Matrix-Particle Interfacial Adhesion on the Mechanical Properties of Poly(lactic acid)/WoodFlour Micro-Composites. Journal Polymer Environ, v. 17, p. 83-94, 2009.

PICKERING, L. Properties and performance of natural-fiber composites. Woodhead Publishing and Maney Publishing Limited, 2008.

PIMENTA, A. S.; GANEM, F. R.; ARAÚJO, S. O.; VITAL, B. R. Adesivos à base de creosoto vegetal desmetilado: efeito dos compostos não fenólicos na eficiência da colagem de madeira. Floresta e Ambiente, v. 9, n.1, p.01, 2002.

PINJARI, D. V.; PANDIT, A. B. Cavitation milling of natural cellulose to nanofibrils. Ultrasonics Sonochemistry. v. 17, p. 845-852, 2010.

PIPPO, A.; GARZONE P.; CORNACCHIA G. Agro-industry sugarcane residues disposal: The trends of their conversion into energy carriers in Cuba. Waste Management, v. 27, p. 869-885, 2007. 
PIZZI, A.; KUENY, R.; LECOANET, F.; MASSETAU, B.; CARPENTIER, D.; KREBS, A.; LOISEAU, F.; MOLINA, S.; RAGOUBI, M. High resin content natural matrix-natural fibre biocomposites. Industrial Crops and Products. v.30, p.235-240, 2009.

POTHAN, L. A.; THOMAS, S. Effect of hybridization and chemical modification on the water-absorption behaviour of banana fiber-reinforced polyester composites. Journal of Applied Polymer Science, v. 91, p. 3856-3865, 2004.

POTHAN, L. A.; THOMAS, S. Effect of hybridization and chemical modification on the water-absorption behaviour of banana fiber-reinforced polyester composites. Journal of Applied Polymer Science, v. 91, p. 3856-3865, 2004.

RAMIRES, E. C. Biocompósitos a partir de matrizes poliméricas baseadas em lignina, tanino e glioxal reforçadas com fibras naturais. 2010. Tese (Doutorado, Físico-Química). Instituto de Química de São Carlos, Universidade de São Paulo, São Carlos, 2010a.

RAMIRES, E. C.; MEGIATTO JR., J. D.; GARDRAT, C.; CASTELLAN, A.; FROLLINI, E. Biocompósitos de Matriz Glioxal-Fenol Reforçada com Celulose Microcristalina. Polímeros, v. 20, nº 2, p. 126-133, 2010.

RAMIRES, E. C.; MEGIATTO JR., J. D.; GARDRAT, C.; CASTELLAN, A.; FROLLINI, E. Biobased composites from glyoxal-phenolic resins and sisal fibers. Bioresource Technology. v. 101, p. 1998-2006, 2009.

RANI, P. R.; RAMANAIAH, S.; REDDY, K. S. Lewis acid-base properties of cellulose acetate butyrate by inverse gas chromatography. Surface and Interface Analysis. v.43, p. 683688, 2011.

RAZERA, I. A. T. Fibras lignocelulósicas como agente de reforço de compósitos de matriz fenólica e lignofenólica. 2006. Tese (Doutorado, Físico-Química). Instituto de Química de São Carlos, Universidade de São Paulo, São Carlos, 2006.

ROLZ, C.; LEÓN, R. Ethanol fermentation from sugarcane at different maturities. Industrial Crops and Products. v.33, p. 333-337, 2011.

ROWELL, R. M.; YOUNG, R. A.; ROWELL, J. K. Paper and Composites from Agro-Based Resources; New York, Ed. By CRC-Lewis, 1996.

SATYANARAYANA, K.G. Biodegradable polymer composites based on brazilian lignocellulosic. Revista Matéria, v. 15, n. 2, p. 088-095, 2010.

SGRICCIA, N.; HAWLEY, M.C.; MISRA, M. Characterization of natural fiber surfaces and natural fiber composites. Composites: Part A. v.39, p.1632-1637, 2008.

SHEEHAN, D. Physical Biochemistry: principles and applications. 2ed Edition Publish by John Wiley and Sons Ltd., 2009.

SHIAU, D.W., DETLEFSEN, W.D. United States Patent, resorcinol-glutaraldeíde resin as an accelerator for curing phenol-formaldehyde resins. US 005700587A, December, 23, 1997. 
SILVA, C. F.; ARCURI, S. L.; CAMPOS, C. R.; VILELA, D. M.; ALVES, J. G. L. F.; SCHWAN, R. F. Using the residue of spirit production and bio-ethanol for protein production by yeasts. Waste Management, v.31, p.108-114, 2011.

SILVA, C. G. Fibras celulósicas têxteis em compósitos de matriz fenólica. 2006. 161 f. Dissertação (Mestrado) - Programa Interunidades em Ciência e Engenharia de MateriaisIQSC/EESC/IFSC, Universidade de São Paulo, São Carlos, 2006.

SILVA, C. G.; FROLLINI, E. Fibras de bagaço de cana de açúcar queimadas e não queimadas em compósitos de matriz termorrígida. $10^{\circ}$ Congresso Brasileiro de Polímeros (CBPol), Foz do Iguaçu, Paraná, 2009.

SILVERSTEIN, R. M.; BASSLER, G. C. Identificação Espectrométrica de Compostos Orgânicos. $5^{\circ}$ Ed. Rio de Janeiro, Edit. Ganabara Koogan S. A., v.110, p.146-151, 1994.

SIMÕES, M., SIMÕES, L. C., VIEIRA, M. J. Species association increases biofilm resistance to chemical and mechanical treatments. Water Research, v.43, p.229 - 237, 2009.

TAN, Y., DENG, W., GE, B., XIE, Q., HUANG, J., YAO, S. Biofuel cell and phenolic biosensor based on acid-resistant laccase-glutaraldehyde functionalized chitosan-multiwalled carbon nanotubes nanocomposite film. Biosensors and Bioelectronics, v.24, p.2225-2231, 2009.

TAPPI Standard Method T19m-54, Tappi Test Methods, 1991.

TAYEB, N. S. M. E., A study on the potential of sugarcane fibers/polyester composite for tribological applications. Wear v. 265, p. 223, 2008.

TRINDADE, W.G., HOAREAU, W., MEGIATTO, J.D., RAZERA, I.A.T., CASTELLAN, A., FROLLINI, E. Thermoset phenolic matrices reinforced with unmodified and surface grafted furfuryl alcohol sugar cane bagasse and curaua fibers: properties of fibers and composites. Biomacromolecules, v.6, p.2485-2496, 2005.

WU, S., ARGYROPOULOS, D.S. An improved method for isolating lignin in High yield and purity. Journal of Pulp Paper Science. v.29, p.235-240, 2003.

YANG, C. C., LIN, C. T., CHIU, S. J. Preparation of the PVA/HAP composite polymer membrane for alkaline DMFC application. Desalination v.233, p.137-146, 2008.

ZÁRATE, C. N., ARANGUREN, M. I., REBOREDO, M. M. Thermal Degradation of a Phenolic Resin, Vegetable Fibers, and Derived Composites. Journal of Applied Polymer Science, v.107, p.2977-2985, 2008.

ZÁRATE, C. N.; ARANGUREN, M. I.; REBOREDO, M. M. Thermal Degradation of a Phenolic Resin, Vegetable Fibers and Derived Composites. Journal of Applied Polymer Science, v.107, p.2977-2985, 2008.

ZHANG, Y., ZENG, G.M., TANG, L., HUANG, D.L., JIANG, X.Y., CHEN Y.N. A hydroquinone biosensor using modified core-shell magnetic nanoparticles supported on carbon paste electrode. Biosensors and Bioelectronics 22, 2121-2126, 2007. 


\section{Anexos}

Espectroscopia na região de infravermelho dos compósitos
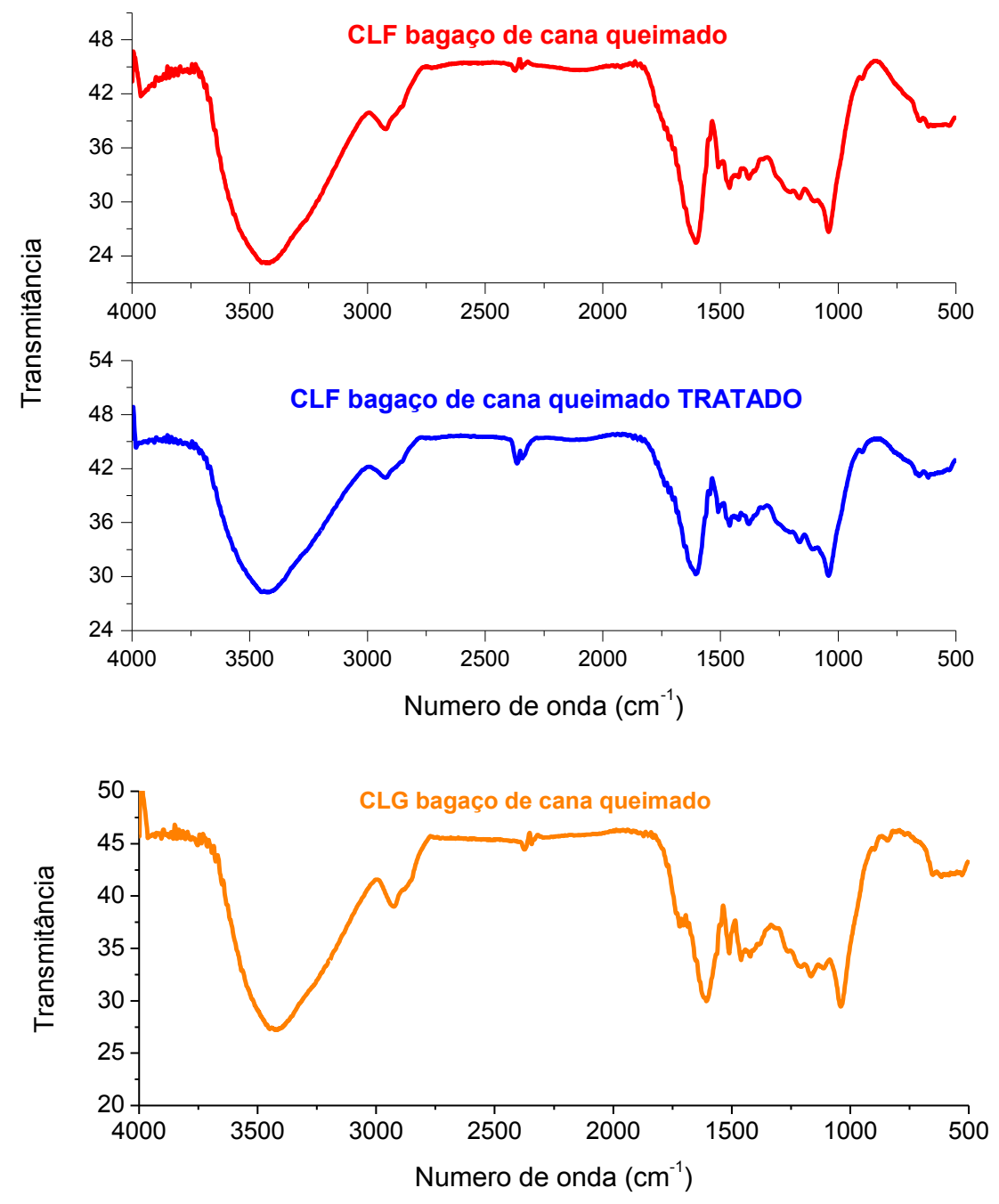

Figura 79: Espectro na região de infravermelho dos compósitos. 

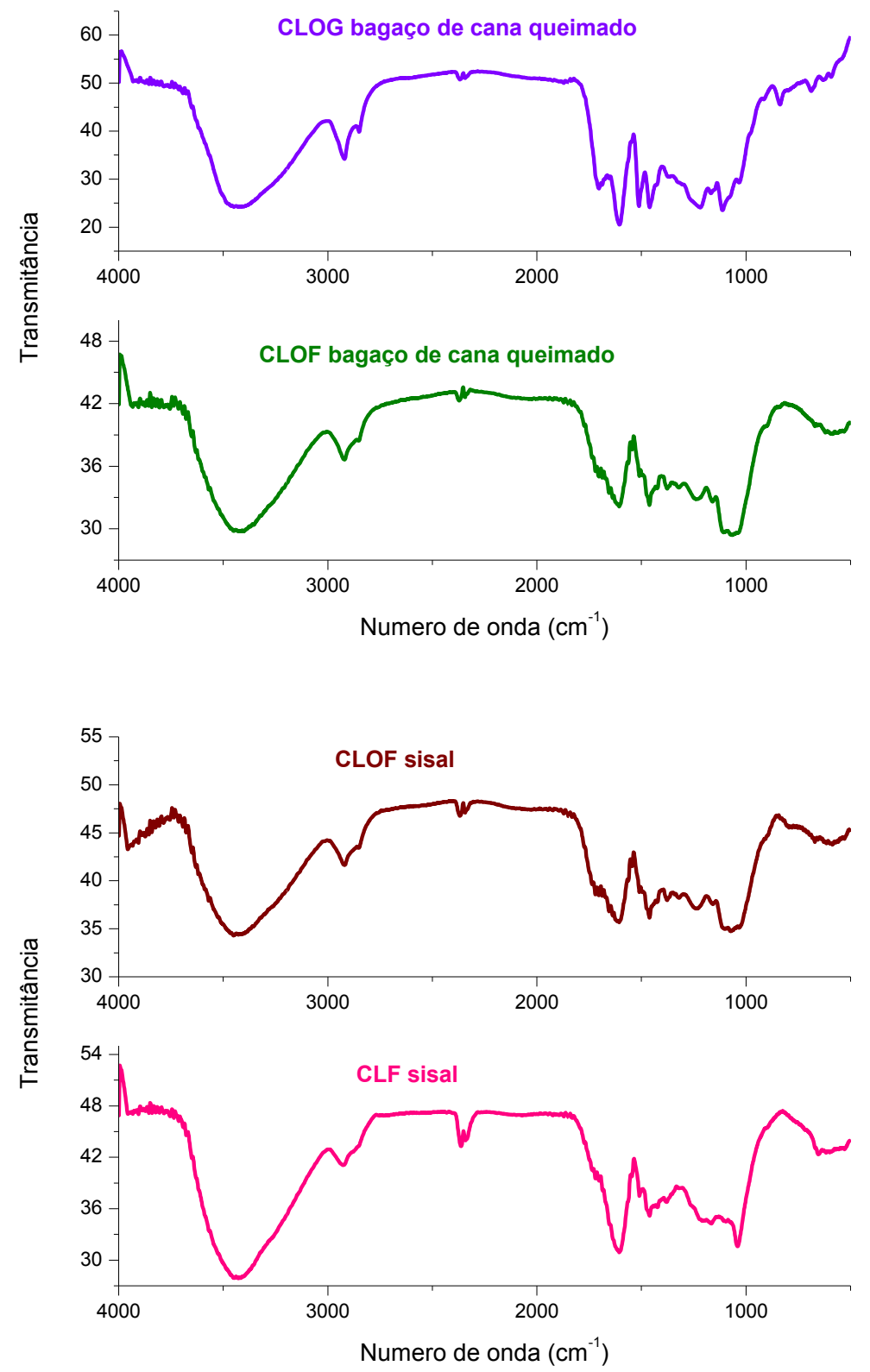

Figura 80: Espectro na região de infravermelho dos compósitos. 


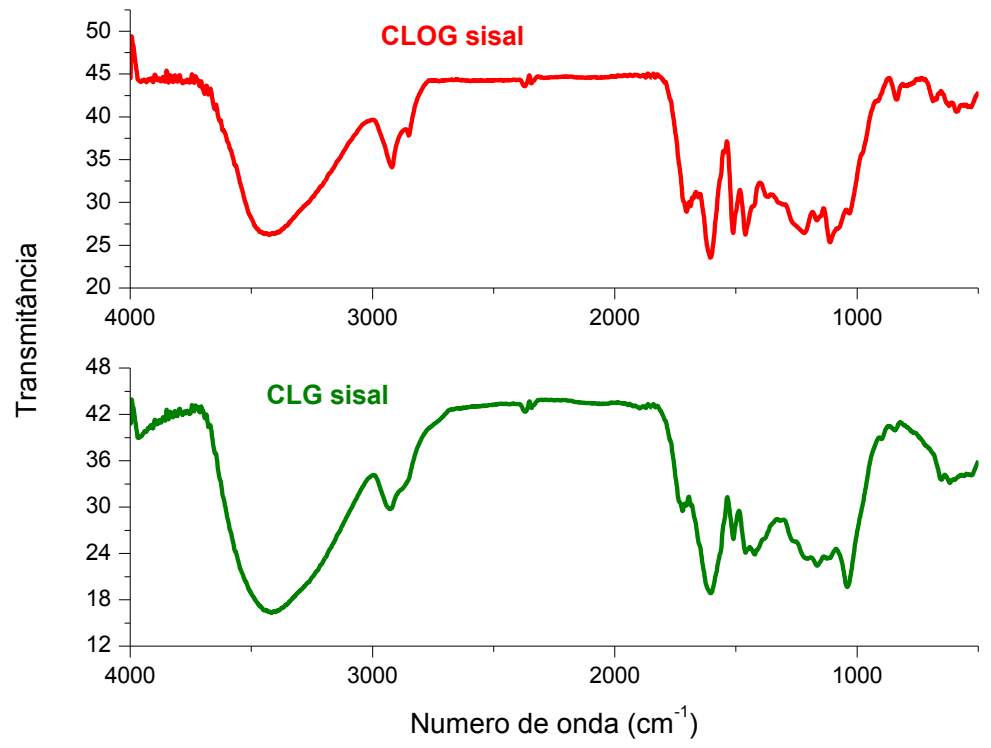

Figura 81: Espectro na região de infravermelho dos compósitos.

\section{Resultados de ensaio de impacto Izod}

Tabela 23: Ensaio de resistência ao impacto $\left(\mathbf{J ~ m}^{-1}\right)$ dos compósitos e termorrígido fenólico (TF).

\begin{tabular}{c|c|c} 
CFenBCQ*(1,5 cm) & Resistência ao Impacto $\left(\mathrm{J} \mathrm{m}^{-1}\right)$ & Erro \\
TF $^{*}$ & 25,10 & 2,30 \\
\hline $\mathbf{3 0 \%}$ & 45,31 & 1,58 \\
\hline $\mathbf{5 0 \%}$ & 58,05 & 4,61 \\
\hline \hline $\mathbf{7 0 \%}$ & 69,52 & 5,11 \\
\hline \hline
\end{tabular}

CFenBCQ: compósito fenólico reforçado com fibras de bagaço de cana queimadas.

*TF: termorrígido fenólico.

Tabela 24: Ensaio de resistência ao impacto $\left(\mathbf{J ~ m}^{-1}\right)$ dos compósitos.

\begin{tabular}{c|c|c} 
CFenBCNQ $(\mathbf{3 0} \%$ em massa) & Resistência ao Impacto $\left(\mathrm{J} \mathrm{m}^{-1}\right)$ & Erro \\
$\mathbf{1} \mathbf{~ c m}$ & 49,47 & 1,77 \\
\hline $\mathbf{2} \mathbf{~ c m}$ & 49,12 & 1,44 \\
\hline $\mathbf{3} \mathbf{~ c m}$ & 53,13 & 0,79 \\
\hline $\mathbf{4} \mathbf{~ c m}$ & 55,8 & 1,29 \\
\hline $\mathbf{5} \mathbf{~ c m}$ & 42,42 & 1,46 \\
\hline \hline
\end{tabular}

queimadas.

*CFenBCNQ: compósito fenólico reforçado com fibras de bagaço de cana não

Tabela 25: Ensaio de resistência ao impacto $\left(\mathbf{J ~ m}^{\mathbf{- 1}}\right)$ dos compósitos. 


\begin{tabular}{c|c|c}
\hline $\mathbf{3 0 \%}$ & 68,55 & 3,95 \\
\hline $\mathbf{5 0 \%}$ & 65,88 & 3,53 \\
\hline \hline $\mathbf{7 0 \%}$ & 79,63 & 5,60 \\
\hline
\end{tabular}

*CFLBCQ: compósito formaldeído-lignossulfonato de sódio reforçado com fibras de bagaço de cana queimadas.

Tabela 26: Ensaio de resistência ao impacto $\left(\mathbf{J ~ m}^{-1}\right)$ dos compósitos.

\begin{tabular}{|c|c|c|}
\hline CFLBCQT" & Resistência ao Impacto $\left(\mathbf{J ~ m}^{-1}\right)$ & Erro \\
\hline $\mathbf{3 0 \%}$ & 48,28 & 4,90 \\
\hline $\mathbf{5 0 \%}$ & 108,31 & 5,95 \\
\hline \hline $\mathbf{7 0 \%}$ & 90,48 & 5,27 \\
\hline
\end{tabular}

*CFLBCQT: compósito formaldeído-lignossulfonato de sódio reforçados com fibras queimadas e tratadas (lignossulfonato de sódio+ ultra-som/1h).

Tabela 27: Ensaio de resistência ao impacto $\left(\mathbf{J ~ m}^{-1}\right)$ dos compósitos e termorrígido fenólico (TF).

\begin{tabular}{c|c|c} 
Compósitos com bagaço de cana & Resistência ao Impacto $\left(\mathrm{J} \mathrm{m}^{-1}\right)$ & Erro \\
\hline TF & 25,10 & 2,30 \\
\hline CF & 45,31 & 1,58 \\
\hline CFL & 68,55 & 3,95 \\
\hline CFLO & 73,81 & 5,45 \\
\hline CGL & 81,81 & 8,37 \\
\hline CGLO & 112,06 & 10,38 \\
\hline
\end{tabular}

